University of Rhode Island

DigitalCommons@URI

Open Access Master's Theses

1989

\title{
Behavior of Masonry Bearing Plates in Highway Bridges: An Experimental Investigation
}

Vimal K. Agarwal

University of Rhode Island

Follow this and additional works at: https://digitalcommons.uri.edu/theses

\section{Recommended Citation}

Agarwal, Vimal K., "Behavior of Masonry Bearing Plates in Highway Bridges: An Experimental Investigation" (1989). Open Access Master's Theses. Paper 929.

https://digitalcommons.uri.edu/theses/929

This Thesis is brought to you for free and open access by DigitalCommons@URI. It has been accepted for inclusion in Open Access Master's Theses by an authorized administrator of DigitalCommons@URI. For more information, please contact digitalcommons-group@uri.edu. 
BEHAVIOR OF MASONRY BEARING PLATES IN HIGHWAY BRIDGES:

AN EXPERIMENTAL INVESTIGATION

$\mathrm{BY}$

VIMAL K. AGRAWAL

A THESIS SUBMITTED IN PARTIAL FULFILLMENT OF THE REQUIREMENT FOR THE DEGREE OF

MASTER OF SCIENCE

IN

CIVIL AND ENVIRONMENTAL ENGINEERING

UNIVERSITY OF RHODE ISLAND

-1989 - 
MASTER OF SCIENCE THESIS

OF

VIMAL K. AGRAWAL

APPROVED:

Thesis Committee

Major Professor
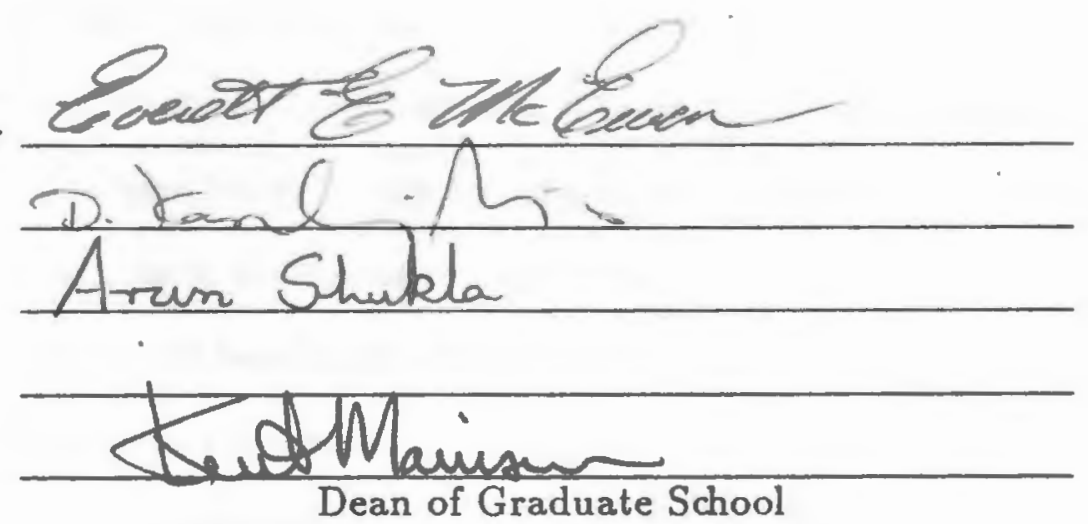

UNIVERSITY OF RHODE ISLAND 


\section{ABSTRACT}

An experimental investigation is conducted on the bridge bearing system and the behavior of the masonry bearing plate on the distribution of stresses is studied.

Four specimens of the concrete substructure are cast in two different sizes and strain gages embedded in the concrete at several locations. The effects of the thickness of the bearing plate, size of the concrete substructure, ratio of the plate area to block area, overhang of the bearing plate beyond the loaded area, and the ratio of the loaded area to plate area have also been studied.

The experimental study comprises of 72 tests in the working stress range and four ultimate load tests. Stresses beneath the bearing plate in the concrete substructure and on the bearing plates are measured and presented. For the ultimate load tests, relative slip between the bearing plate and the concrete, and the relative lift of the plate edge in relation to concrete is measured and presented.

Experimental-analytical comparisons of stress distribution are made for some cases. Recommendations are made for designing the bearing plates. 


\section{ACKNOWLEDGEMENTS}

I would like to thank my advisor, Dr. Everett E. McEwen for his guidance and encouragement throughout the course of this investigation.

I would like to thank Dr. Arun Shukla for his assistance with strain measuring instrumentation.

I would also like to thank Mr. Milton Huston, Mr. George Huston, and Mr. Ray Maclaughlin for their assistance in the specimen preparation and building the experimental apparatus. Thanks are also due to Pawtucket Ready Mix for providing the concrete.

This research effort was funded by a Grant from the Rhode Island Department of Transportation. 


\section{CONTENTS}

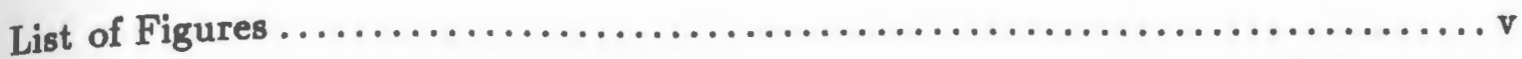

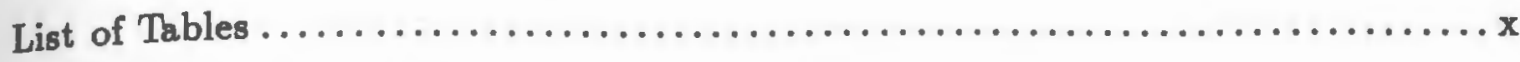

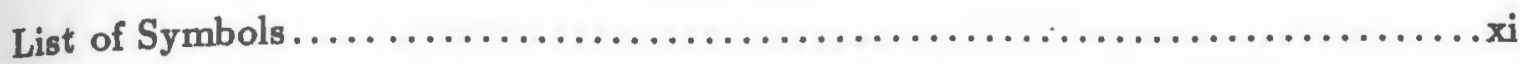

Chapter 1 Introduction 1

Chapter 2 Experimental Program

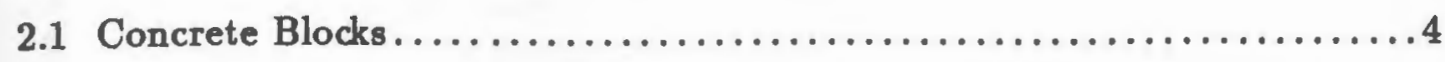

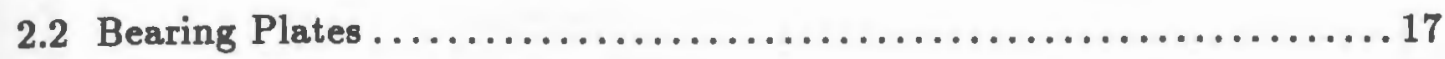

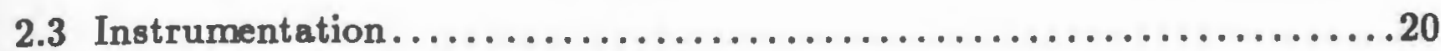

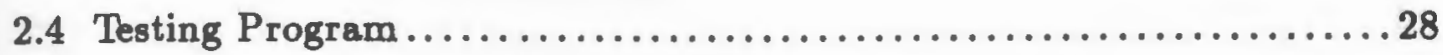

Chapter 3 Test Results

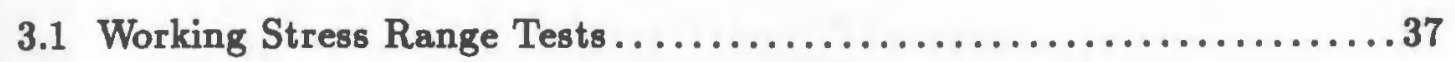

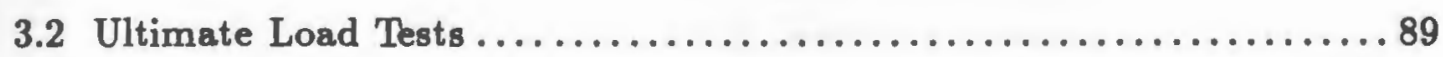

Chapter 4 Discussion of Results

4.1 Working Stress Range Tests...................................

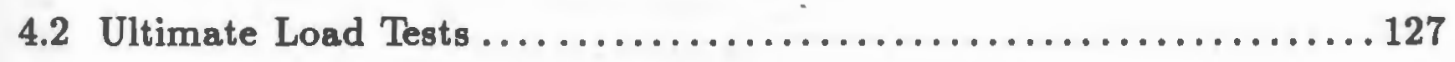

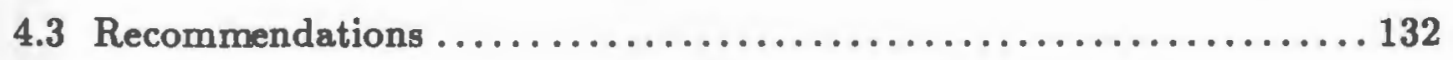

Chapter 5 Finite Element Analysis

5.1 Finite Element Model......................................

5.2 Comparison of Experimental and Finite Elelment Results...........139

Chapter 6 Summary and Conclusions $\quad 145$

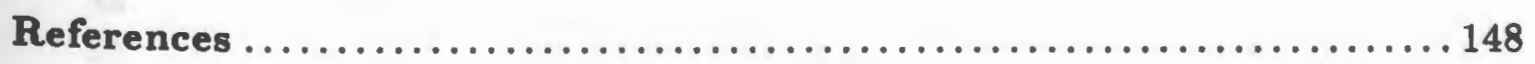

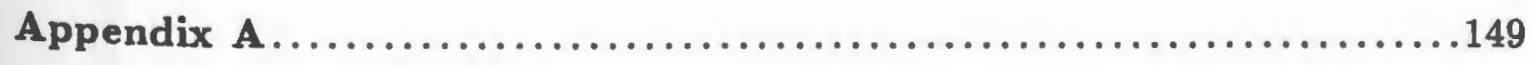

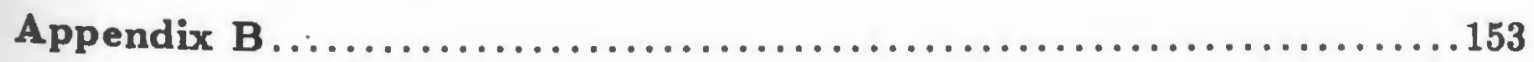

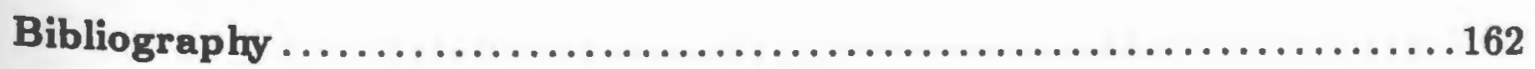




\section{LIST OF FIGURES}

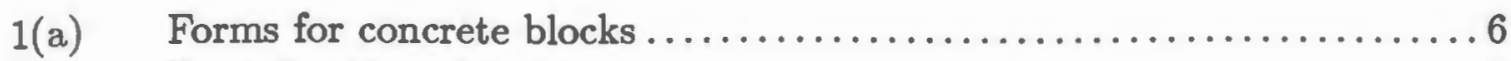

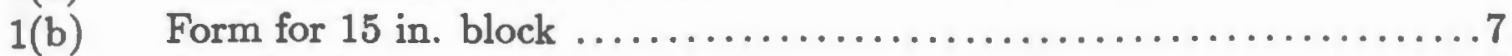

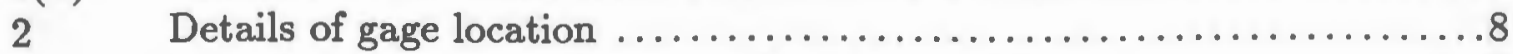

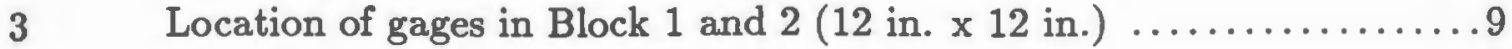

4 Location of gages in Block 3 and 4 (15 in. $x 15$ in.) ................. 10

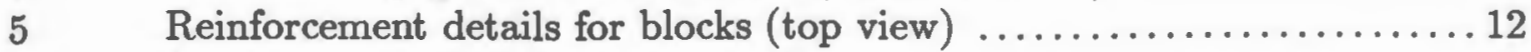

6 Reinforcement case for 15 in. block ............................ 13

$7 \quad$ Form for 15 in. block after gages were installed .................. 14

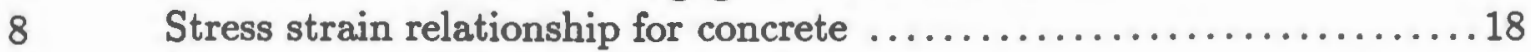

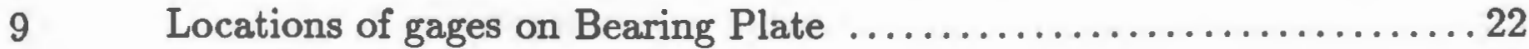

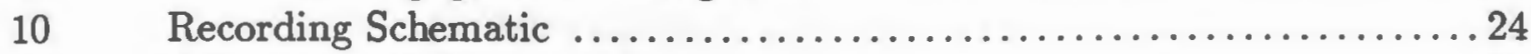

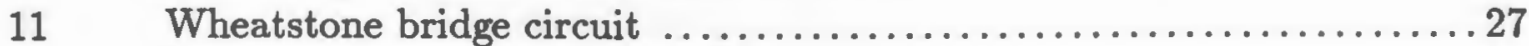

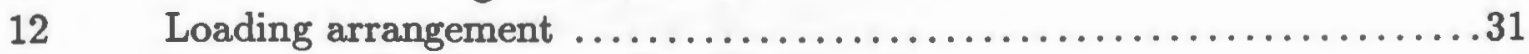

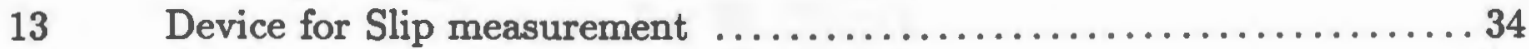

14 Device for Lift measurement ...............................

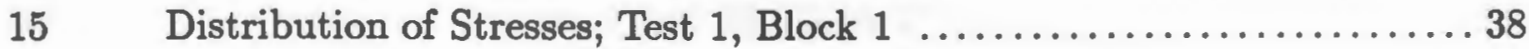

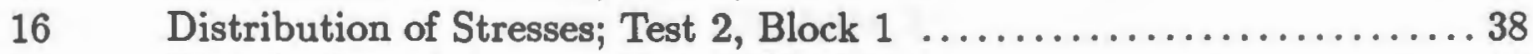

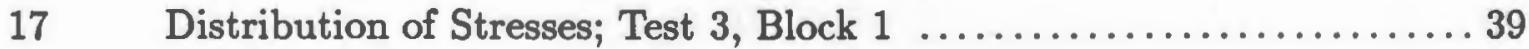

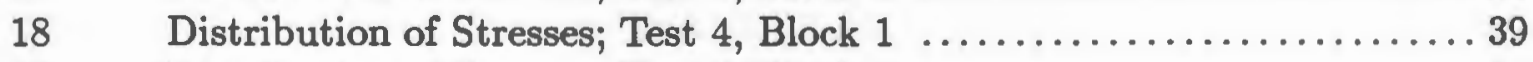

19 Distribution of Stresses; Test 5, Block $1 \ldots \ldots \ldots \ldots \ldots \ldots \ldots \ldots . \ldots . \ldots 40$

20 Distribution of Stresses; Test 6, Block $1 \ldots \ldots \ldots \ldots \ldots \ldots \ldots \ldots . \ldots 40$

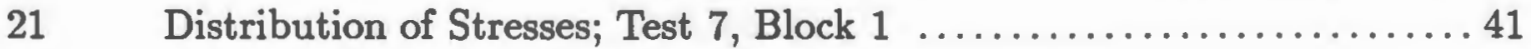

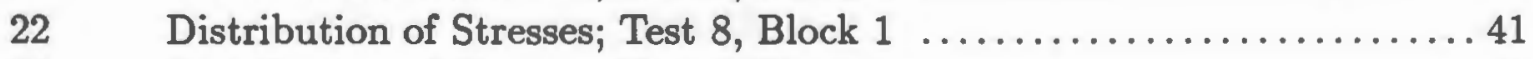

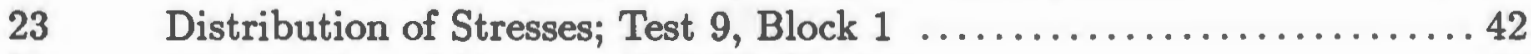

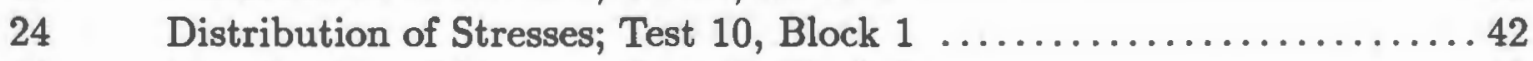

25 Distribution of Stresses; Test 11, Block $1 \ldots \ldots \ldots \ldots \ldots \ldots \ldots \ldots . \ldots . \ldots . \ldots . \ldots 4$

26 Distribution of Stresses; Test 12, Block $1 \ldots \ldots \ldots \ldots \ldots \ldots \ldots \ldots . \ldots . \ldots . \ldots . \ldots$

27 Distribution of Stresses; Test 13, Block $1 \ldots \ldots \ldots \ldots \ldots \ldots \ldots \ldots . \ldots . \ldots . \ldots 4$

28 Distribution of Stresses; Test 14, Block $1 \ldots \ldots \ldots \ldots \ldots \ldots \ldots \ldots . \ldots 4$

29 Distribution of Stresses; Test 15, Block $2 \ldots \ldots \ldots \ldots \ldots \ldots \ldots \ldots . \ldots 45$

30 Distribution of Stresses; Test 16, Block $2 \ldots \ldots \ldots \ldots \ldots \ldots \ldots \ldots . \ldots . \ldots . \ldots 45$

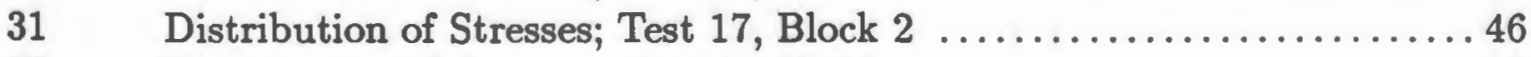

32 Distribution of Stresses; Test 18, Block $2 \ldots \ldots \ldots \ldots \ldots \ldots \ldots \ldots . \ldots 46$

33 Distribution of Stresses; Test 19, Block $2 \ldots \ldots \ldots \ldots \ldots \ldots \ldots \ldots . \ldots 4$

34 Distribution of Stresses; Test 20, Block $2 \ldots \ldots \ldots \ldots \ldots \ldots \ldots \ldots . \ldots 4$

35 Distribution of Stresses; Test 21, Block $2 \ldots \ldots \ldots \ldots \ldots \ldots \ldots \ldots$

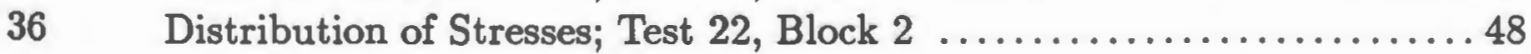




\section{LIST OF FIGURES (cont.)}

Distribution of Stresses; Test 23, Block 2 


\section{LIST OF FIGURES (cont.)}

Distribution of Stresses; Test 59, Block 4

Distribution of Stresses; Test 61 , Block $4 \ldots \ldots \ldots \ldots \ldots \ldots \ldots . \ldots 68$

Distribution of Stresses; Test 62, Block $4 \ldots \ldots \ldots \ldots \ldots \ldots \ldots \ldots 6 . \ldots \ldots$

Distribution of Stresses; Test 63, Block 4 ...................69 69

Distribution of Stresses; Test 64, Block $4 \ldots \ldots \ldots \ldots \ldots \ldots \ldots \ldots . \ldots 6$

Distribution of Stresses; Test 65, Block $4 \ldots \ldots \ldots \ldots \ldots \ldots \ldots \ldots . \ldots . \ldots . \ldots 70$

Distribution of Stresses; Test 66, Block $4 \ldots \ldots \ldots \ldots \ldots \ldots \ldots \ldots$

Distribution of Stresses; Test 67, Block 4 ................... 71

Distribution of Stresses; Test 68 , Block $4 \ldots \ldots \ldots \ldots \ldots \ldots \ldots \ldots \ldots \ldots \ldots \ldots$

Distribution of Stresses; Test 69, Block 4 ................... 72

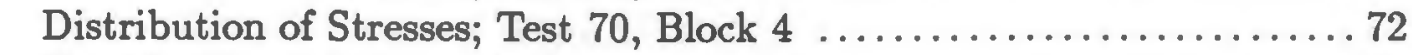

Distribution of Stresses; Test 71, Block $4 \ldots \ldots \ldots \ldots \ldots \ldots \ldots \ldots$

Distribution of Stresses; Test 72, Block $4 \ldots \ldots \ldots \ldots \ldots \ldots \ldots \ldots \ldots$

Stresses in Bearing Plate; Test 21, gage location bot(c) $\ldots \ldots \ldots \ldots \ldots 80$

Stresses in Bearing Plate; Test 21, gage location top(c) $\ldots \ldots \ldots \ldots \ldots 81$

Stresses in Bearing Plate; Test 15, gage location bot(c) $\ldots \ldots \ldots \ldots . . .82$

Stresses in Bearing Plate; Test 15, gage location top(c) ...........83

Stresses in Bearing Plate; Test 12, gage location bot(c) ........... 84

Stresses in Bearing Plate; Test 12, gage location top(c) ...........85

Distribution of Stresses; Test 73, Block 4 .................. 87

Distribution of Stresses; Test 74, Block $4 \ldots \ldots \ldots \ldots \ldots \ldots \ldots \ldots 7$

Distribution of Stresses; Test 75 , Block $3 \ldots \ldots \ldots \ldots \ldots \ldots \ldots . \ldots . \ldots 8$

Distribution of Stresses; Test 76 , Block $2 \ldots \ldots \ldots \ldots \ldots \ldots \ldots \ldots$

Distribution of Stresses; Test 77, Block $1 \ldots \ldots \ldots \ldots \ldots \ldots \ldots . \ldots . \ldots . \ldots . \ldots$

Internal Strain Distribution; Test 74, Block $4 \ldots \ldots \ldots \ldots \ldots \ldots \ldots . \ldots 91$

Internal Strain Distribution; Test 75, Block $3 \ldots \ldots \ldots \ldots \ldots \ldots . \ldots 91$

Internal Strain Distribution; Test 76, Block $2 \ldots \ldots \ldots \ldots \ldots \ldots \ldots 92$

Internal Strain Distribution; Test 77 , Block $1 \ldots \ldots \ldots \ldots \ldots \ldots . \ldots 92$

Internal Stress Distribution; Test 74, Block $4 \ldots \ldots \ldots \ldots \ldots \ldots \ldots . \ldots 3$

Internal Stress Distribution; Test 75 , Block $3 \ldots \ldots \ldots \ldots \ldots \ldots \ldots 9$

Internal Stress Distribution; Test 76, Block $2 \ldots \ldots \ldots \ldots \ldots \ldots . . \ldots 9$

Internal Stress Distribution; Test 77, Block $1 \ldots \ldots \ldots \ldots \ldots \ldots . \ldots 9$

Slip of plate relative to concrete; Test 74 , Block $4 \ldots \ldots \ldots \ldots \ldots . . . . .97$

Slip of plate relative to concrete; Test 75 , Block $3 \ldots \ldots \ldots \ldots \ldots . . \ldots 8$

Slip of plate relative to concrete; Test 76 , Block $2 \ldots \ldots \ldots \ldots . . \ldots 9$ 


\section{LIST OF FIGURES (cont.)}

109 Slip of plate relative to concrete; Test 77, Block $1 \ldots \ldots \ldots \ldots \ldots \ldots 100$

110 Lift of plate corner relative to concrete; Test 75, Block 3 ............ 101

111 Lift of plate corner relative to concrete; Test 76, Block $2 \ldots \ldots \ldots \ldots \ldots 102$

112 Lift of plate corner relative to concrete; Test 77, Block $1 \ldots \ldots \ldots \ldots 103$

113 Effect of plate thickness, Tests $1,3,4$, Block $1 \ldots \ldots \ldots \ldots \ldots \ldots \ldots \ldots$

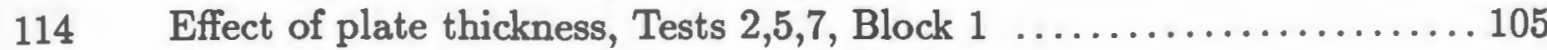

115 Effect of plate thickness, Tests 6,8,9, Block $1 \ldots \ldots \ldots \ldots \ldots \ldots \ldots \ldots \ldots$

116 Effect of plate thickness, Tests $16,18,19$, Block $2 \ldots \ldots \ldots \ldots \ldots \ldots \ldots 106$

117 Effect of plate thickness, Tests $17,20,22$, Block 2 .................. 107

118 Effect of plate thickness, Tests 21,23,24, Block 2 .................. 107

119 Effect of plate thickness, Tests $34,36,37$, Block $3 \ldots \ldots \ldots \ldots \ldots \ldots \ldots$

120 Effect of plate thickness, Tests $35,38,40$, Block 3 .................. 108

121 Effect of plate thickness, Tests 39,41,42, Block 3 .................. 109

122 Effect of plate thickness, Tests 43,45,46, Block 3 .................. 109

123 Effect of plate thickness, Tests $44,47,49$, Block 3 ................. 110

124 Effect of plate thickness, Tests $48,50,51$, Block $3 \ldots \ldots \ldots \ldots \ldots \ldots 110$

125 Effect of plate thickness, Tests $55,57,58$, Block $4 \ldots \ldots \ldots \ldots \ldots \ldots 111$

126 Effect of plate thickness, Tests $56,59,61$, Block $4 \ldots \ldots \ldots \ldots \ldots \ldots \ldots 11$

127 Effect of plate thickness, Tests $60,62,63$, Block $4 \ldots \ldots \ldots \ldots \ldots \ldots . \ldots 112$

128 Effect of plate thickness, Tests $64,66,67$, Block $4 \ldots \ldots \ldots \ldots \ldots \ldots \ldots 112$

129 Effect of plate thickness, Tests $65,68,70$, Block $4 \ldots \ldots \ldots \ldots \ldots \ldots . \ldots 113$

130 Effect of plate thickness, Tests $69,71,72$, Block $4 \ldots \ldots \ldots \ldots \ldots \ldots . \ldots 113$

131 Effect of Pl. thick. and Ld. Area/ Pl. Area; Pl./ Bl. Area $=0.77 \ldots \ldots 114$

132 Effect of Pl. thick. and Ld. Area/ Pl. Area; Pl./ Bl. Area $=0.50 \ldots \ldots 115$

133 Effect of Pl. thick. and Ld. Area/ Pl. Area; Pl./ Bl. Area $=0.25 \ldots \ldots 116$

134 Effect of Pl. Area/ Bl. area , Test 1,10,13, Block $1 \ldots \ldots \ldots \ldots \ldots \ldots . . .118$

135 Effect of Pl. Area/ Bl. area, Test 2,11,14, Block $1 \ldots \ldots \ldots \ldots \ldots \ldots . .118$

136 Effect of Pl. Area/ Bl. area, Test 6,12,15, Block 1 ..................119

137 Effect of Pl. Area/ Bl. area, Test 16,25,28, Block 2 ............... 119

138 Effect of Pl. Area/ Bl. area , Test 17,26,29, Block 2 ............... 120

139 Effect of Pl. Area/ Bl. area, Test 21,27,30, Block $2 \ldots \ldots \ldots \ldots \ldots . . . .120$

140 Effect of Pl. Area/ Bl. area, Test 31,34,43, Block 3 ............... 121

$141 \quad$ Effect of Pl. Area/ Bl. area, Test 32,35,44, Block 3 .............. 121

142 Effect of Pl. Area/ Bl. area , Test 33,39,48, Block 3 .............. 122

$143 \quad$ Effect of Pl. Area/ Bl. area , Test 52,55,64, Block $4 \ldots \ldots \ldots \ldots \ldots . \ldots 122$

144 Effect of Pl. Area/ Bl. area, Test 53,56,65, Block $4 \ldots \ldots \ldots \ldots \ldots . . .123$ 


\section{LIST OF FIGURES (cont.)}

145 Effect of Pl. Area/ Bl. area, Test 54,60,69, Block $4 \ldots \ldots \ldots \ldots \ldots . .123$

146 Effect of Ld. Area / Pl. Area; Plate / Block area $=.77 \ldots \ldots . . . . .124$

147 Effect of Ld. Area / Pl. Area; Plate / Block area $=.50 \ldots \ldots \ldots \ldots . .125$

148 Effect of Ld. Area / Pl. Area; Plate / Block area $=.26 \ldots \ldots . . . . . .126$

149 Effect of Ld. Area / Pl. Area; Plate / Block area $=.77 \ldots \ldots \ldots \ldots . .128$

150 Effect of Ld. Area / Pl. Area; Plate / Block area $=.50 \ldots \ldots \ldots \ldots . . .129$

151 Effect of Ld. Area / Pl. Area; Plate / Block area $=.26 \ldots \ldots \ldots \ldots . . .130$

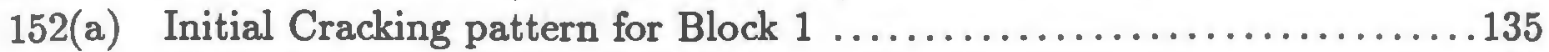

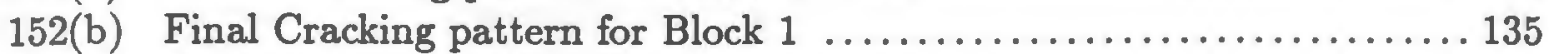

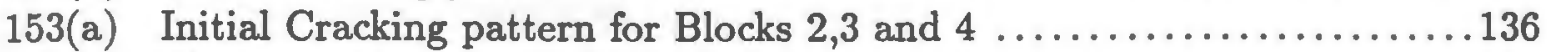

153(b) Final Cracking pattern for Blocks 2,3 and $4 \ldots \ldots \ldots \ldots \ldots \ldots \ldots \ldots \ldots \ldots \ldots \ldots$

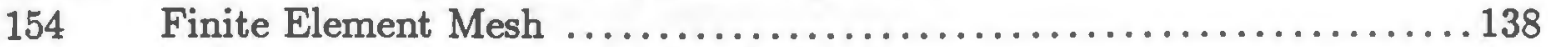

155 Vertical stresses in concrete at Strain Gages level ................. 140

$156 \quad$ Variation of Concrete Stresses ................................ 141

157 Strain Distribution at failure ................................ 142

158 Vertical Displacement at Centerline ............................ 143

159 Calibration Curve, Pressure Transducer ....................... 150

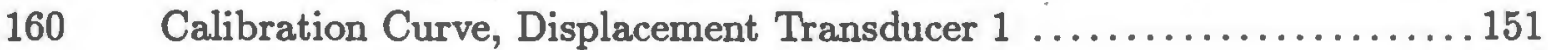

161 Calibration Curve, Displacement Transducer $2 \ldots \ldots \ldots \ldots \ldots \ldots \ldots \ldots \ldots \ldots$ 


\section{LIST OF TABLES}

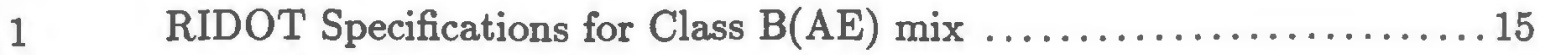

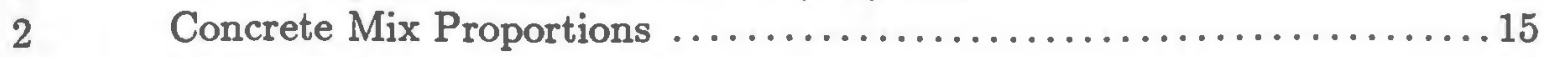

$3 \quad$ Cylinder Compression Test results ............................ 15

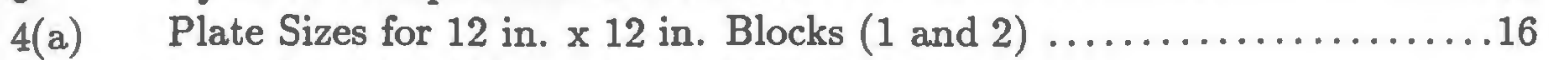

4(b) Plate Sizes for 15 in. $x 15$ in. Blocks (3 and 4) ...................

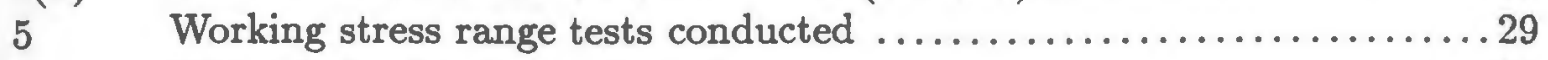

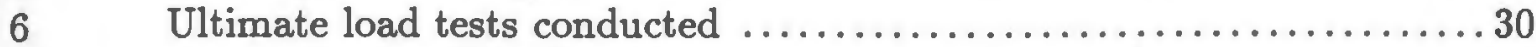

$7 \quad$ Stresses in bearing plates (working stress range tests) $\ldots \ldots \ldots \ldots \ldots . \ldots 75$

8 Stress in top horizontal rebar (working stress tests) $\ldots \ldots \ldots \ldots \ldots \ldots . \ldots 6$

$9 \quad$ Stresses in bearing plates (ultimate load tests) ...................95

10 Stress in top horizontal rebar (ultimate load tests) ...............96

11 Stress ratios at the end of Loaded area and at Plate edge ........... 134

12 Factor of safety against failure from Ultimate load tests .............134 


\section{LIST OF SYMBOLS}

a Square bearing plate dimension

$A_{1} \quad$ Loaded area

$A_{2} \quad$ Area of the concrete substructure

$c$ Distance of the extreme fiber from the neutral axis

$d \quad$ Diameter of the loaded area

$\epsilon \quad$ Strain

$E \quad$ Modulus of Elasticity

$f_{b} \quad$ Allowable bearing stress in concrete

$f_{b a} \quad$ Allowable bending stress in steel

$F_{v} \quad$ Allowable shear stress in steel

$F_{y} \quad$ Yield stress for steel

$f_{c}^{\prime} \quad$ Ultimate compressive strength of concrete in uniaxial compression

I Moment of Inertia

$l \quad$ Overhang of the bearing plate

$M \quad$ Maximum bending moment

$\sigma \quad$ Stress

$S_{\text {req }} \quad$ Required section modulus

$t \quad$ Plate thickness

$V \quad$ Shear force

$V_{\text {in }} \quad$ Input voltage to the wheatstone bridge circuit

$V_{\text {out }} \quad$ Output voltage from the wheatstone bridge circuit

$w \quad$ Uniformly distributed Stress

$w / c \quad$ Water to cement ratio by weight 


\section{CHAPTER 1}

\section{INTRODUCTION}

Masonry bearing plates are used extensively in highway bridges throughout the United States. These bearing plates serve the purpose of uniformly distributing the load from the superstructure to the supporting concrete substructure.

The design of the bearing plate currently is based on the assumption that the bearing stresses in concrete are uniform across the entire area of the plate [1],[2]. This thesis project involves investigation of the behavior of the bearing plate in terms of transferring the loads from the superstructure to the concrete substructure.

McEwen et al. [4], and Saxena et al. [8], performed an inelastic finite element analysis of the bearing system in 1985 . It was seen that the bearing stress distribution was uniform only under the loaded portion of the bearing plate and cont rary to the normal assumption in design, very little lateral distribution of the applied load was observed. The analytical parametric study of the bearing plate and geometry showed that the stresses in concrete are only slightly affected by the pla te thickness. Bending stresses in the plate were found to be much lower than the nominal design stresses, and the bearing load seemed to be carried to the concrete almost entirely in direct compression.

The above results were completely analytical in nature and numerous assumptions were made in order to model the system. Assumptions were made for stress strain relations and the failure criteria of concrete. Many constitutive theories have been developed for multidimensional nonlinear bahavior of concrete [5]. The model 
of Chen \& Chen [6] was used, which models the plastic yielding and failure of the concrete by means of a two part yield surface in principal stress space which expands as plastic strain occurs up to a limiting value which defines failure. The failure criteria used have been verified for only a limited number of three dimensional stress states and not for the conditions present in the bearing system.

If the analytical results are correct, the significance of these differences with the acceptable design methods is that not only is the design of the bearing plate overly conservative but that the ultimate capacity of the concrete is considerably greater than normally assumed by the present specifications. A literature search on this project failed however, to locate any experimental studies conducted on the behavior of masonry bearing plates. An experimental investigation was therefore conducted to study the behavior of the masonry bearing plates.

Concrete blocks were cast in two different sizes to study the effect of confining stress. Two blocks of each size were cast for duplication of data. The concrete mix was designed to conform with the Rhode Island Standard Specifications for Road and Bridge Constructions [7] and cylinders were cast and the ultimate strength of the concrete was determined. Stress strain relationship for the concrete was also determined for uniaxial compression. Bearing plates were designed based on the Standard Specifications of Highway B ridges.

For the purpose of the experimental study seventy two tests were conducted within the elastic range and the effect of the following parameters on the stress distribution was studied:

1. Plate thickness: Thicknesses greater than design were chosen.

2. Ratio of loaded plate area to bearing plate area: Ratios of $0.75,0.50,0.25$ were chosen.

3. Ratio of bearing plate area to the area of the concrete block: Ratios of 0.75 , 
$0.50,0.25$ were chosen.

Four ultimate load tests were also conducted, one on each block to determine the ultimate capacity of each block.

Strain gages were installed inside each form at the desired locations to measure stresses in the concrete substructure. Gages were also installed at various locations on each of the bearing plates and the bending stresses were measured. A cquisition of data was controlled by an a utomatic data acquisition system. Load readings and strain readings were recorded at desired intervals.

The stress distribution (both in concrete as well as steel) resulting from the experiments has been compared to the stresses resulting from the current design assumption of uniform distribution of the stresses.

For the ultimate load tests, lateral distribution of stresses was also studied. The lateral movement of the plate relative to the concrete was also measured during the ultimate load tests. It was observed during the first ultimate load test that the plate edges lifted up from the concrete surface considerably. The lift of the plate corner relative to the concrete was measured for the remaining three ultimate load tests.

The results obtained are presented and discussed. Conclusions are drawn and recommendations made based on test results. 
$0.50,0.25$ were chosen.

Four ultimate load tests were also conducted, one on each block to determine the ultimate capacity of each block.

Strain gages were installed inside each form at the desired locations to measure stresses in the concrete substructure. Gages were also installed at various locations on each of the bearing plates and the bending stresses were measured. Acquisition of data was controlled by an a utomatic data acquisition system. Load readings and strain readings were recorded at desired intervals.

The stress distribution (both in concrete as well as steel) resulting from the experiments has been compared to the stresses resulting from the current design assumption of uniform distribution of the stresses.

For the ultimate load tests, lateral distribution of stresses was also studied. The lateral movement of the plate relative to the concrete was also measured during the ultimate load tests. It was observed during the first ultimate load test that the plate edges lifted up from the concrete surface considerably. The lift of the plate corner relative to the concrete was measured for the remaining three ultimate load tests.

The results obtained are presented and discussed. Conclusions are drawn and recommendations made based on test results. 


\section{CHAPTER 2}

\section{EXPERIMENTAL PROGRAM}

The experimental program was designed to study the behavior of masonry bearing plates, and to experimentally measure the stresses occuring in the bearing plates as well as within the concrete substructure. The effect of the following parameters was studied:

(a) Thickness of the bearing plate,

(b) Size of the concrete substructure,

(c) Ratio of plate area to block a rea,

(d) Overhang of the bearing plate beyond the loaded area,

(e) Ratio of loaded area to plate area.

\subsection{CONCRETE BLOCKS:}

For the purpose of experimental testing four concrete blocks were designed. Two blocks were 12 inches by 12 inches by 12 inches and the other two were 15 inches by 15 inches by 15 inches.

\subsubsection{PREPARATION OF FORMWORK:}

The main consideration in the preparation of formwork was to keep the adjacent surfaces of the form perpendicular to each other and to stiffen them enough to prevent any kind of warping or shearing in the forms until the concrete was poured and set. Another consideration was to place the strain gages at the desired locations where stresses were to be measured and to take the leads from the gages out without affecting the stress distribution in the the block. 
To prevent warping three quarter inch thick plywood was used. To stiffen the forms framing lumber ( 2 " by 3 ") was used at the top and bottom (Fig.1(a)). Half inch holes were drilled on opposite sides of the forms approximately two and half inches from the bottom to receive half inch wide electrical conduits. Holes one eighth inch in diameter were drilled in these conduits to take the leads of the strain gages out of the concrete blocks. For placing the strain gages two steel strips (3/16" wide and $1 / 64$ " thick) were run taut directly over the conduits ( 3 " from top surface) and anchored on the plywood. A nother strip was run across the diagonal at the same height (Fig.1(b)).

Strain gages used inside the blocks were Polyester Mold Gages PMLS-10 (Made by Tokyo Sokki Kenkyujo Co. of J apan and supplied by Texas Measurements Inc.). These gages are especially designed for short and long term measurements of internal strains in concrete. The gage is completely waterproof and is coated with a coarse grit which gives the gage excellent bonding characteristics. The gages were glued to the steel strips using an epoxy adhesive PS (also made and supplied by the above mentioned companies). The gages were glued such that the actual gage length was not attached to the strip (Fig.2) . The location of the gages can be seen in Fig.3 and Fig.4. A strain gage was also attached to the reinforcement. The convention used for naming the gages inside the block is as follows:

(a). The four sides of each block were named North, East, West and South.

(b). The gages were named based on their locations, and the numbering started from the one closest to the center, e.g. E1, E2, NE1, etc.

(c). The horizontal gages were named as EH1, EH2, SWH1, etc.

(d). The gage attached to the reinforcement was called RE1.

The reinforcement used was nominal $0.2 \%$ for the larger block and $0.24 \%$ for the smaller. The spacing between vertical bars was 2.5 " and between horizontal 


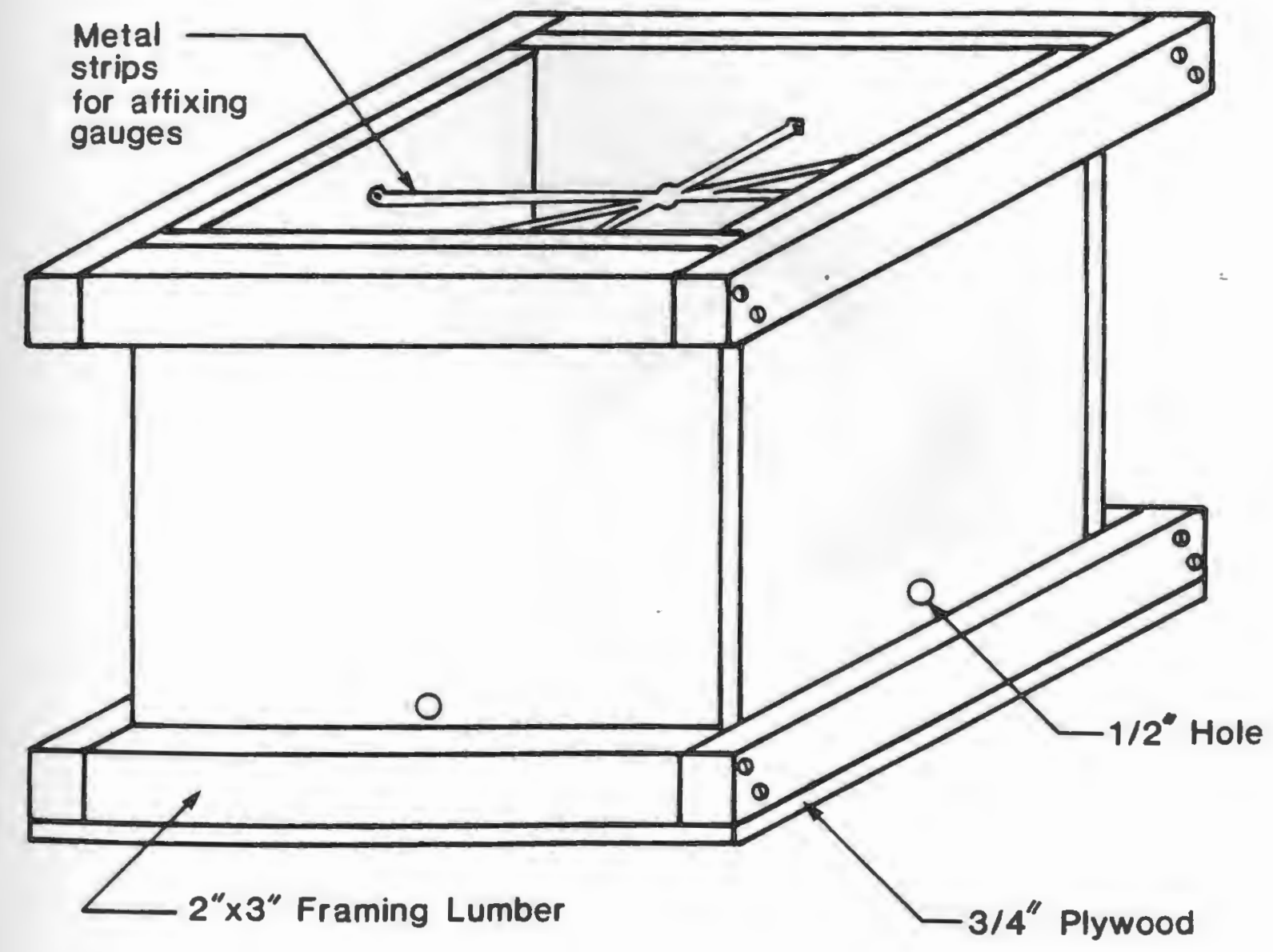

Fig.1(a): Forms for Concrete Blocks. 


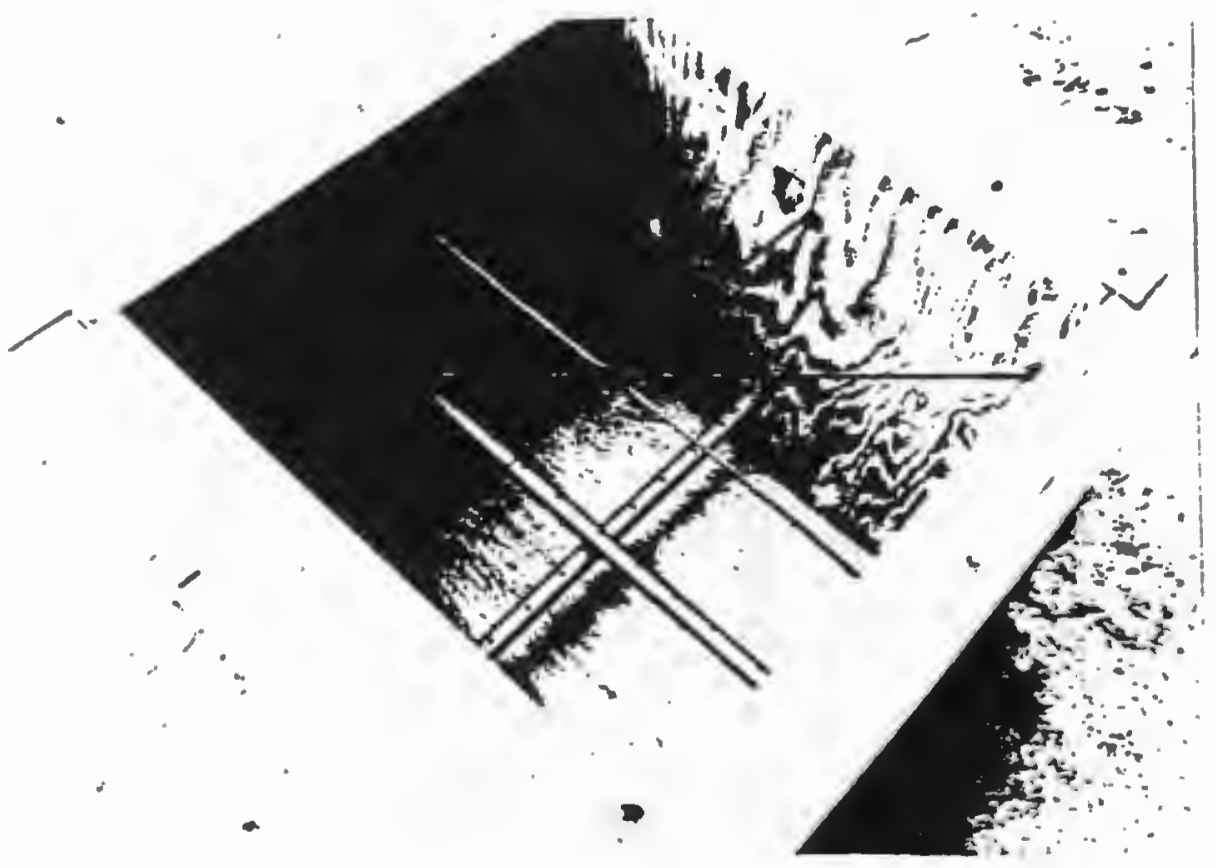

Fig.1(b): Form for 15" block. 


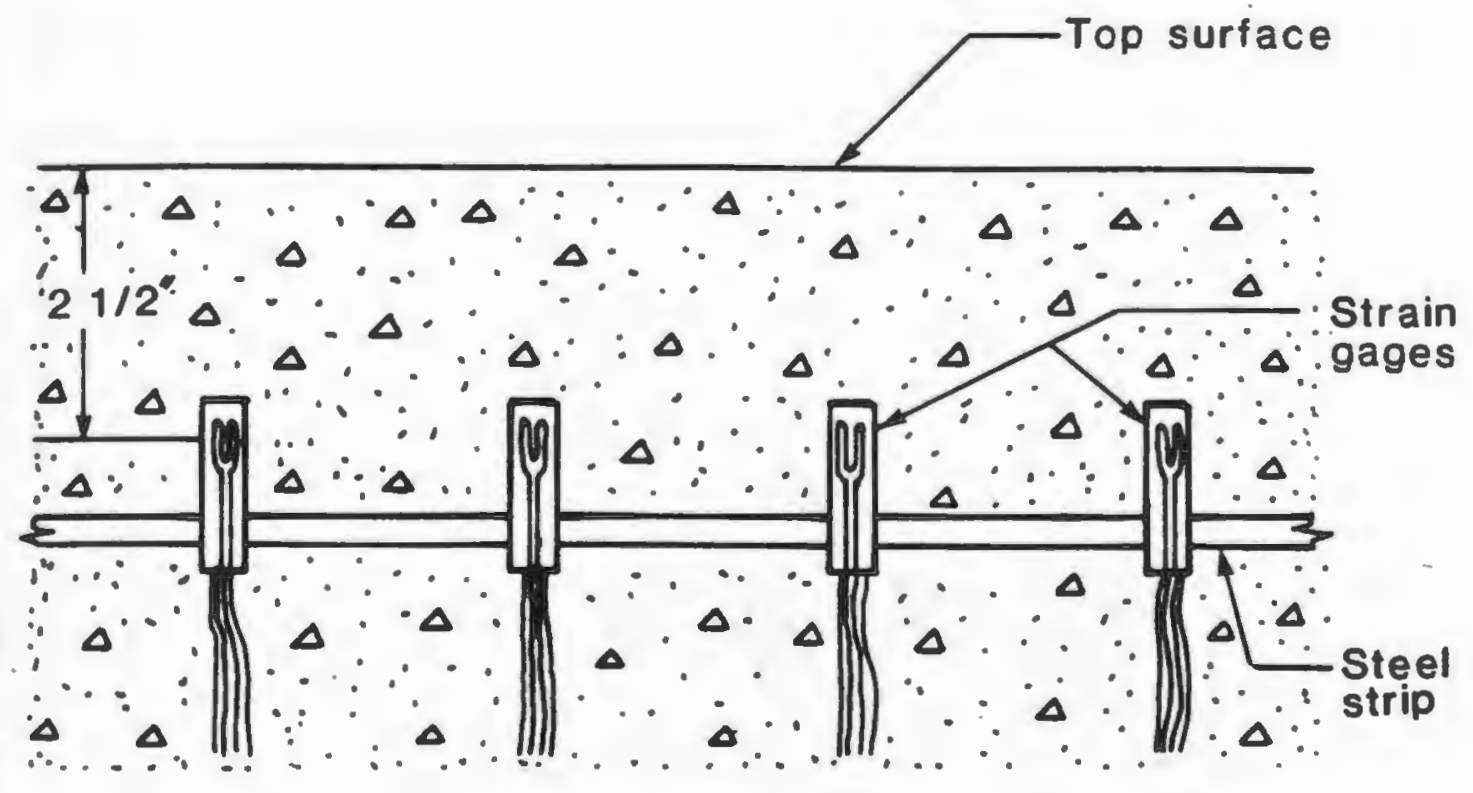

Fig.2: Details of gage location 


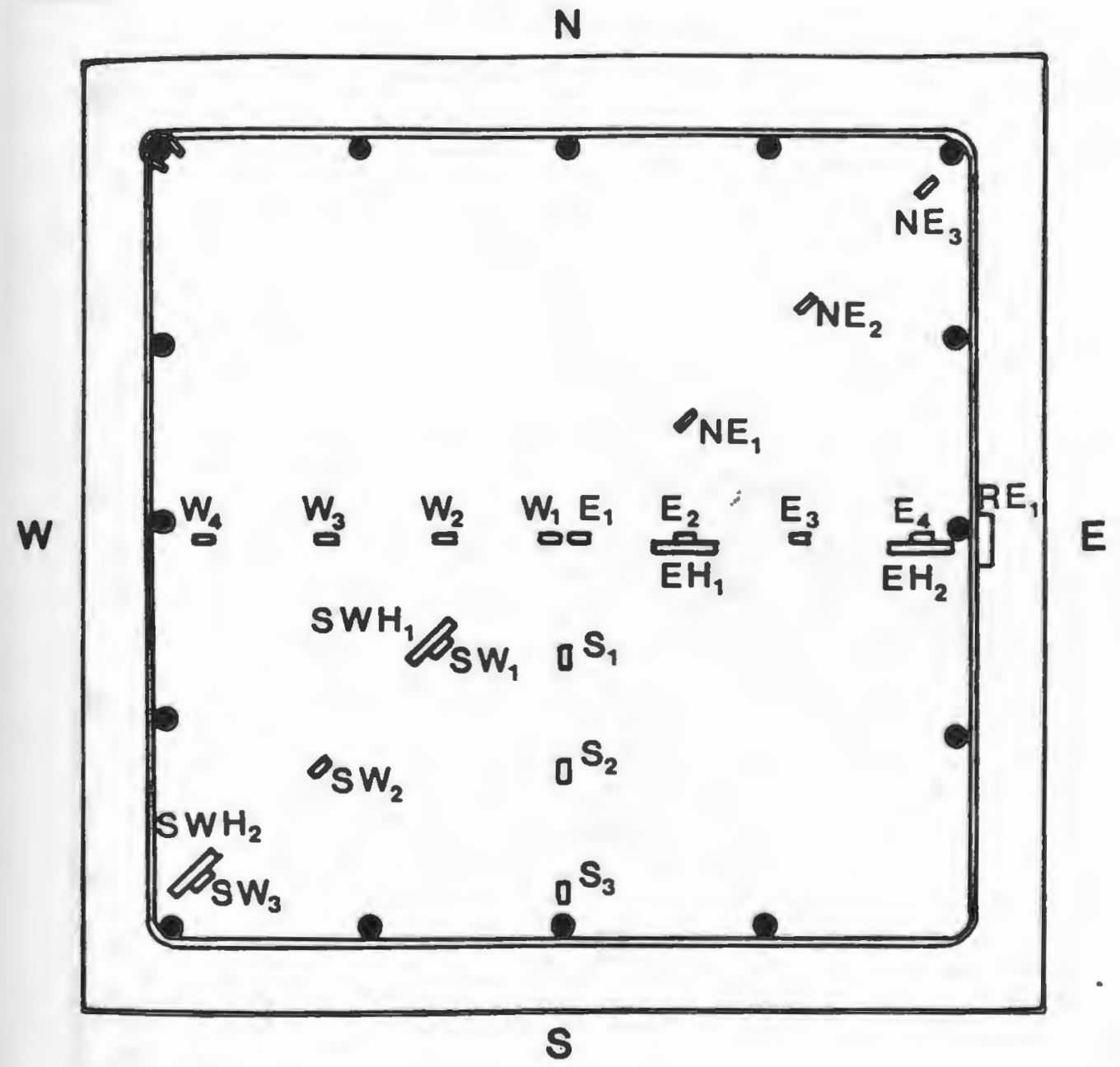

Fig.3: Location of gages in block 1 and block $2\left(12^{\prime \prime} \times 12^{\prime \prime}\right)$ 


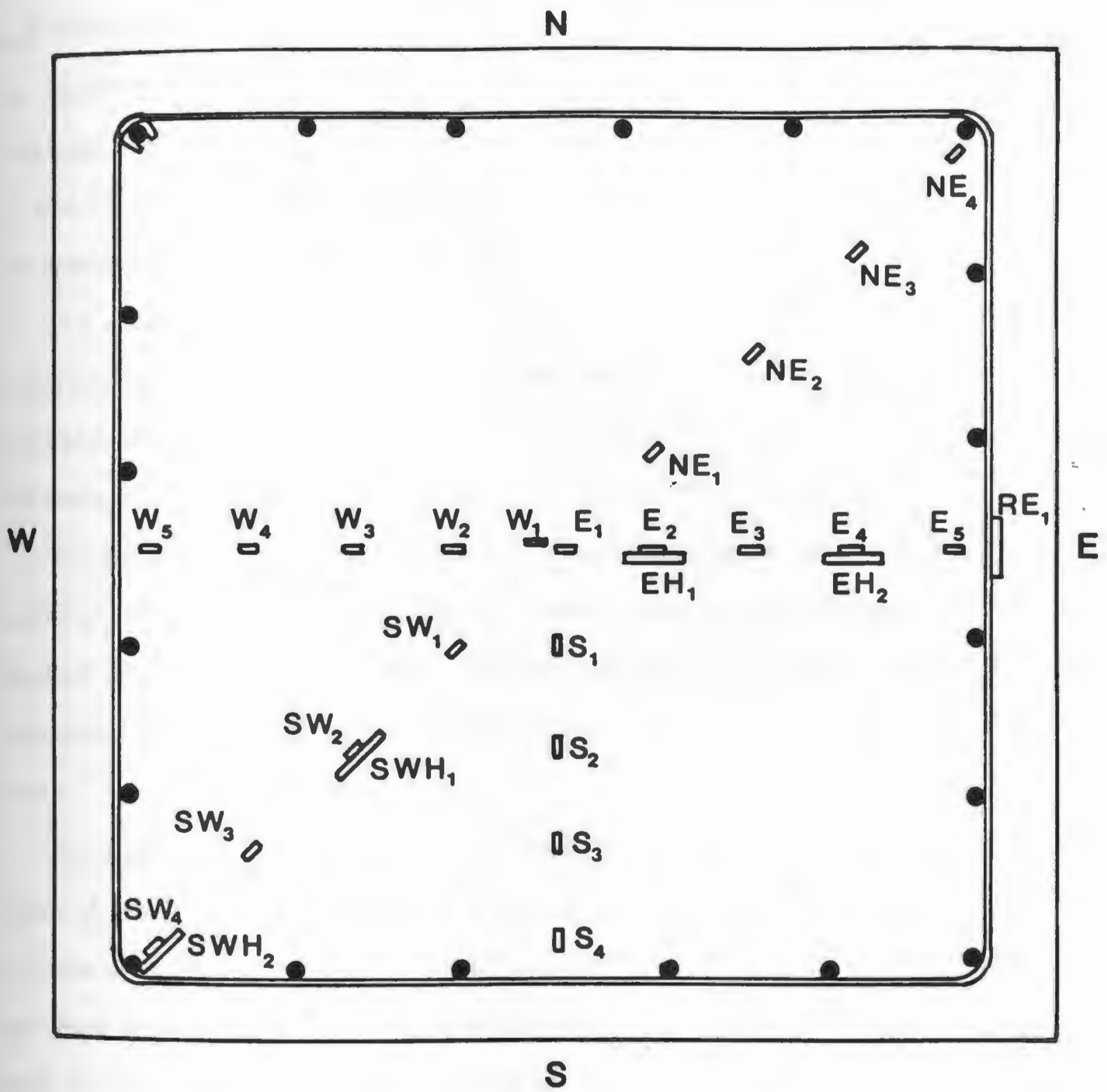

Fig.4: Location of gages in block 3 and block $4\left(15^{\prime \prime} \times 15^{\prime \prime}\right)$. 
bars was 3.0". The details can be seen in Fig.5. A typical reinforcement cage used for the 15" block can be seen in Fig.6.

Fig.7 shows a photograph of a typical 15 " form after gages were installed.

\subsubsection{CONCRETE MIX AND CYLINDERS:}

The concrete mix was designed according to the specifications of Rhode Island Department of Transportation [7] to meet classification B with Air Entrainment i.e. B(AE). Section 600 of [7] gives the specifications for different classes of mix. The specifications for class $\mathrm{B}(\mathrm{AE})$ are listed in Table 1 .

The concrete was supplied by a company, Pawtucket Ready Mix, and the proportions are given in Table 2. Concrete was used from a freshly mixed two cubic yard batch of standard 3000 psi. design mix with $1 / 2$ inch maximum size aggregate. The cement factor was $516 \mathrm{lbs} . / \mathrm{cu}$. $\mathrm{yd}$. and $w / \mathrm{c}$ ratio was 0.5 .

The forms were oiled and transported to the mixing plant. The concrete was poured carefully in order not to snap any leads from the gages or change the inclination of the gages. Vibratory compaction was used for the blocks. Slump was determined in accordance with ASTM C-143 and was found to be three and half inches.

Six 6 inch by 12 inch cylinders were cast (ASTM C-192 "Laboratory preparation of Molded Concrete cylinders") for testing the compressive strength of the concrete at seven and twentyeight days. In addition twelve 4 inch by 8 inch cylinders were also cast and three were tested at the start of testing of each block to know the compressive strength of concrete at that time.

The concrete blocks and cylinders were cured at about 70 deg. F. and at a relative humidity of $95 \%$ for seven days. Curing was stopped after seven days as the strength exceeded 3000 psi. Seven and twenty eight day compressive tests on cylinders were done in accordance with AST M C-39. The results of these compres- 


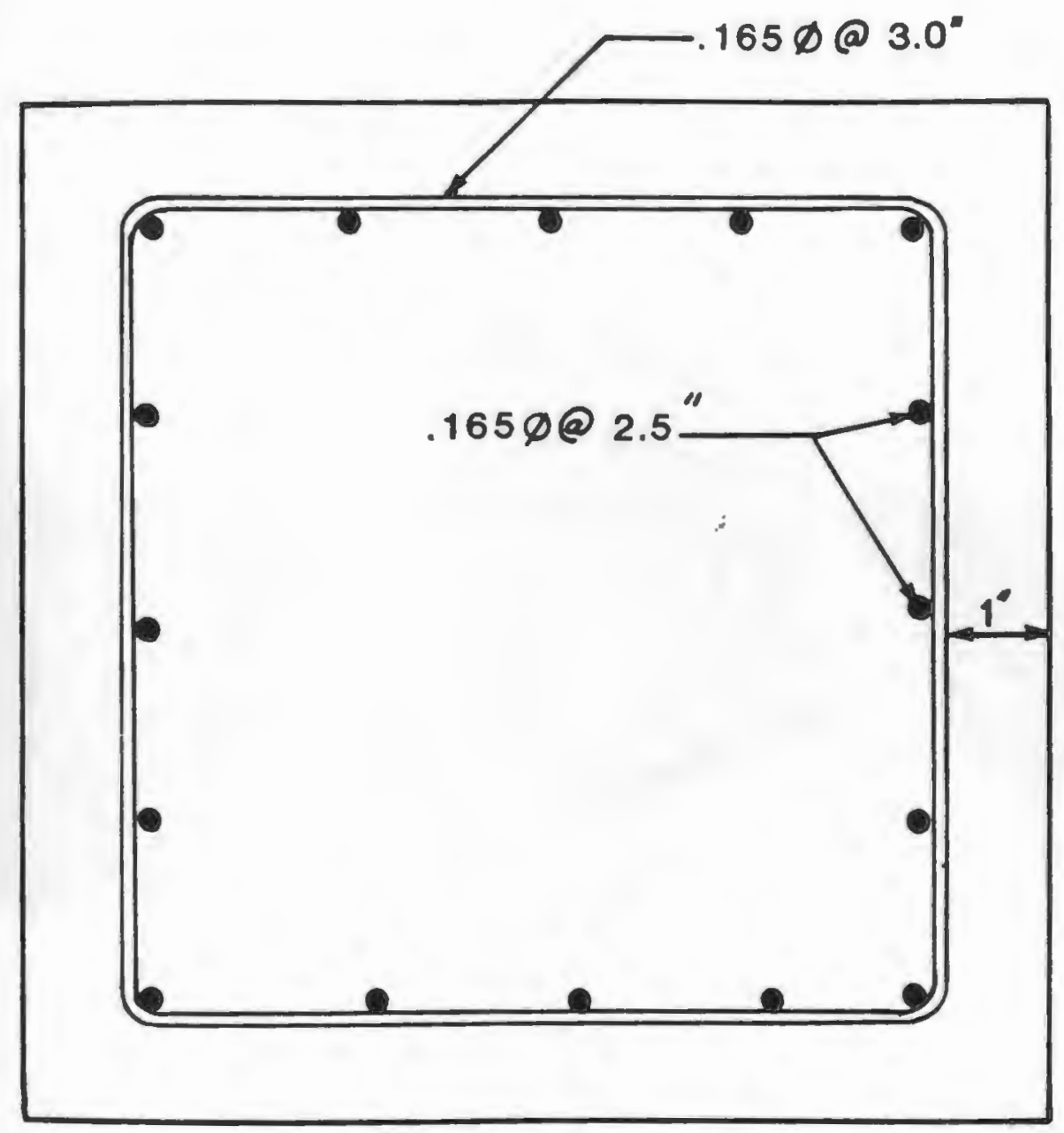

Fig.5: Reinforcement details for blocks(top view). 


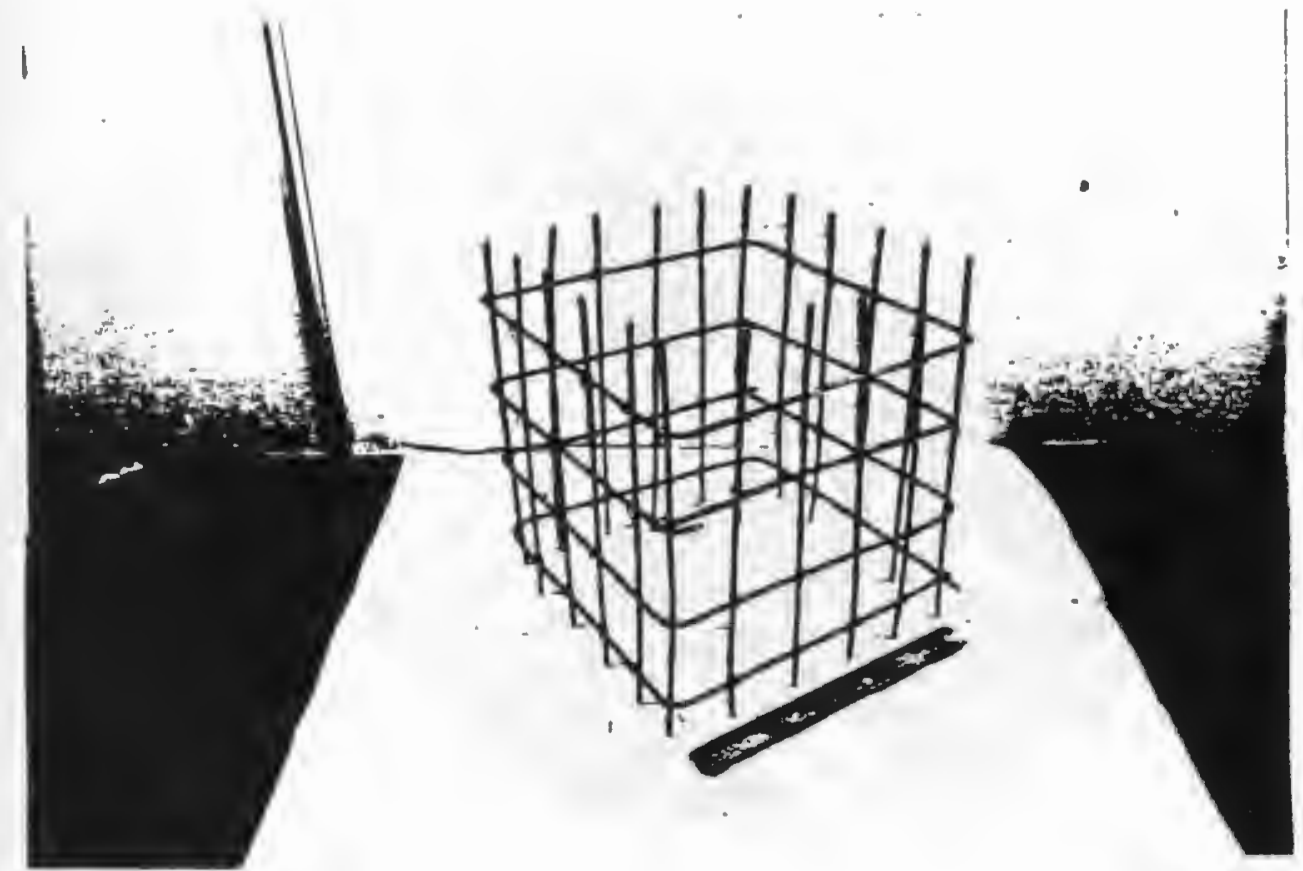

Fig.6: Reinforcement case for $15^{\circ}$ block. 


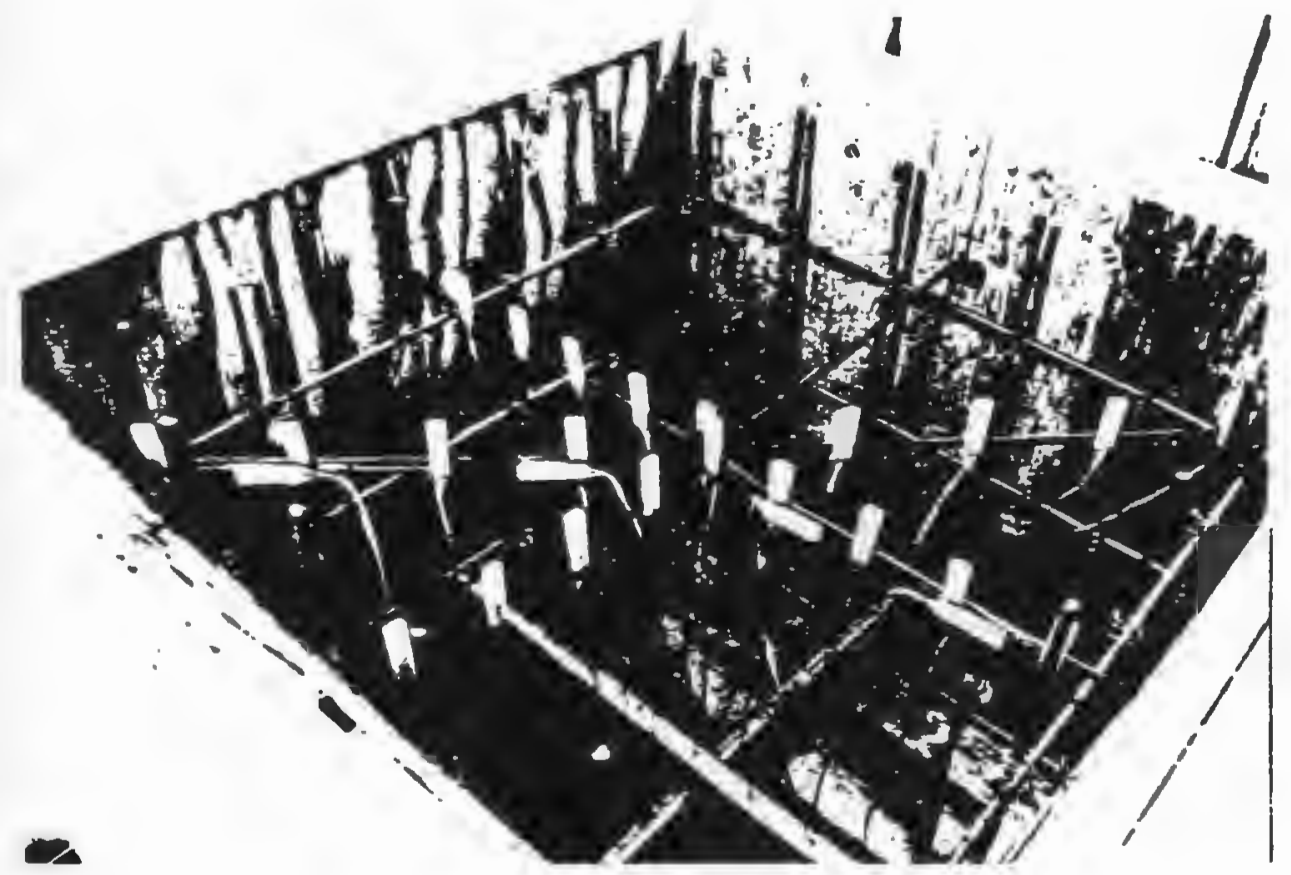

Fig.7: Form for $15^{\prime \prime}$ block after gages were installed. 


\begin{tabular}{||l|c||}
\hline Minimum cement factor: & 5.5 \\
Bags per cu. yd. & 517 \\
Lbs. per cu. yd. & \\
\hline Maximum net water content: & 6.5 \\
Per bag of cement; gal. & 35.75 \\
Per cubic yard, gal. & \\
\hline Consistency range in slump: & $2-3$ \\
Regular placing, in. & $1-2$ \\
\hline Vibrated, in. & 1600 \\
\hline Minirnum compression strength & \\
7 day, poi. & 3000 \\
\hline 28 day, psi.
\end{tabular}

Table 1: RIDOT Specifications for Class B(AE) mix.

\begin{tabular}{||l|c||}
\hline $\begin{array}{l}\text { Date: } \\
\text { Time: }\end{array}$ & $\begin{array}{c}\text { June 14, } 1988 \\
10: 21 \text { a.m. }\end{array}$ \\
\hline Batch Number: & 25 \\
Job Number: & 16 \\
Formula Number: & $71\left(3000\right.$ psi. $1 / 2^{n}$ Standard) \\
\hline Batch Volume: & 2.0 cu. yds. \\
\hline Aggregate 1 (sand): & 3040 lbs. (moisture content $=3.5 \%)$ \\
Aggregate 2 (1/2"): & 3060 lbs. (moisture content $=0.0 \%)$ \\
\hline Cement: & 1032 lbs. \\
\hline Water: & 62 gallons \\
\hline Additives: & A iron= 4.0 os. \\
& Water Reducer WRDA15=32.0 os. \\
\hline
\end{tabular}

Table 2: Concrete Miz proportions.

\begin{tabular}{||c|l|c||}
\hline \hline Cylinder No. & Date tested & Strength (psi.) \\
\hline \hline 1 & June 21 (7 days) & 3978.8 \\
2 & June 21 (7 days) & 4102.7 \\
3 & June 21 (7 days) & 3077.0 \\
\hline
\end{tabular}

Table 3: Cylinder compression test results. 


\begin{tabular}{||c|l|c||}
\hline \hline Cylinder No. & Date tested & Strength (psi.) \\
\hline \hline 4 & July 12(28 days) & 5871.0 \\
5 & July 12 (28 days) & 5818.0 \\
6 & July 12(28 days) & 5835.7 \\
\hline 7 & Sept. 23 & 6286.6 \\
8 & Sept. 23 & 5769.4 \\
9 & Sept. 23 & 5809.1 \\
\hline 10 & Oct. 22 & 6008.0 \\
11 & Oct. 22 & 5810.0 \\
12 & Oct. 22 & 5848.9 \\
\hline 13 & Dec. 19 & 5849.0 \\
14 & Dec. 19 & 5888.7 \\
15 & Dec. 19 & 6167.3 \\
\hline
\end{tabular}

Table 3(continued): Cylinder compression test results.

\begin{tabular}{||l|c|c|c|c|c|c|c|c|c||}
\hline Plate sise: & \multicolumn{3}{|c|}{$10.5 \times 10.5$} & \multicolumn{3}{c|}{$8.5 \times 8.5$} & \multicolumn{3}{|c|}{$6.0 \times 6.0$} \\
\hline Loaded diameter: & 10.3 & 8.3 & 6.0 & 8.3 & 6.8 & 4.8 & 6.0 & 4.8 & 3.4 \\
\hline Overhang: & 0.1 & 1.1 & 2.25 & 0.1 & 0.85 & 1.85 & 0.0 & 0.6 & 1.3 \\
\hline Plate thickness: & & & & & & & & & \\
based on bending: & .037 & .4042 & .827 & .037 & .3123 & .68 & 0.0 & 0.22 & .478 \\
based on shear: & .06 & .16 & .329 & .05 & .127 & .27 & .03 & .09 & .19 \\
Design: & 0.06 & .4042 & .827 & .05 & .3123 & .68 & .03 & .22 & .478 \\
\hline Selected: & .122 & .405 & .836 & .123 & .315 & .685 & .123 & .222 & .478 \\
& .476 & .837 & 1.203 & & & & & & \\
& .837 & 1.203 & 1.626 & & & & & & \\
\hline
\end{tabular}

Table 4(a): Plate Sizes for 12 in. $\times 12$ in. Blocks (1 8 2).

\begin{tabular}{|c|c|c|c|c|c|c|c|c|c|}
\hline Plate sise: & \multicolumn{3}{|c|}{$13.0 \times 13.0$} & \multicolumn{3}{|c|}{$10.5 \times 10.5$} & \multicolumn{3}{|c|}{$7.5 \times 7.5$} \\
\hline Loaded diameter: & 12.7 & 10.3 & 7.3 & 10.3 & 8.3 & 06.0 & 7.3 & 6.0 & 4.25 \\
\hline Overhang: & $\overline{0.15}$ & 1.35 & 2.85 & 0.1 & 1.1 & 2.25 & 0.1 & 0.75 & 1.625 \\
\hline $\begin{array}{l}\text { Plate thickness: } \\
\text { based on bending: }\end{array}$ & .056 & .496 & 1.047 & .0367 & .4042 & .827 & .036 & .276 & .597 \\
\hline based on shear: & .08 & .20 & .42 & .063 & .163 & .33 & .05 & .112 & .24 \\
\hline Design: & 0.08 & .496 & 1.047 & .063 & .4042 & .827 & .05 & .276 & .597 \\
\hline Selected: & .124 & .50 & 1.05 & .122 & .405 & .837 & .123 & .28 & .605 \\
\hline & & & & .476 & .837 & 1.203 & .368 & .605 & .856 \\
\hline & & & & .837 & 1.203 & 1.626 & .605 & .856 & 1.168 \\
\hline
\end{tabular}

Table 4(b): Plate Sizes for 15 in. $\times 15$ in. Blacks (3 \& 1). 
sive tests are given in Table 3 . In addition to this, strain gages were mounted on the surface of one of the cylinders to determine the stress strain relation for the concrete. The stress strain relation obtained can be seen in Fig.8. The slope of the curve in the linear portion of the curve gives the modulus of elasticity for concrete. The modulus of elasticity from this curve came out to $4.55 \times 10^{6}$ psi.

The value of E for concrete as given by ASTM C 469

$$
E=57000 \sqrt{f_{c}^{\prime}}
$$

comes out to $4.36 \times 10^{6}$ psi., using an average value of 5841.6 psi. for $f_{c}^{\prime}$ at 28 days.

\subsection{BEARING PLATES:}

In all twentyone bearing plates were prepared from A-36 steel to study the effect of various parameters such as edge distance, ratio of plate area to block area and plate thickness. The plates were machined by TAB Enterprises, Pawtucket, R.I. The plate edges were cut by flame and had a rough finish. The plate thicknesses were machined by blanchard grinding and had a smooth finish on the top and bottom surfaces.

\subsubsection{SELECTION OF PLATE SIZES:}

Bearing plate sizes were determined on the basis of the ratio of plate area to block area to study the effect of edge distance of plates. Plate area to block area ratios of $0.75,0.50$ and 0.25 were selected. The plate sizes selected are listed in Table 4.

\subsubsection{DESIGN OF PLATE THICKNESSES:}

The design of the bearing plate currently is based on the assumption that the bearing plate distributes the load uniformly from the bearing to the concrete substructure [1], [2]. The thicknesses of the bearing plates were determined based on this assumption. The portion of the plate extending out from the loaded area 


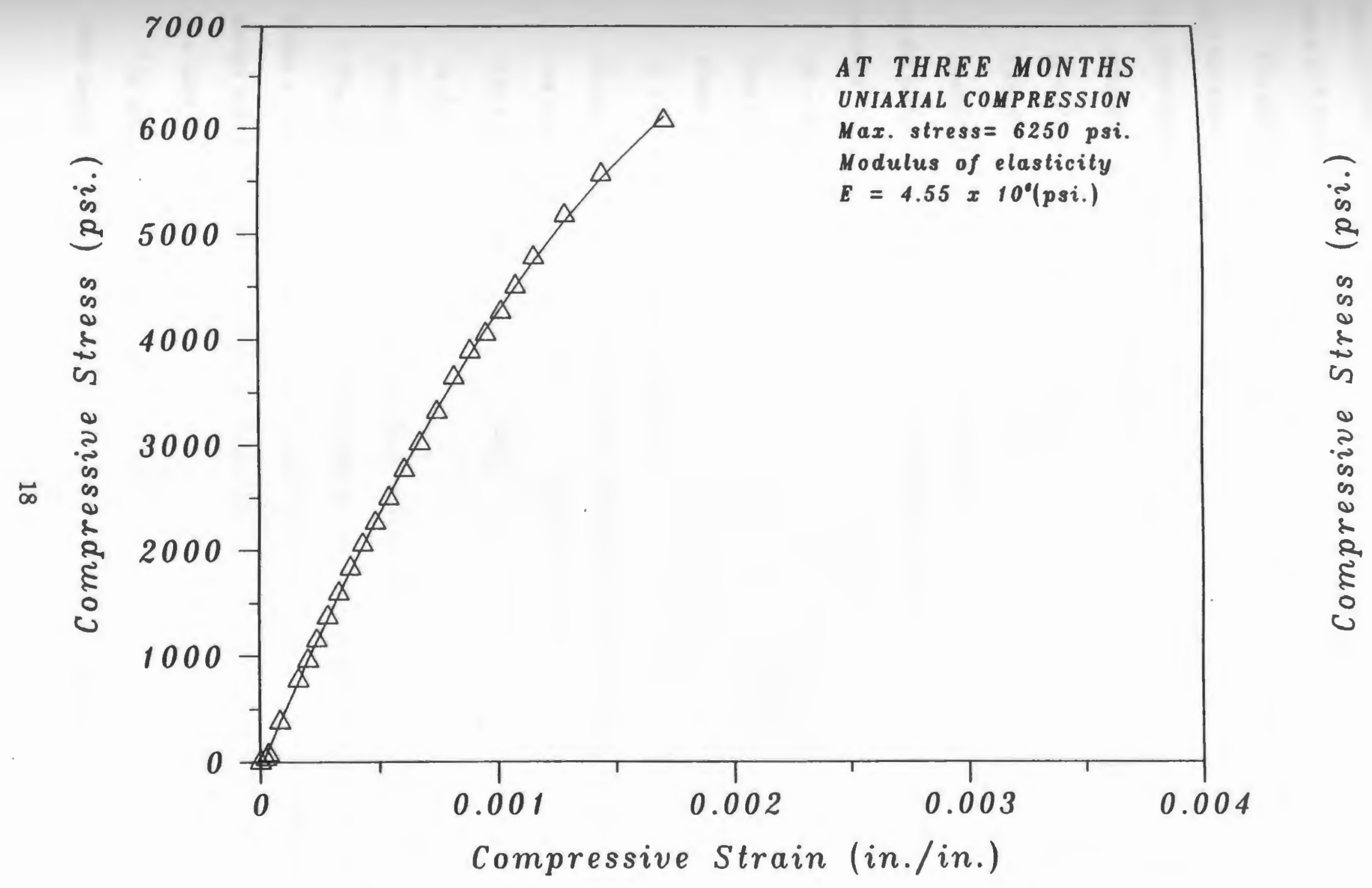

Fig.8: STRESS STRAIN RELATION FOR CONCRETE 
Ferpendicular to the edge of the plate was used as the overhang for designing the plate as a cantilever.

The overhang of the plate varied $b$ ased on the ratio of load area to plate area and the ratio of plate area to block area. The loaded area were selected based on the ratio of load area to plate area ratios of $0.75,0.50$ and 0.25 .

Allowable bearing stress in concrete

$f_{b}=0.3 f_{c}^{\prime} \ldots \ldots . . .$. (AASHTO sec. 1.5.26.(A).(3)) [1]

Therefore for $f_{c}^{\prime}=3000$ psi., $f_{b}=900$ psi.

Designing for bending, assuming a uniformly distributed stress of 900 psi acts on the plate, with an overhang $l$ and assuming a unit width, the maximum bending moment

$M=900 l^{2} / 2$

$S_{\text {req }}=M / f_{b a} ; f_{b a}=0.55 F_{y} \ldots \ldots .$. (AASHTO table 1.7.1A) [1]

Plate thickness $t=\sqrt{6 \times S_{\text {req }}}$

$\Rightarrow t=0.3674 \times l$; where $F_{y}=36 \mathrm{ksi}$.

Designing for shear, assuming square plate size $a \times a$ and loaded diameter $d$, the punching shear force $V=\left(a \times a-\pi d^{2} / 4\right) \times 900$

The allowable shear stress $F_{v}=.33 F_{y} \ldots . . .$. (AASHTO table 1.7.1A) [1]

$\Rightarrow F_{v}=11880$ psi.

Minimum thickness required for shear resistance $=V /(\pi \times d \times 11880)$

The thicknesses of plates based on design for bending and shear are listed in Table 4. The greater of the two was chosen as design thickness. In cases where the design thickness came out to be less than 0.125 in. , a 0.125 in. design thickness was used.

In addition to this to study the effect of thickness some thicknesses greater than design thickness were chosen for plate sizes 10.5in. $\times 10.5 \mathrm{in}$. and for plate sizes 
7.5in. $\times 7.5 i n$.

\subsubsection{MOUNTING OF GAGES ON THE BEARING PLATE:}

The strain gages used for measuring stresses in the steel plate were $120 \Omega$ gages supplied by Micro Measurements and designated as EA-13-125BT-120. These were constantan strain gages and were of open faced construction with a tough flexible polymide film backing.

Gages were mounted on top surface as well as the bottom surface of the bearing plate, close to the loaded area of the overhang to measure the expected maximum stresses resulting from the bending of the plate. Locations of gages on the plate can be seen in Fig.9. The convention used for the nomenclature of the gages is as follows:

(a). The gage located along the diagonal of the plate was called e.g. top(d), if it was on the top surface of the plate.

(b). The gage located on the line joining the centers of the two opposite edges was called e.g. top(c) if it was on the top surface of the plate, and bot(c) if it was on the bottom surface of the plate.

For achieving perfect bonding between the gage and the plate, the steel plate surface was cleaned with degreasing agent, sanded with a fine paper and cleaned with alcohol. Krazy glue extra strength gel was used for attaching the gages to the surface. After the gages were mounted on the bearing plate they were left for 24 hours for the glue to dry. After the glue had dried, leads were carefully soldered to the gages.

\subsection{INSTRUMENTATION:}

The loading apparatus and the data acquisition system were about 70 feet apart, therefore twisted and shielded low voltage cables had to be run from the strain gauges on the specimen to the data acquisition system. Since there were over thirty 
strain gages it was decided to have a separate wheatstone bridge circuit for each gage rather than having a single bridge and switching gages. This helped to keep the gages energized at all times and minimised the dynamic heating and cooling effects. For measuring strains in the gages simultaneously and avoiding the process of balancing the wheatstone bridge each time, the method of unbalanced wheatstone bridge strain measurement was used [9].

\subsubsection{DESCRIPTION OF EQUIPMENT USED:}

The instruments and equipment used during the experiments are described as follows:

1. Tinius Olsen 300,000 lbs. capacity Super-L Universal Testing Machine, located in the Civil Engineering laboratory.

2. Hydraulic pressure transducer, Dynisco; PT 310J 1M. This transducer was used for measuring load applied to the specimen. It was inserted in the middle range hydraulic lines of the testing machine, which pressurize the piston applying the load to the specimen. The transducer was calibrated against the load dial of the machine. The calibration curve is given in Appendix A.

3. Linear displacement transducer, HP 24DCDT-250. for measuring slip between the bearing plate and the concrete. The transducer was calibrated and the calibration curve is given in Appendix A.

4. Linear displacement transducer, HP 24DCDT-500. for measuring lift at the corner of the bearing plate. The calibration curve is given in Appendix A.

5. Thirty four wheatstone bridge circuits with $120 \Omega$ resistor in each arm and one strain gage as the active arm.

6. A 24 volt regulated power supply for displacement transducers, a 10 volt power supply for pressure transducer, and a 5 volt regulated power supply for the wheatstone bridge circuits. 

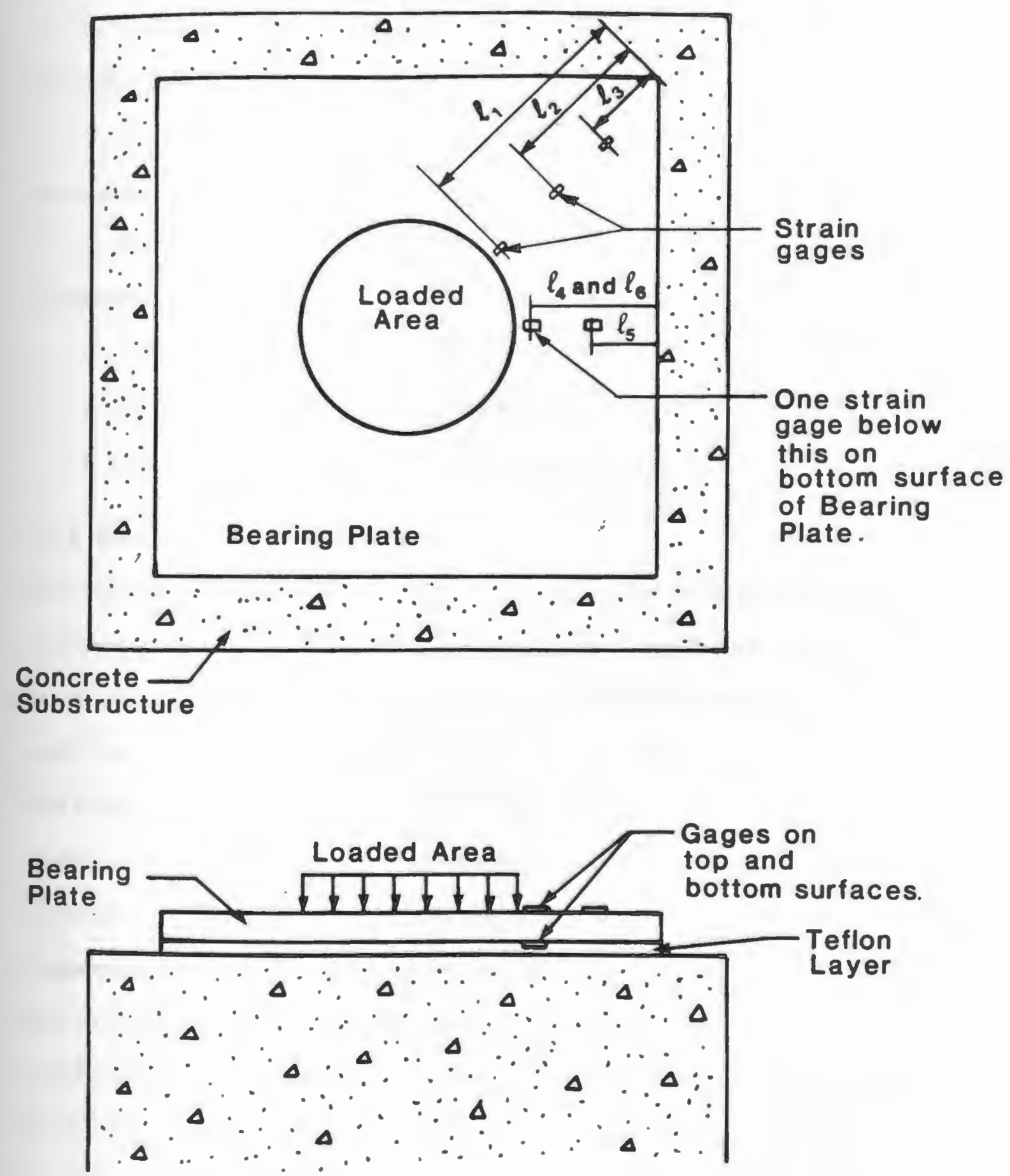

Fig.9: Locations of gages on Bearing Plate. 
7. Hewlett Packard Data Acquisition System, HP 3052A. This includes the following:

a. Scanner - HP 3495A. Scans analog signals from preselected or programmed channels at preselected time intervals.

b. Voltmeter - HP 3455A. Measures analog signal from scanner and converts into digital signal precisely upto 1 microvolt.

c. Computer - HP 9816. Helps control the data acquisition and performs the computations.

d. Plotter - HP 9872A. Plots desired data and is controlled by the computer.

e. Printer - HP 2671G. Prints desired output or listing of programs.

f. Disk drive - HP 9121, used for accessing programs and data files.

\subsubsection{RECORDING SCHEMATIC:}

The recording schematic can be seen in Fig.10. The leads from the strain gages were connected to the wheatstone bridges with each gage acting as an active arm of the wheatstone bridge. The wheatstone bridges had a power supply of 5 volts and the output from the bridges went to the 20-channel connector assemblies at the back of the scanner. These assemblies acted as interface to the scanner. Each assembly handled 20 differential channels (i.e. 20 high and 20 low inputs). The common from these assemblies was connected to the 2 wire and 4 wire ground connectors at the back. The pressure transducer has a power supply of 10 volts and the output from the pressure transducer went to the scanner. Leads from the linear displacement transducers for measuring the slip and lift of the bearing plate relative to the concrete block were also connected to the scanner. The digital voltmeter was connected to the scanner and read the voltage from the channel scanned. The digital output from the voltmeter went to the computer from which the data was processed and sent to the printer, the plotter and the magnetic disk drive. 


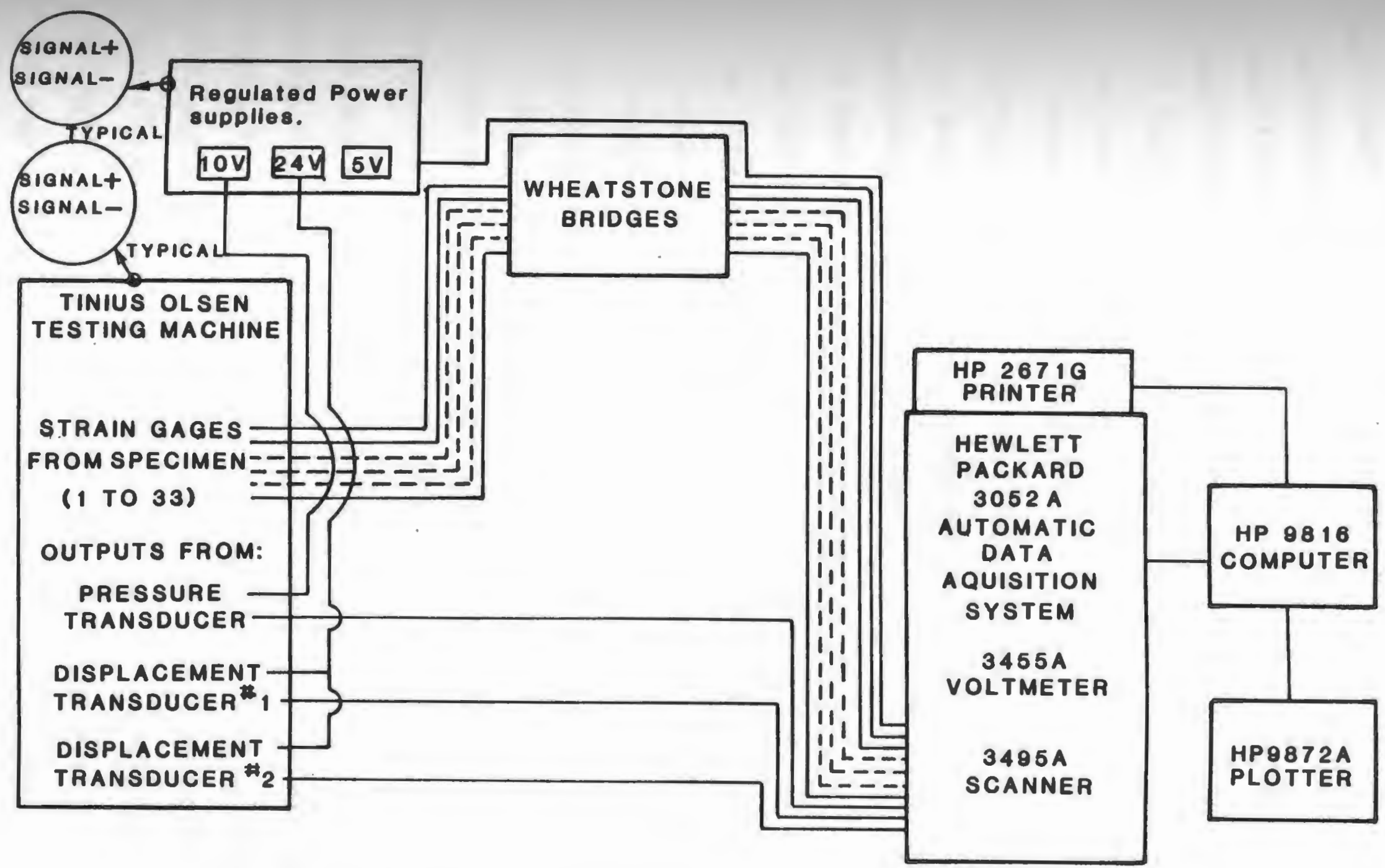

Fig.10: Recording Schematic. 
2.3.3 COMPUTER PROGRAMS USED FOR TESTING:

The computer programs used for monitoring the testing are given in Appendix B. Program 1 was used for the working stress range tests. Program 2 was used for the ultimate load tests. Input to the programs included the following:

a. Bearing Number, i.e. the number of the concrete block .

b. Number of strain gages, including both steel and concrete.

c. Number of types of gages being used.

d. Type of gage, Start channel, End channel and Gage factor for each type.

e. Slope and intercept from the calibration curve for pressure transducer to convert pressure transducer readings to load.

f. Name of Operator, Date and time of Test.

g. Dimensions of the bearing plate.

h. Diameter of the loaded area.

i. Name of data file for storing raw data.

j. Name of data file for storing processed data.

k. Number of readings to be taken for each gage.

1. Delay between two sets of readings in milliseconds.

After all the necessary input had been fed in, the program paused until the "continue" key was pressed and the first set of readings started after 5 seconds.

\subsubsection{DATA ACQUISITION AND CONTROL:}

Once the "continue" key was pressed the data acquisition started and the preselected channels were scanned for each set of readings and readings were printed on the screen and stored in the previously named data file. Initial readings were taken close to zero load and then the bearing system was loaded slowly. The load was held appraximately constant when each set of readings were taken. The following values were read: 
a. Channel 1 thru a maximum of channel 33 , voltage outputs from the gage wheatstone bridges.

b. Channel 38 read the output from the pressure transducer, which was read twice, once before each set of readings were taken and once after.

c. Channel 39 read the input voltage supplied to the wheatstone bridges at the time each set of readings was taken.

d. Channel 37 read the output from the transducer used to measure slip between the bearing plate and concrete block (only for ultimate load tests).

e. Channel 34 read the output from the transducer used to measure lift at the edge of the plate relative to the concrete block (only for ultimate load tests).

\subsubsection{DATA REDUCTION AND PROCESSING:}

The strains were calculated as [9]

$$
\begin{aligned}
& \epsilon=\left[\frac{-4 V_{r}}{G F \times\left(1+2 V_{r}\right)}\right] \\
& \text { where } V_{r}=\left[\left(\frac{V_{\text {out }}}{V_{\text {in }}}\right)_{\text {strained }}-\left(\frac{V_{\text {out }}}{V_{\text {in }}}\right)_{\text {unotrained }}\right]
\end{aligned}
$$

$V_{i n}$ and $V_{\text {out }}$ being the input and output voltages to the wheatstone bridge (Fig.11) and GF being the gage factor for the gage.

The first set of readings close to zero load were regarded as unstrained and the remainder were considered to be under strained condition. For each gage the ratio $V_{\text {out }} / V_{i n}$ was calculated at each set of readings and strain $\epsilon$ was computed.

The wheatstone bridge circuits set up in the lab gave satisfactory results. The modulus of elasticity computed for concrete from the stress strain curve came out to be very close to the expected theoretical value. However, it should be noted that no calibration of the wheatstone bridges was done.

Readings from the pressure transducer were converted to load based on the slope and intercept from the calibration curve Appendix A.

For the ultimate load tests, the readings from the displacement transducers 


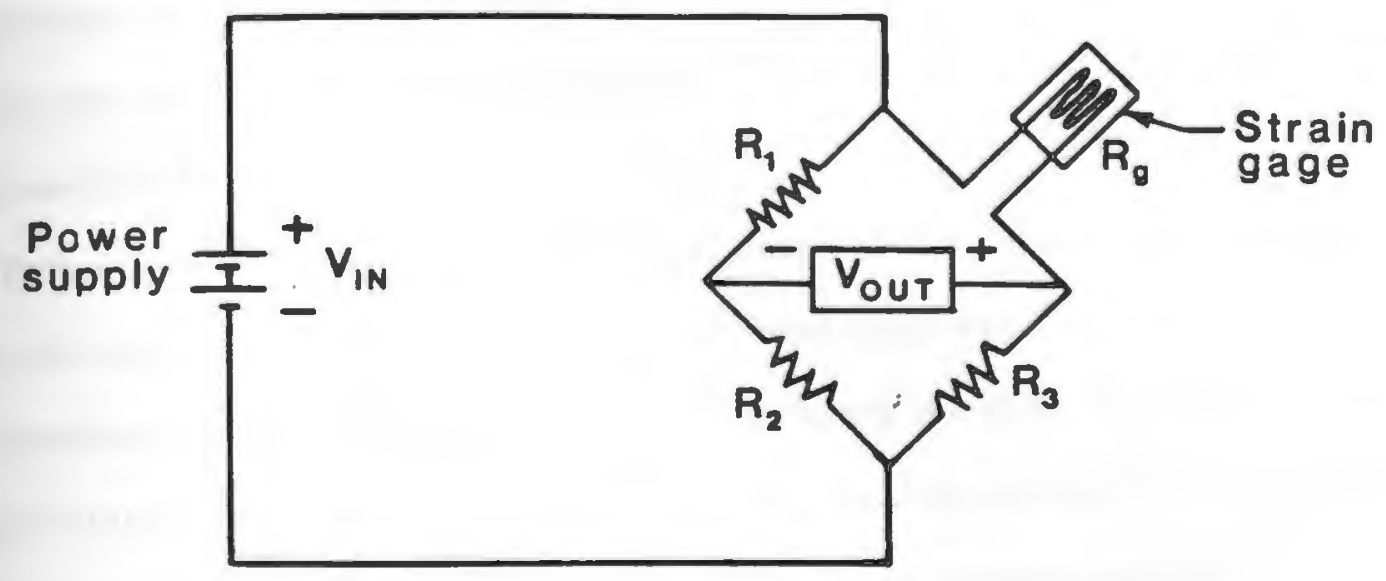

Fig.11: Wheatstone bridge circuit with a strain gage as its active arm. 
were converted to displacements based on the slopes and intercepts from the calibration curves Appendix A.

\subsection{TESTING PROGRAM:}

The intention of this experimental investigation was to study the effect of various parameters such as plate thickness, ratio of load area to plate area, ratio of plate area to block area, and blocksize on distribution of stresses the concreete substructure. The testing program consisted of 72 tests in the working stress range and 4 tests, one for each concrete block, to ultimate load. Table 5. gives the description of the tests conducted.

Before the actual tests were conducted, some preliminary tests were done to verify the accuracy of the equipment, e.g. a three point bend test on a plate was conducted and stresses were measured on the surface of the plate by attaching strain gages to the surface of the plate. Another test was done to determine the stress strain relation for steel in uniaxial tension. The results were satisfactory.

\subsubsection{TESTING PROCEDURE:}

The top surface of the concrete blocks were leveled using a high strength leveling compound (Savogran's level best floor leveler). An eighth inch thick teflon sheet was used beneath the bearing plate to even out any unevenness on the concrete surface. A concrete block was then put on the Tinius Olsen testing machine and all the working stress range tests corresponding to that block were conducted. Once all the tests in the working stress range were complete, the ultimate load tests were done.

The loading arrangement can be seen in Fig.12.

The procedure used during testing is elaborated as follows:

1. Strain gages were mounted on the bearing plate at the desired locations and the bearing plate was put on the concrete block. 


\begin{tabular}{|c|c|c|c|c|}
\hline \multirow[b]{2}{*}{ Block No. } & \multirow[b]{2}{*}{ Test No. } & \multicolumn{2}{|c|}{ Bearing Plate } & \multirow{2}{*}{$\begin{array}{c}\text { Loaded Area } \\
\text { (circular) } \\
\text { (sq.in.) }\end{array}$} \\
\hline & & $\begin{array}{l}\text { Thickness } \\
\text { (inches.) }\end{array}$ & $\begin{array}{c}\text { Area } \\
\text { (sq.in.) }\end{array}$ & \\
\hline \multirow[t]{15}{*}{ One } & 1 & 0.122 & 110.36 & 87.25 \\
\hline & 2 & 0.405 & 114.06 & 58.09 \\
\hline & 3 & 0.476 & 113.63 & 87.25 \\
\hline & 4 & 0.837 & 113.84 & 87.25 \\
\hline & 5 & 0.837 & 113.84 & 58.09 \\
\hline & 6 & 0.837 & 113.84 & 30.09 \\
\hline & 7 & 1.203 & 113.85 & 58.09 \\
\hline & 8 & 1.203 & 113.85 & 30.09 \\
\hline & 9 & 1.626 & 113.95 & 30.09 \\
\hline & 10 & 0.123 & 72.16 & 58.09 \\
\hline & 11 & 0.315 & 75.04 & 39.26 \\
\hline & 12 & 0.685 & 75.08 & 19.17 \\
\hline & 13 & 0.123 & 36.12 & 30.09 \\
\hline & 14 & 0.222 & 38.19 & 19.17 \\
\hline & 15 & 0.478 & 37.70 & 10.64 \\
\hline \multirow[t]{15}{*}{ Two } & 16 & 0.122 & 110.36 & 87.25 \\
\hline & 17 & 0.405 & 114.06 & 58.09 \\
\hline & 18 & 0.476 & 113.63 & 87.25 \\
\hline & 19 & 0.837 & 113.84 & 87.25 \\
\hline & 20 & 0.837 & 113.84 & 58.09 \\
\hline & 21 & 0.837 & 113.84 & 30.09 \\
\hline & 22 & 1.203 & 113.85 & 58.09 \\
\hline & 23 & 1.203 & 113.85 & 30.09 \\
\hline & 24 & 1.626 & 113.95 & 30.09 \\
\hline & 25 & 0.123 & 72.16 & 58.09 \\
\hline & 26 & 0.315 & 75.04 & 39.26 \\
\hline & 27 & 0.685 & 75.08 & 19.17 \\
\hline & 28 & 0.123 & 36.12 & 30.09 \\
\hline & 29 & 0.222 & 38.19 & 19.17 \\
\hline & 30 & 0.478 & 37.70 & 10.64 \\
\hline \multirow[t]{8}{*}{ Three } & 31 & 0.124 & 168.93 & 130.9 \\
\hline & 32 & 0.500 & 173.58 & 87.25 \\
\hline & 33 & 1.050 & 172.92 & 45.25 \\
\hline & 34 & 0.122 & 110.36 & 87.25 \\
\hline & 35 & 0.405 & 114.06 & 58.09 \\
\hline & 36 & 0.476 & 113.63 & 87.25 \\
\hline & 37 & 0.837 & 113.84 & 87.25 \\
\hline & 38 & 0.837 & 113.84 & 58.09 \\
\hline
\end{tabular}

Toble 5: Working stress range tests conducted 


\begin{tabular}{|c|c|c|c|c|}
\hline \multirow[b]{2}{*}{ Black No. } & \multirow[b]{2}{*}{ Test No. } & \multicolumn{2}{|c|}{ Bearing Plate } & \multirow{2}{*}{$\begin{array}{c}\text { Loaded Area } \\
\text { (circuler) } \\
\text { (sq.in.) }\end{array}$} \\
\hline & & $\begin{array}{l}\text { Thickness } \\
\text { (irches.) }\end{array}$ & $\begin{array}{c}\text { Area } \\
\text { (sq.in.) }\end{array}$ & \\
\hline \multirow[t]{13}{*}{ Three } & 39 & 0.837 & 113.84 & 30.09 \\
\hline & 40 & 1.203 & 113.85 & 58.09 \\
\hline & 41 & 1.203 & 113.85 & 58.09 \\
\hline & 42 & 1.627 & 113.96 & 30.08 \\
\hline & 43 & 0.123 & 56.33 & 45.25 \\
\hline & 44 & 0.280 & 58.36 & 30.09 \\
\hline & 45 & 0.368 & 58.06 & 45.25 \\
\hline & 46 & 0.605 & 58.91 & 45.25 \\
\hline & 47 & 0.605 & 58.91 & 30.09 \\
\hline & 48 & 0.605 & 58.91 & 15.62 \\
\hline & 49 & 0.856 & 58.60 & 30.09 \\
\hline & 50 & 0.856 & 58.60 & 15.62 \\
\hline & 51 & 1.168 & 58.91 & 15.62 \\
\hline \multirow[t]{21}{*}{ Four } & 62 & 0.124 & 168.93 & 130.9 \\
\hline & 53 & 0.500 & 173.58 & 87.25 \\
\hline & 54 & 1.050 & 172.92 & 45.25 \\
\hline & 55 & 0.122 & 110.36 & 87.25 \\
\hline & 56 & 0.405 & 114.06 & 58.09 \\
\hline & 57 & 0.476 & 113.63 & 87.25 \\
\hline & 58 & 0.837 & 113.84 & 87.25 \\
\hline & 69 & 0.837 & 113.84 & 58.09 \\
\hline & 60 & 0.837 & 113.84 & 30.09 \\
\hline & 61 & 1.203 & 113.85 & 58.09 \\
\hline & 62 & 1.203 & 113.85 & 58.09 \\
\hline & 63 & 1.627 & 113.96 & 30.09 \\
\hline & 64 & 0.123 & 56.33 & 45.25 \\
\hline & 65 & 0.280 & 58.36 & 30.09 \\
\hline & 66 & 0.368 & 58.06 & 45.25 \\
\hline & 67 & 0.605 & 58.91 & 45.25 \\
\hline & 68 & 0.605 & 58.91 & 30.08 \\
\hline & 69 & 0.605 & 58.91 & 15.62 \\
\hline & 70 & 0.856 & 58.60 & 30.09 \\
\hline & 71 & 0.856 & 58.60 & 15.62 \\
\hline & 72 & 1.168 & 58.91 & 15.62 \\
\hline
\end{tabular}

Table 5(continued): Working stress range tests conducted

\begin{tabular}{||c|c|c|c|c|c|c||}
\hline \hline \multirow{2}{*}{$\begin{array}{c}\text { Test } \\
\text { No. }\end{array}$} & \multirow{3}{*}{$\begin{array}{c}\text { Black } \\
\text { No. }\end{array}$} & $\begin{array}{c}\text { Thickness } \\
\text { (in.) }\end{array}$ & $\begin{array}{c}\text { Area } \\
\text { (sq.in.) }\end{array}$ & $\begin{array}{c}\text { Area } \\
\text { (sq.in.) }\end{array}$ & $\begin{array}{c}\text { Plate Area } \\
\text { to }\end{array}$ & $\begin{array}{c}\text { Load Area } \\
\text { to } \\
\text { Plate Area }\end{array}$ \\
\hline \hline $73^{*}$ & 4 & 0.837 (design) & 113.84 & 30.09 & 0.50 & 0.26 \\
74 & 4 & 0.605 (design) & 58.91 & 15.62 & 0.26 & 0.26 \\
75 & 3 & 0.856 (>design) & 58.60 & 15.62 & 0.26 & 0.26 \\
76 & 2 & 0.685 (design) & 75.08 & 19.17 & 0.52 & 0.26 \\
77 & 1 & 0.315 (<design) & 75.04 & 19.17 & 0.52 & 0.26 \\
\hline
\end{tabular}

Block did not fail at 250 kips. (maximum capacity of pressure transducer).

Table 6: Untimate load tests conducted on Blocks 


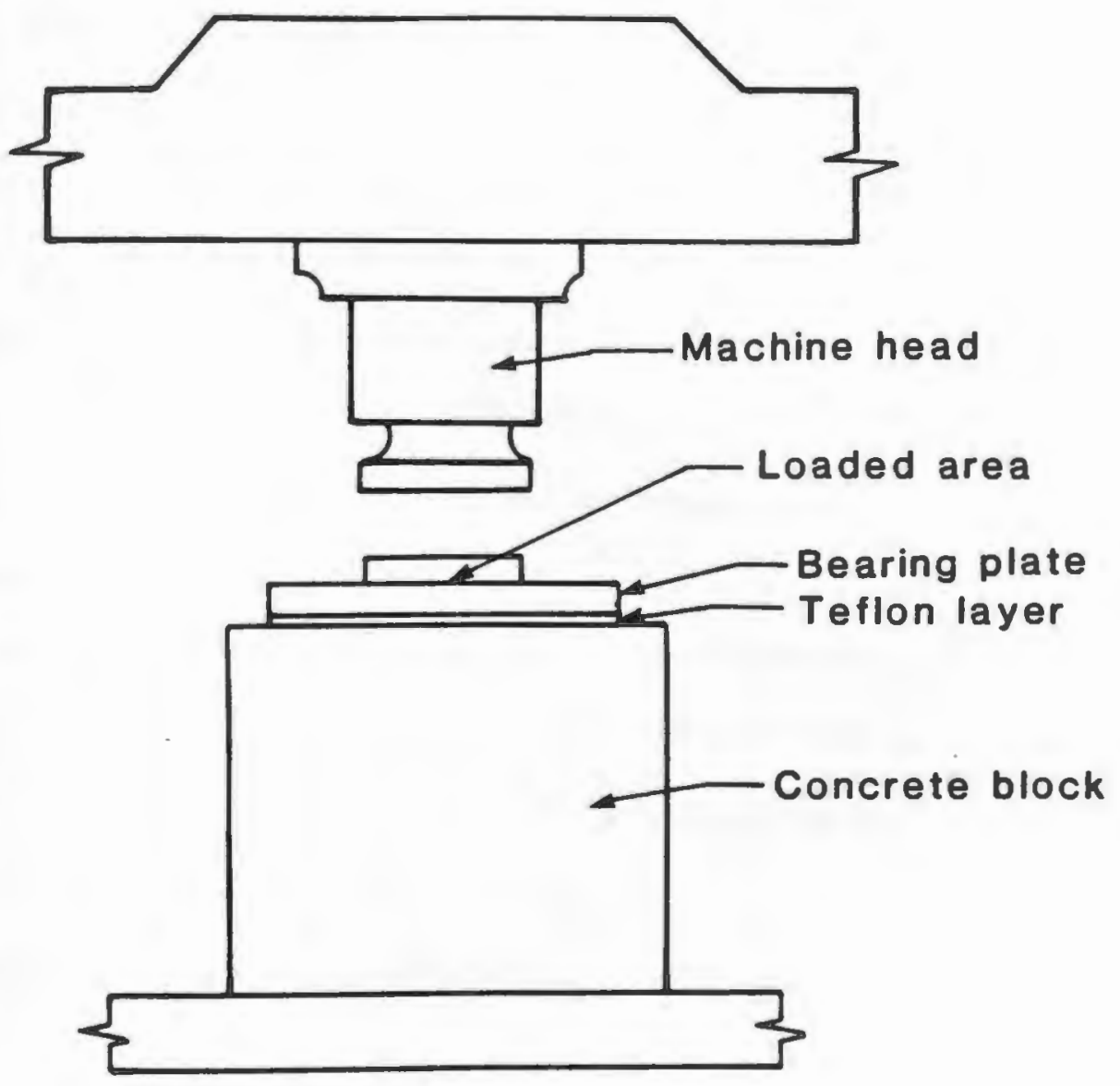

Fig.12: Loading arrangement 
2. Leads from all the gages were connected to the wheatstone bridges making note of each particular gage and its corresponding channel number.

3. The power supply for the wheatstone bridges and transducers were turned on for 15 minutes to stabilize the circuits.

4. A circular plate of desired size for the required loaded area was put on the bearing plate. (The loading head of the testing machine was of 8.5 " diameter therefore the thickness of circular plates for loaded diameter close to 8.5" or less than 8.5" were not important and were chosen as 0.5 ". For the loaded diameter greater than 8.5 " the thickness of circular plates was chosen as $1.5^{\prime \prime}$ ).

5. In case of the ultimate load tests, the transducers were mounted for measuring slip at the edge of the bearing plate and for measuring lift at the corner of the bearing plate relative to the concrete.

6. The computer program was loaded, run and the necessary information was input. An interval of about 60 seconds was specified between each set of readings.

7. The Tinius Olsen machine was started and a negligible load of about 0.1 kips was put on the bearing.

8. The data acquisition was started by pressing the "continue" key on the kyboard.

9. The load was then applied to the bearing at the rate of approximately 15 kips. per minute. The load was held approximately constant when the data was being acquired.

10. The last reading was taken at a predetermined maximum applied load.

\subsubsection{TESTS WITHIN WORKING STRESS RANGE:}

For the tests under the working stress range the data was acquired only while loading the bearing. Tests 1 through 72 were conducted under the working stress range. The maximum load applied to the bearing was determined by assuming that 
the load was being distributed uniformly to, just under the loaded area and not under the entire bearing plate. So to get the maximum load applied, the allowable bearing stress was multiplied by the loaded area. This was done to make sure that the stresses in concrete did not exceed the allowable stresses.

\subsubsection{ULTIMATE LOAD TESTS:}

Load was applied to each block till the block failed or to the maximum capacity of the machine. Table 6 lists the ultimate load tests conducted on the four blocks.

Test 73 was done on block 4 , but the block did not fail so another test 74 had to be conducted on block 4 .

The criteria for selection of the plate sizes and the loaded area were:

(a). Wanted the block to fail within the capacity of the testing machine so that the ultimate load could be determined.

(b). Study the effect of plate thickness.

For one of the 15" blocks, design thickness was used and for the other 15 " block bearing plate thickness greater than design thickness was used. Rest parameters were kept the same for both.

For one of the 12" blocks, design thickness was used and for the other 12 " block plate thickness less than design thickness was used. Rest parameters were kept the same for both.

Strain gage and slip data was acquired while loading as well as unloading the bearing. The measurement of slip is described in the next subsection.

While performing the ultimate test on block 4 (test 74) it was observed that the edges of the bearing plate lifted away up from the concrete block by a considerable amount, so it was decided to measure the lift at the corner of the bearing plate with the help of another transducer. This is described in subsection 2.5.1.2.(b). 


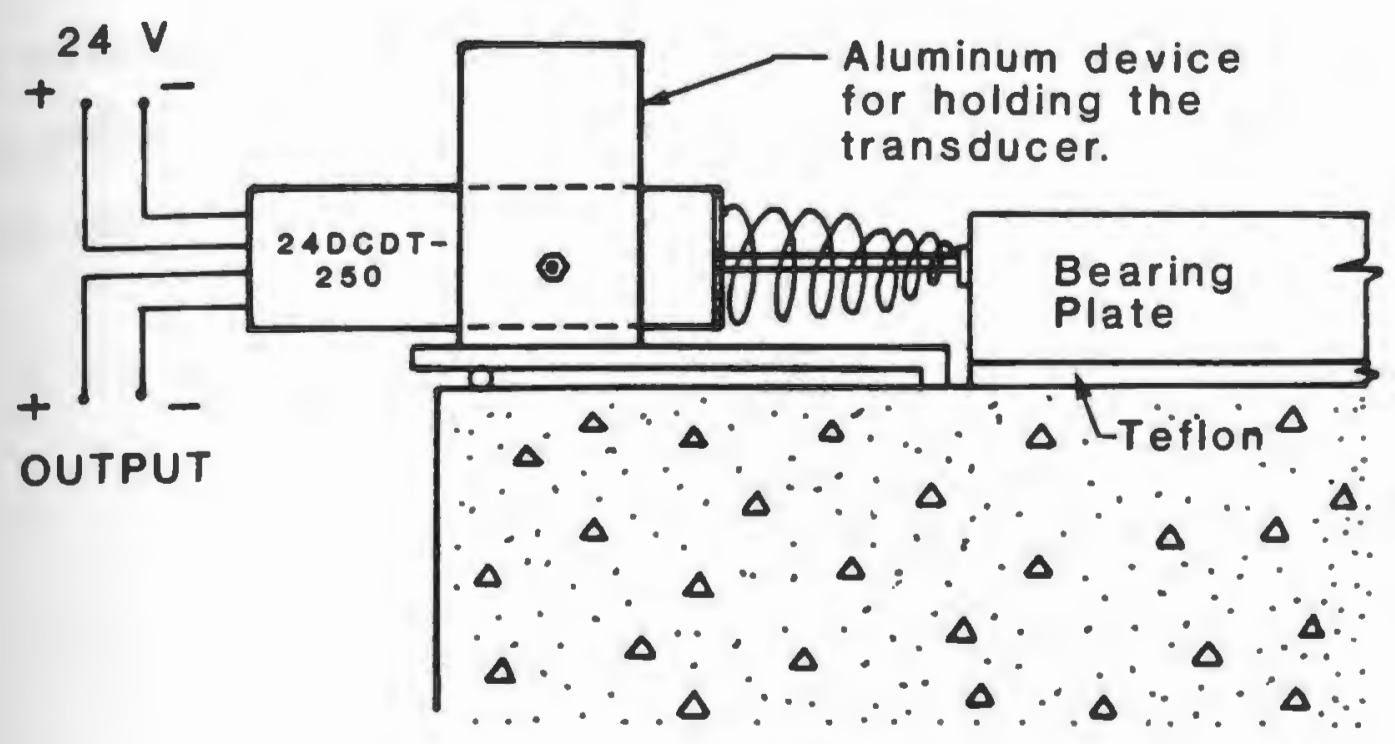

Concrete Block

Fig.13: Device for slip measurement 


\subsubsection{2.(a) SLIP MEASUREMENT:}

Horizontal slip at the edge of the bearing plate relative to the concrete block was vaccessfully measured with the help of a linear displacement transducer for tests 74 , 75, 76 and 77. The device used for slip measurement can be seen in Fig.13.

\subsubsection{2.(b) LIFT MEASUREMENT:}

Lift of the bearing plate relative to the concrete at the corner of the plate was successfully measured for tests $75,76 \& 77$. The device used for lift measurement can be seen in Fig.14. 


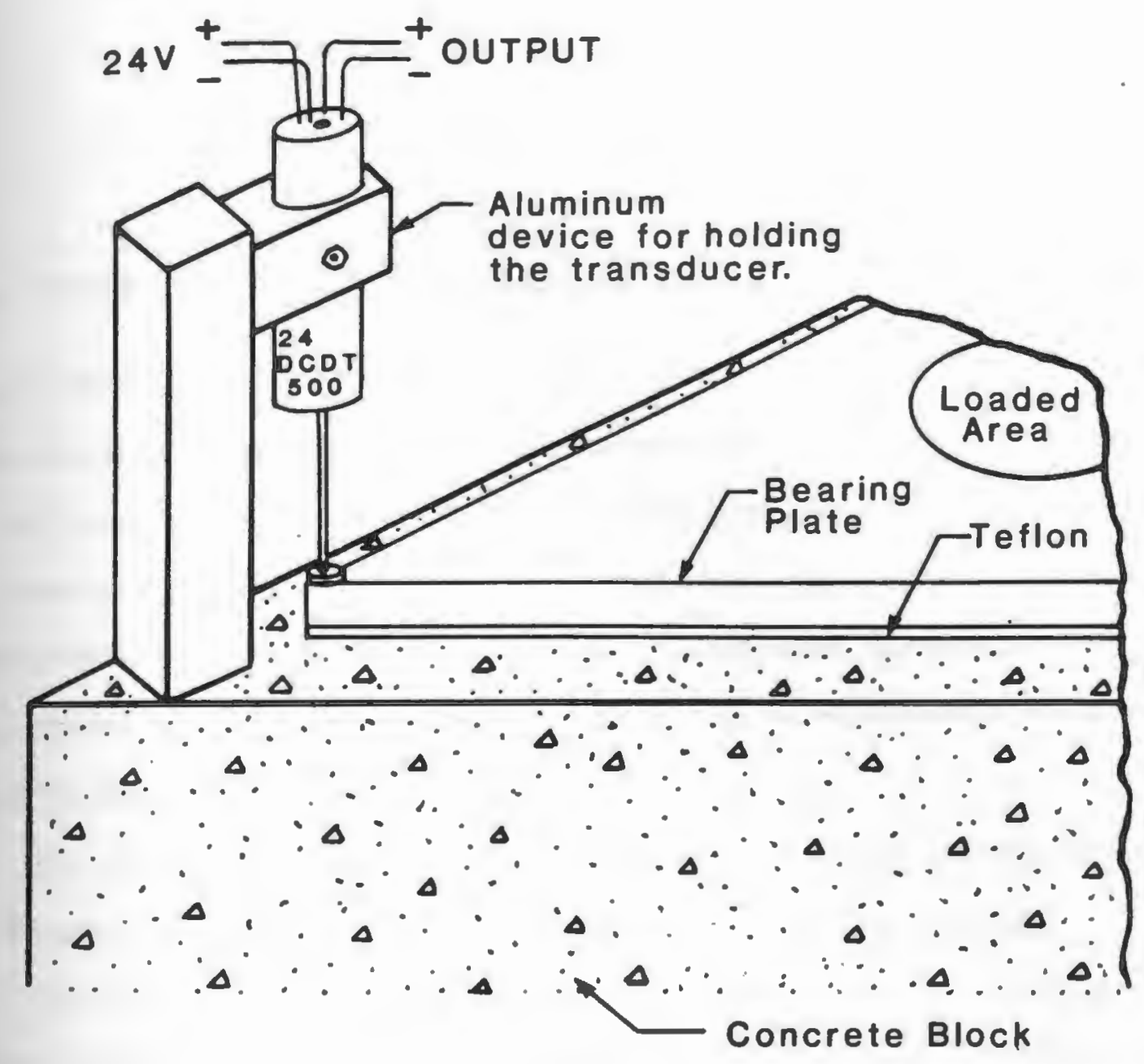

Fig.14: Device used for Lift measurement. 


\section{CHAPTER 3}

\section{TEST RESULTS}

\subsection{WORKING STRESS RANGE TESTS:}

\subsubsection{STRESSES IN CONCRETE:}

The vertical stress distribution inside the concrete substructure (at a load level of $\sim 0.4 f_{c}^{\prime}$ based on loaded area) at a distance of 2.5 inches below the bearing plate is shown in Figs. 15 thru 86. A ratio of actual stress measured to the uniformly distributed stress beneath the total plate area (as expected based on the current assumption), called the stress ratio from hereon is plotted as a function of distance from the center of the block.

The plots show the actual data points as well as a least squares fit cubic polynomial. The scatter in the data could be attributed to the following:

(a). The gage readings were highly sensitive to the evenness of the concrete surface, which could not be made perfectly even and horizontal. The thin teflon layer used between the bearing plate and the concrete minimised the unevenness but did not eliminate it completely.

(b). The inclination of the gage might have changed while pouring or compacting the concrete.

As it can be noted from the plots that the stress distribution in the concrete beneath the bearing plate is not at all uniform, but on the contrary to the assumption varies nonlinearly with very high stresses resulting in the center and low stresses near the edges of the bearing plate. In a few cases the stress ratio at the center was 


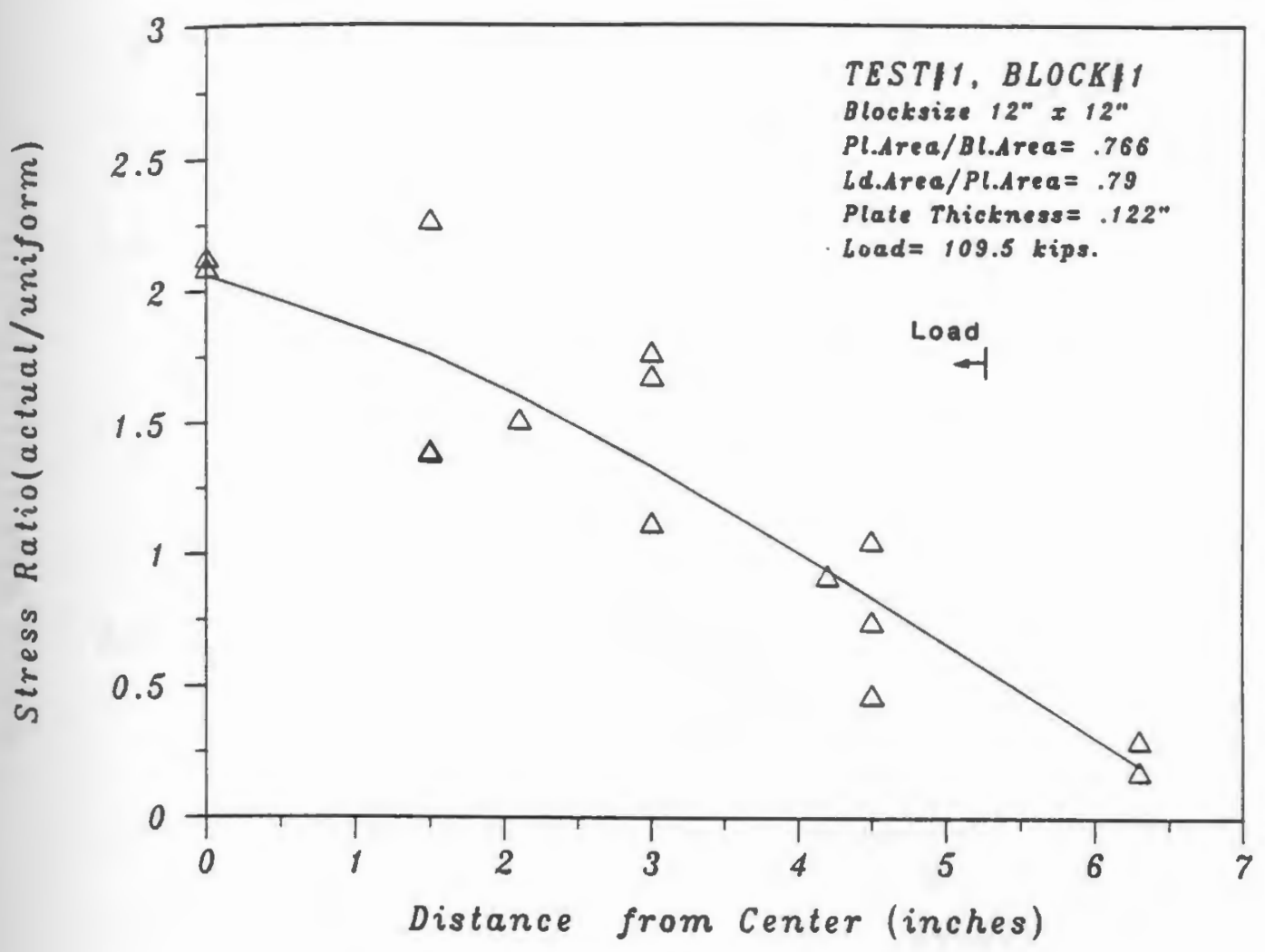

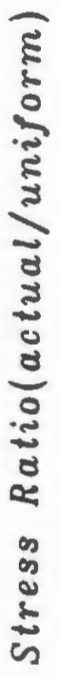

Fig.15: DISTRIBUTION OF STRESSES

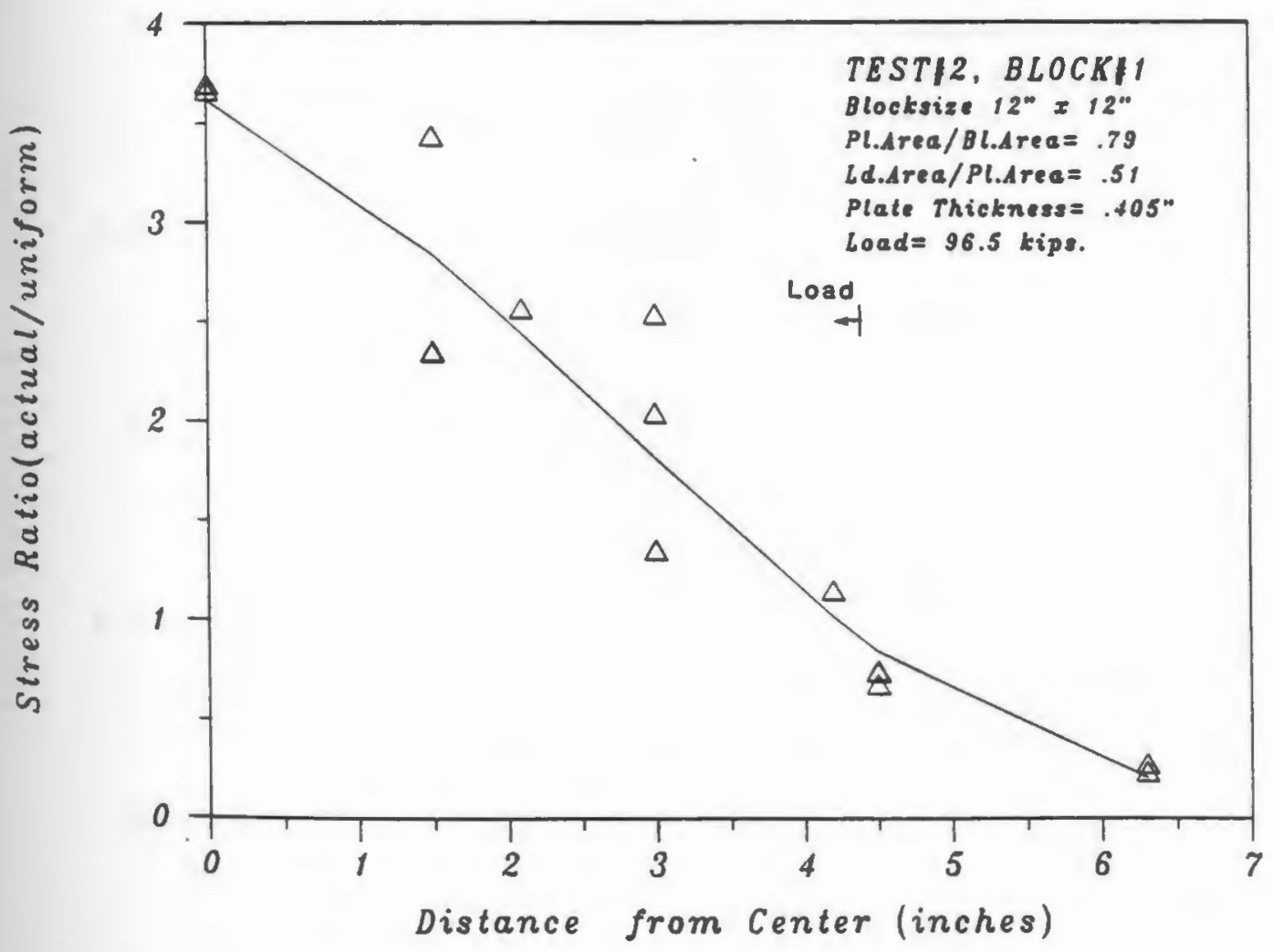

है

Fig.16: DISTRIBUTION OF STRESSES 


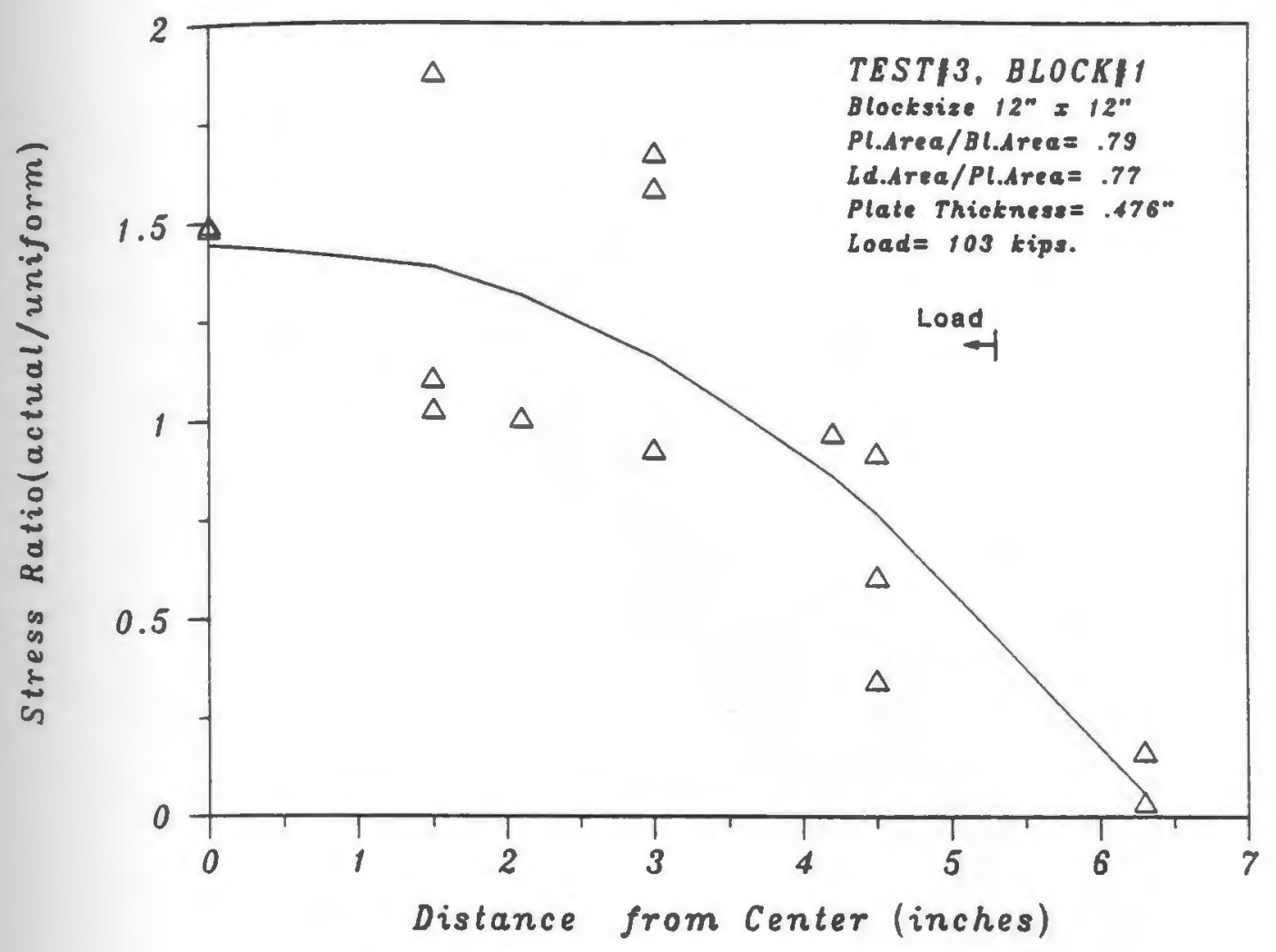

है

Fig.17: DISTRIBUTION OF STRESSES

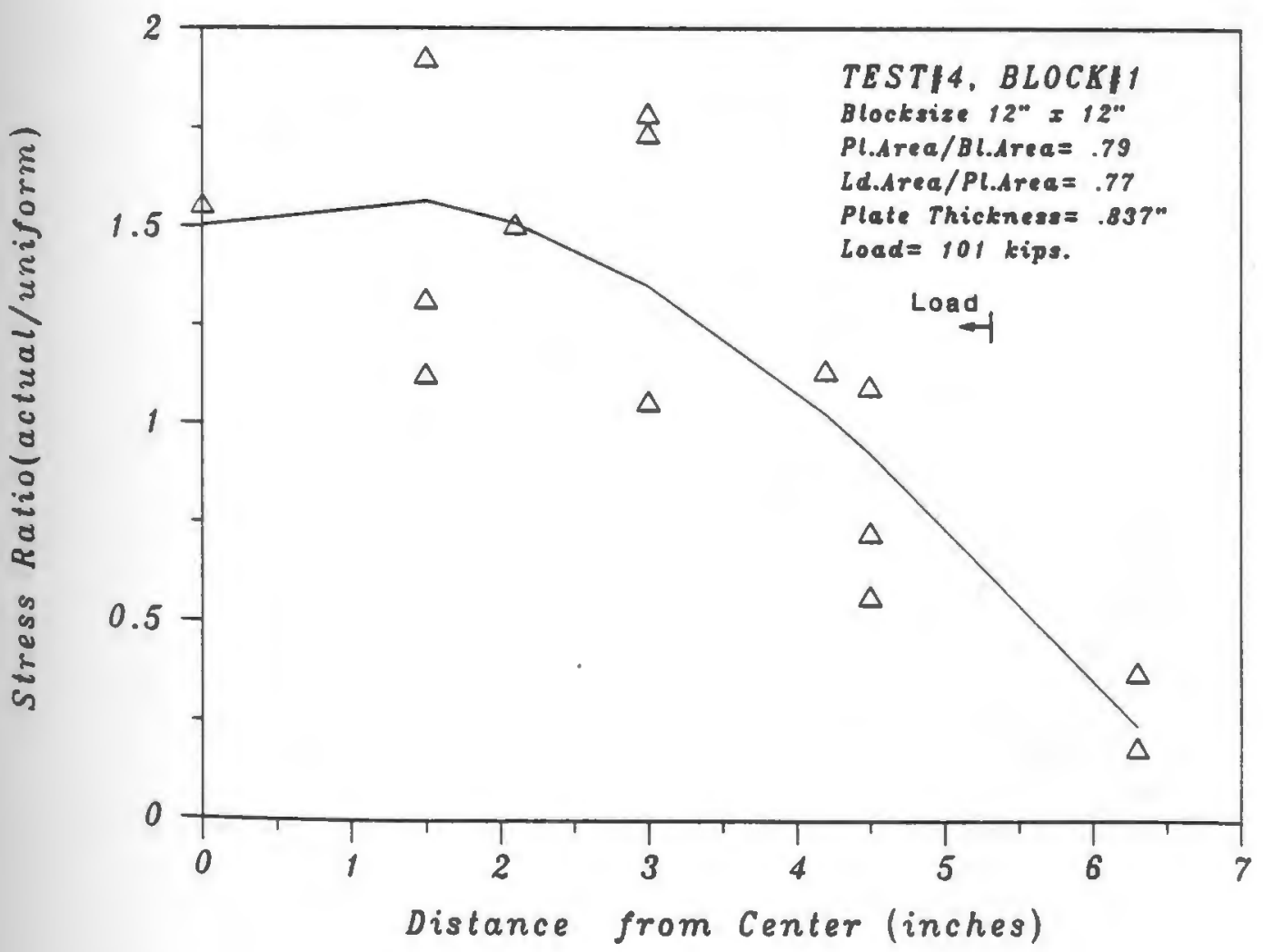

ह

Fig.18: DISTRIBUTION OF STRESSES 


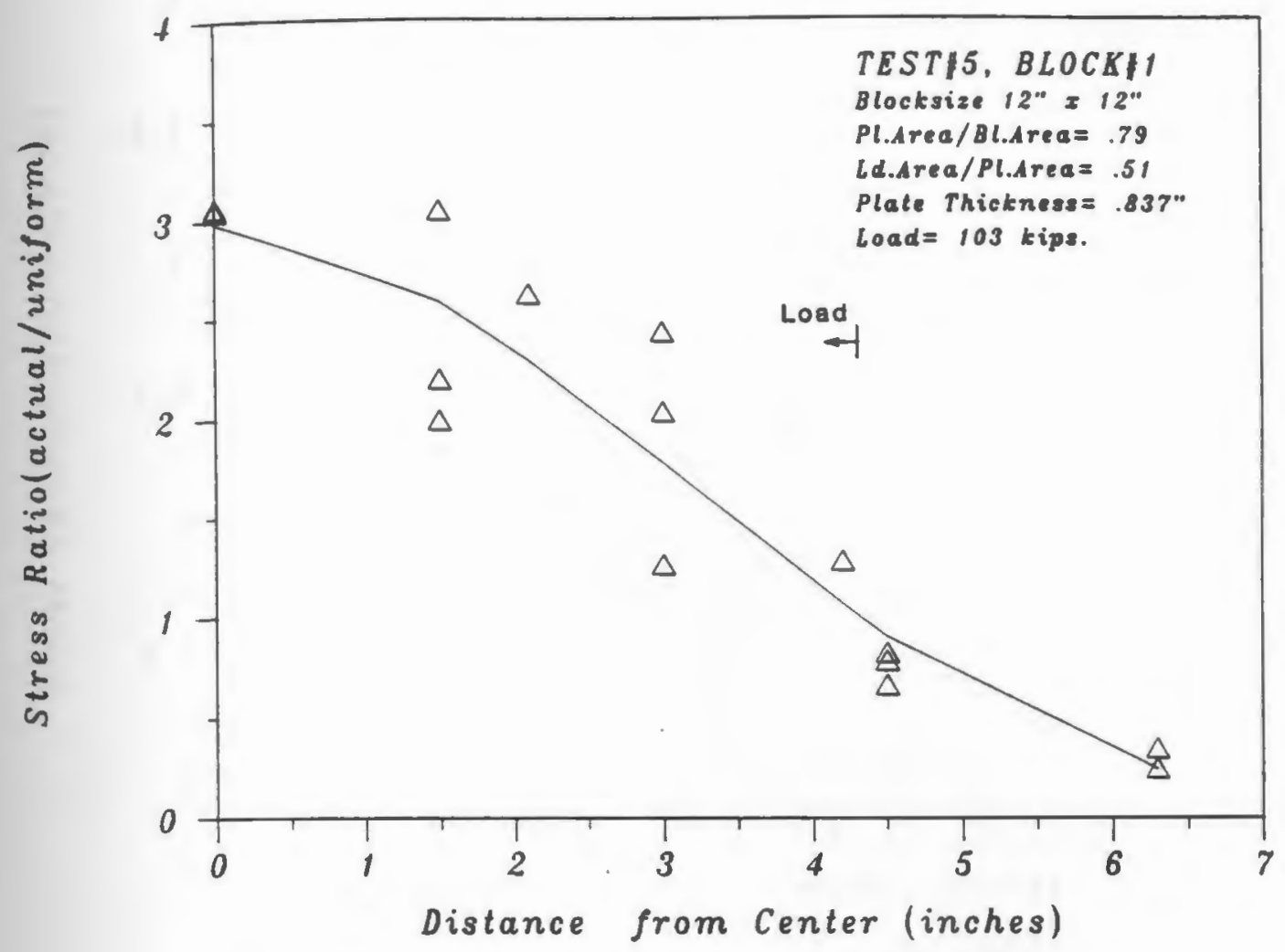

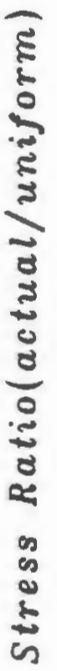

Fig.19: DISTRIBUTION OF STRESSES

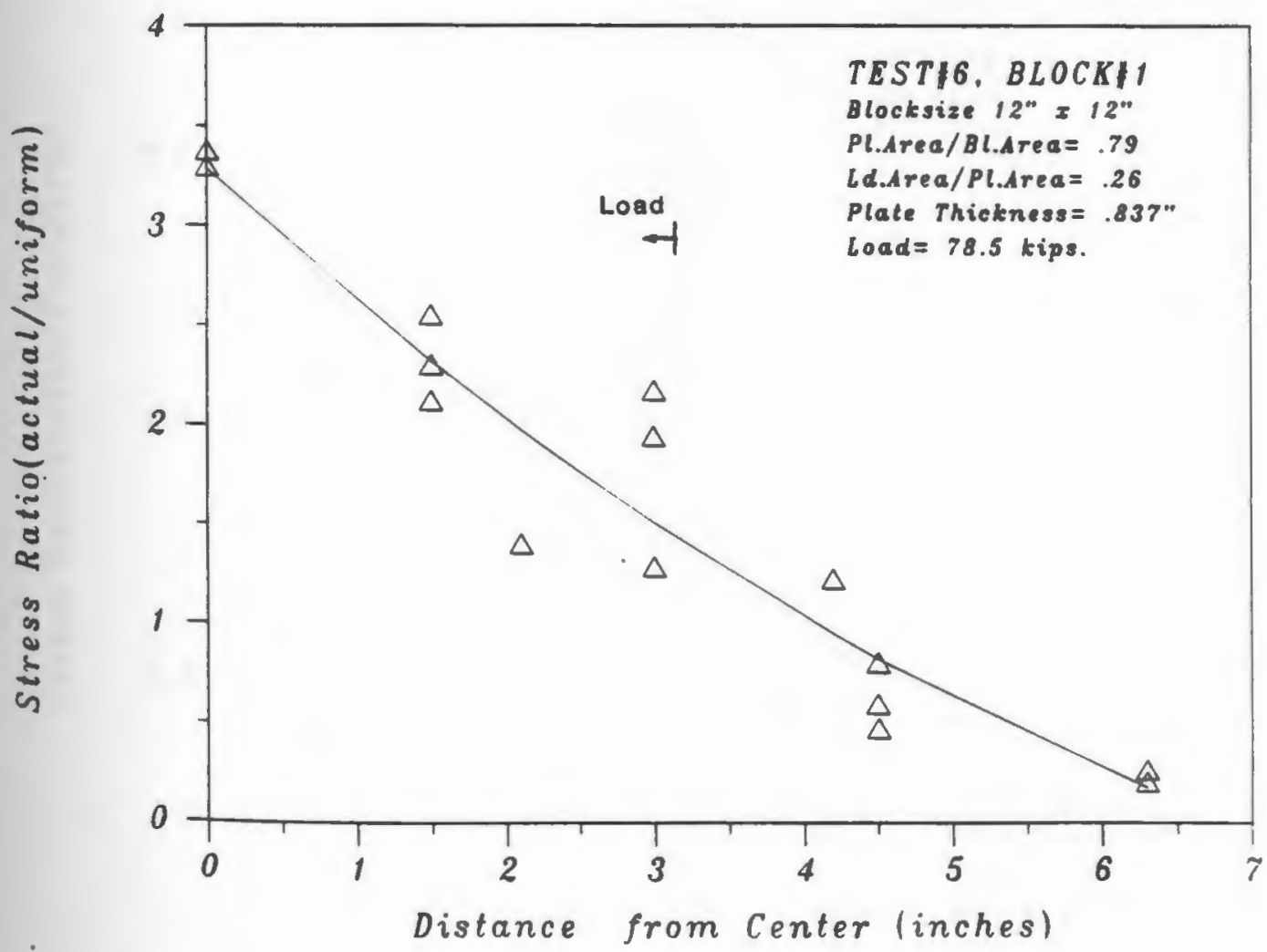




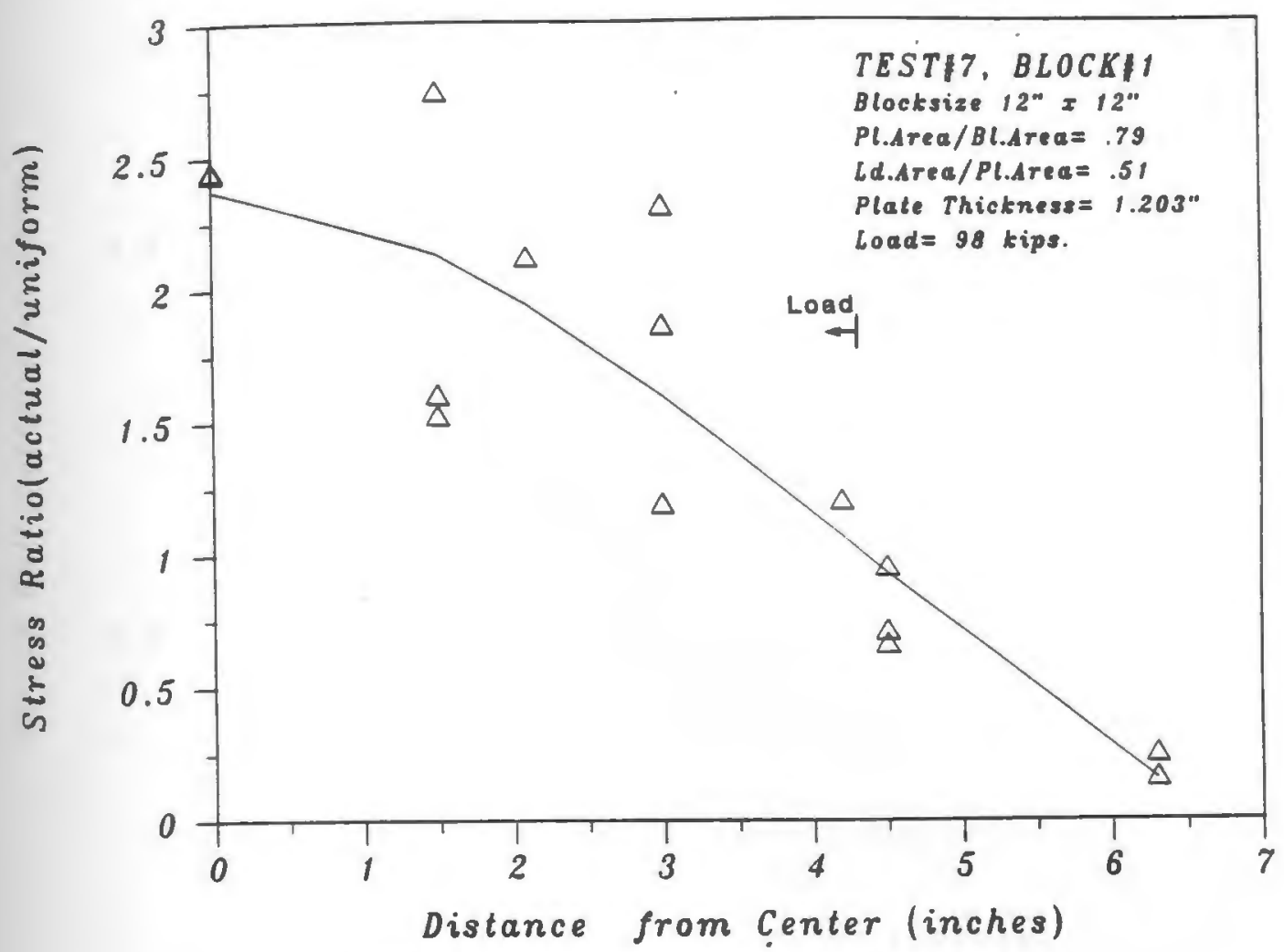

Fig.21: DISTRIBUTION OF STRESSES

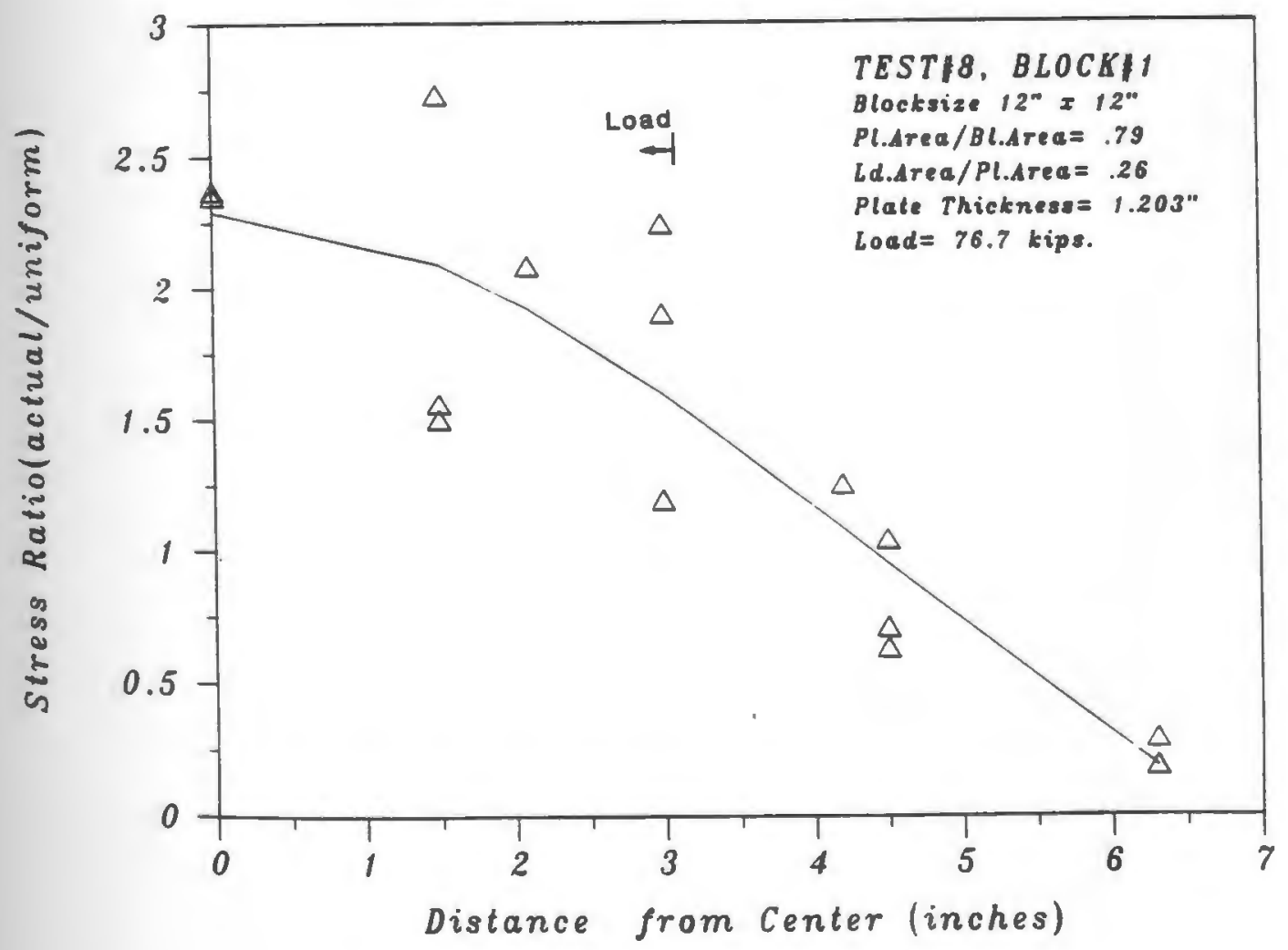

Fig.22: DISTRIBUTION OF STRESSES 


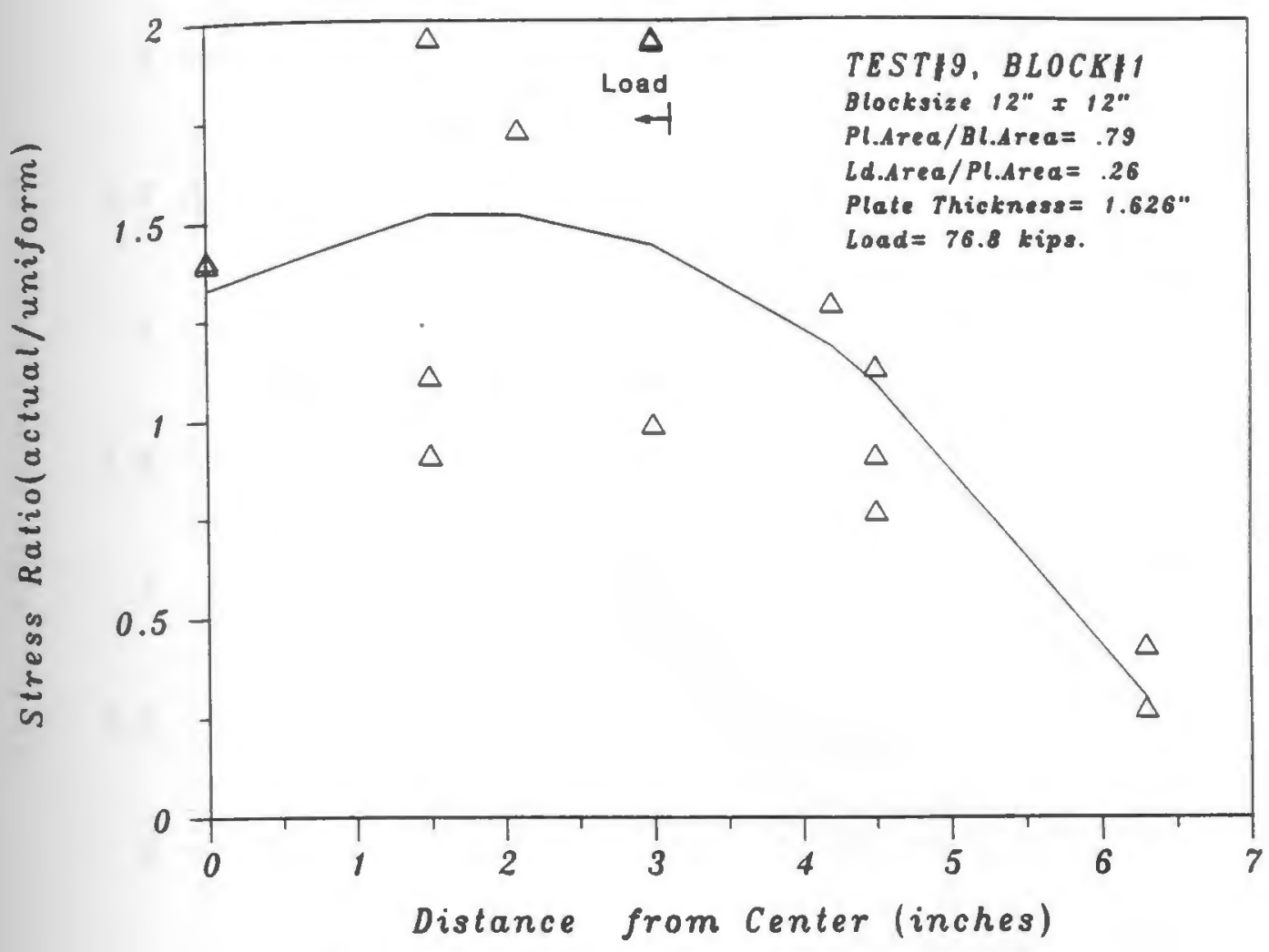

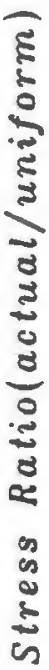

Fig.23: DISTRIBUTION OF STRESSES

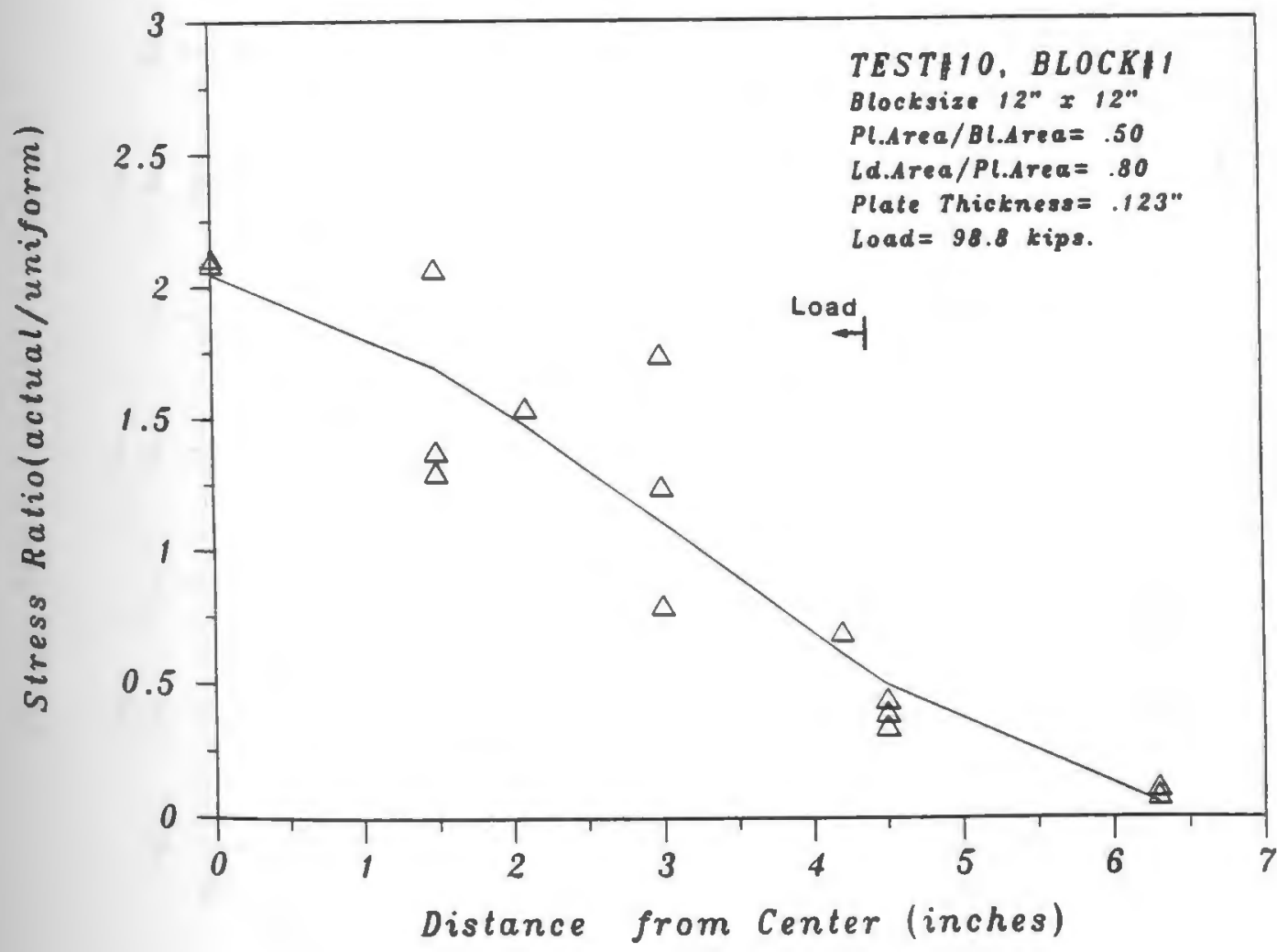

है

Fig.24: DISTRIBUTION OF STRESSES 


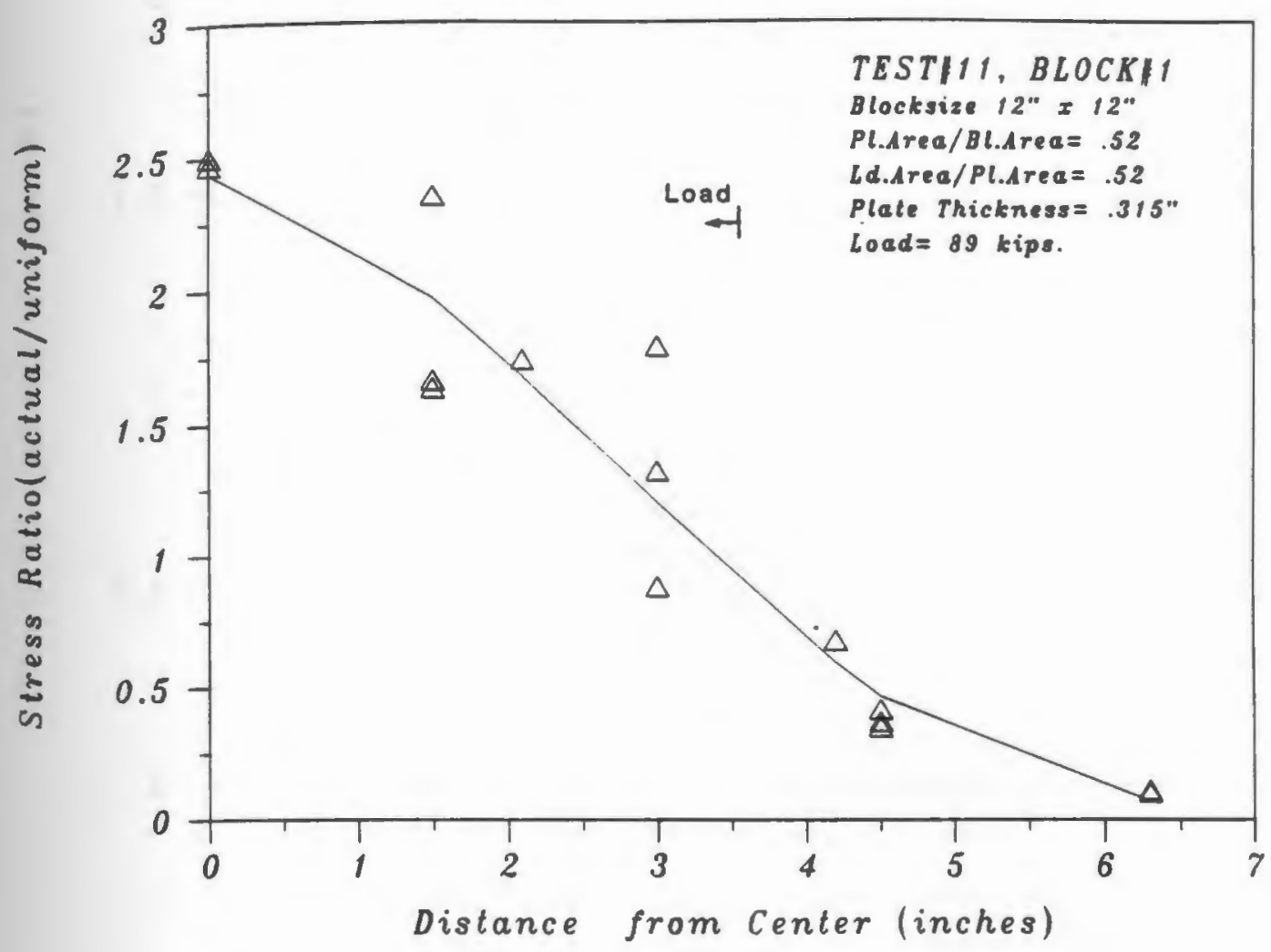

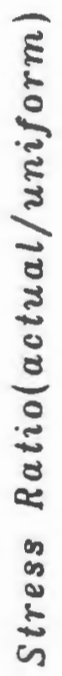

Fig.25: DISTRIBUTION OF STRESSES

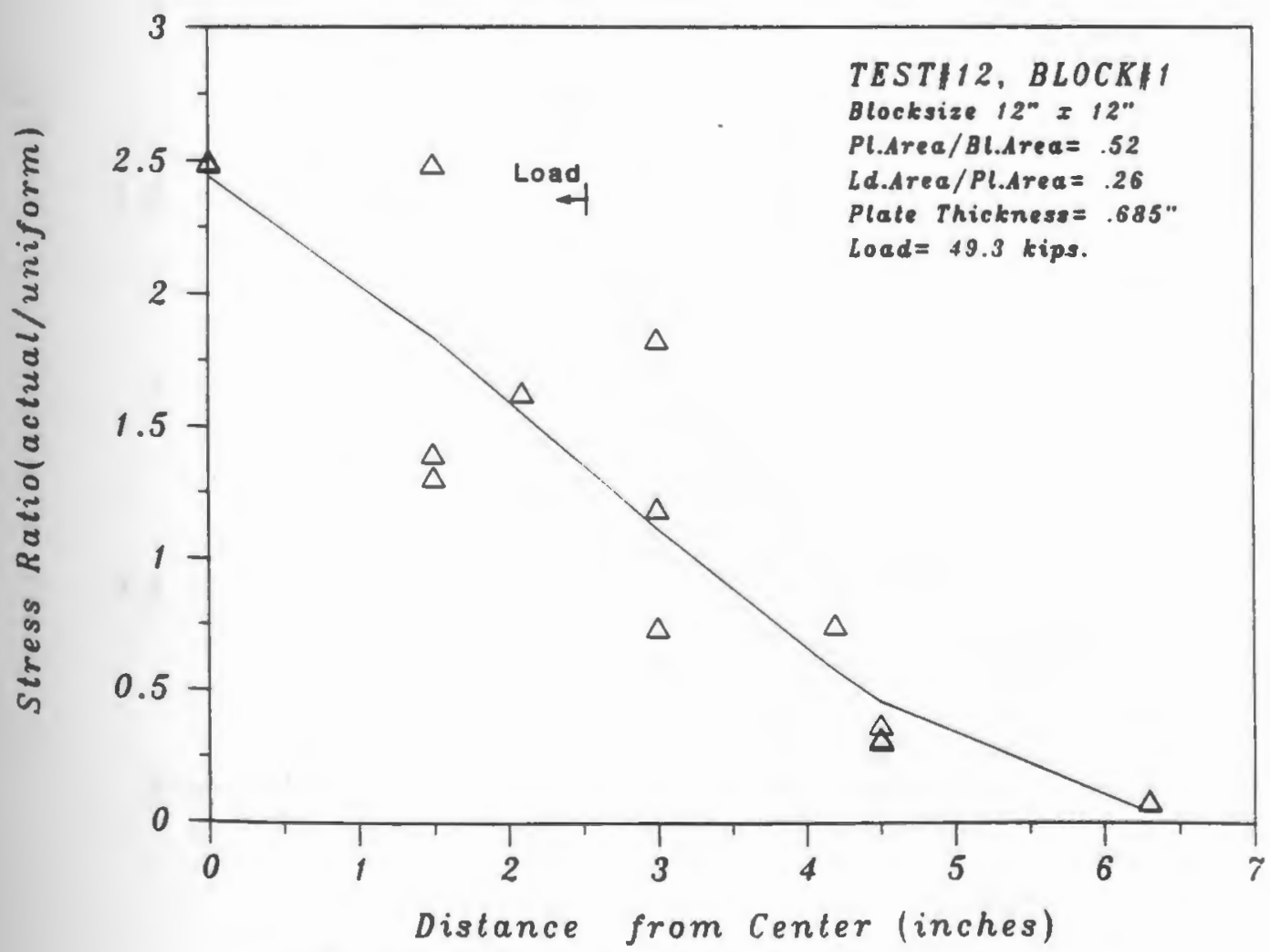

Fig.26: DISTRIBUTION OF STRESSES 


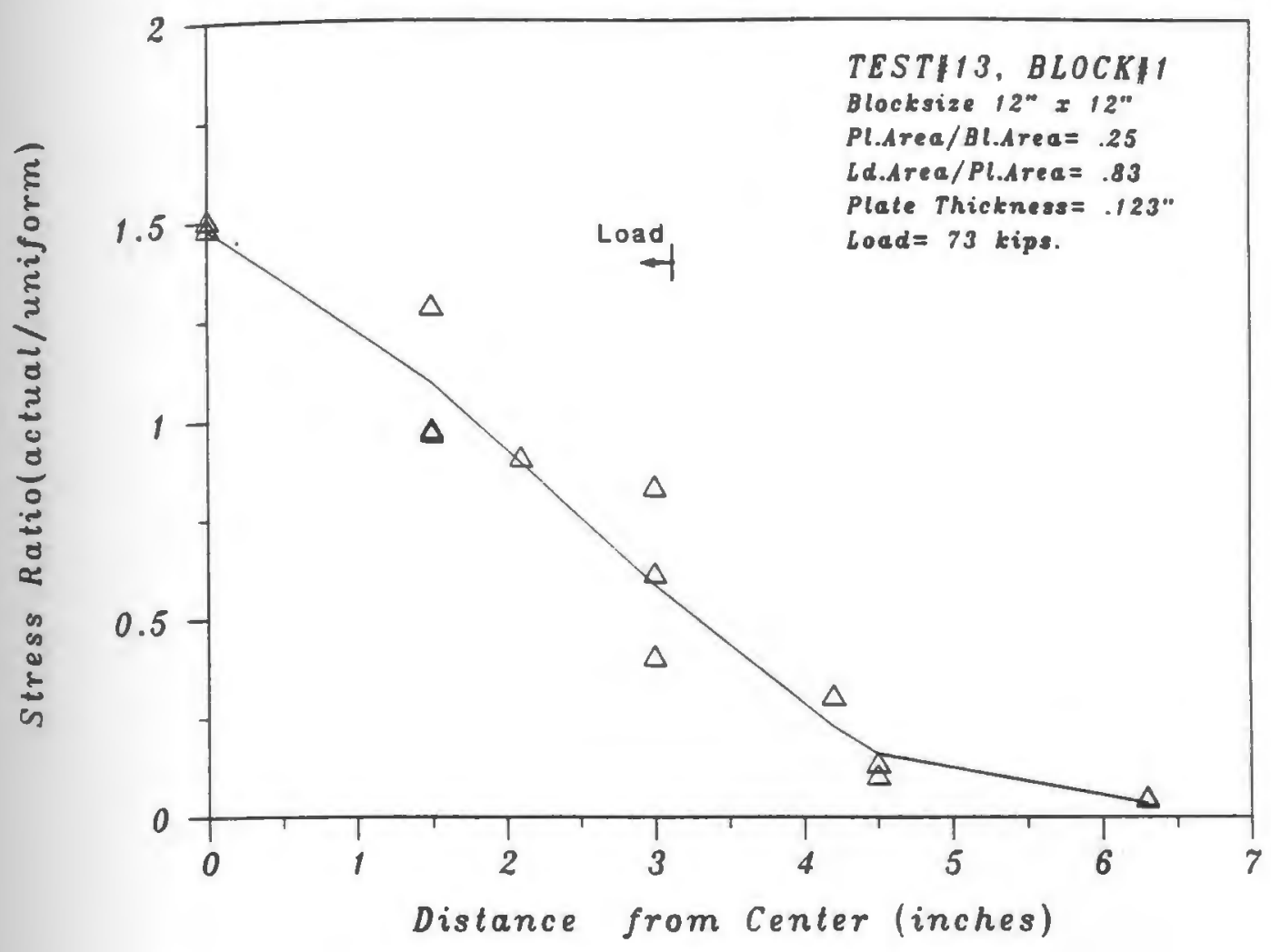

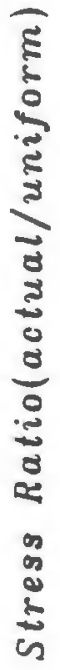

Fig.27: DISTRIBUTION OF STRESSES

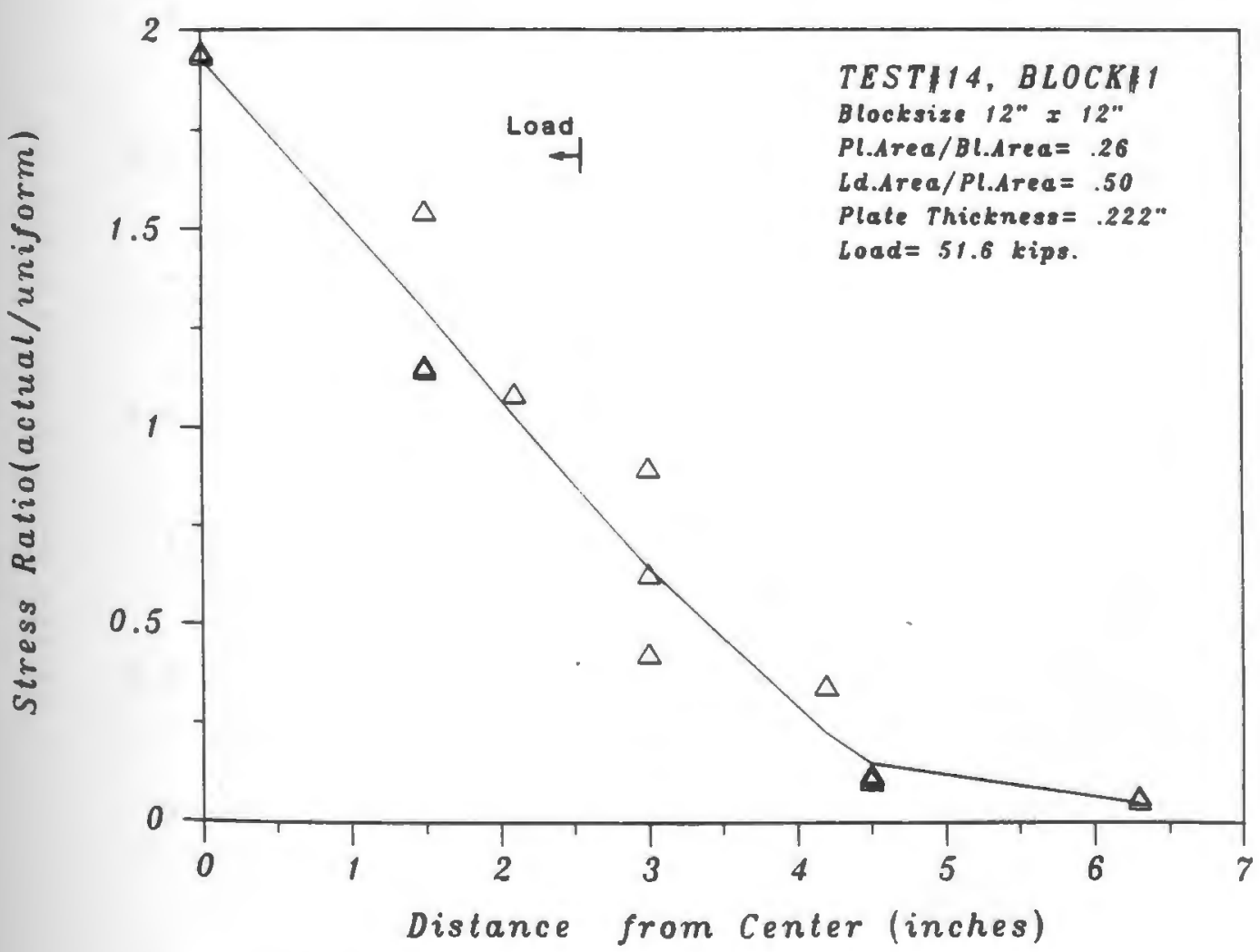

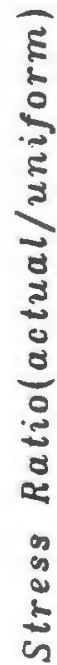

Fig.28: DISTRIBUTION OF STRESSES 


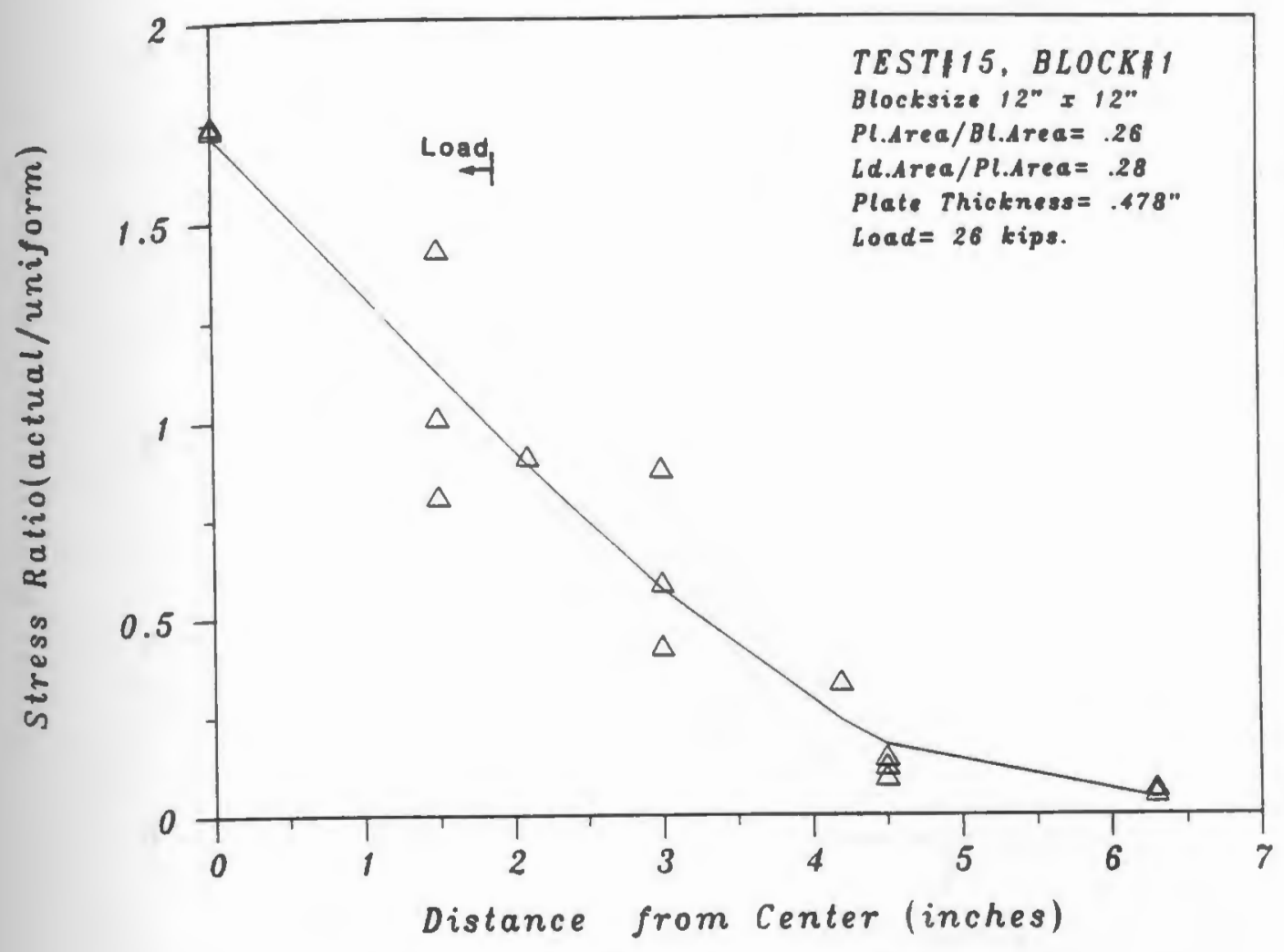

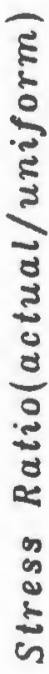

Fig.29: DISTRIBUTION OF STRESSES

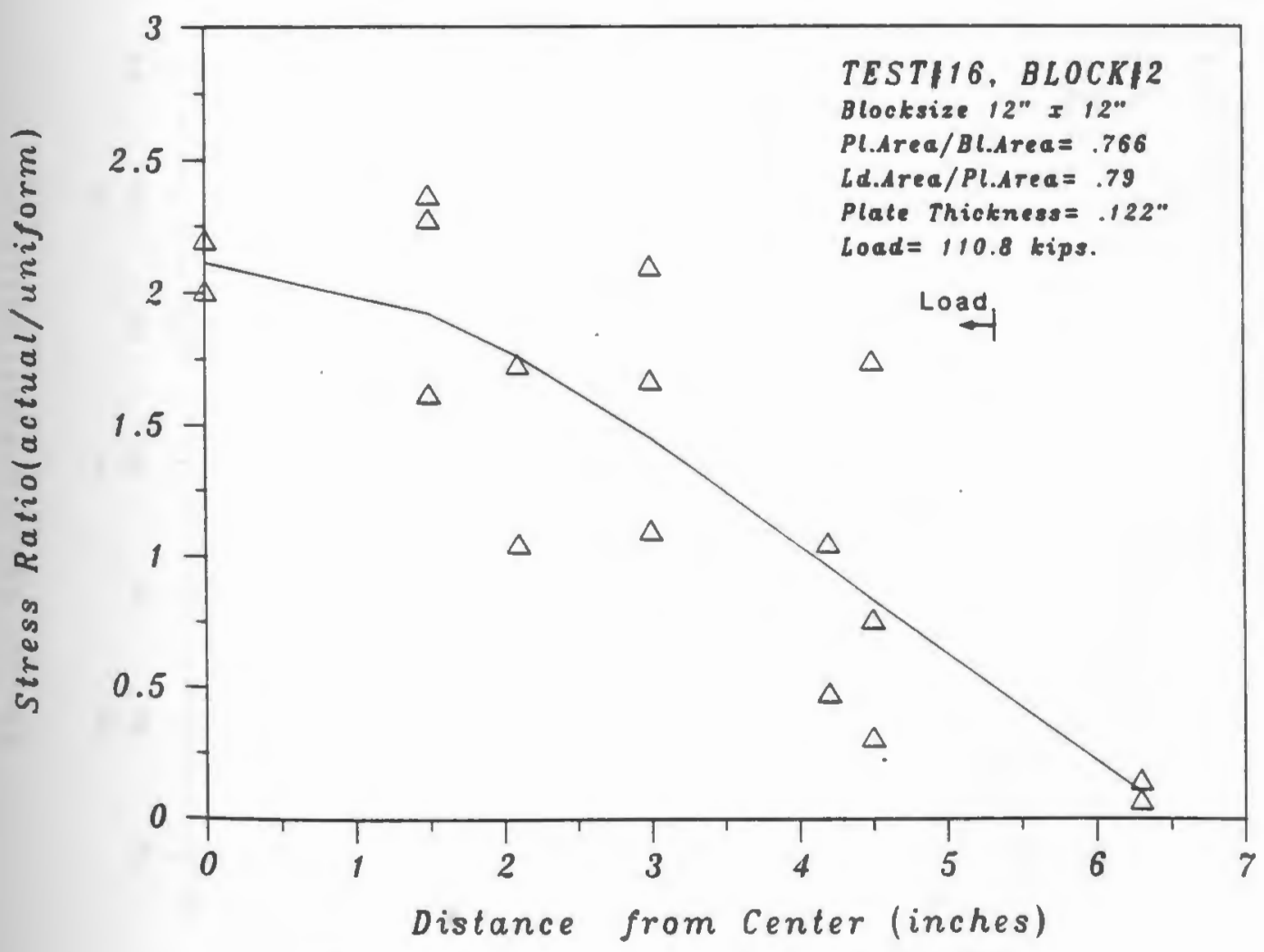

Fig.30: DISTRIBUTION OF STRESSES 


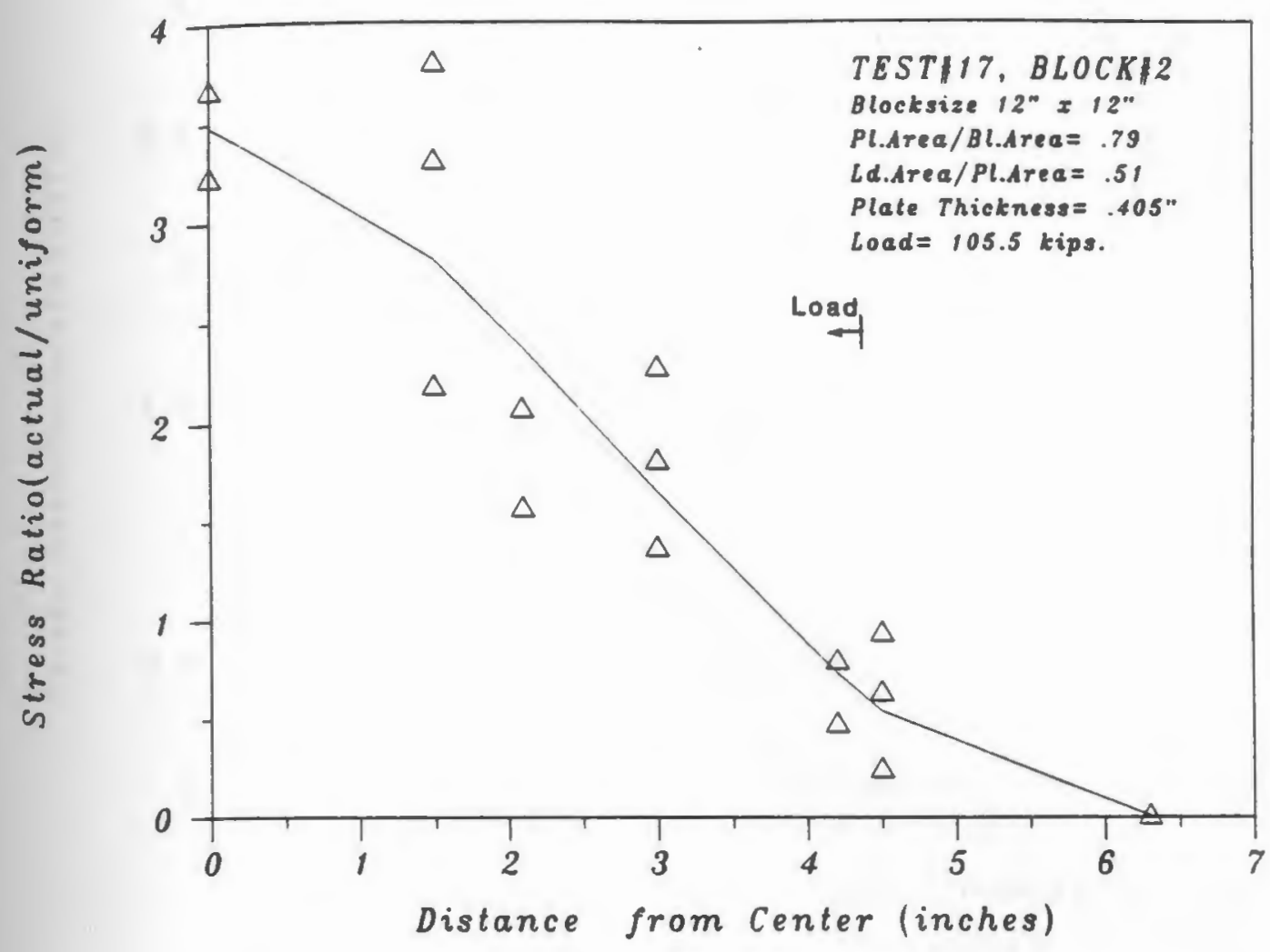

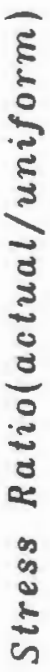

Fig.31: DISTRIBUTION OF STRESSES

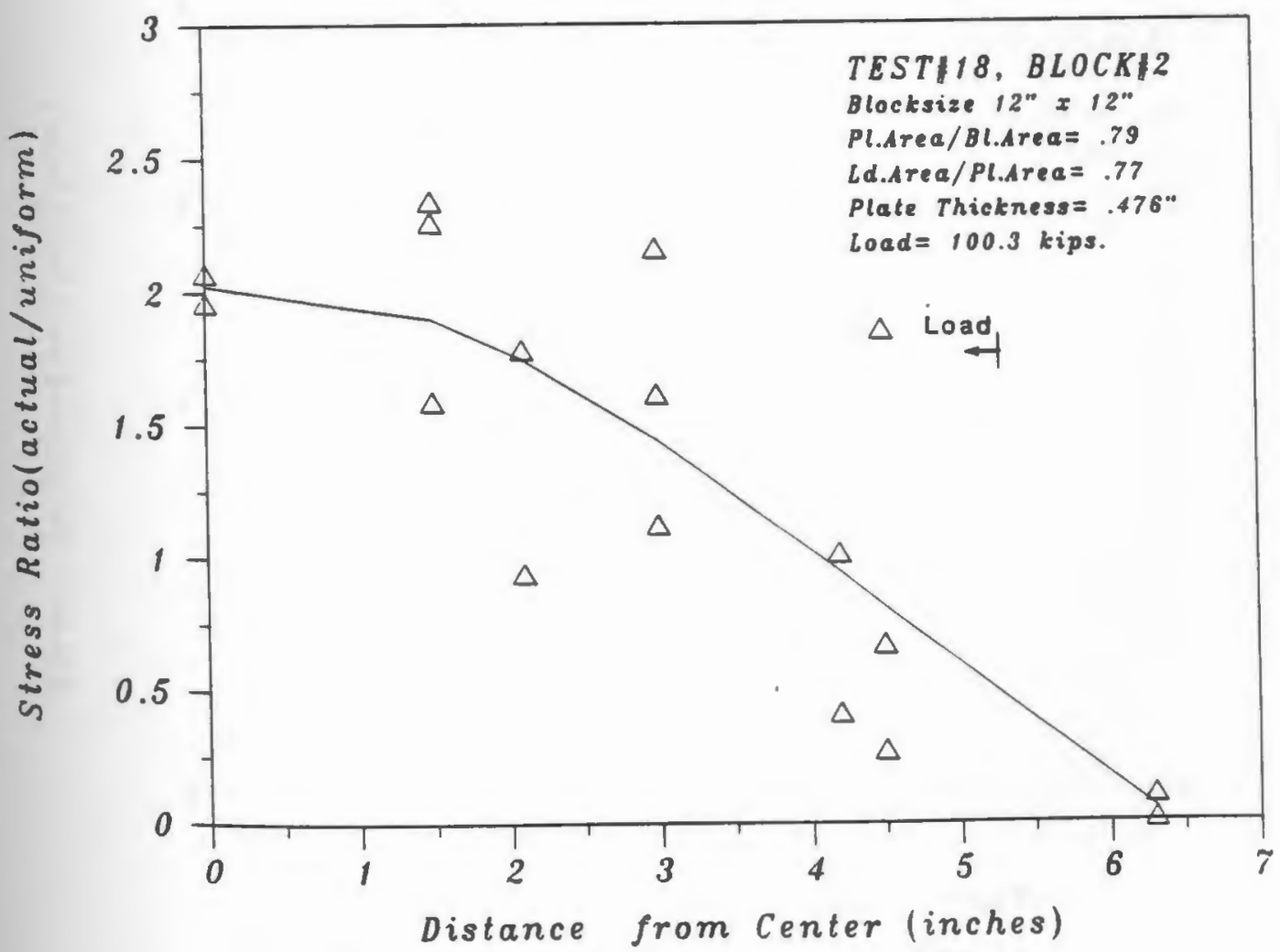

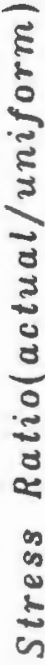

Fig.32: DISTRIBUTION OF STRESSES 


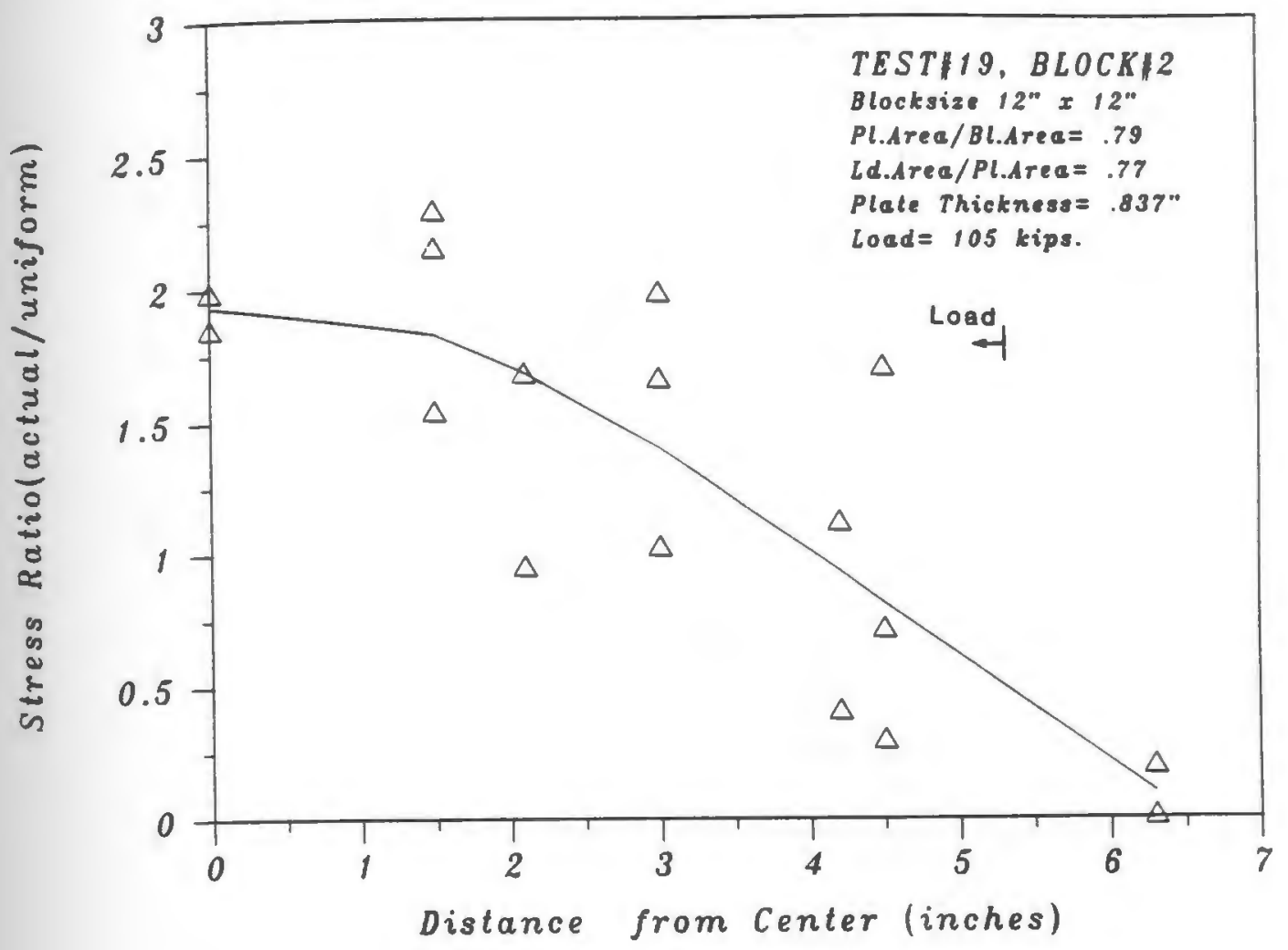

है

Fig.33: DISTRIBUTION OF STRESSES

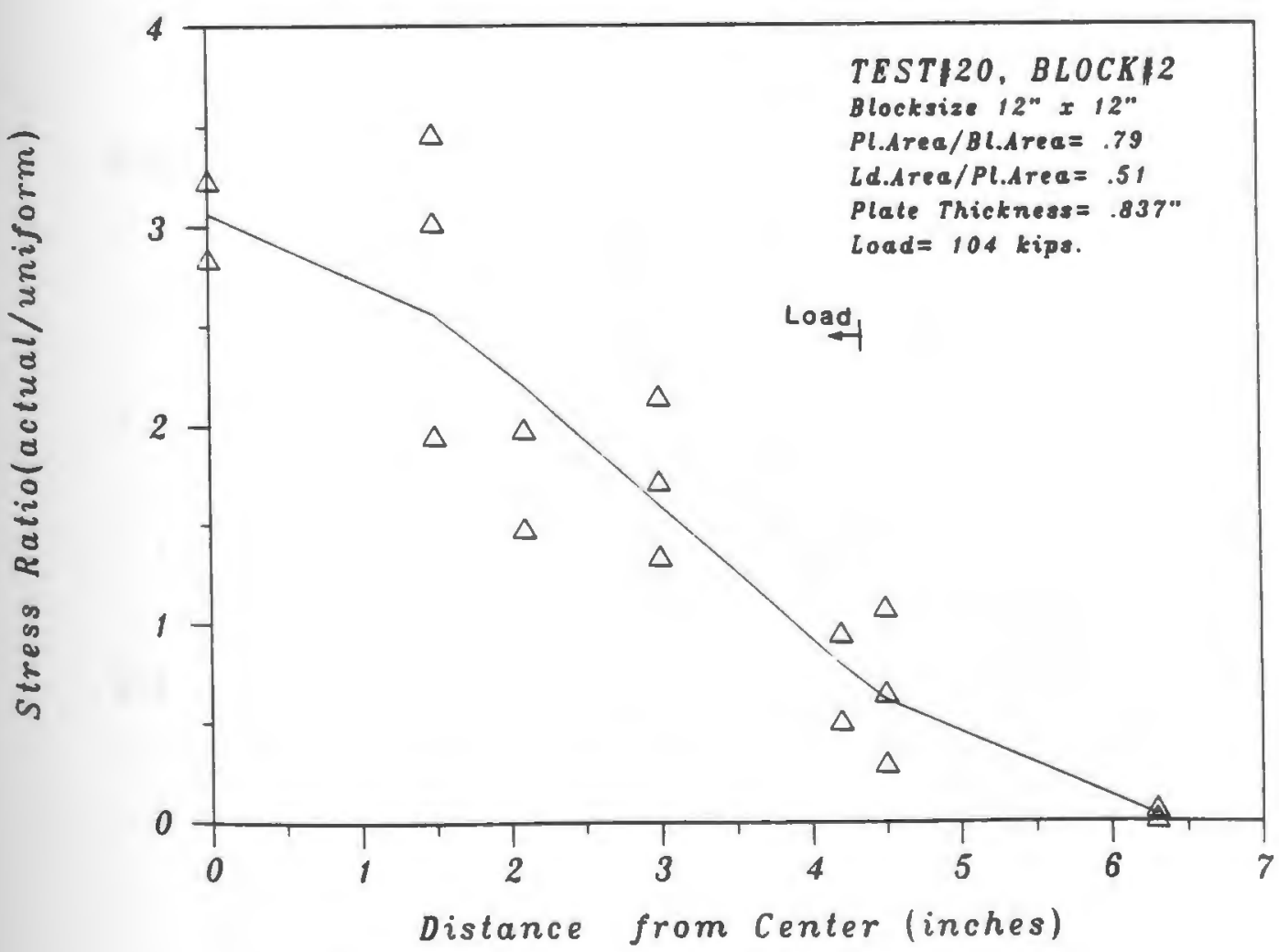

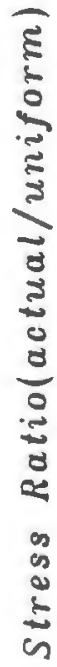

Fig.34: DISTRIBUTION OF STRESSES 


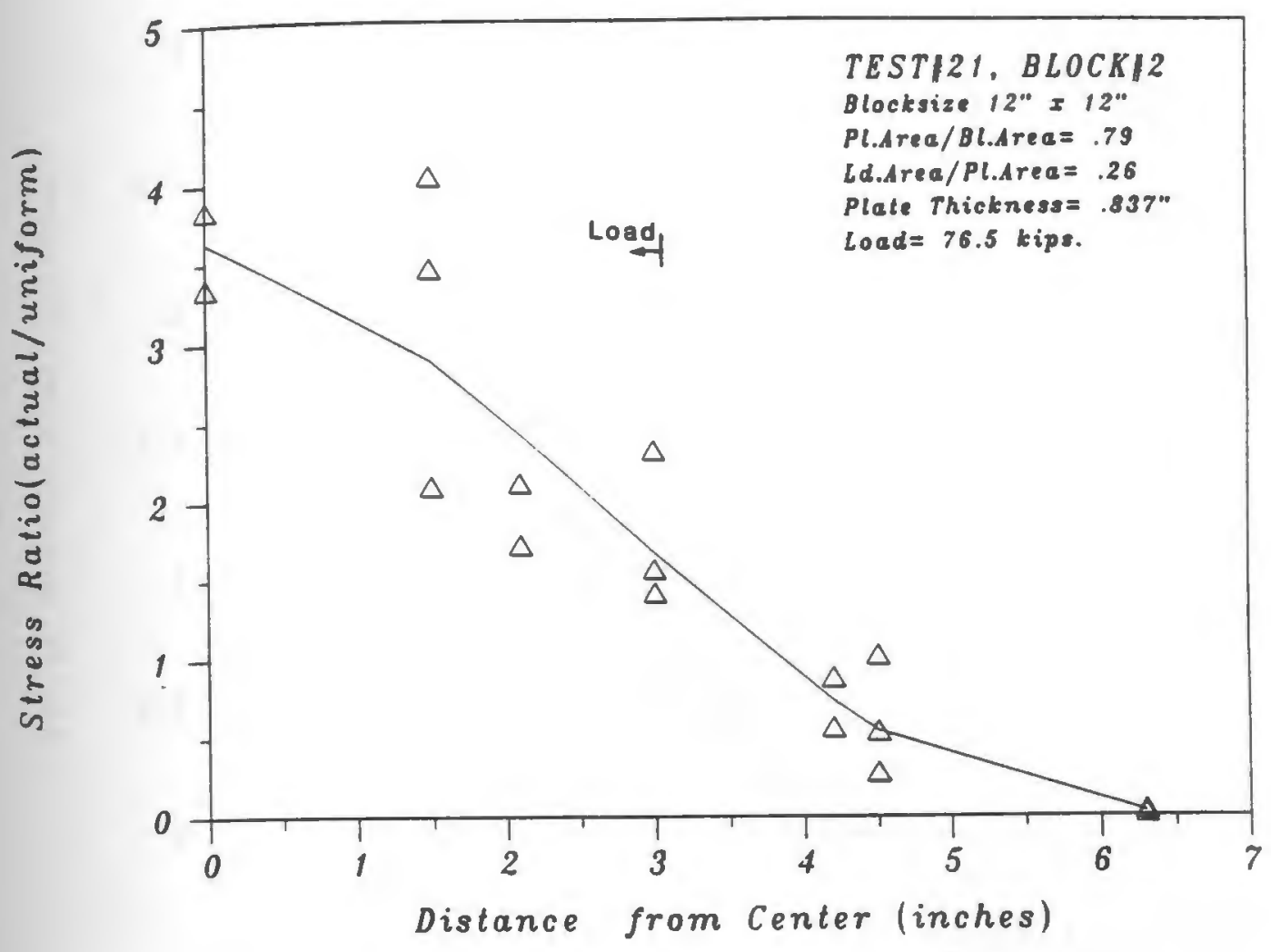

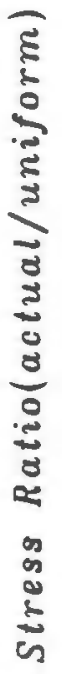

Fig.35: DISTRIBUTION OF STRESSES

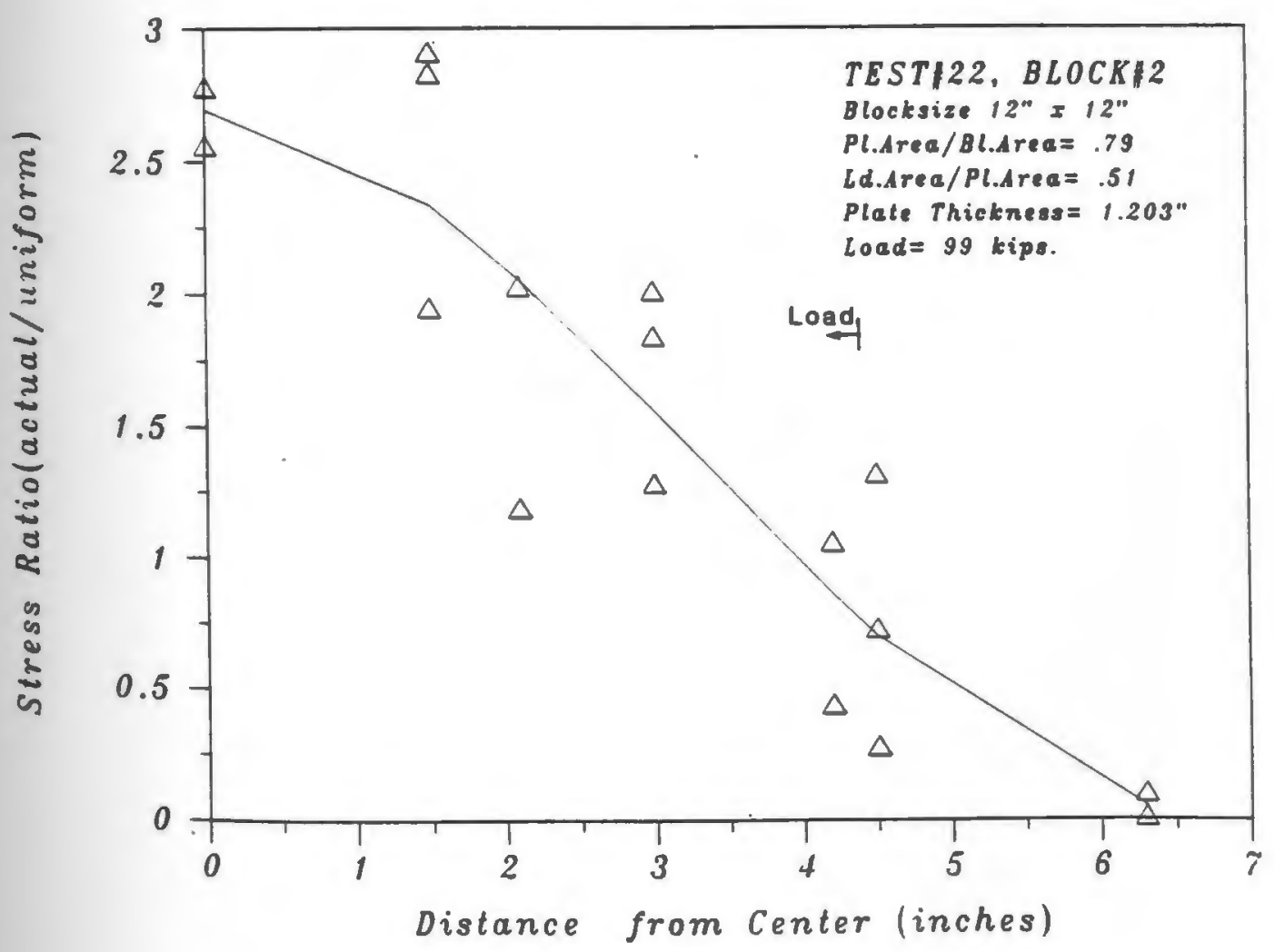

Fig.36: DISTRIBUTION OF STRESSES 


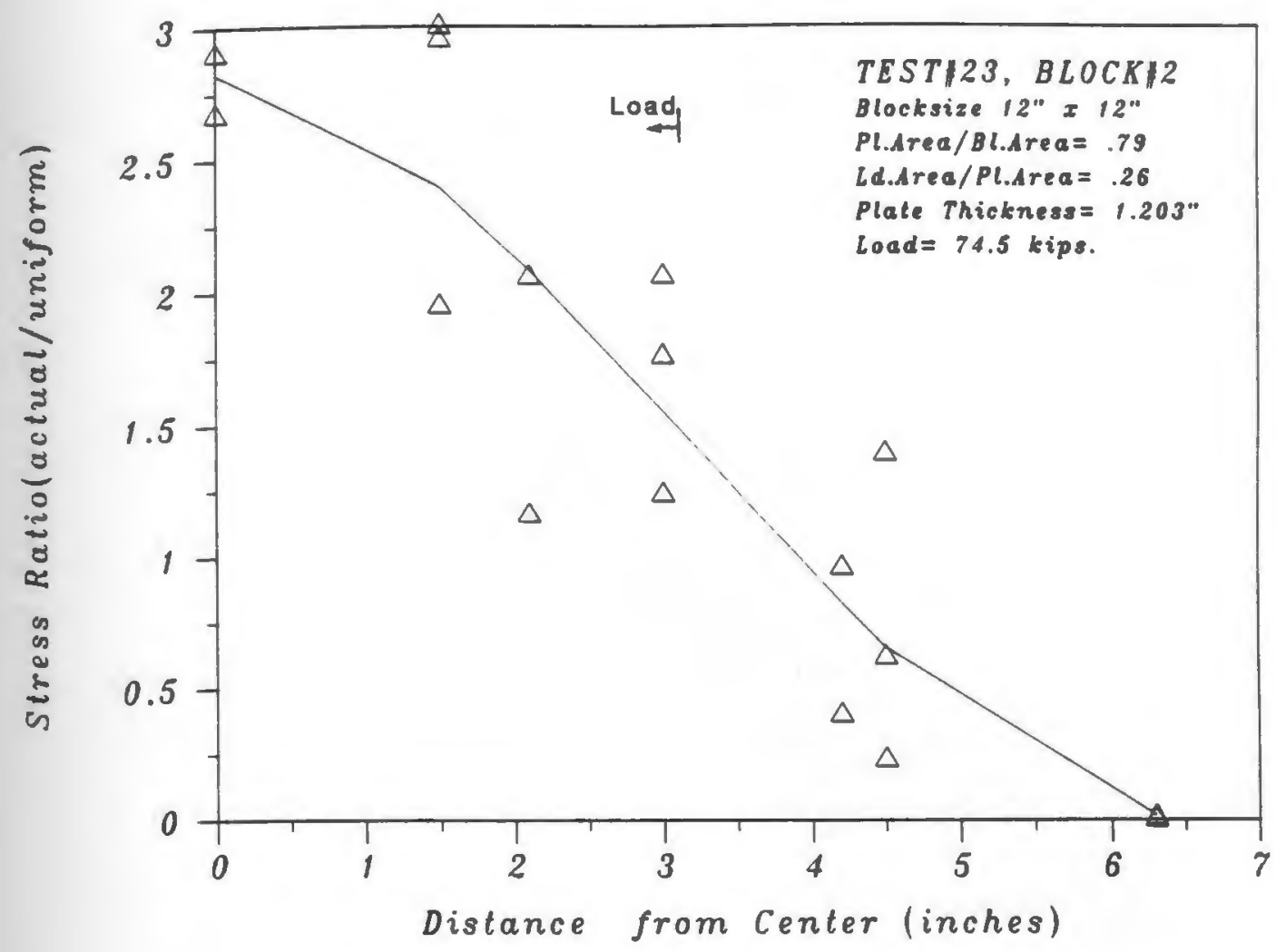

Fig.37: DISTRIBUTION OF STRESSES

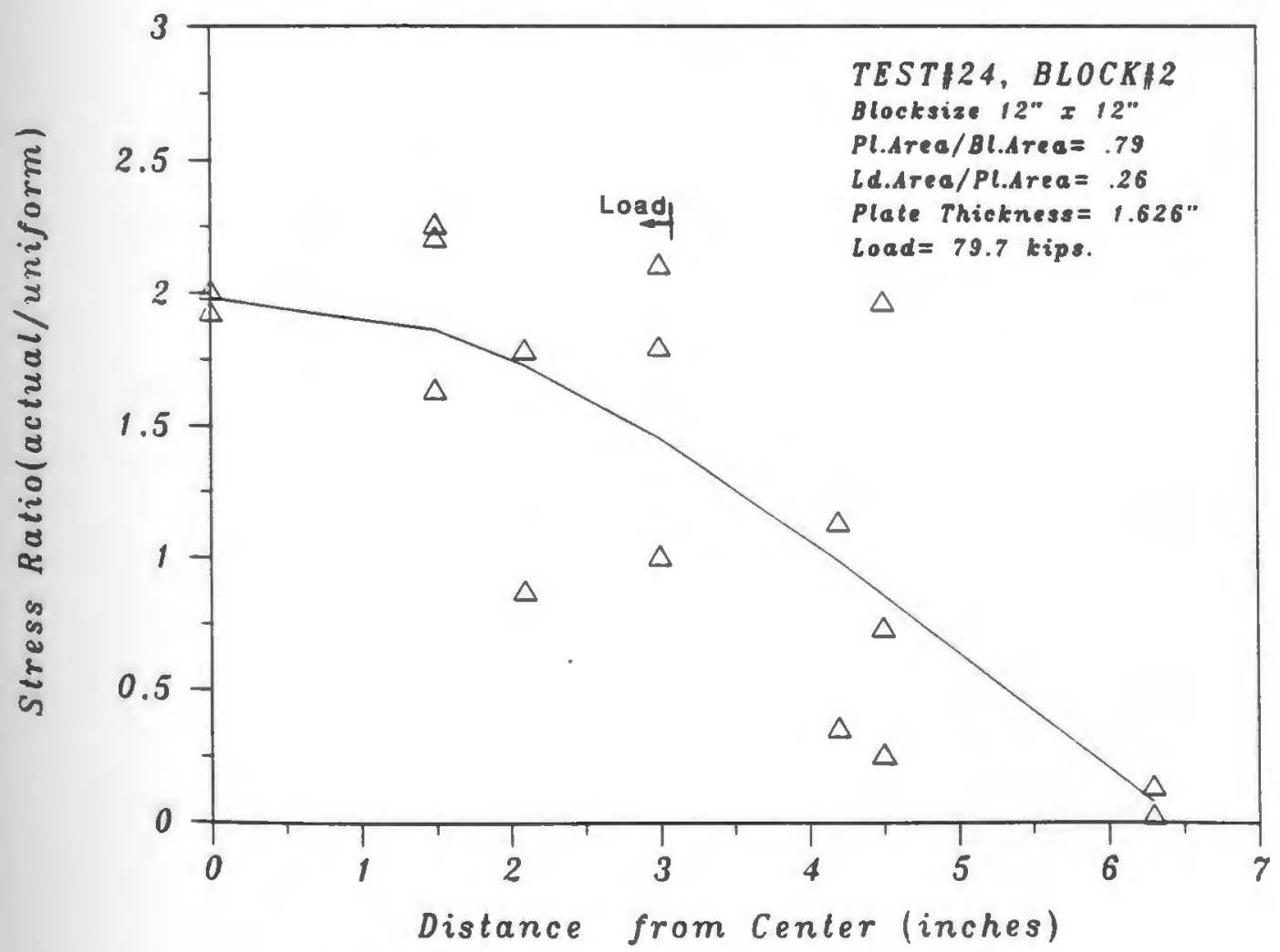

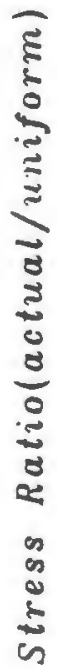

Fig.38: DISTRIBUTION OF STRESSES 


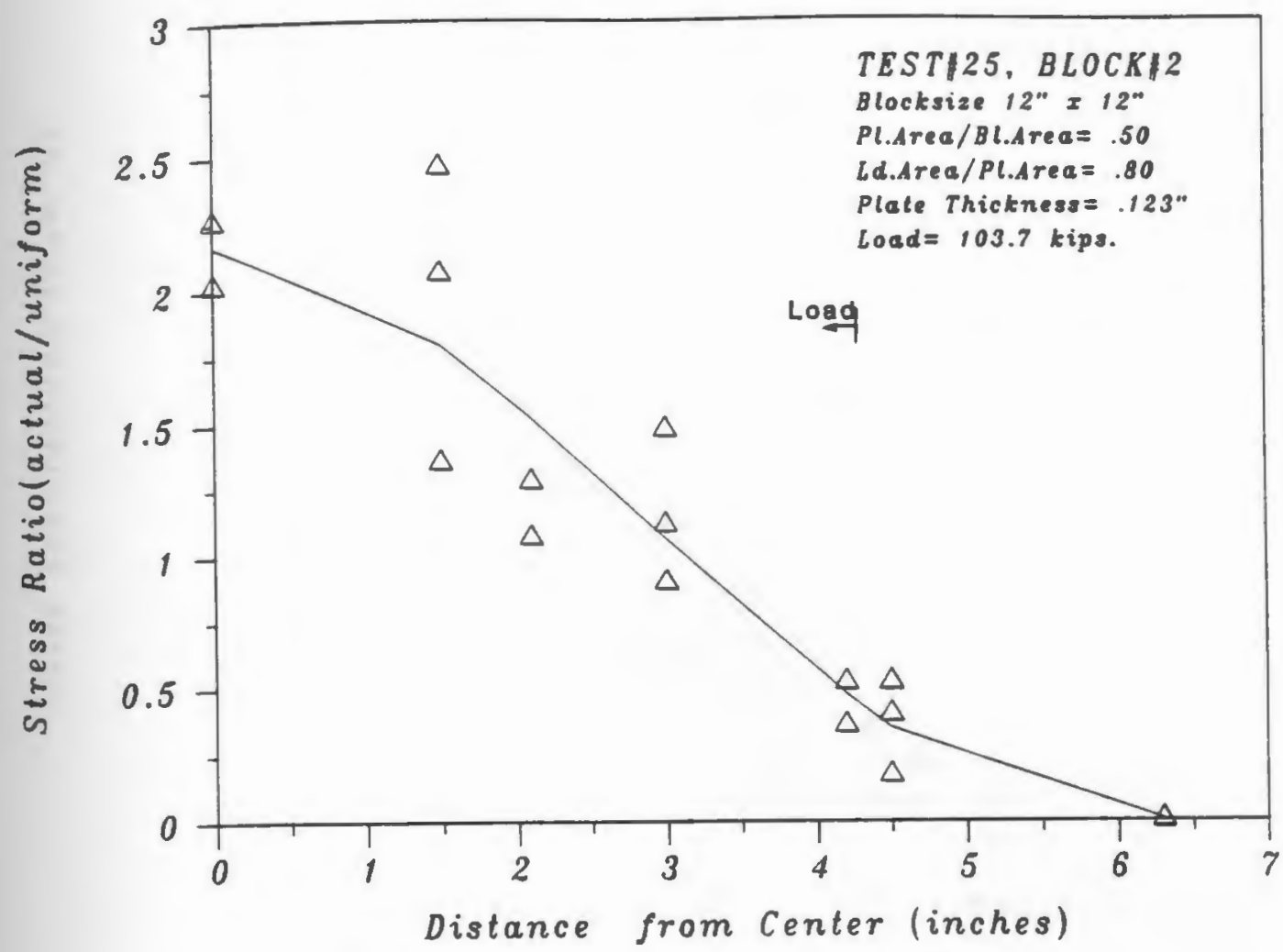

है

Fig.39: DISTRIBUTION OF STRESSES

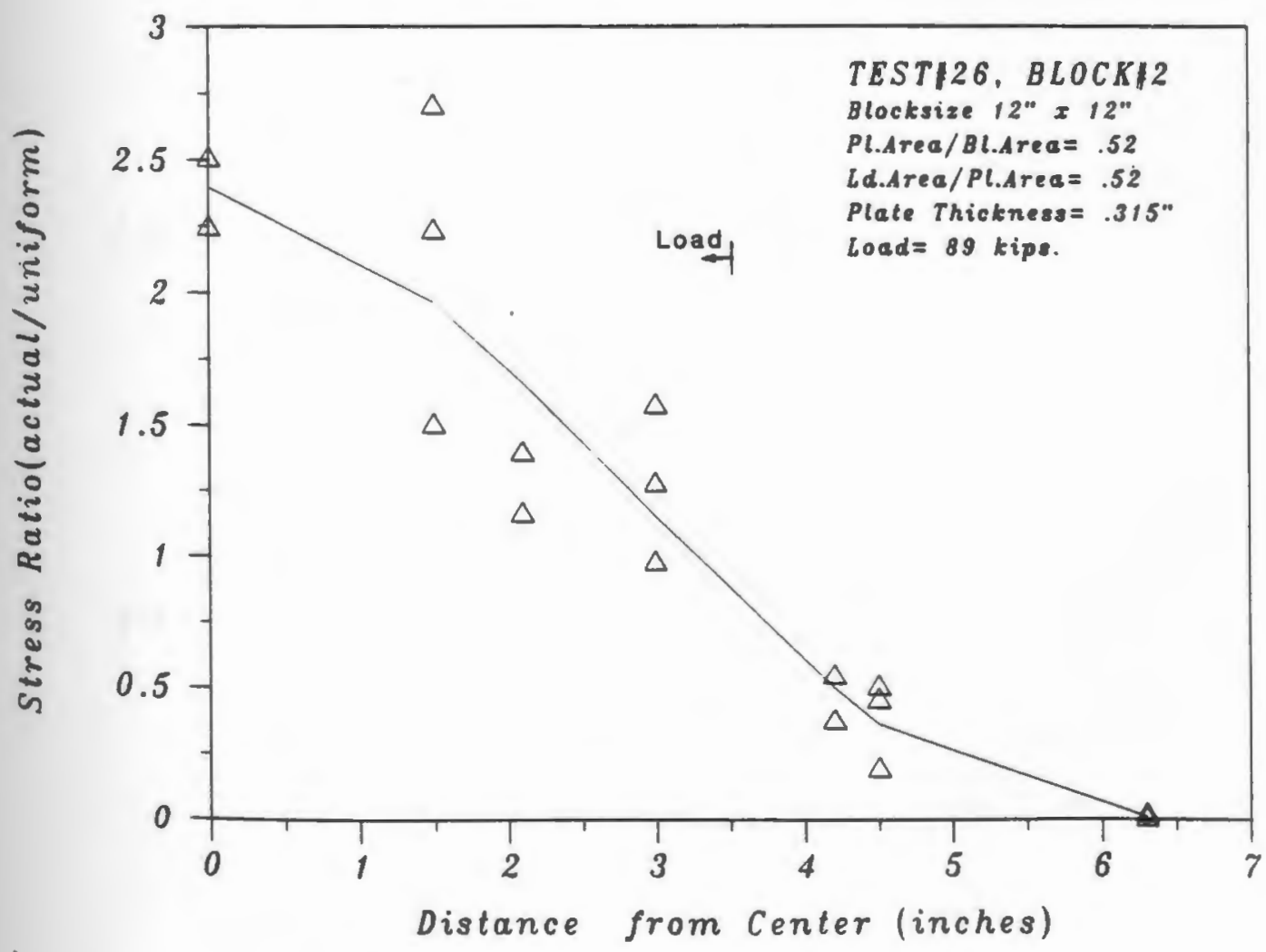

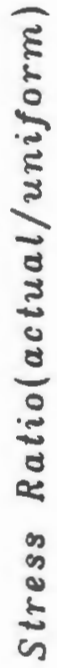

Fig.40: DISTRIBUTION OF STRESSES 


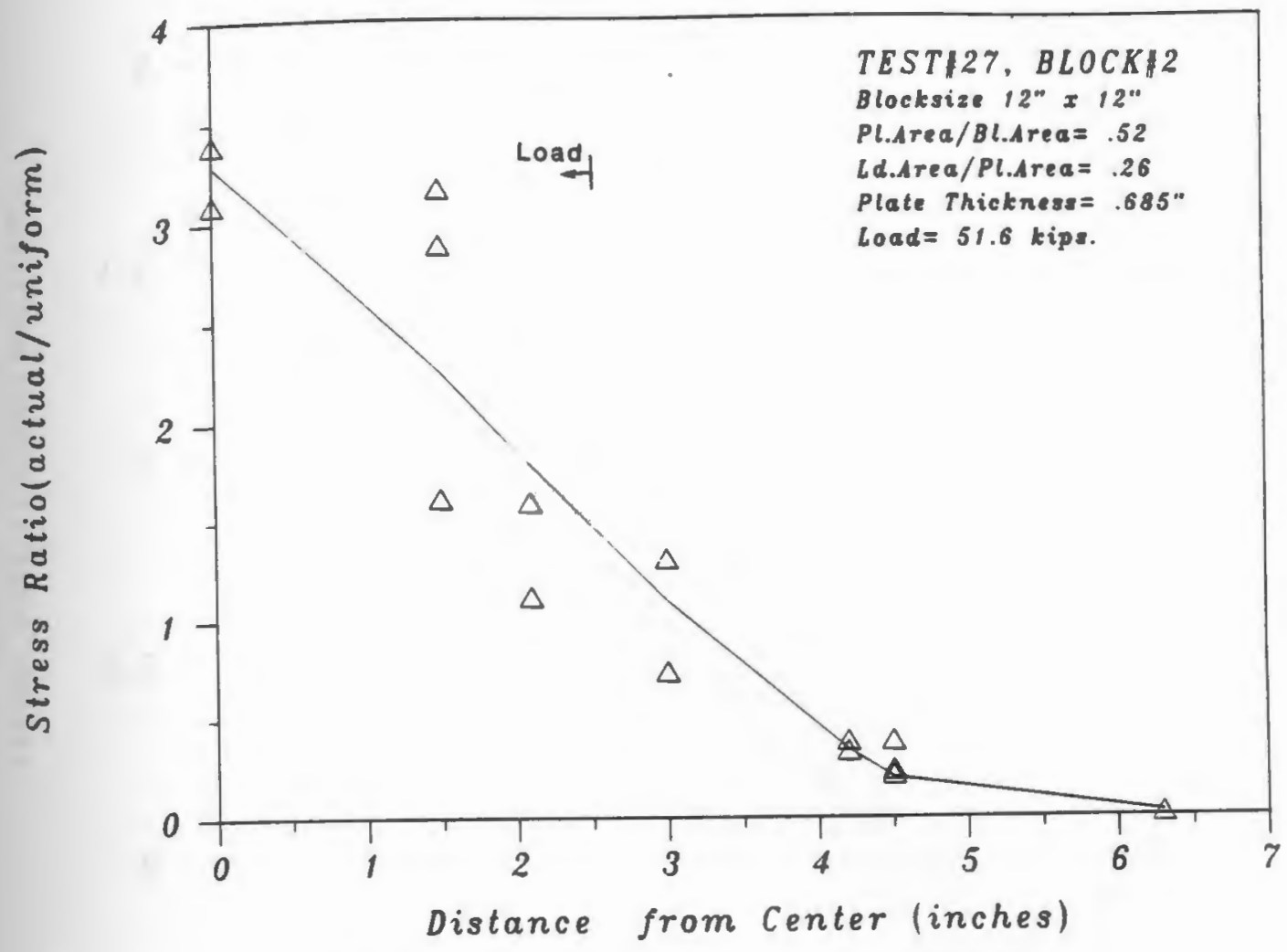

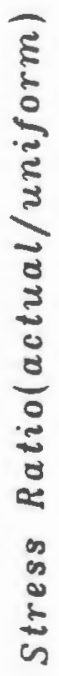

Fig.41: DISTRIBUTION OF STRESSES

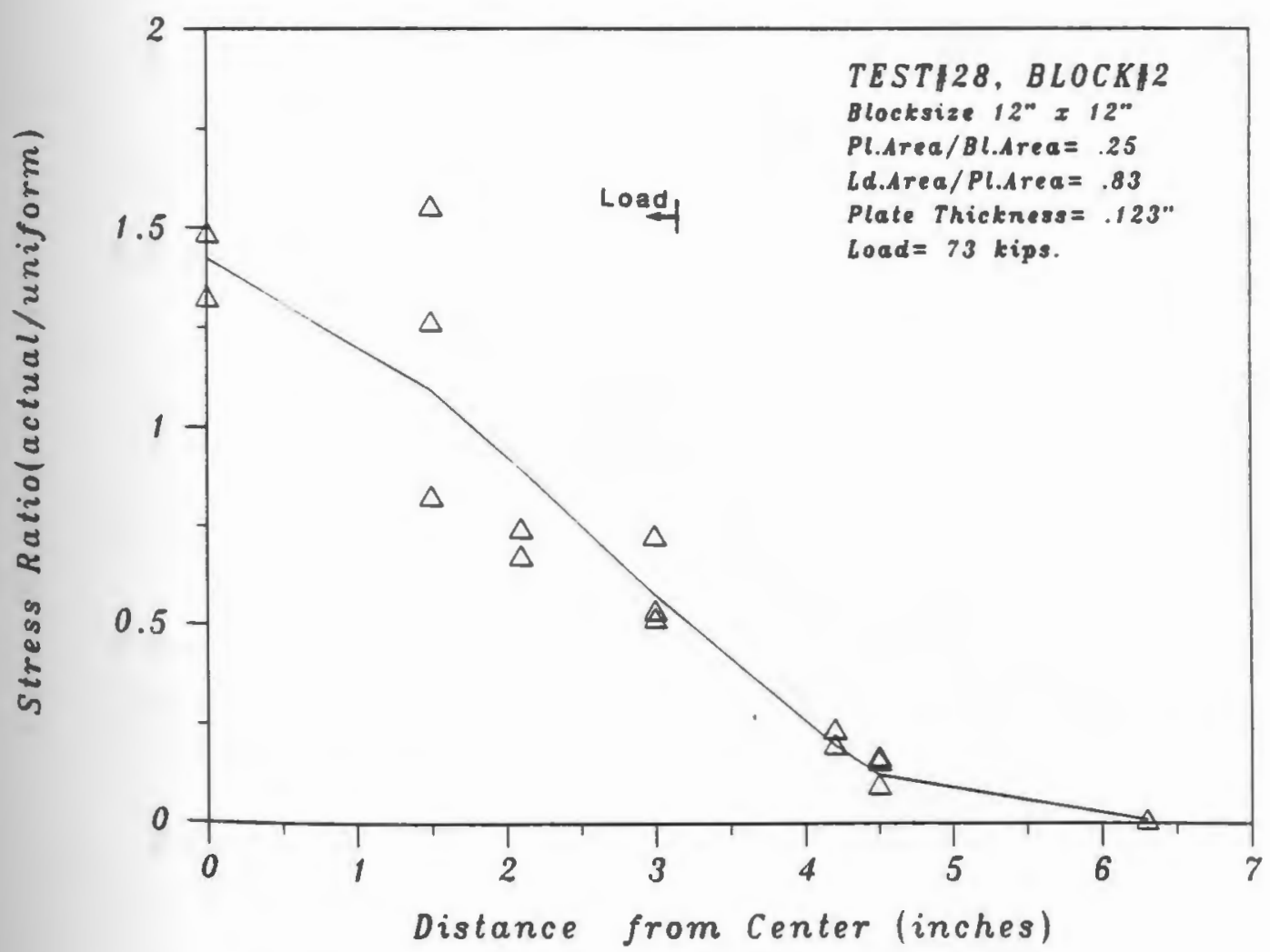

है

Fig.42: DISTRIBUTION OF STRESSES 


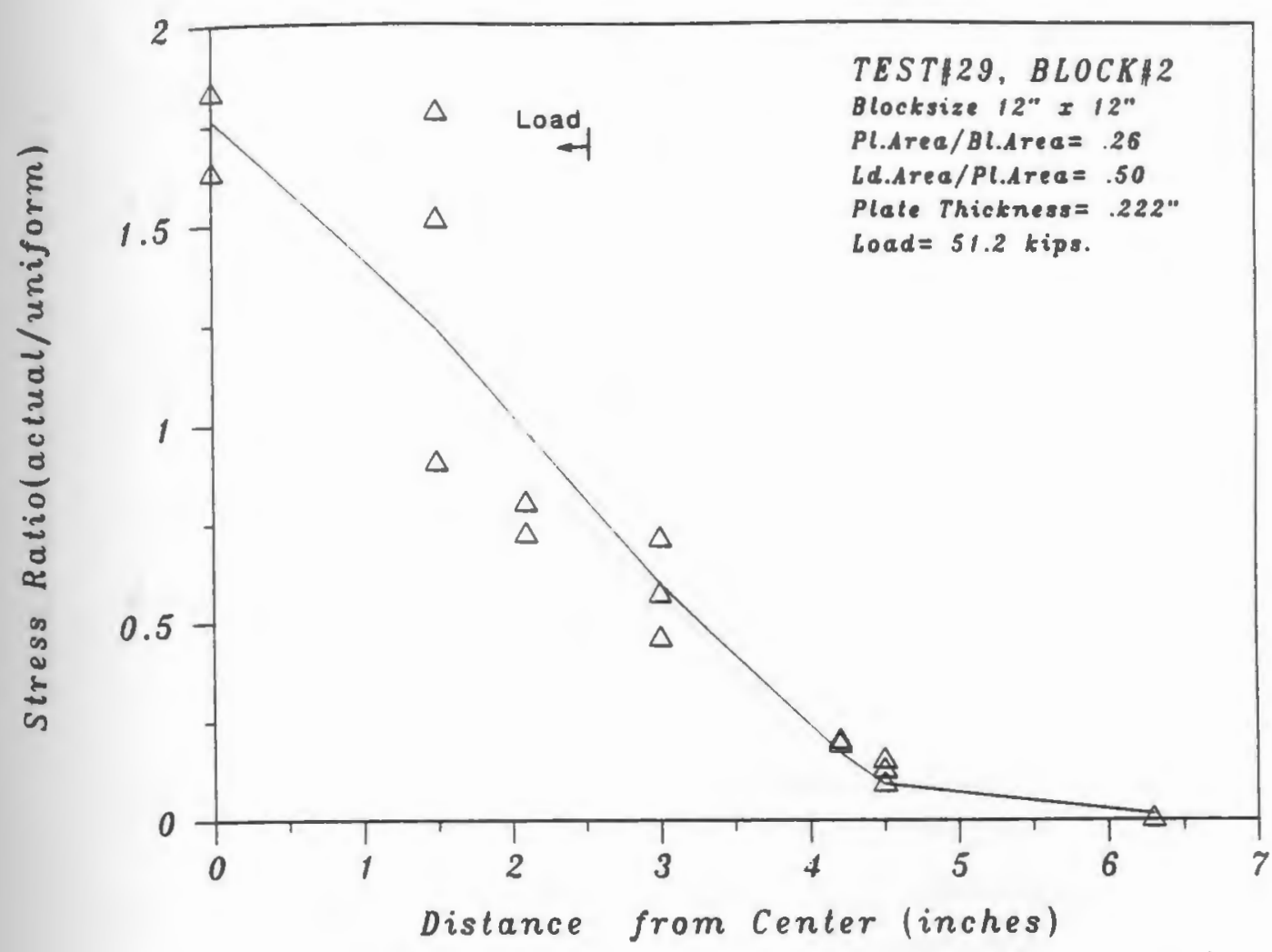

TESTI29, BLOCK\#2

Pl.Area/Bl.Area $=.26$

Ld.Area/Pl.Area $=.50$

Plate Thickness= $.222^{\prime \prime}$

oad $=51.2 \mathrm{kips}$.

Fig.43: DISTRIBUTION OF STRESSES

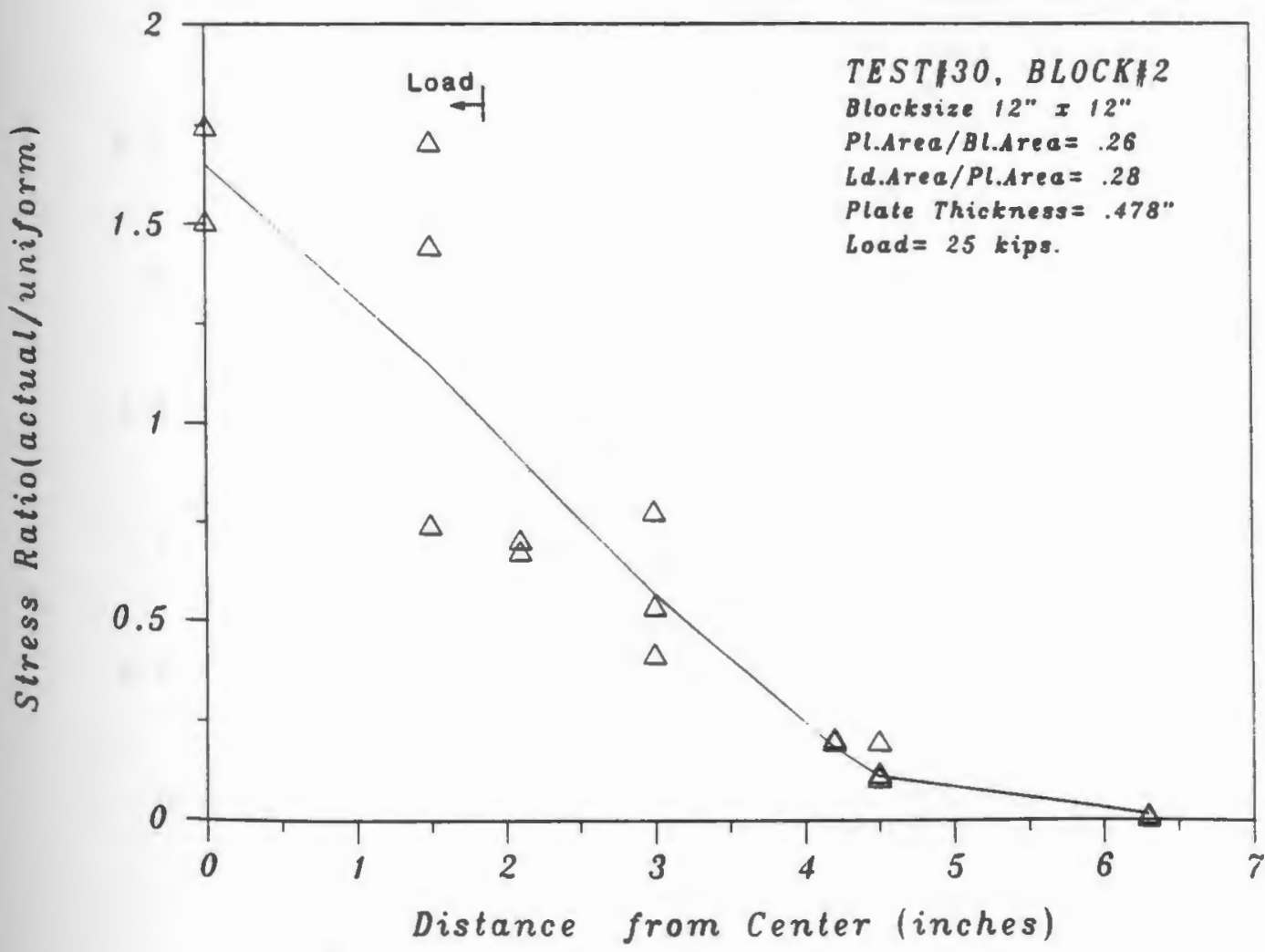

Fig.44: DISTRIBUTION OF STRESSES 


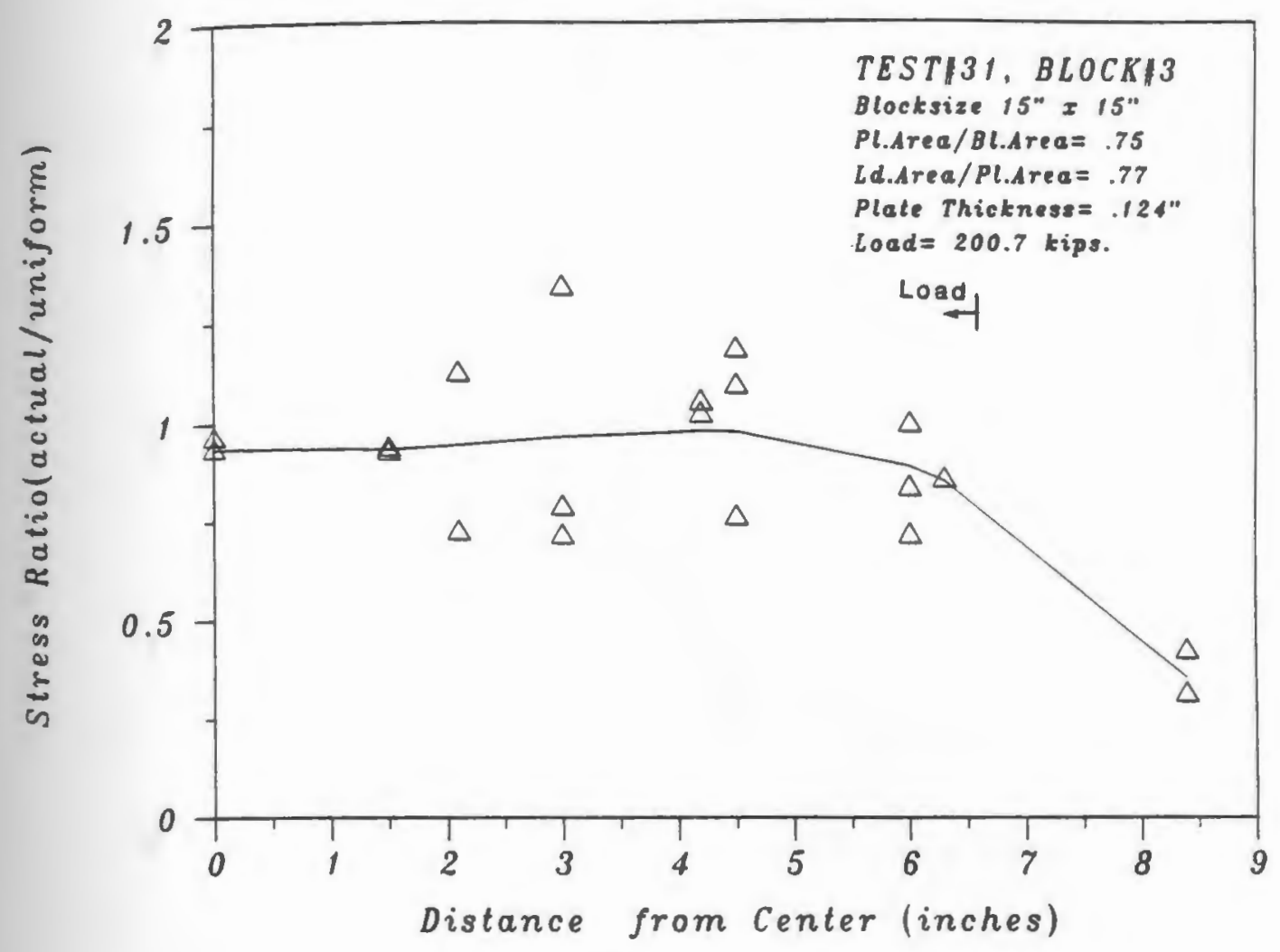

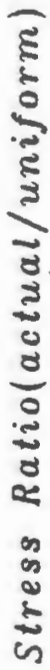

Fig.45: DISTRIBUTION OF STRESSES

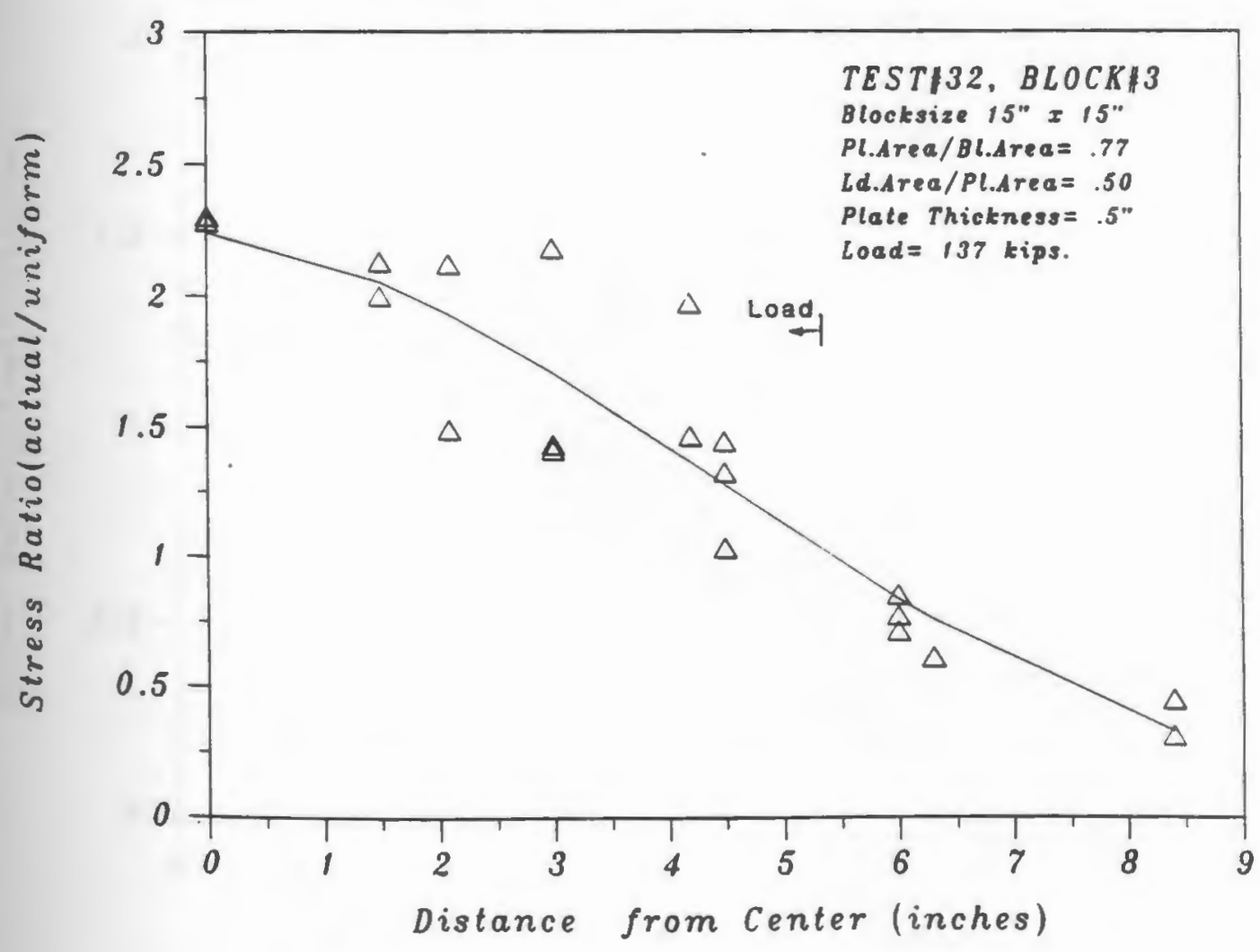

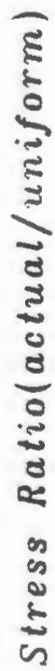

Fig.46: DISTRIBUTION OF STRESSES 


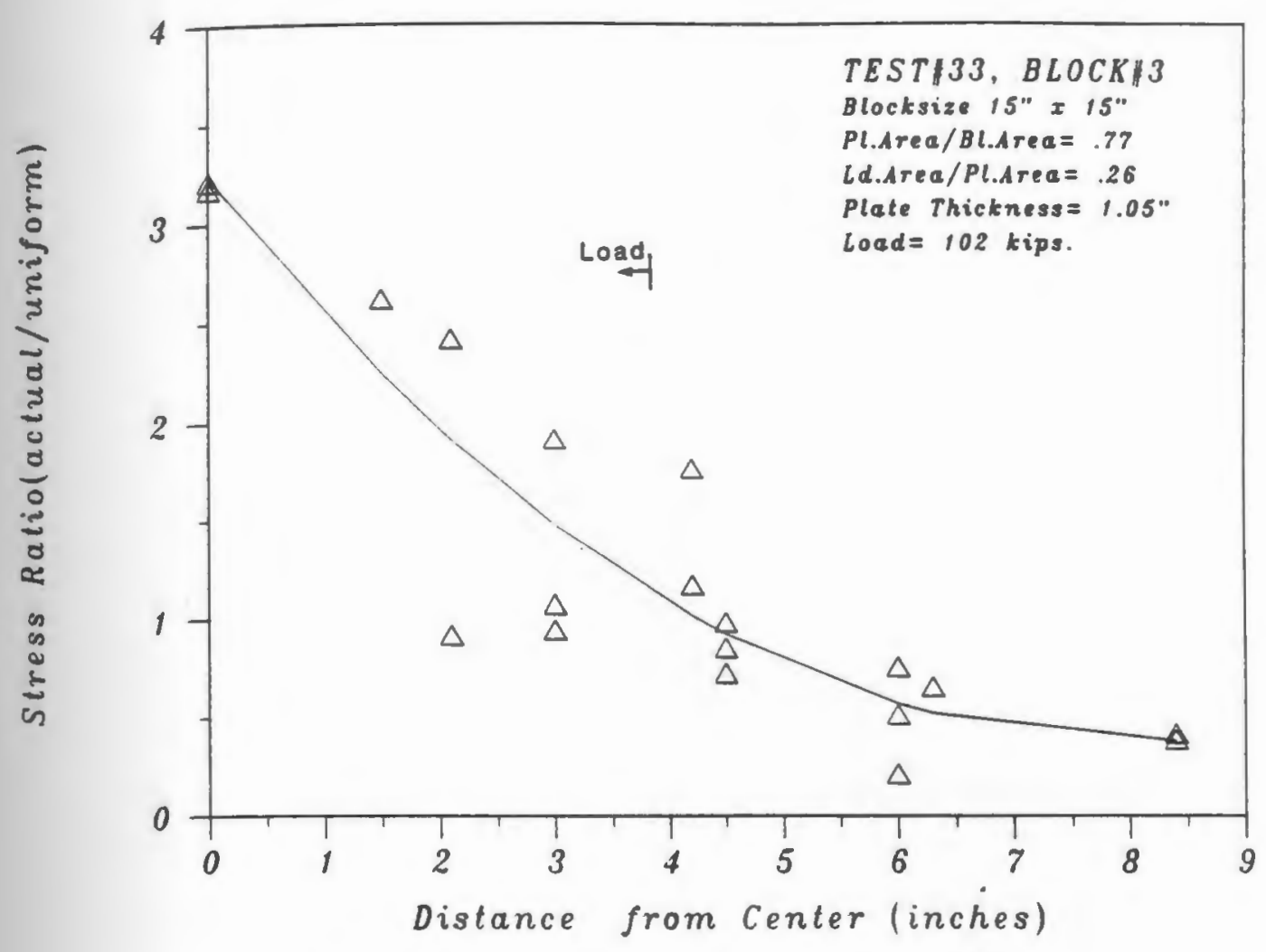

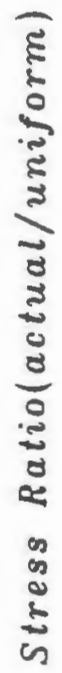

Fig.47: DISTRIBUTION OF STRESSES

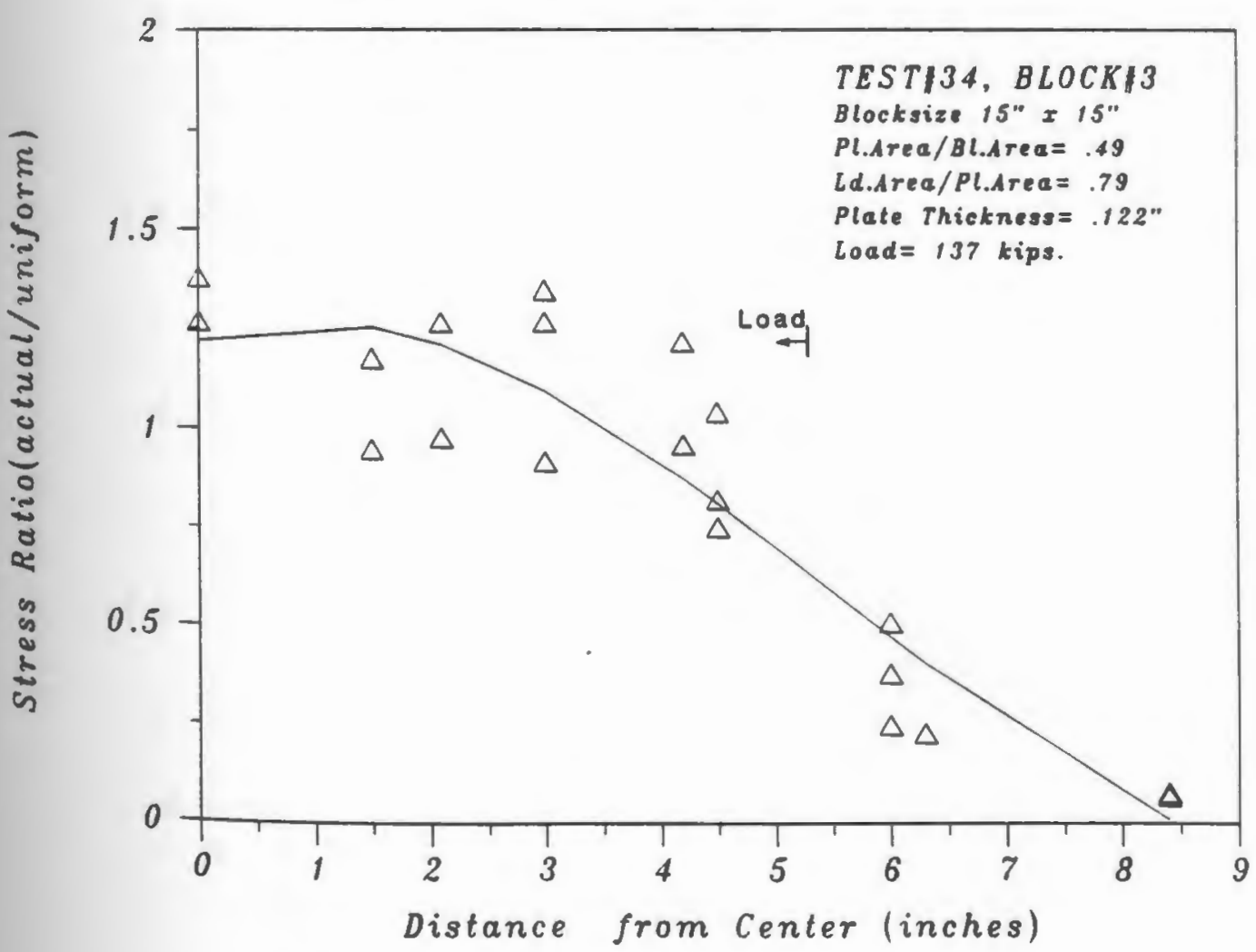

Fig.48: DISTRIBUTION OF STRESSES 


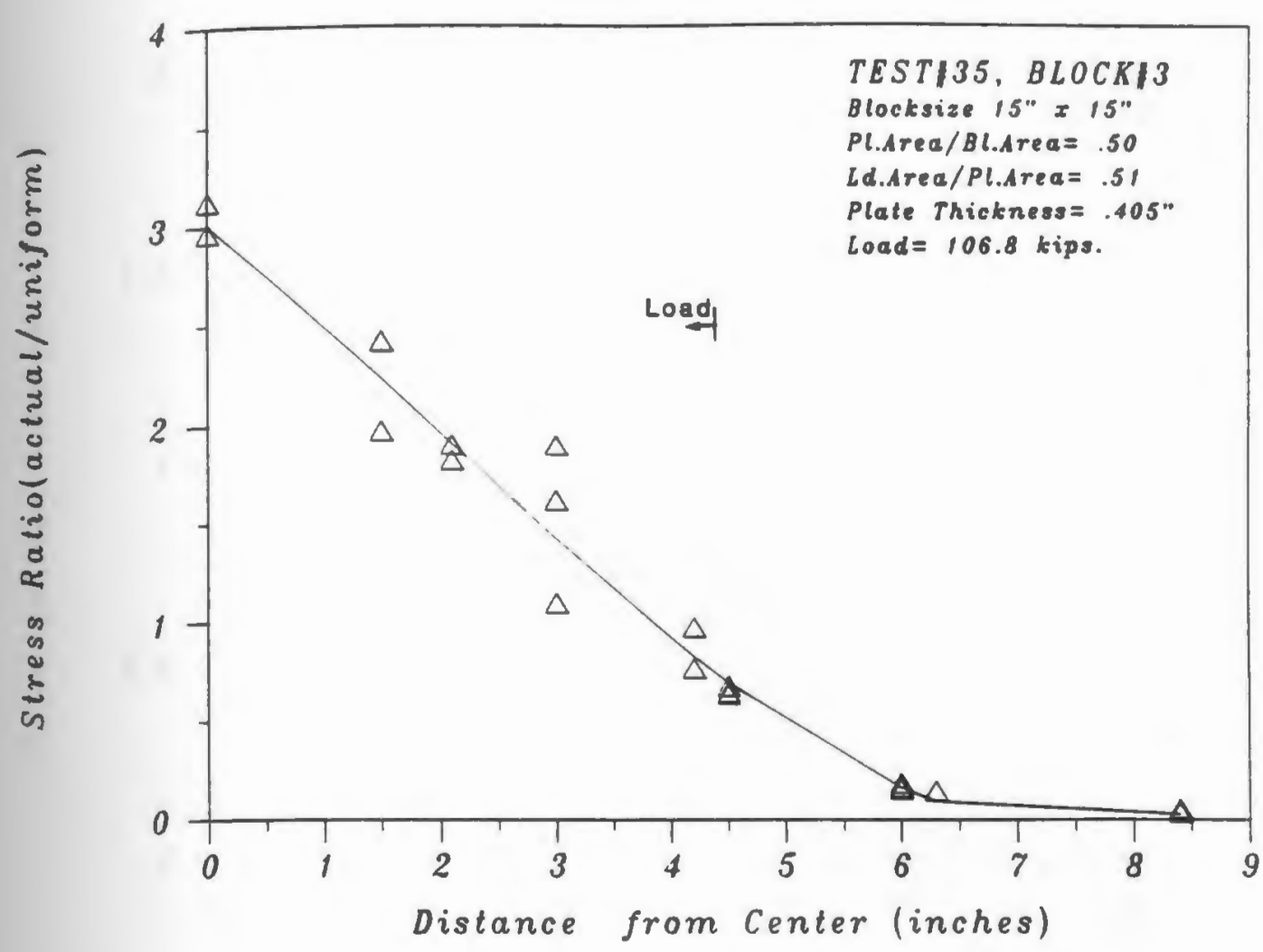

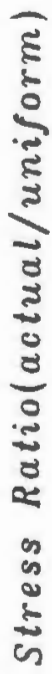

Fig.49: DISTRIBUTION OF STRESSES

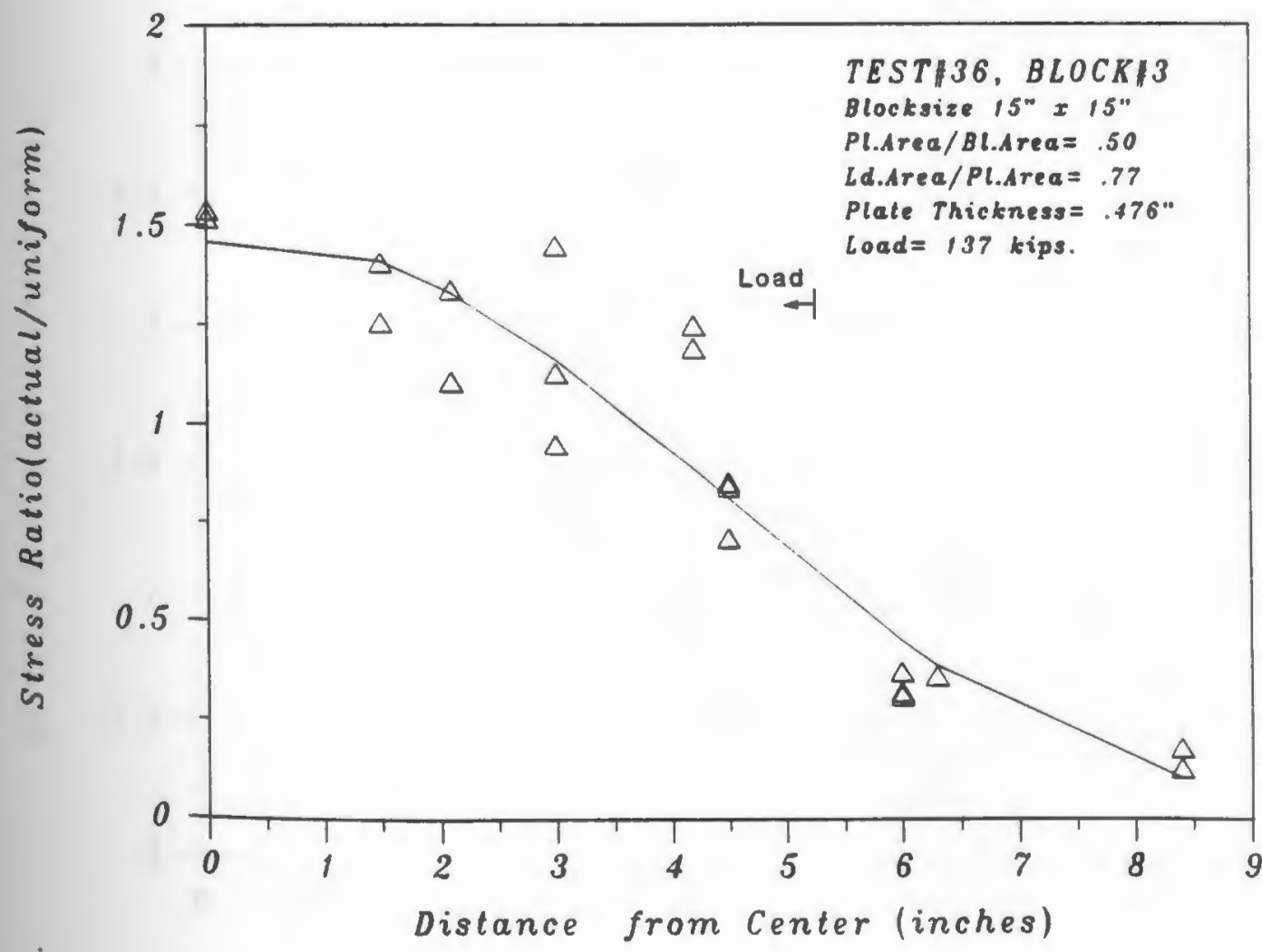

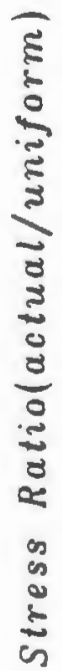

Fig.50: DISTRIBUTION OF STRESSES 


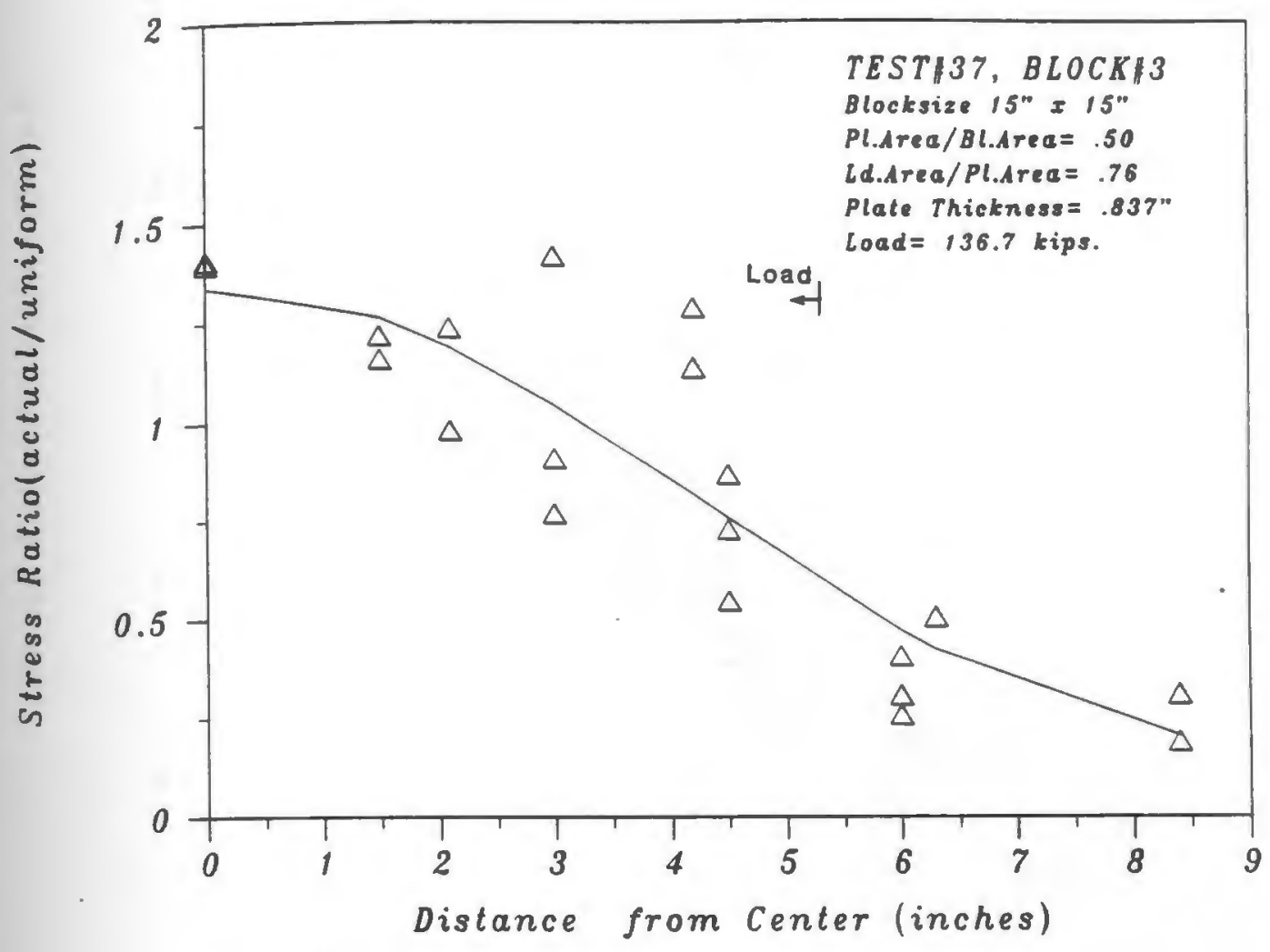

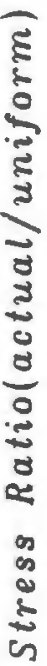

Fig.51: DISTRIBUTION OF STRESSES

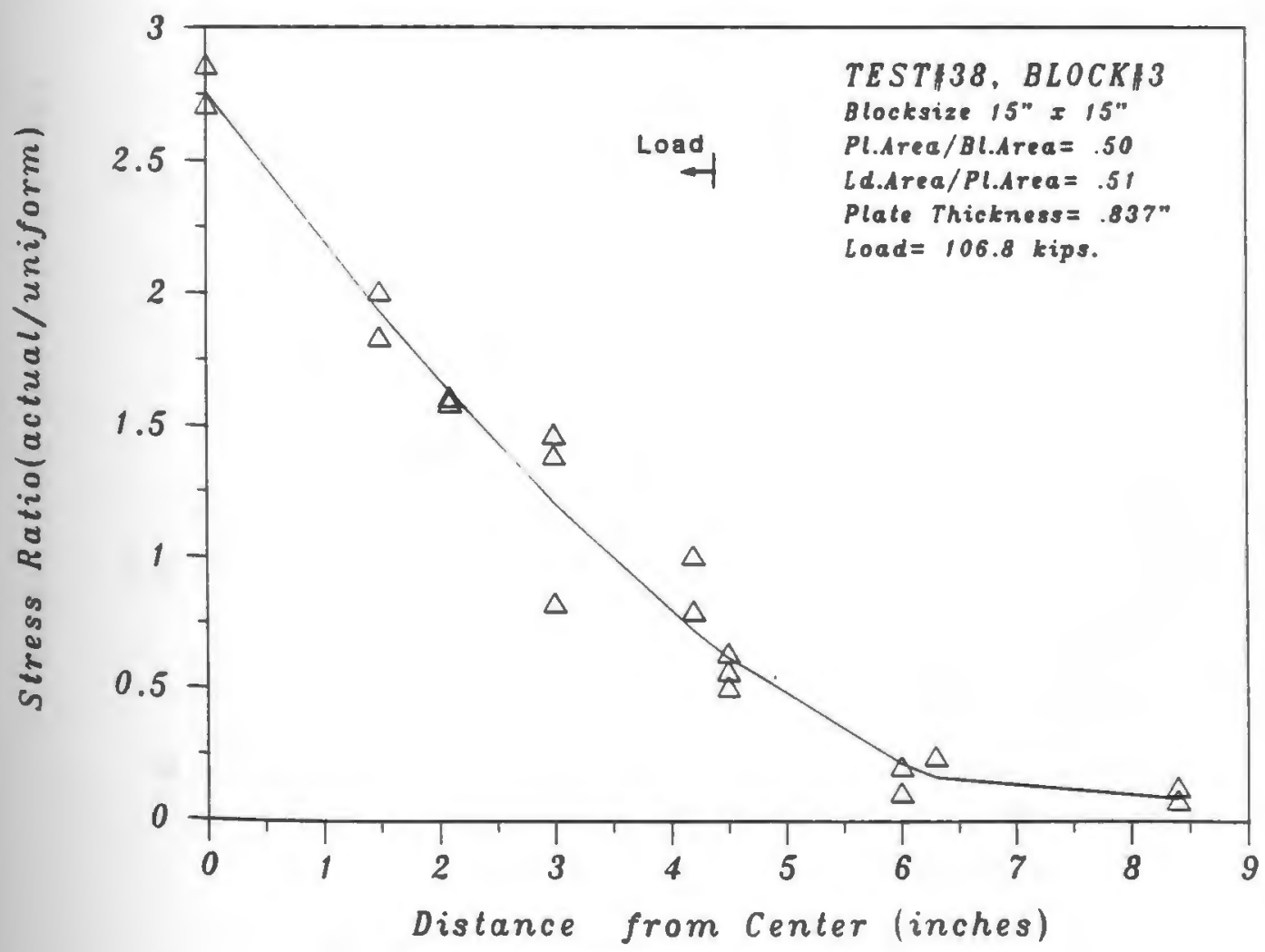

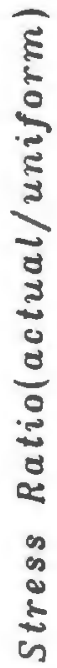

Fig.52: DISTRIBUTION OF STRESSES 


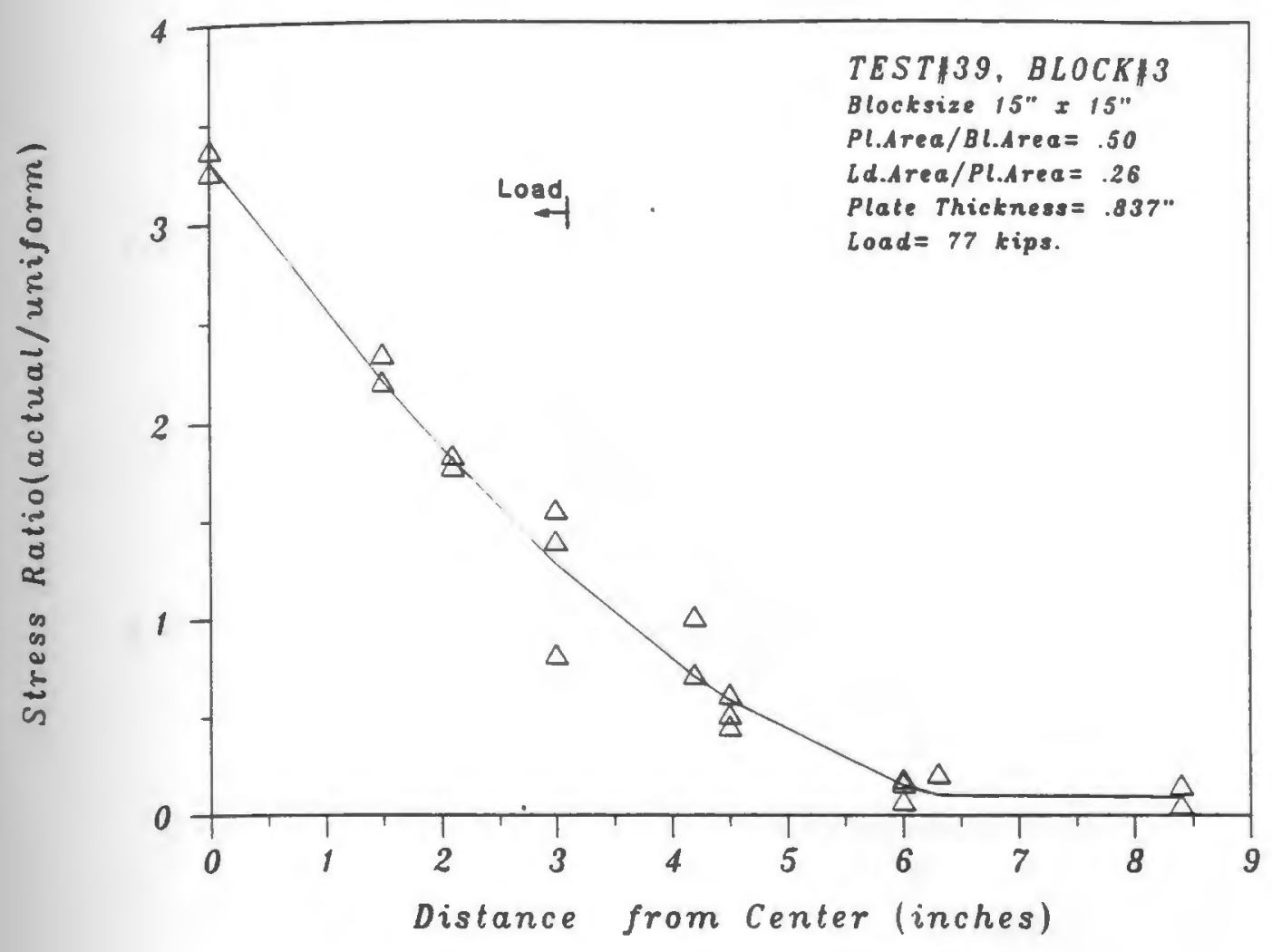

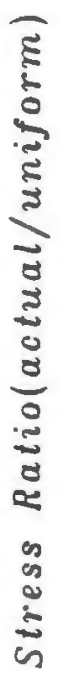

Fig.53: DISTRIBUTION OF STRESSES

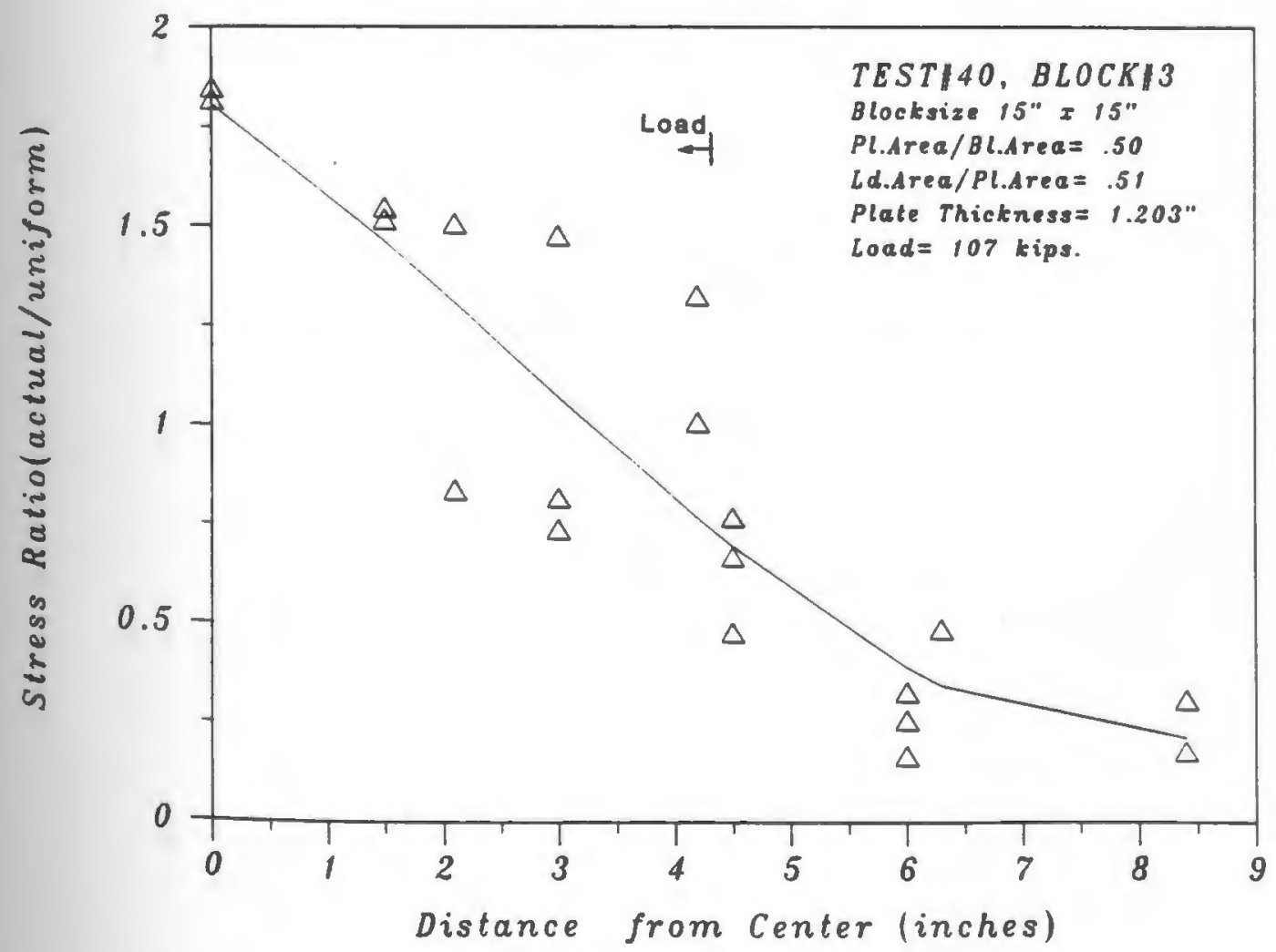

Fig.54: DISTRIBUTION OF STRESSES 


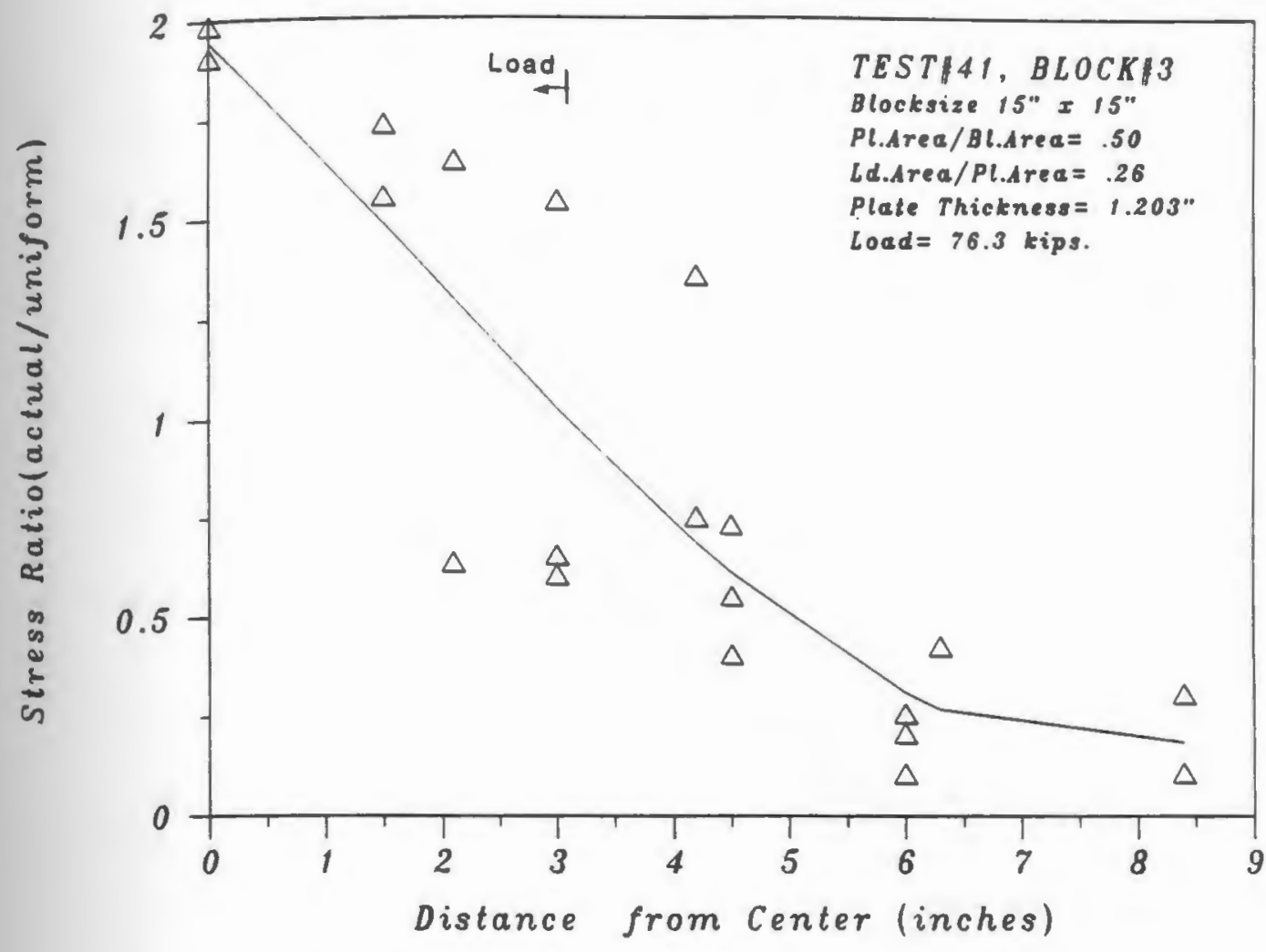

TEST 41, BLOCK\$3

Blocksize 15" $x$ 15"

Pl.Area $/$ Bl.Area $=.50$

Ld.drea/Pl.Area $=.26$

Plate Thickness = 1.203"

load $=76.3 \mathrm{kips}$.

Fig.55: DISTRIBUTION OF STRESSES

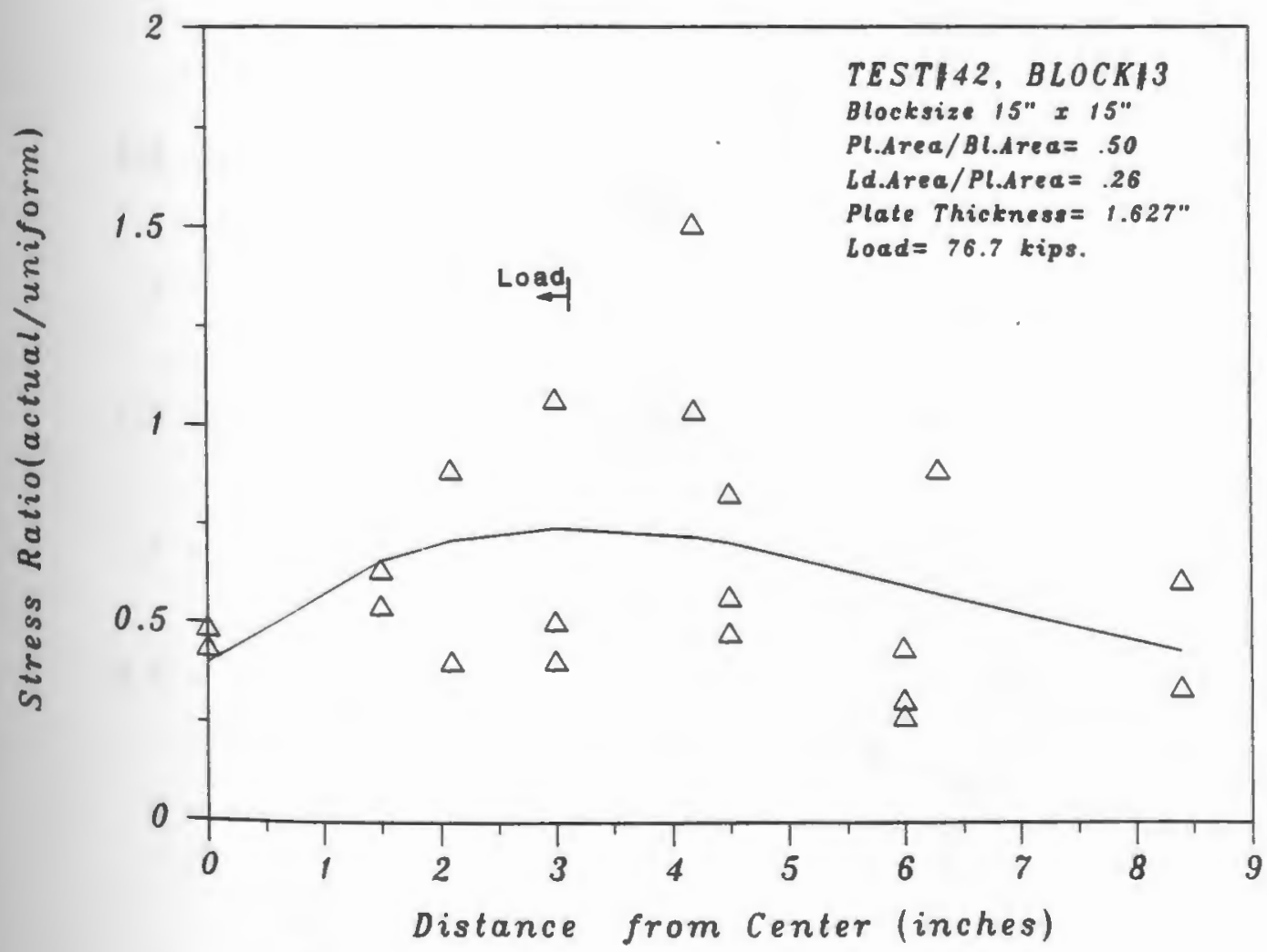

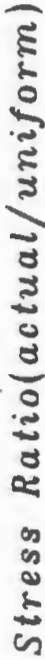

Fig.56: DISTRIBUTION OF STRESSES 


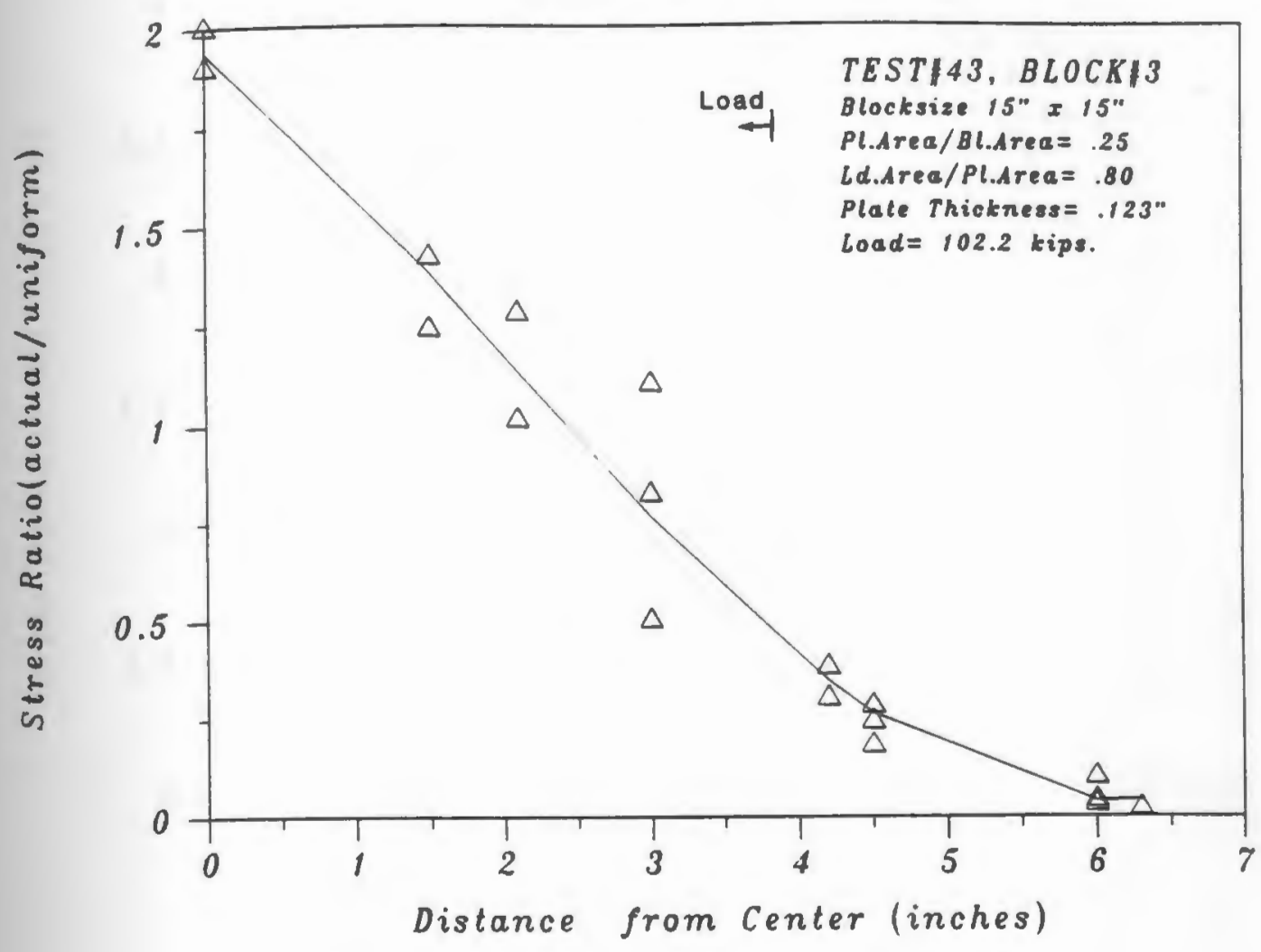

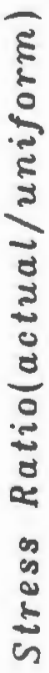

Fig.57: DISTRIBUTION OF STRESSES

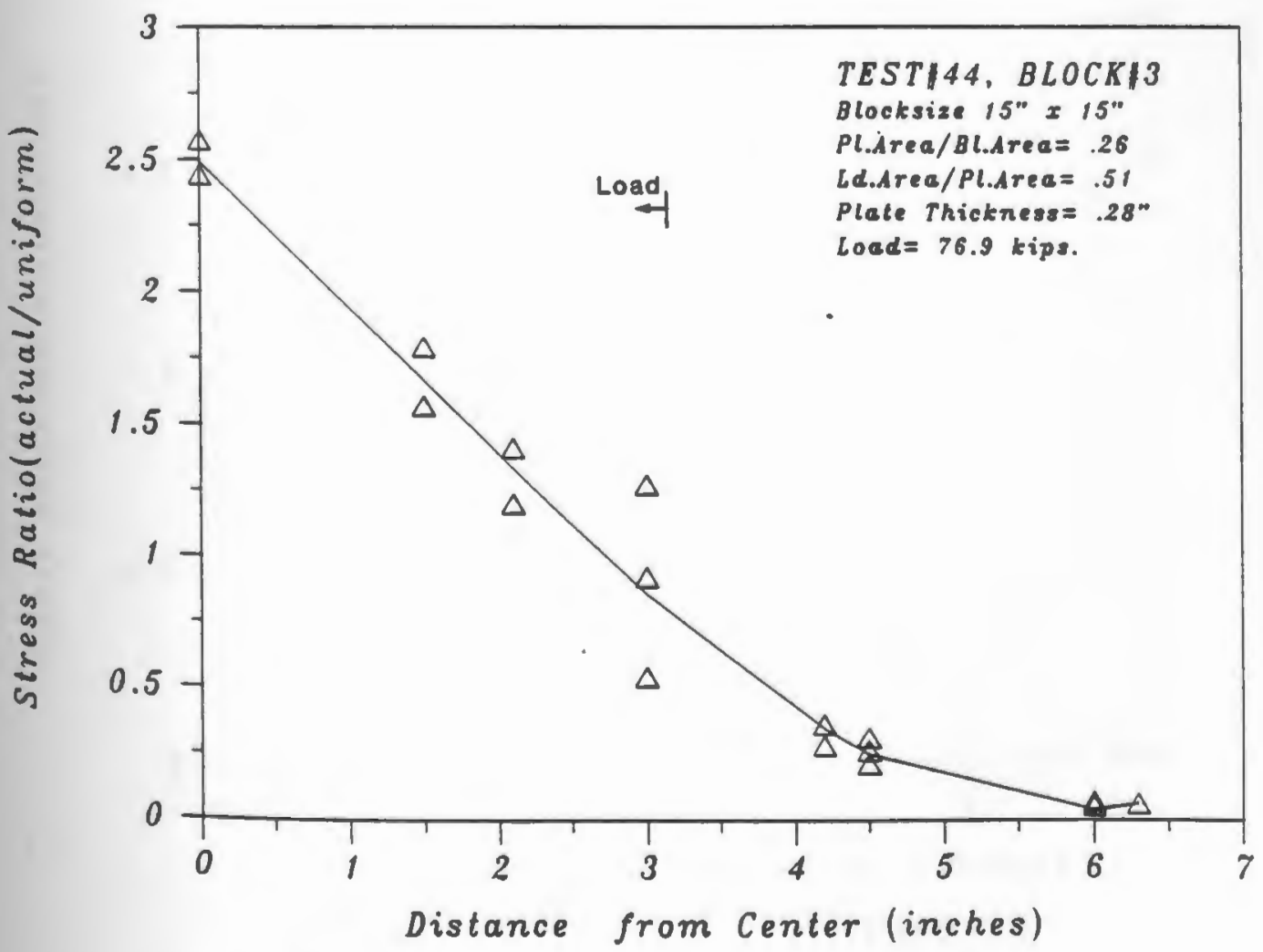

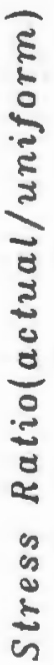

Fig.58: DISTRIBUTION OF STRESSES 


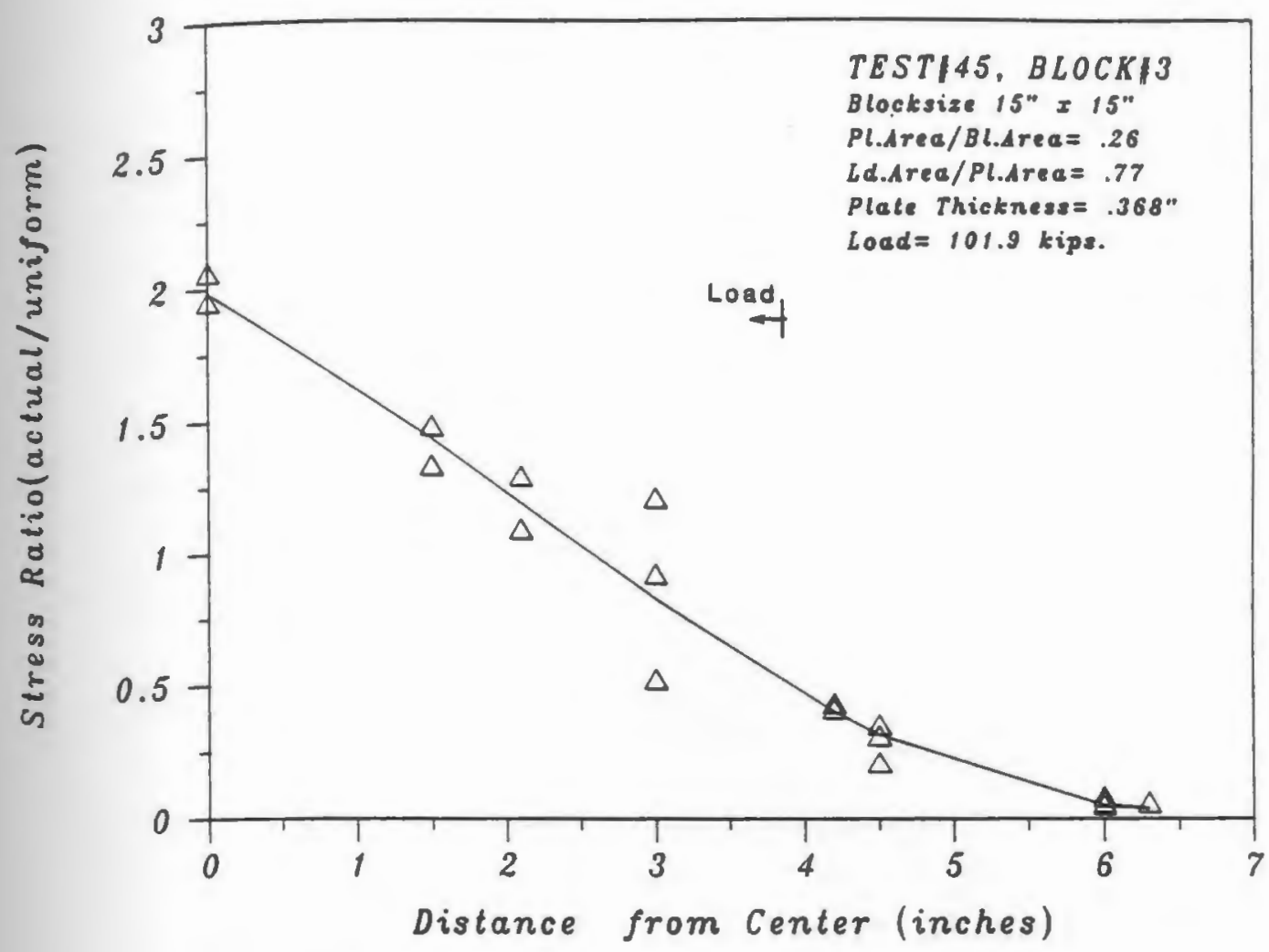

है

Fig.59: DISTRIBUTION OF STRESSES

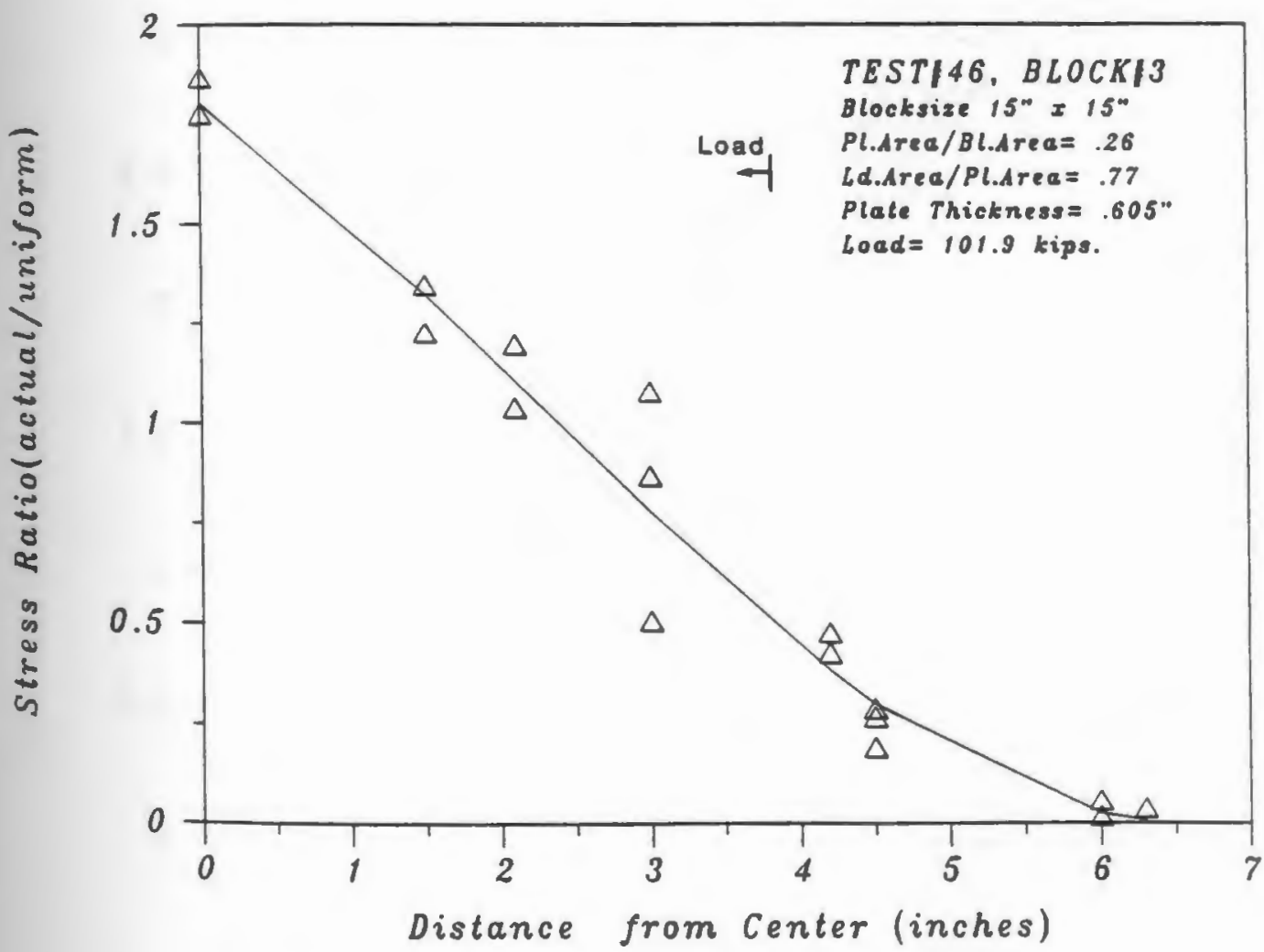

Fig.60: DISTRIBUTION OF STRESSES 


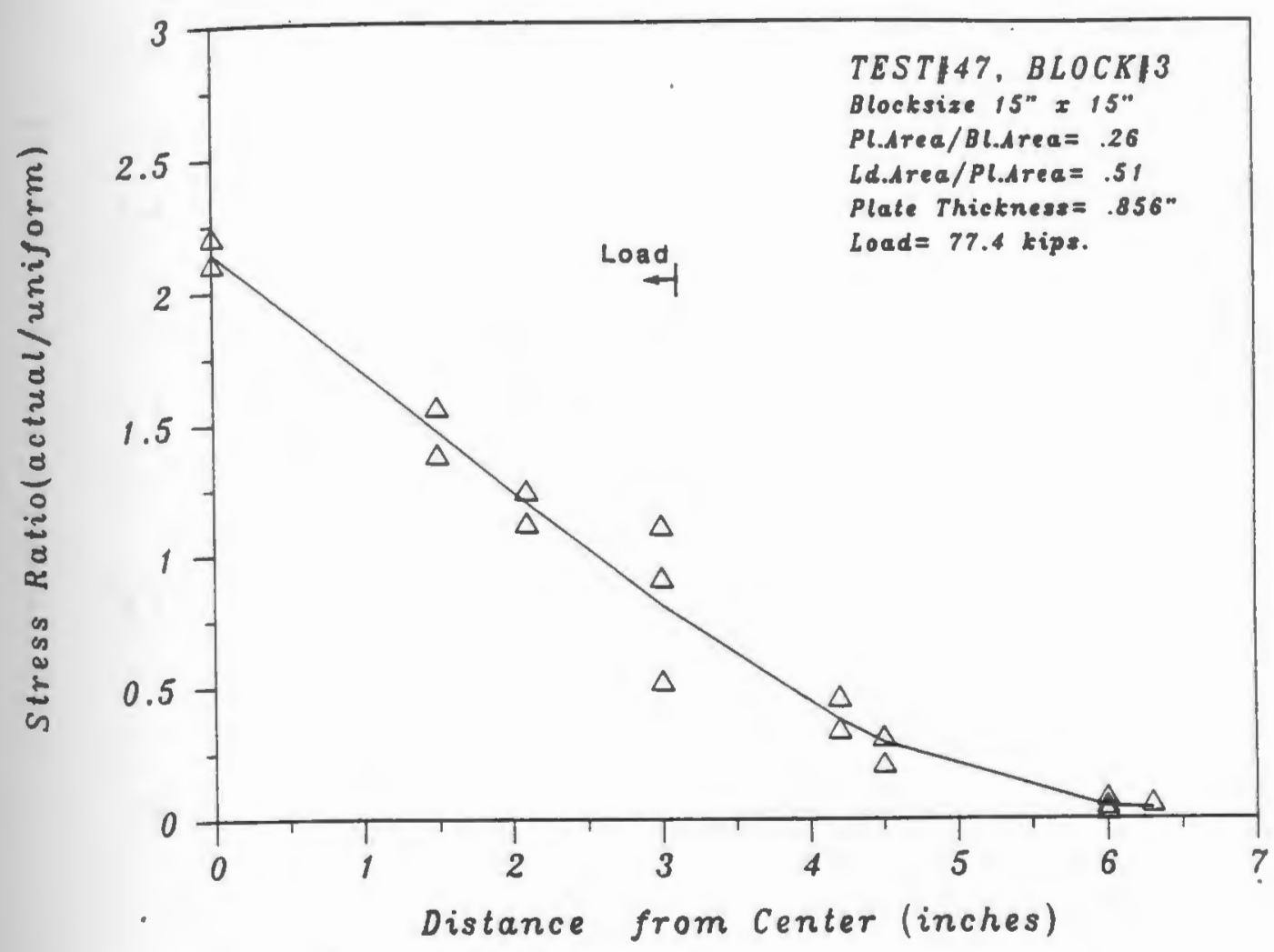

Fig.61: DISTRIBUTION OF STRESSES

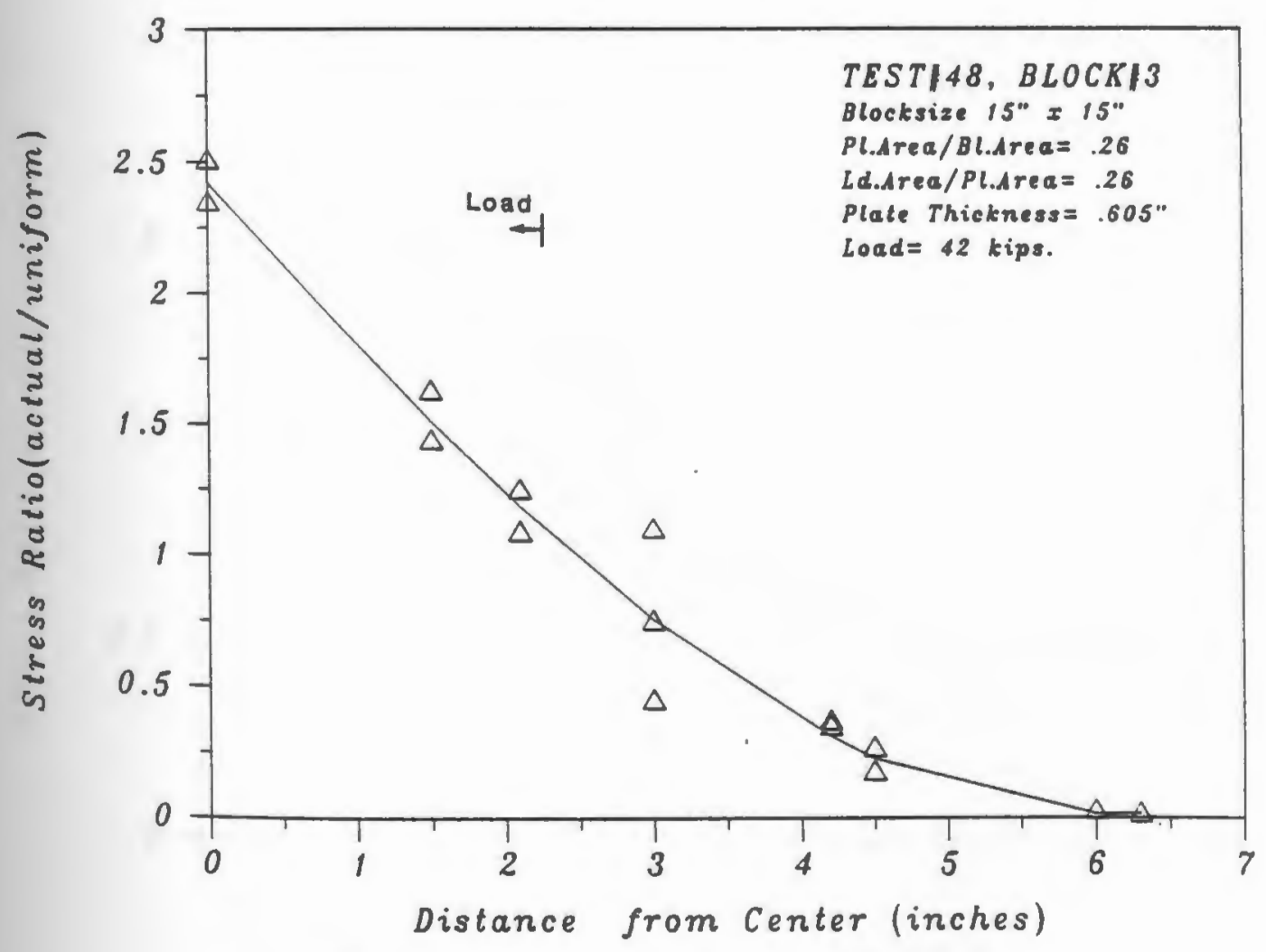

Fig.62: DISTRIBUTION OF STRESSES 


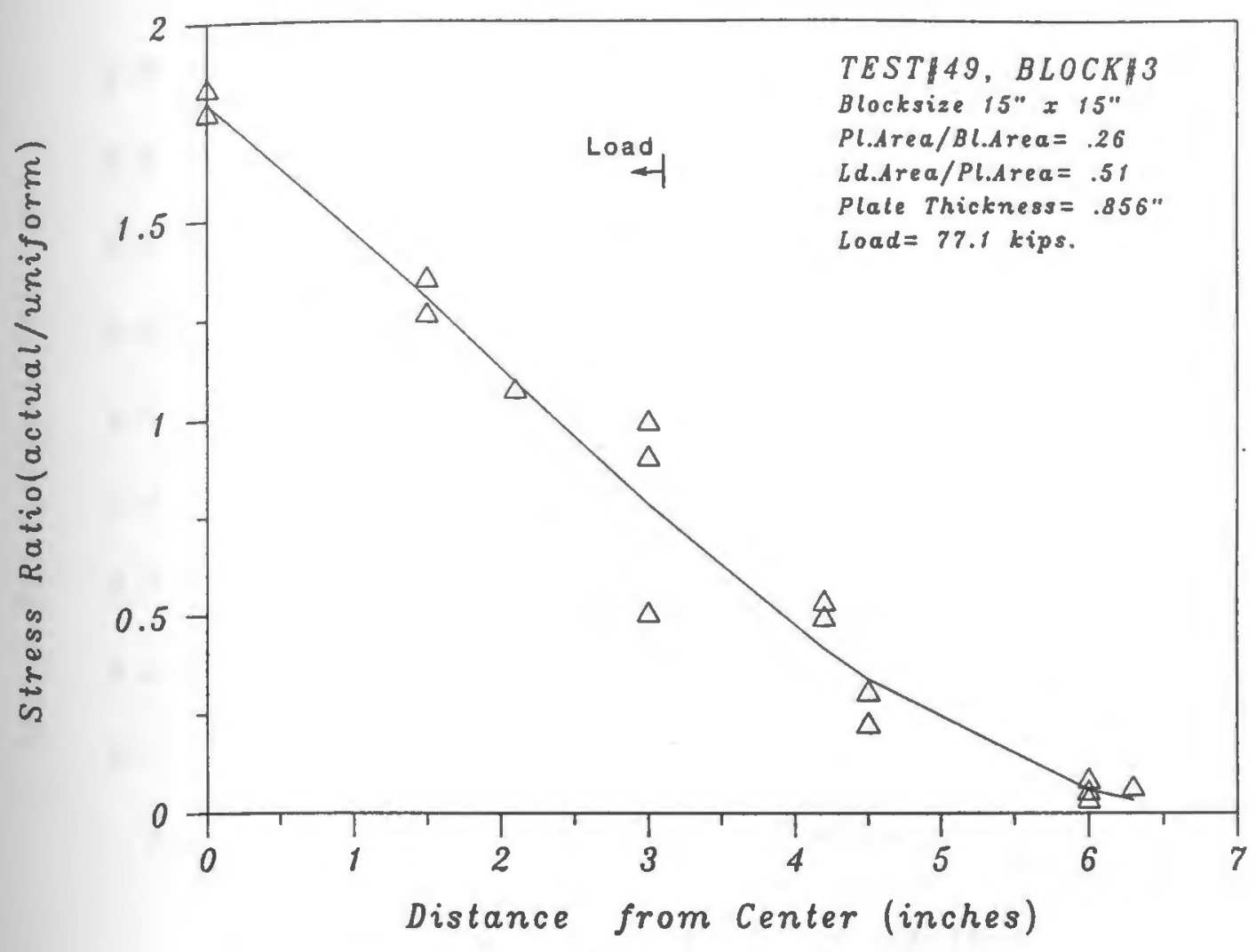

TEST\&49, BLOCK\#3

Blocksize $15^{\prime \prime} \times 15^{\prime \prime}$

Pl.Area/Bl.Area $=.26$

Ld.Area/Pl.Area $=.51$

Plate Thickness $=.856^{\prime \prime}$

Load $=77.1$ kips.

Fig.63: DISTRIBUTION OF STRESSES

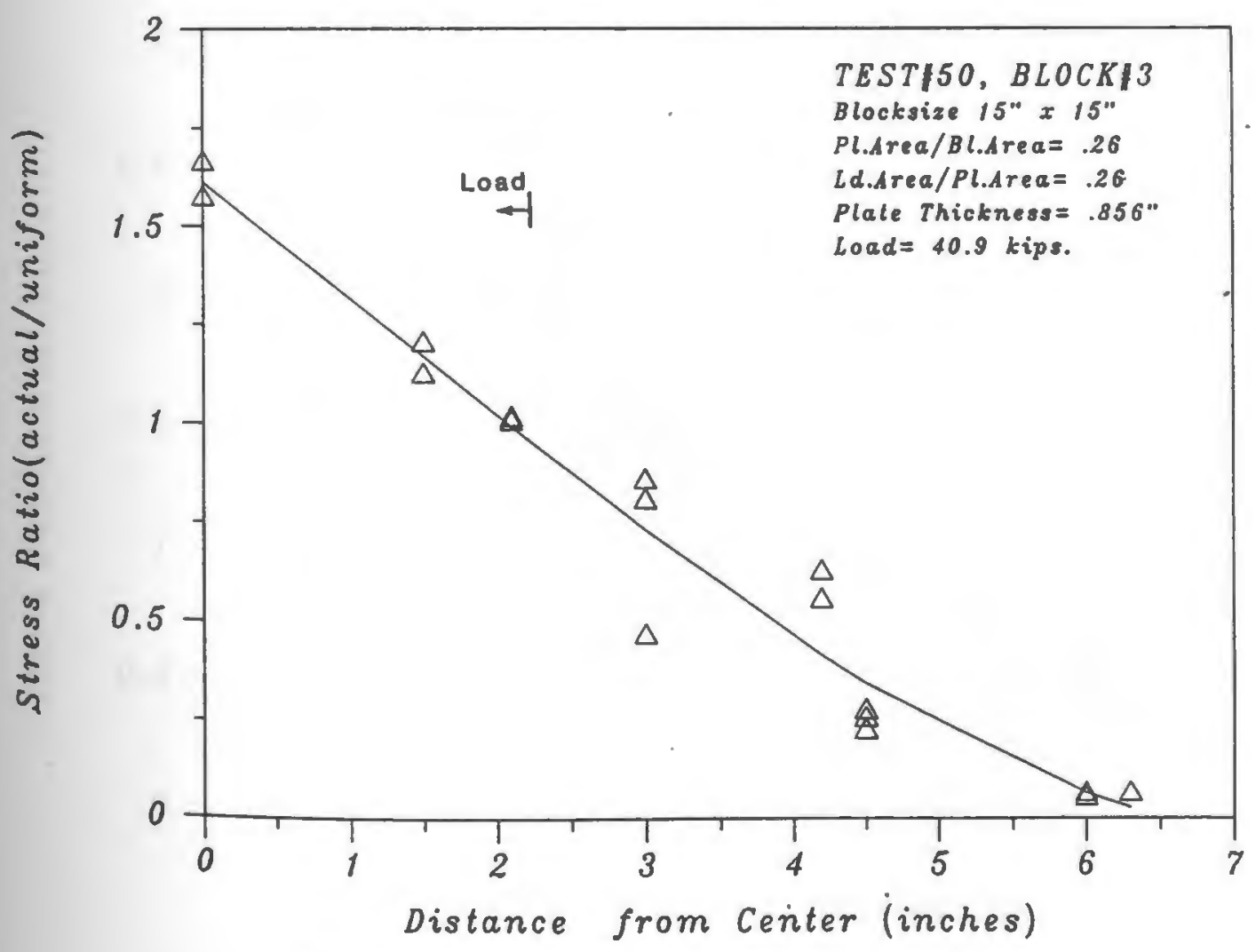

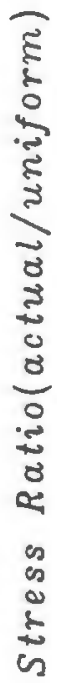

Fig.64: DISTRIBUTION OF STRESSES 


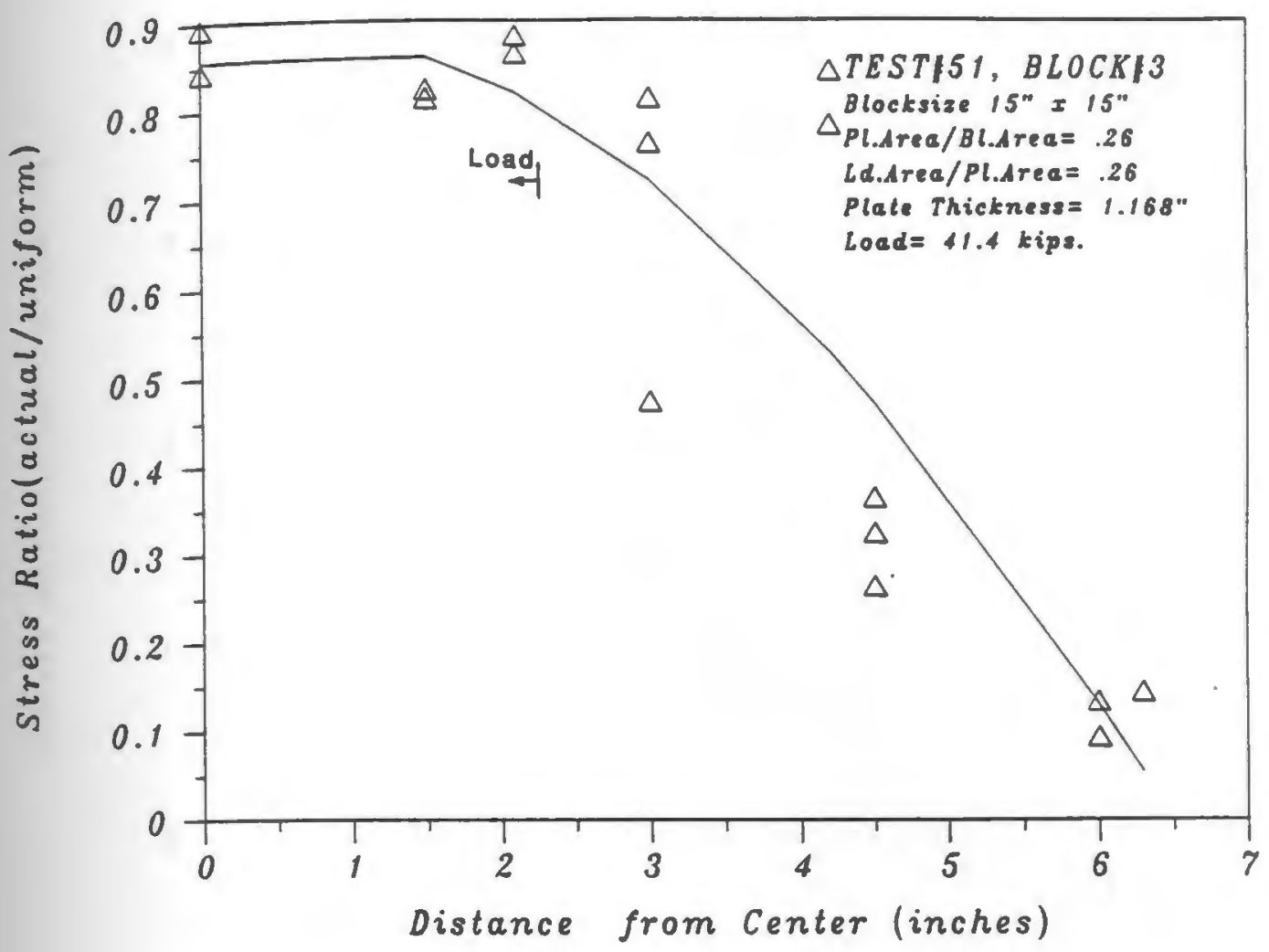

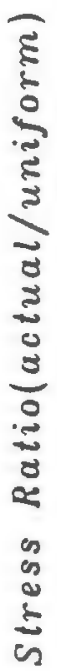

Fig.65: DISTRIBUTION OF STRESSES

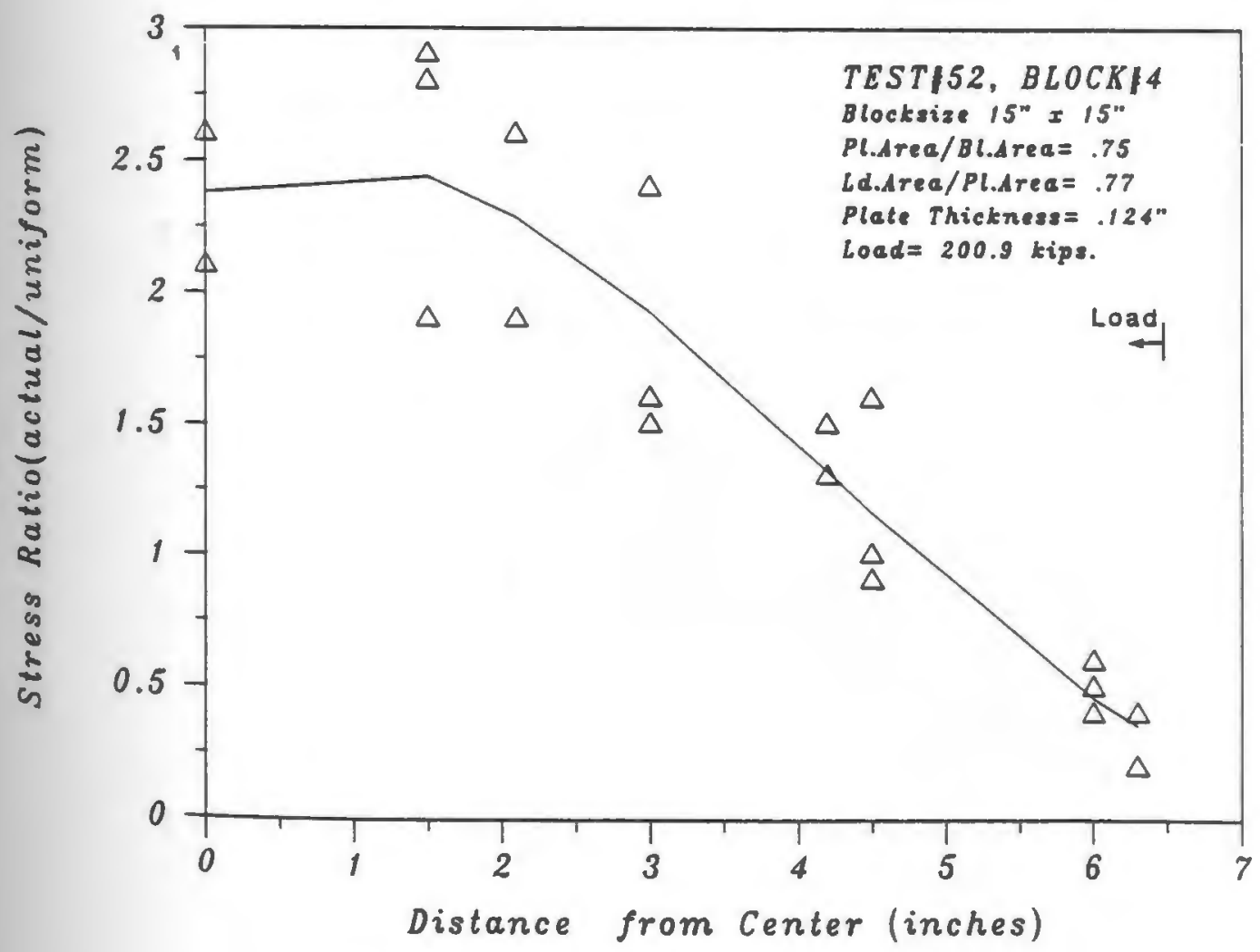

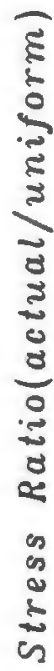

Fig.66: DISTRIBUTION OF STRESSES 


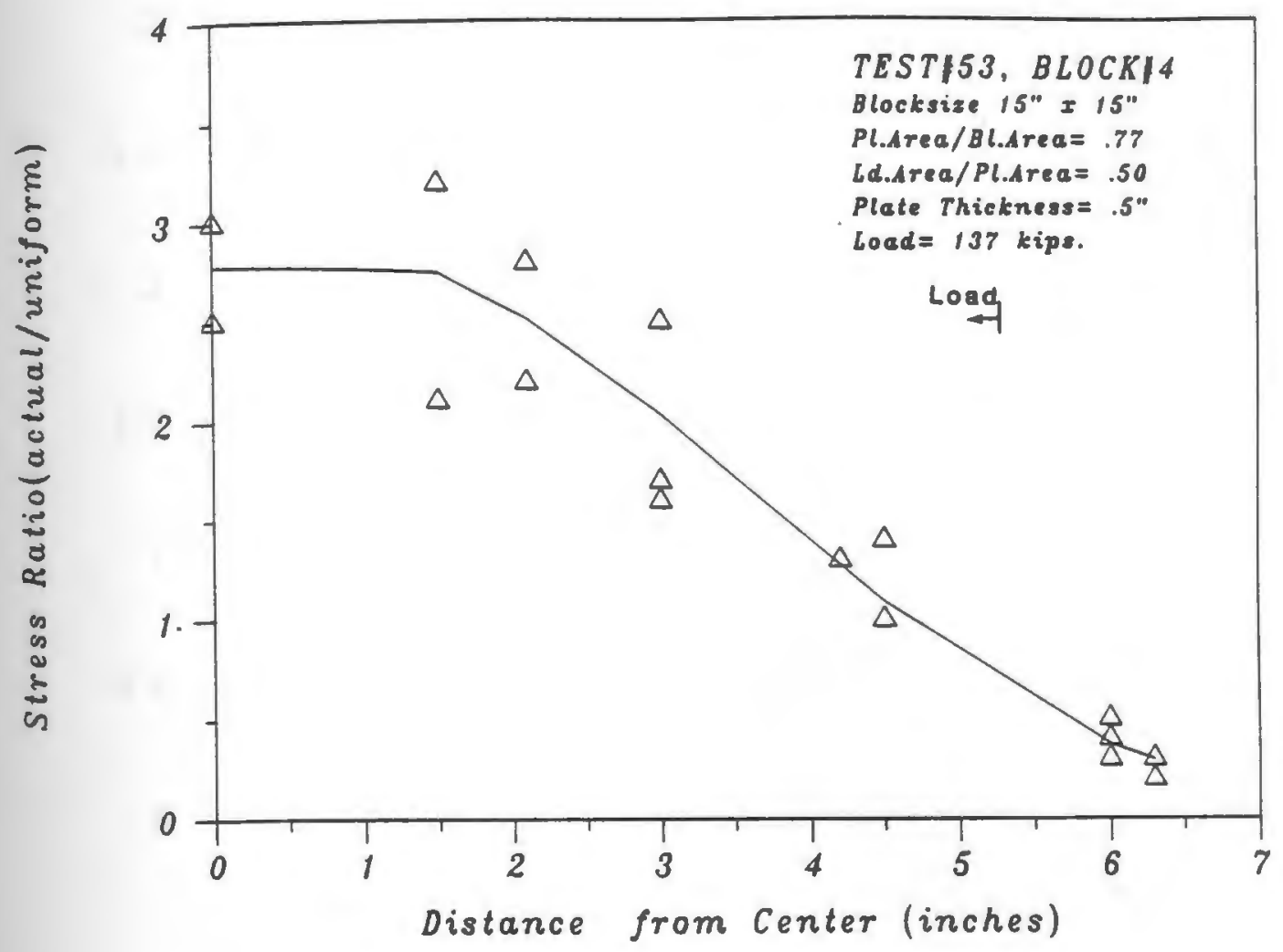

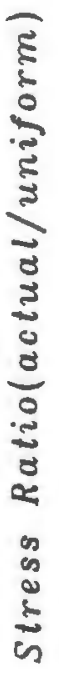

Fig.67: DISTRIBUTION OF STRESSES

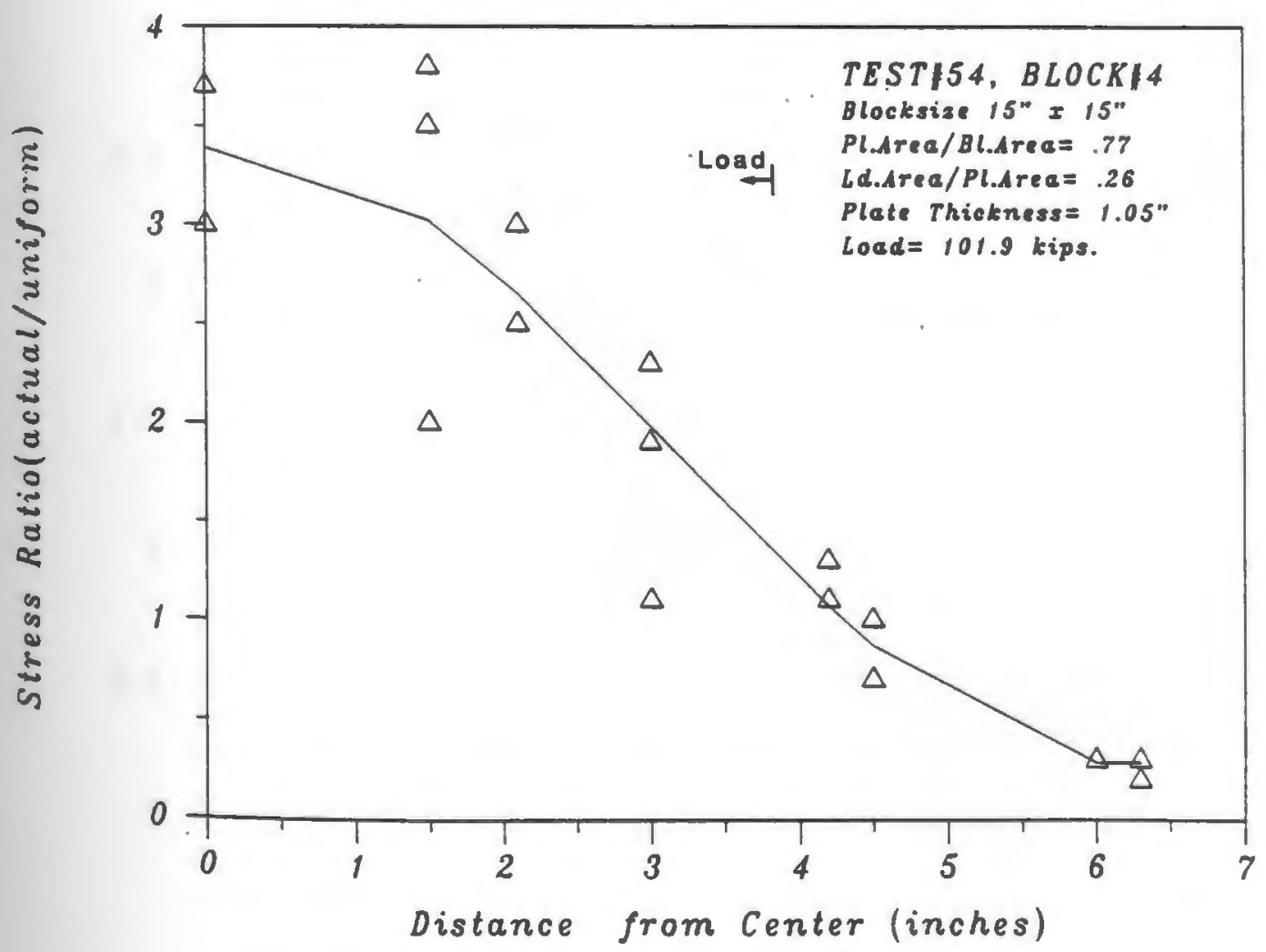

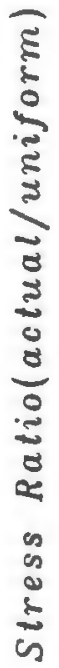

Fig.68: DISTRIBUTION OF STRESSES 


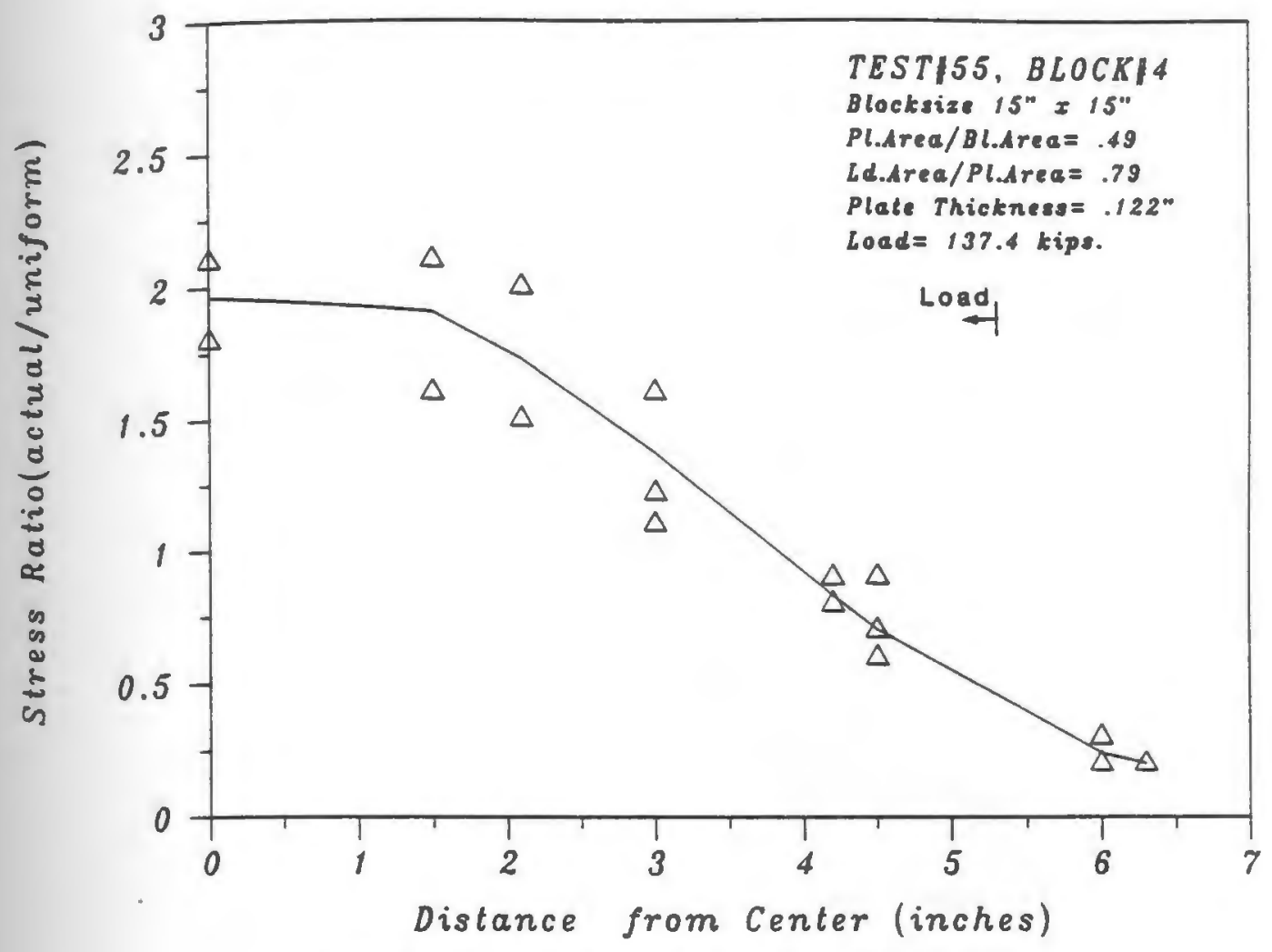

TESTI55, BLOCK/4

Pl.Area $/$ Bl.Area $=.49$

Ld.Area/PL.Area $=.79$

Plate Thickness= $.122^{\mathrm{N}}$

oad $=137.4$ kips.

Fig.69: DISTRIBUTION OF STRESSES

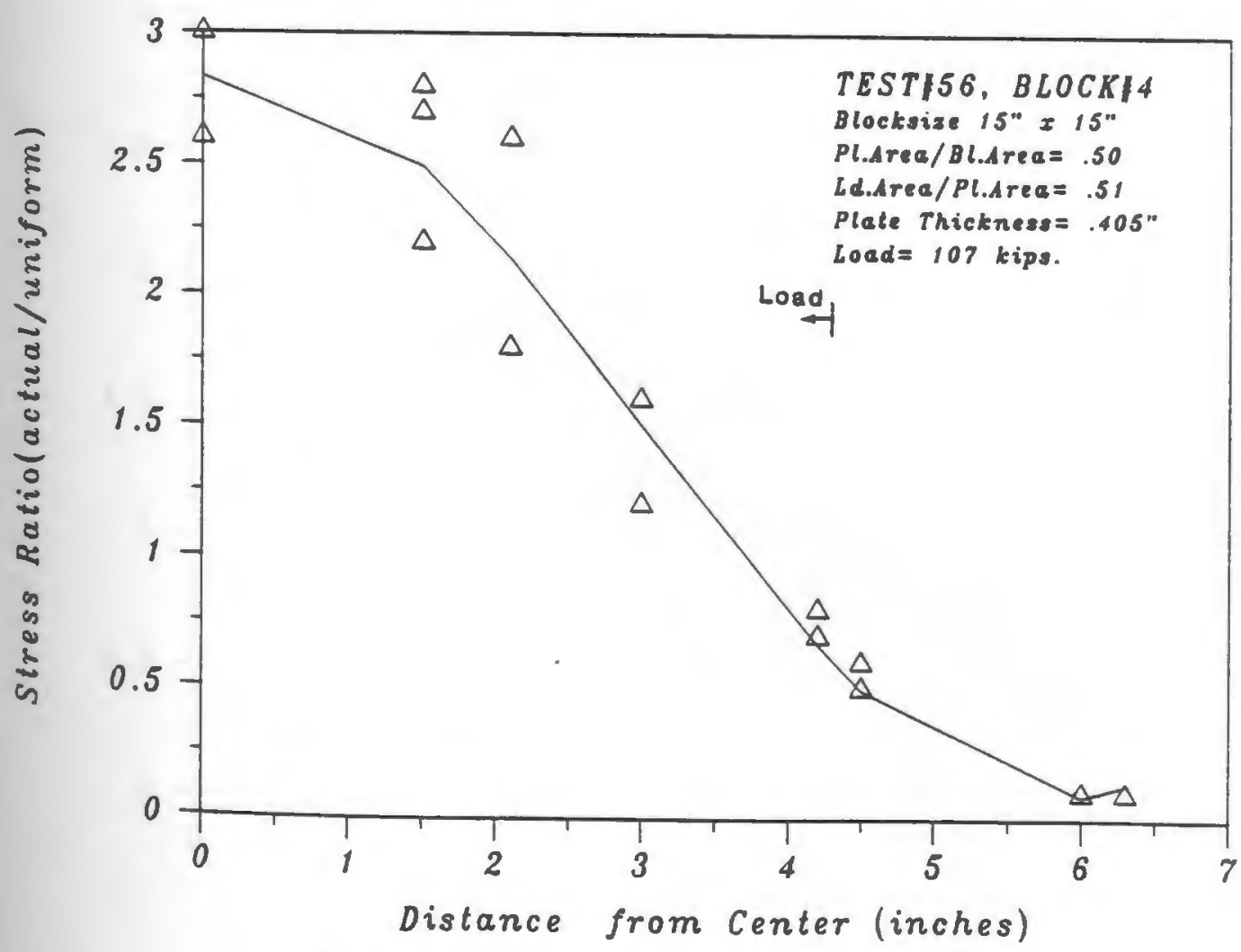

है

Fig.70: DISTRIBUTION OF STRESSES 


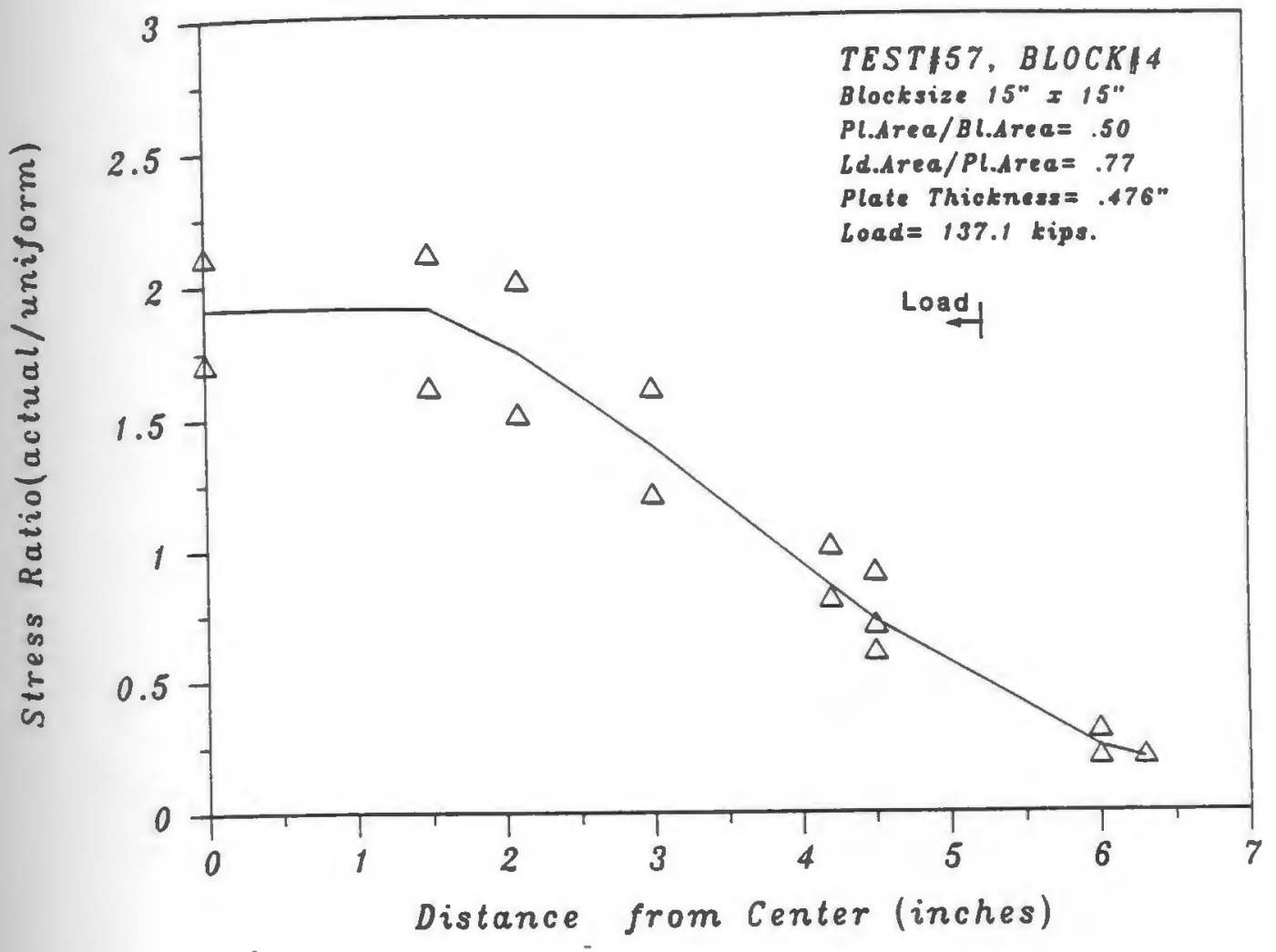

TEST157, BLOCK\$4

Blocksize $15^{\circ}$ I $15^{\circ}$

rea $=.50$

Load

Fig.71: DISTRIBUTION OF STRESSES

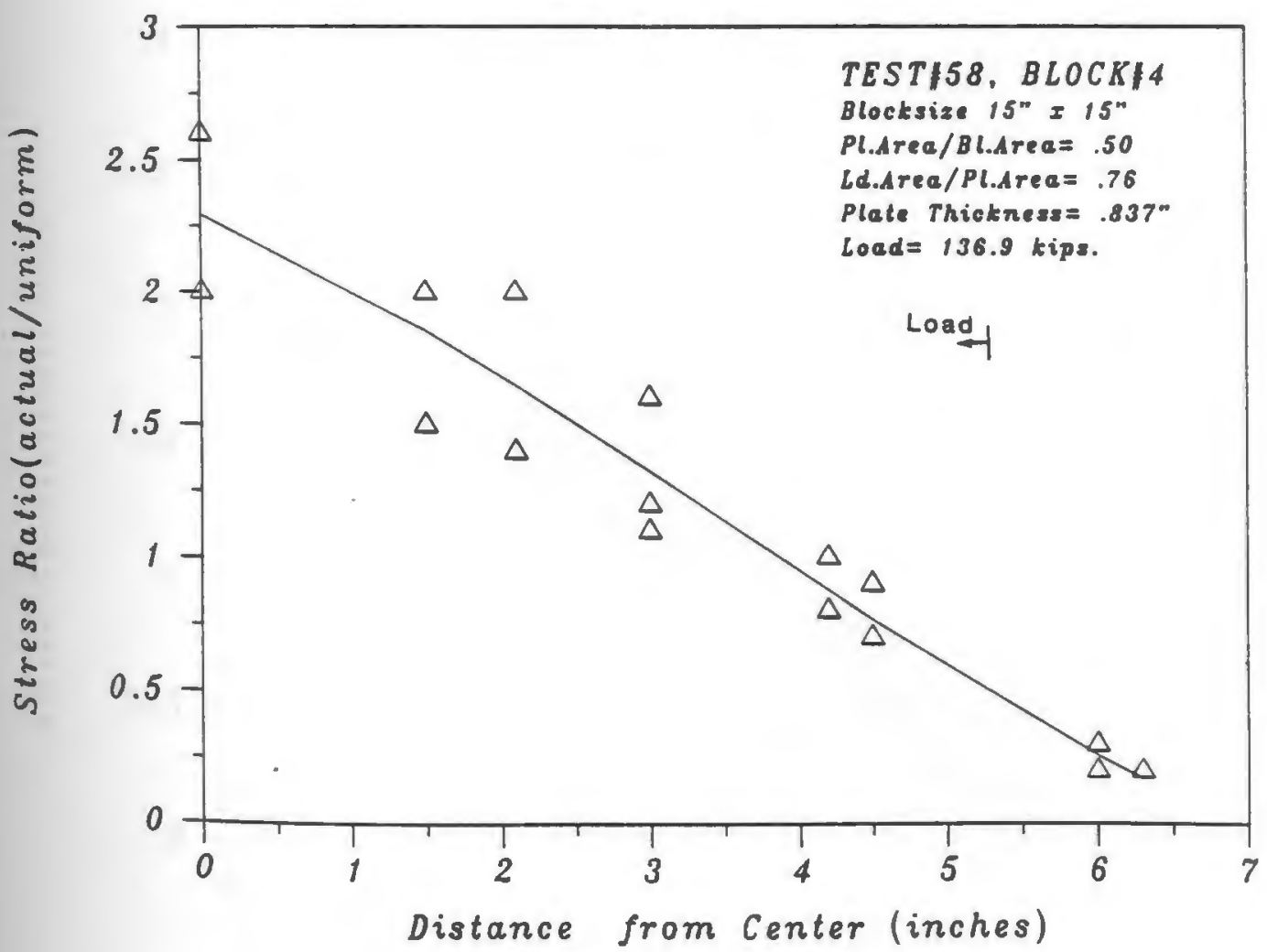

Fig.72: DISTRIBUTION OF STRESSES 


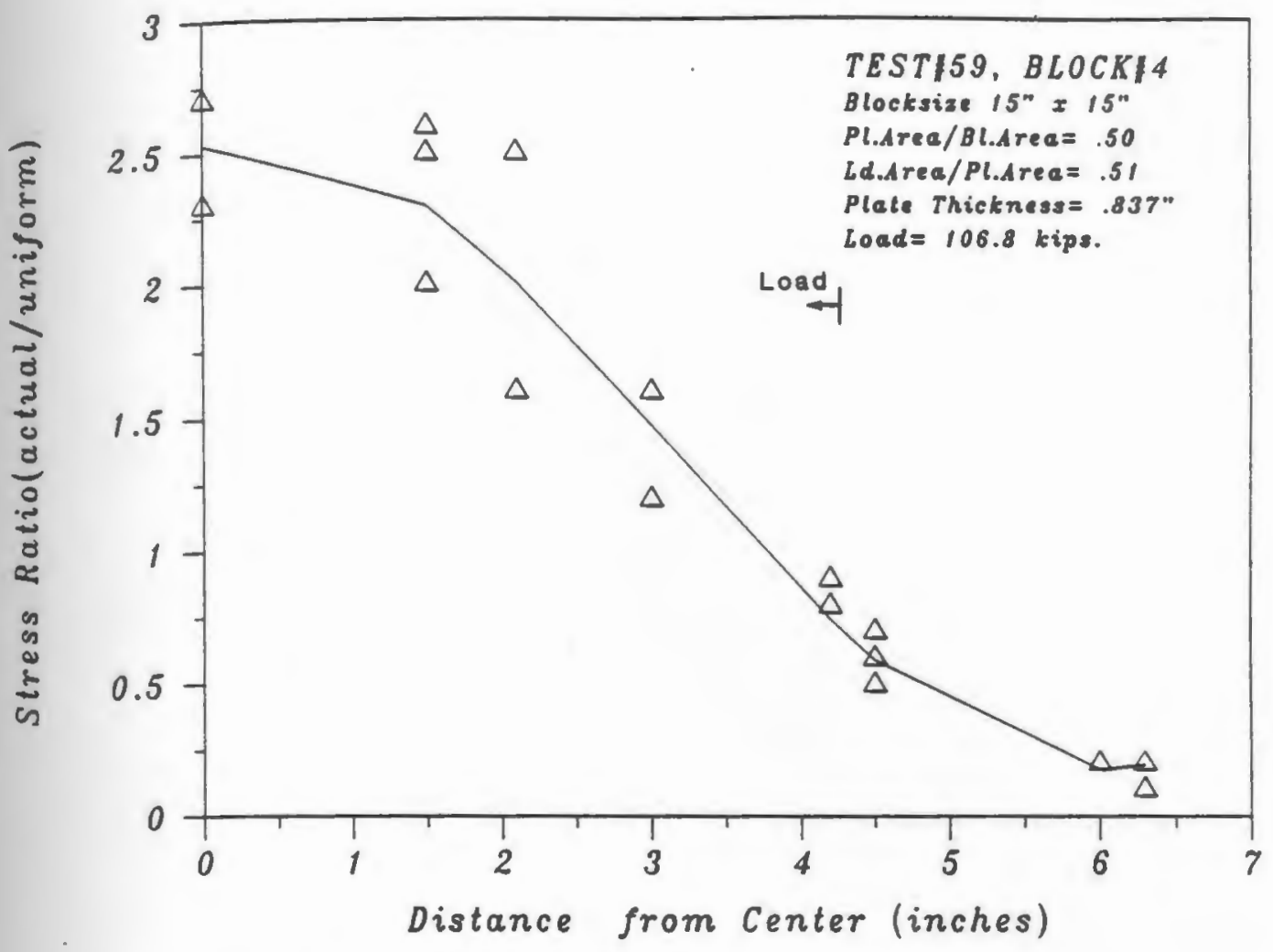

TESTI59, BLOCKI4

Blocksize $15^{\prime \prime} \times 15^{\prime \prime}$

Pl.Area/Bl.Area $=.50$

Ld.Area/Pl.Area $=.51$

Plate Thickness $=.837 "$

Load $=106.8$ kips.

Fig.73: DISTRIBUTION OF STRESSES

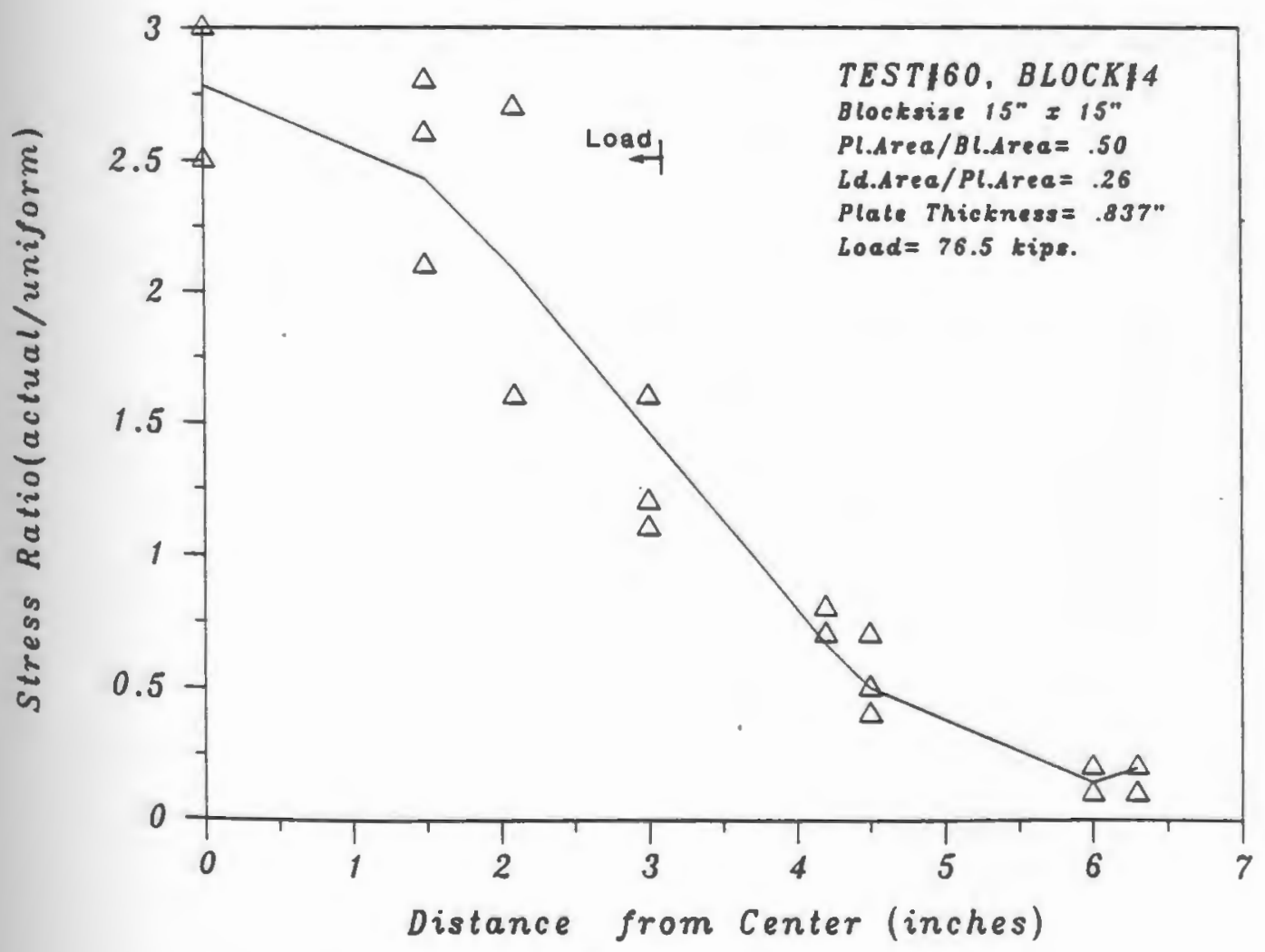

Fig.74: DISTRIBUTION OF. STRESSES 


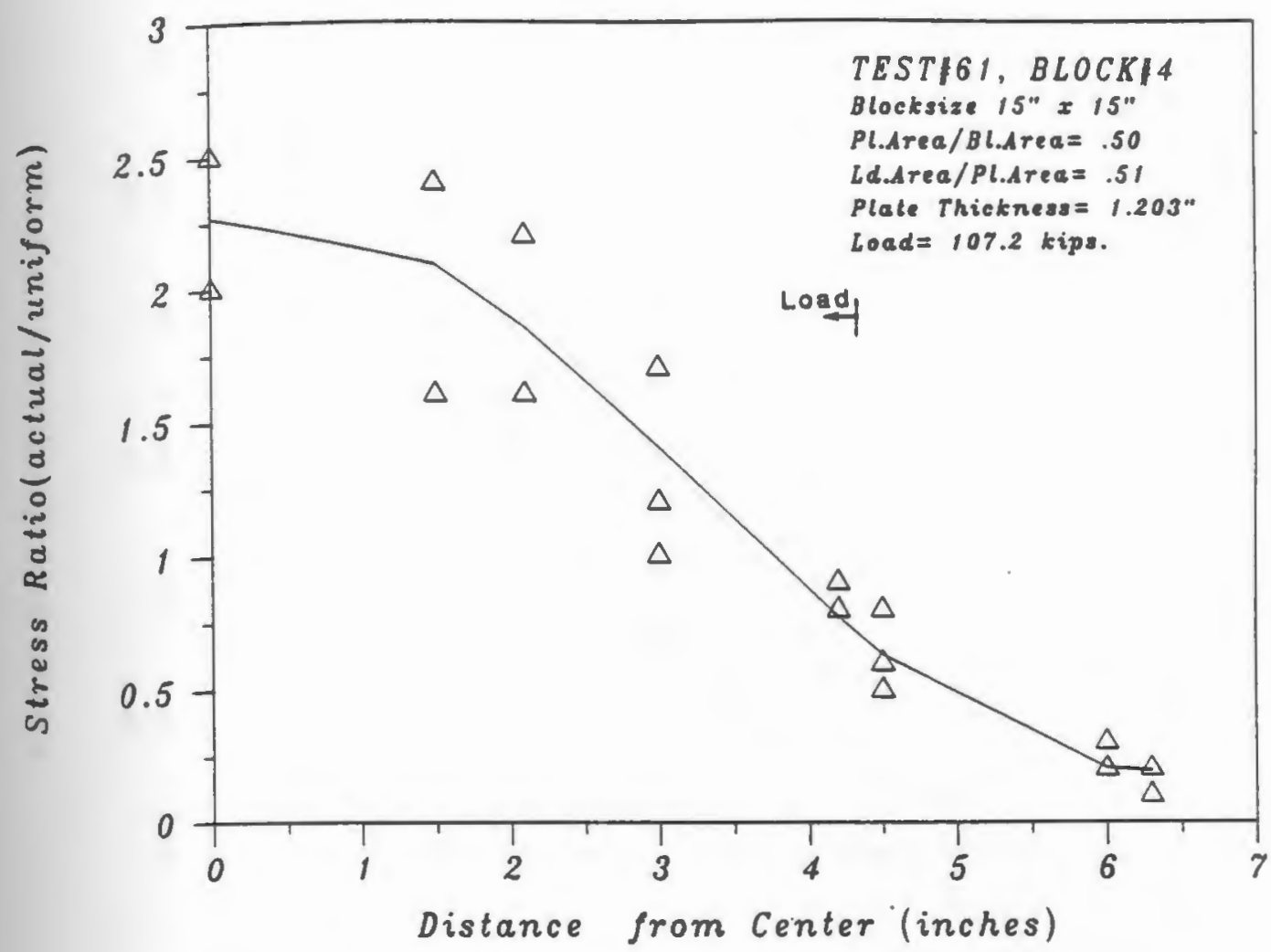

TEST\#61, BLOCK 14

Blocksize 15" $x$ 15"

Pl.Area/Bl.Area $=.50$

Ld.Area/PL.Area $=.51$

Plate Thickness = $1.203^{\prime \prime}$

load $=107.2$ kips.

Fig.75: DISTRIBUTION OF STRESSES

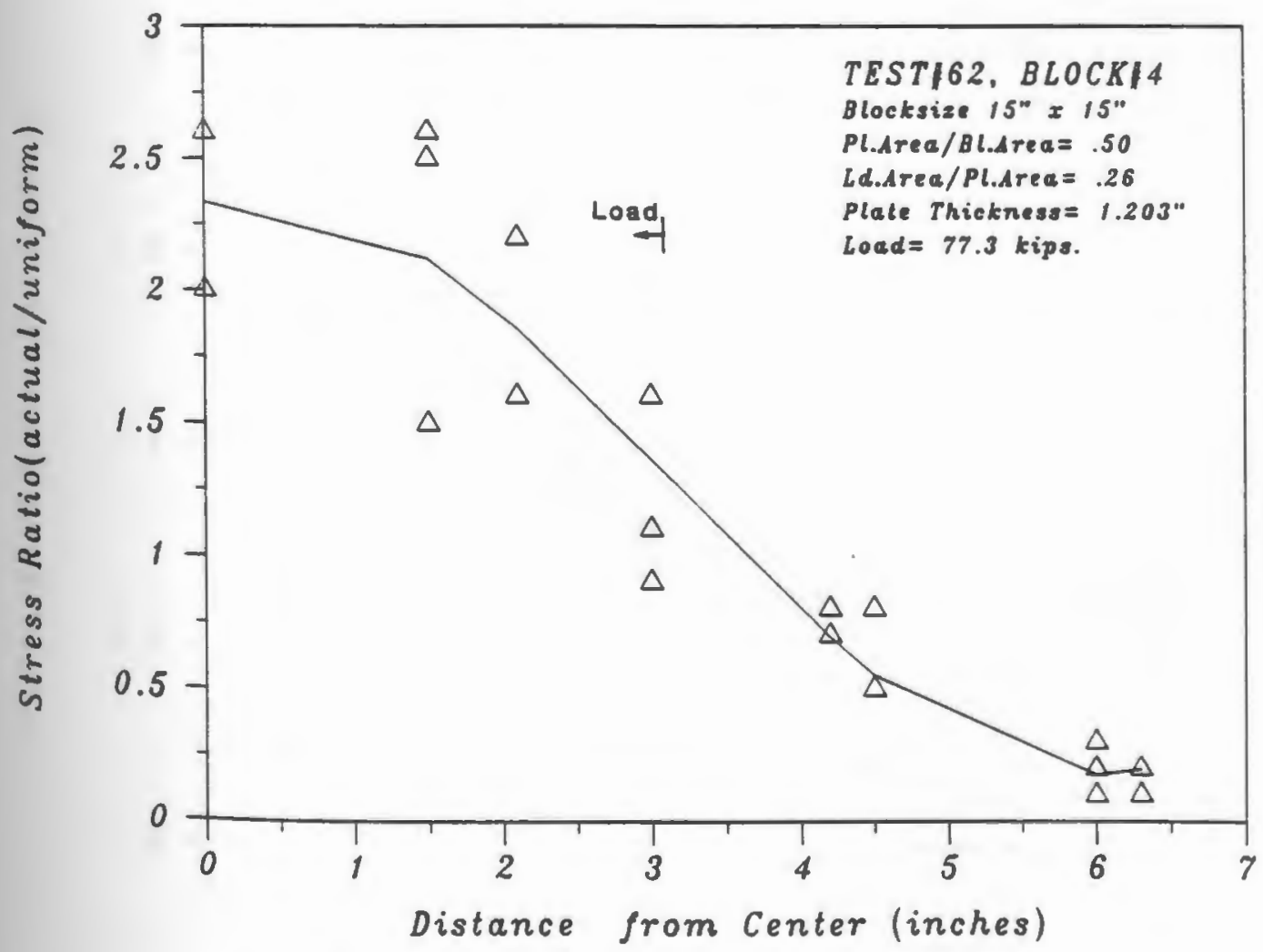

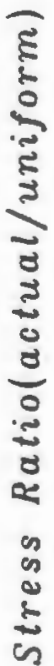

Fig.76: DISTRIBUTION OF STRESSES 


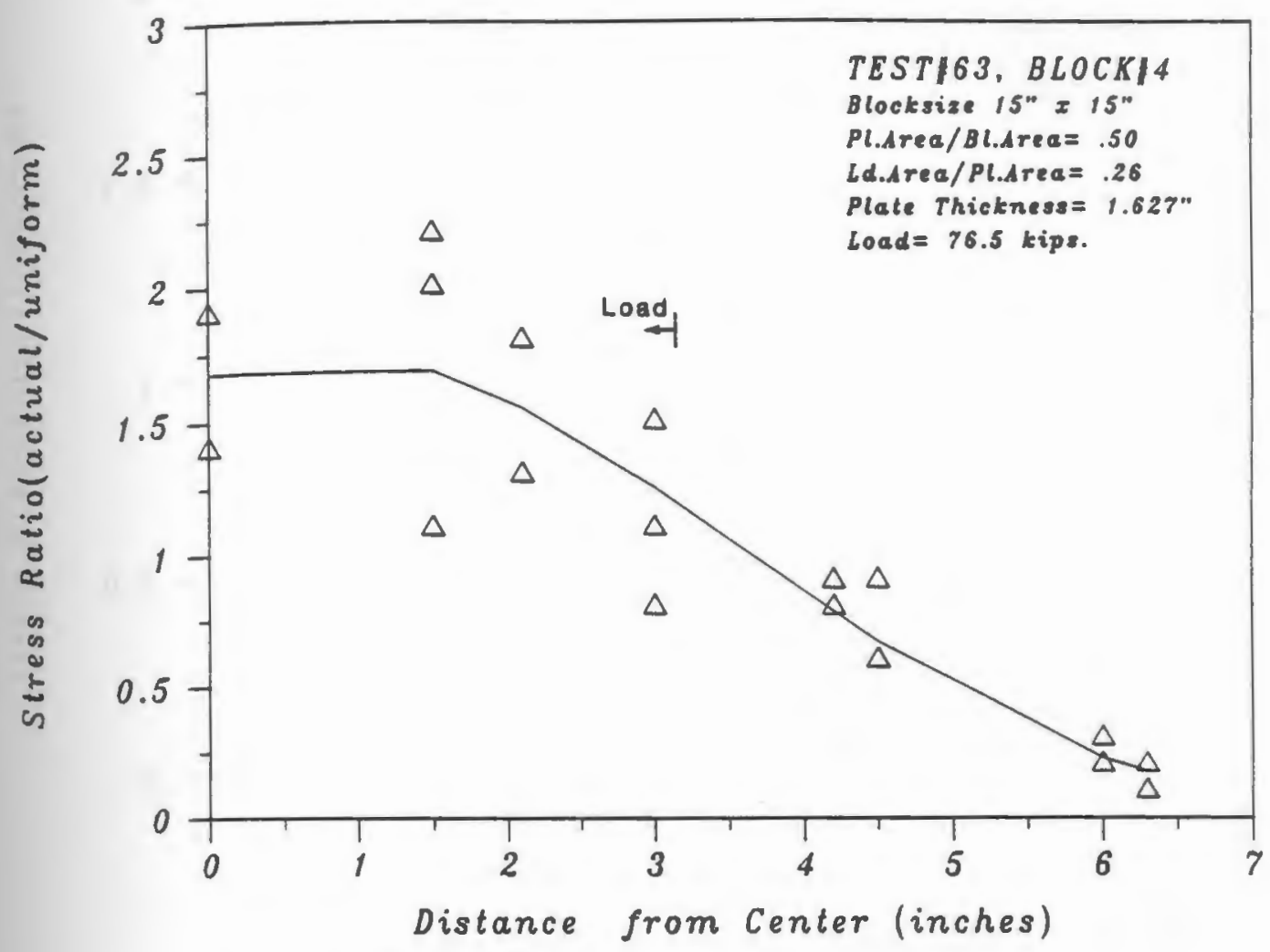

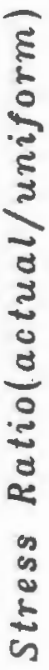

Fig.77: DISTRIBUTION OF STRESSES

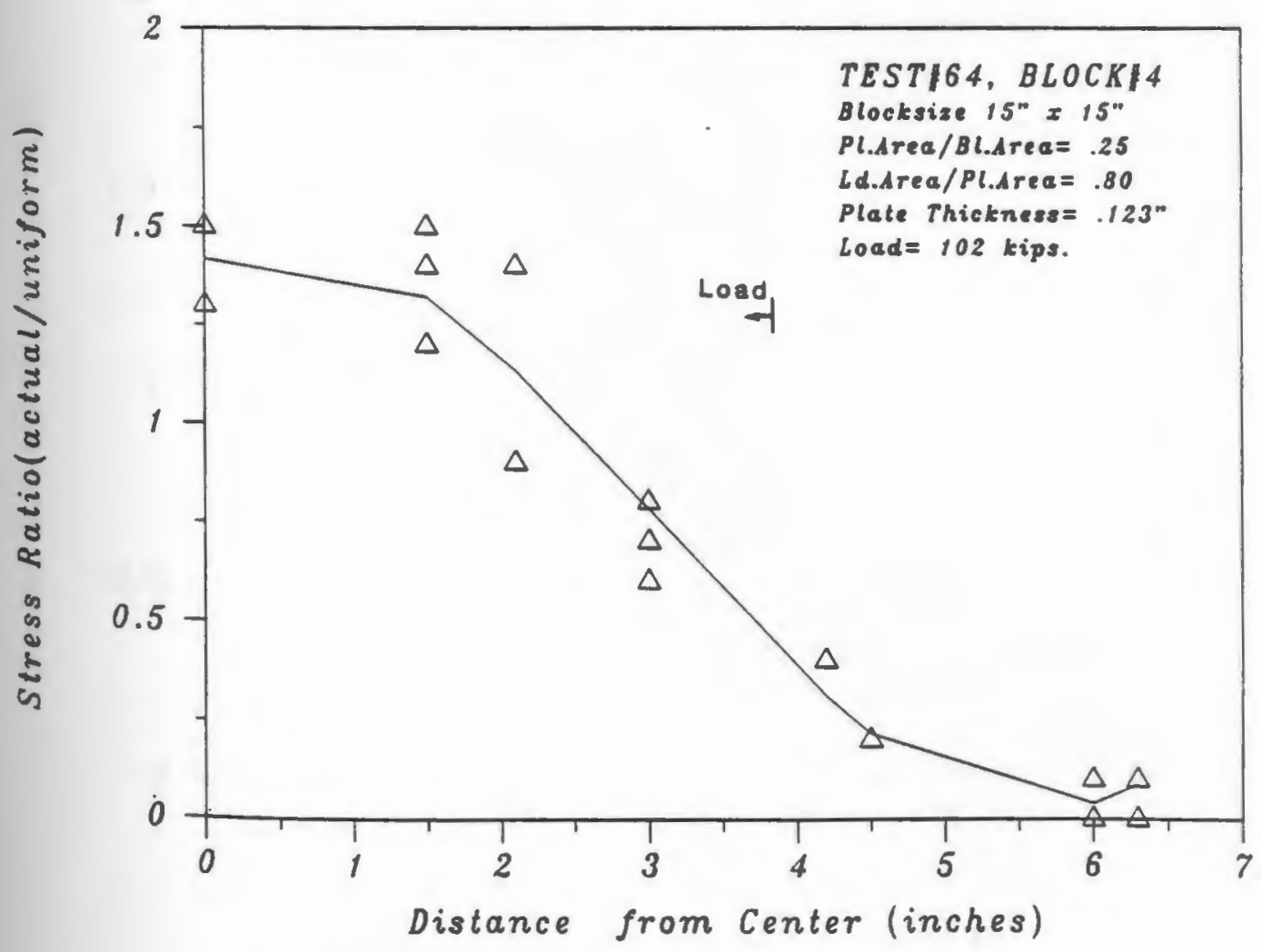

है

Fig.78: DISTRIBUTION OF STRESSES 


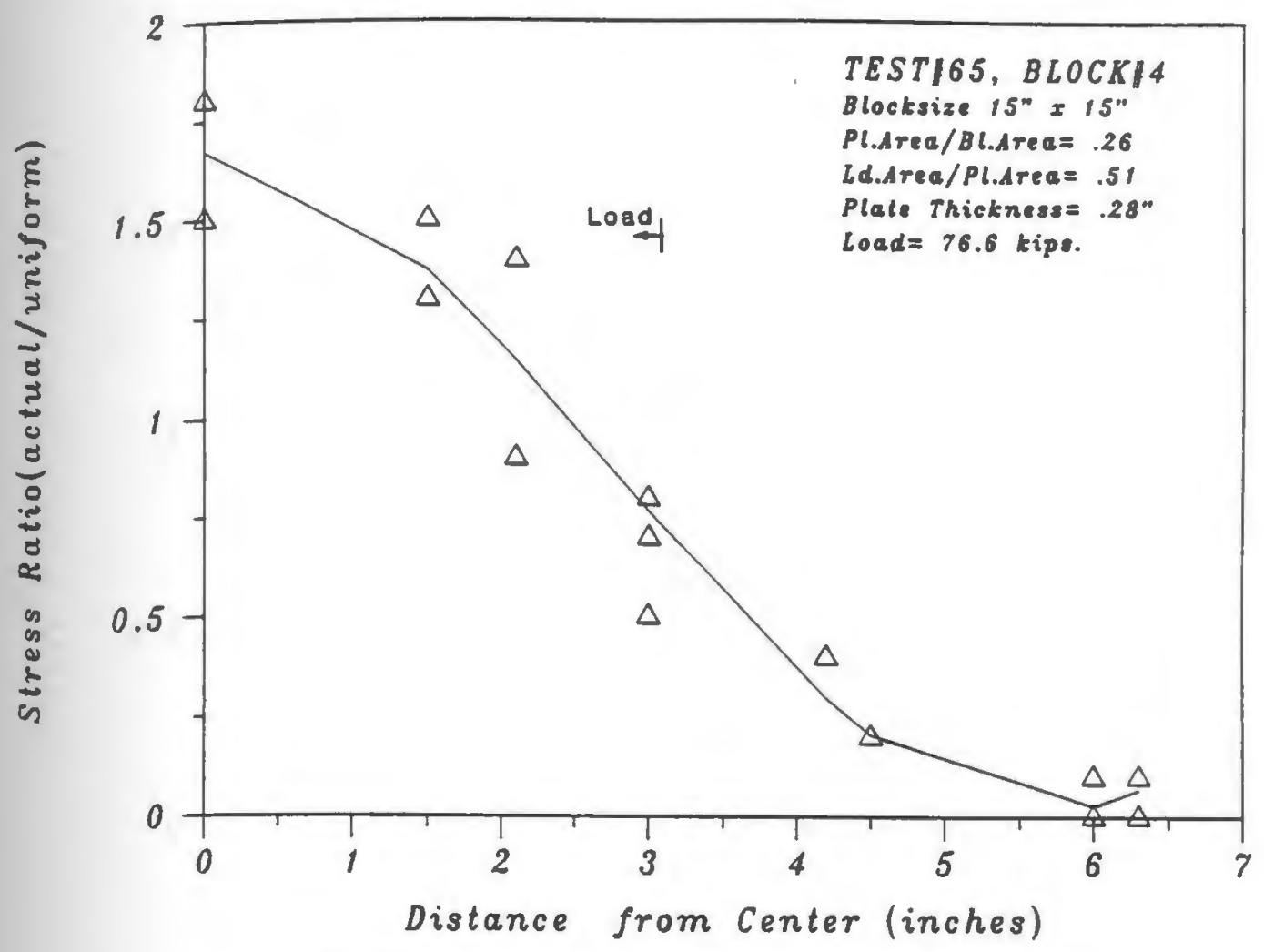

Fig.79: DISTRIBUTION OF STRESSES

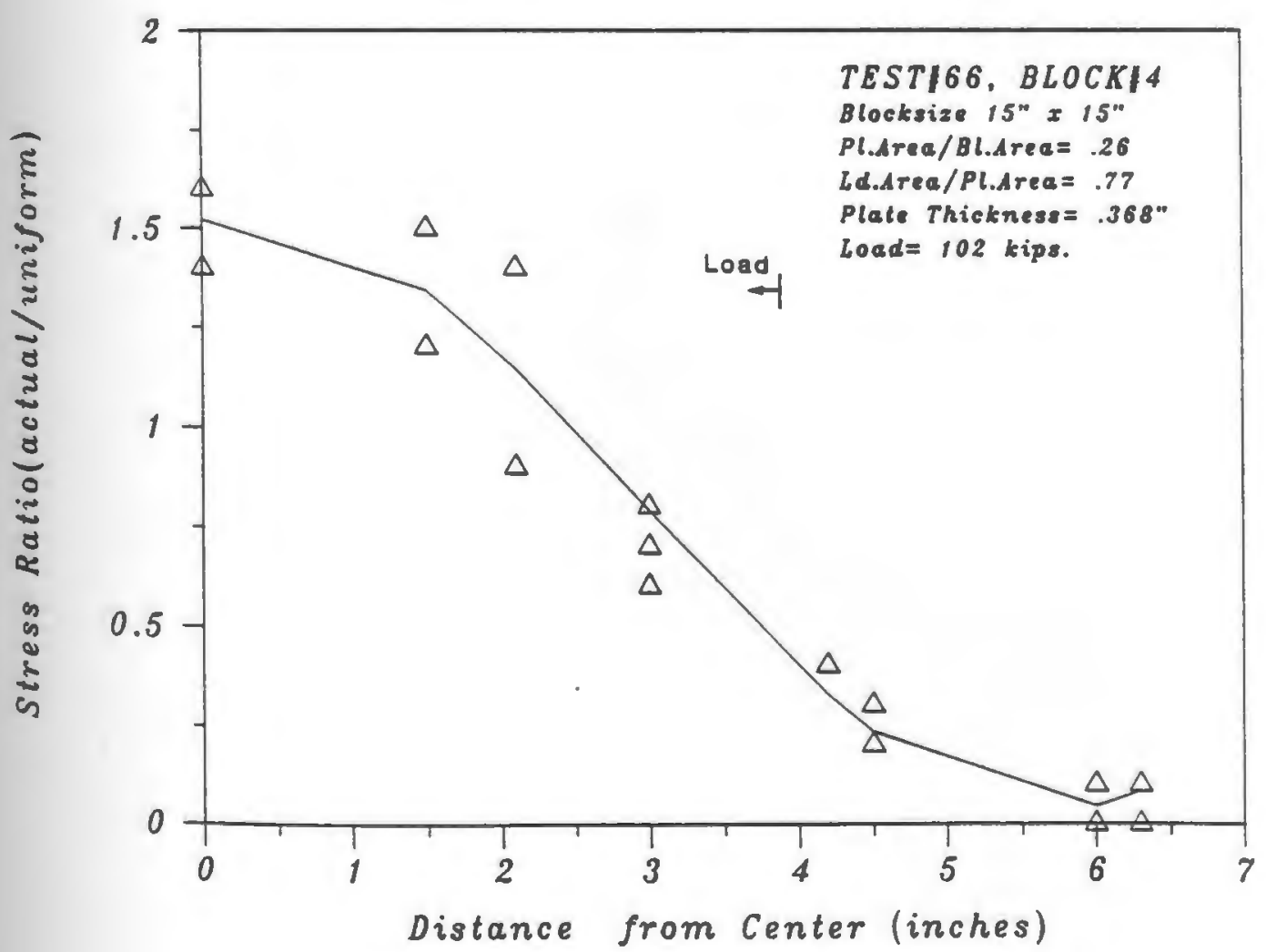

है

Fig.80: DISTRIBUTION OF STRESSES 


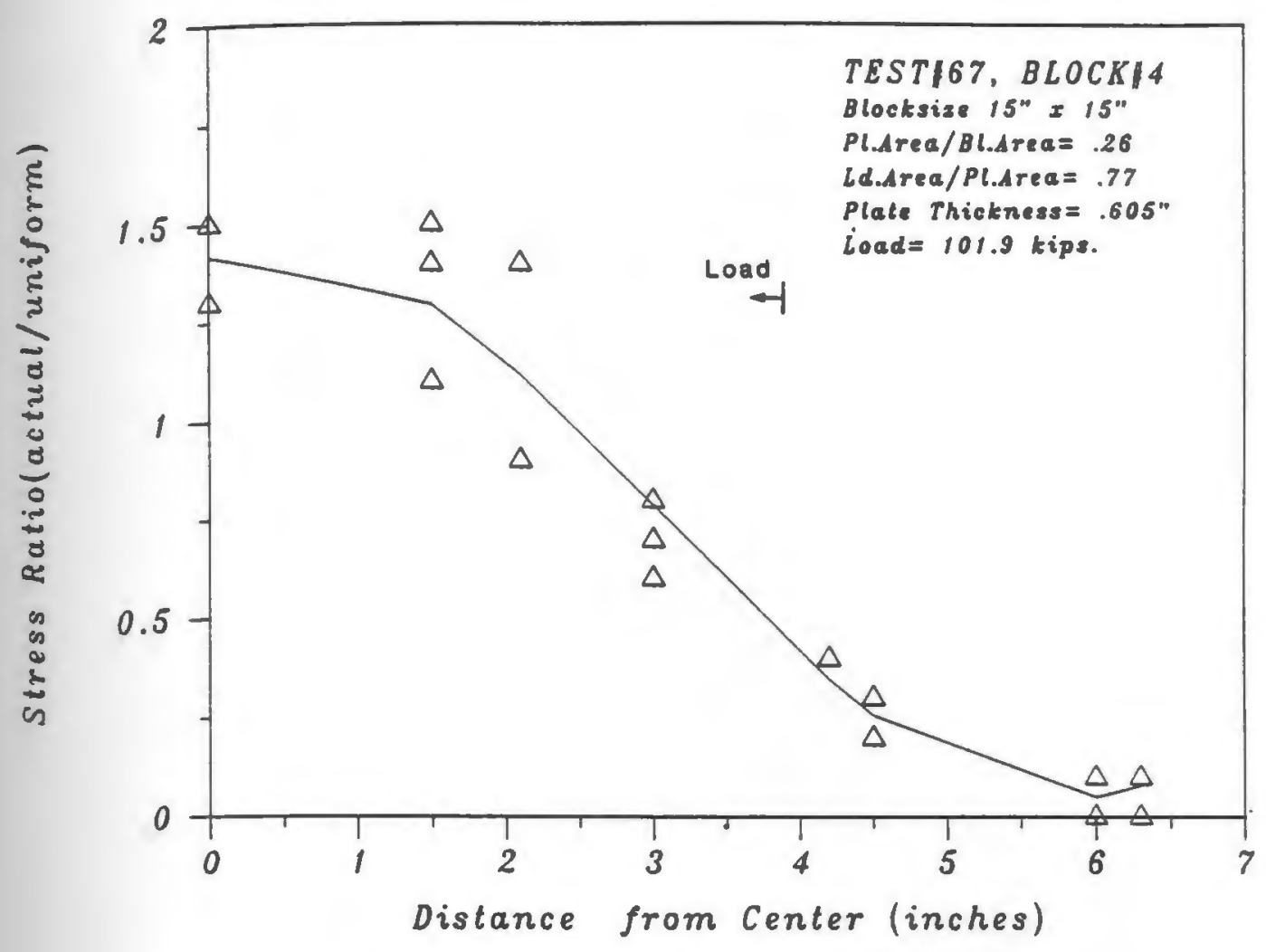

TEST167, BLOCK 14

Platea/Bl Area $=26$

Ld.Area/Pl.Area $=.77$

Plate Thickness $=.605^{\circ}$

Load $=101.9 \mathrm{kips}$.

Fig.81: DISTRIBUTION OF STRESSES

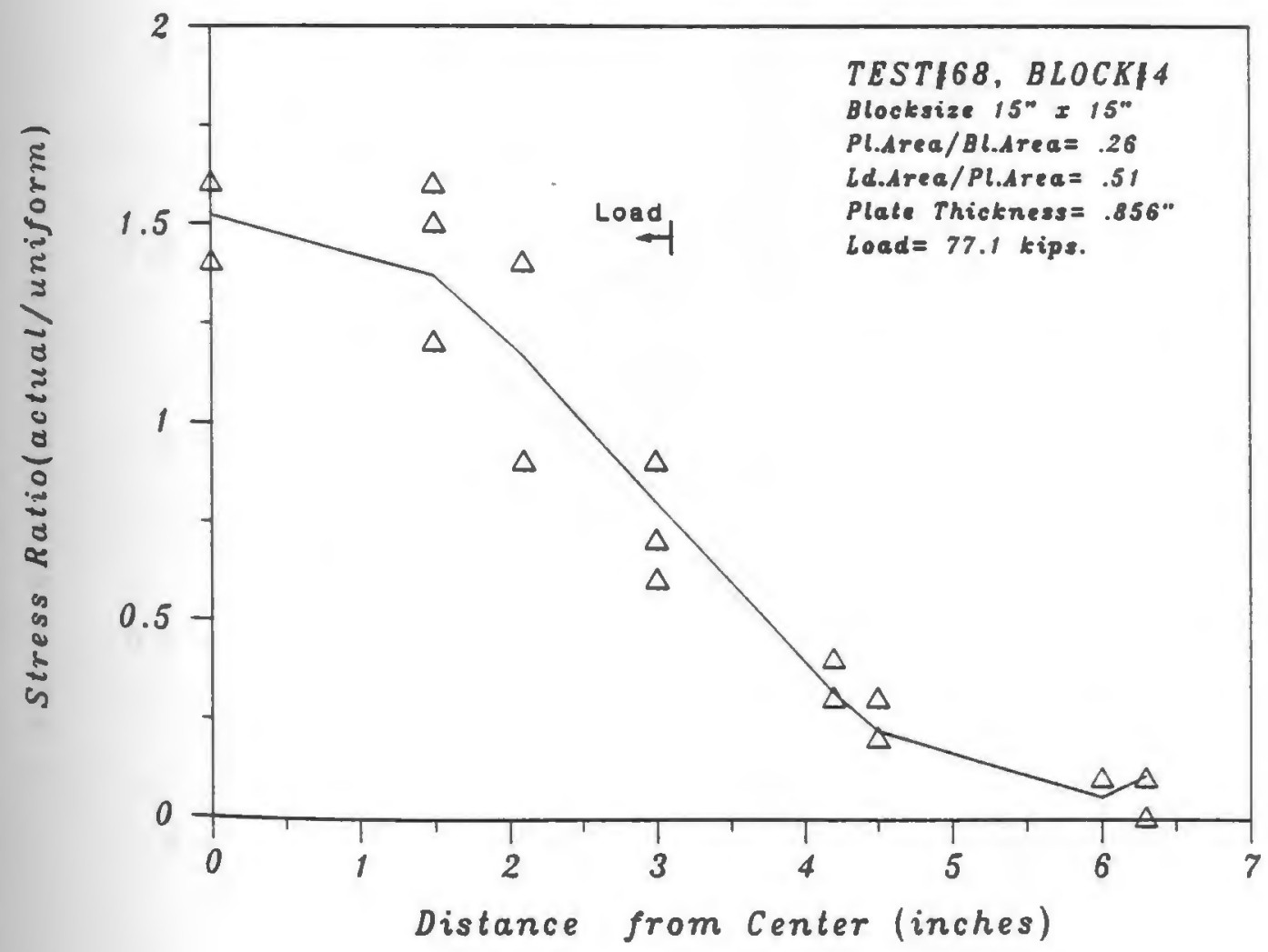

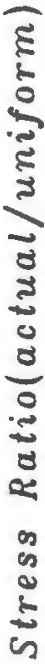

Fig.82: DISTRIBUTION OF STRESSES 


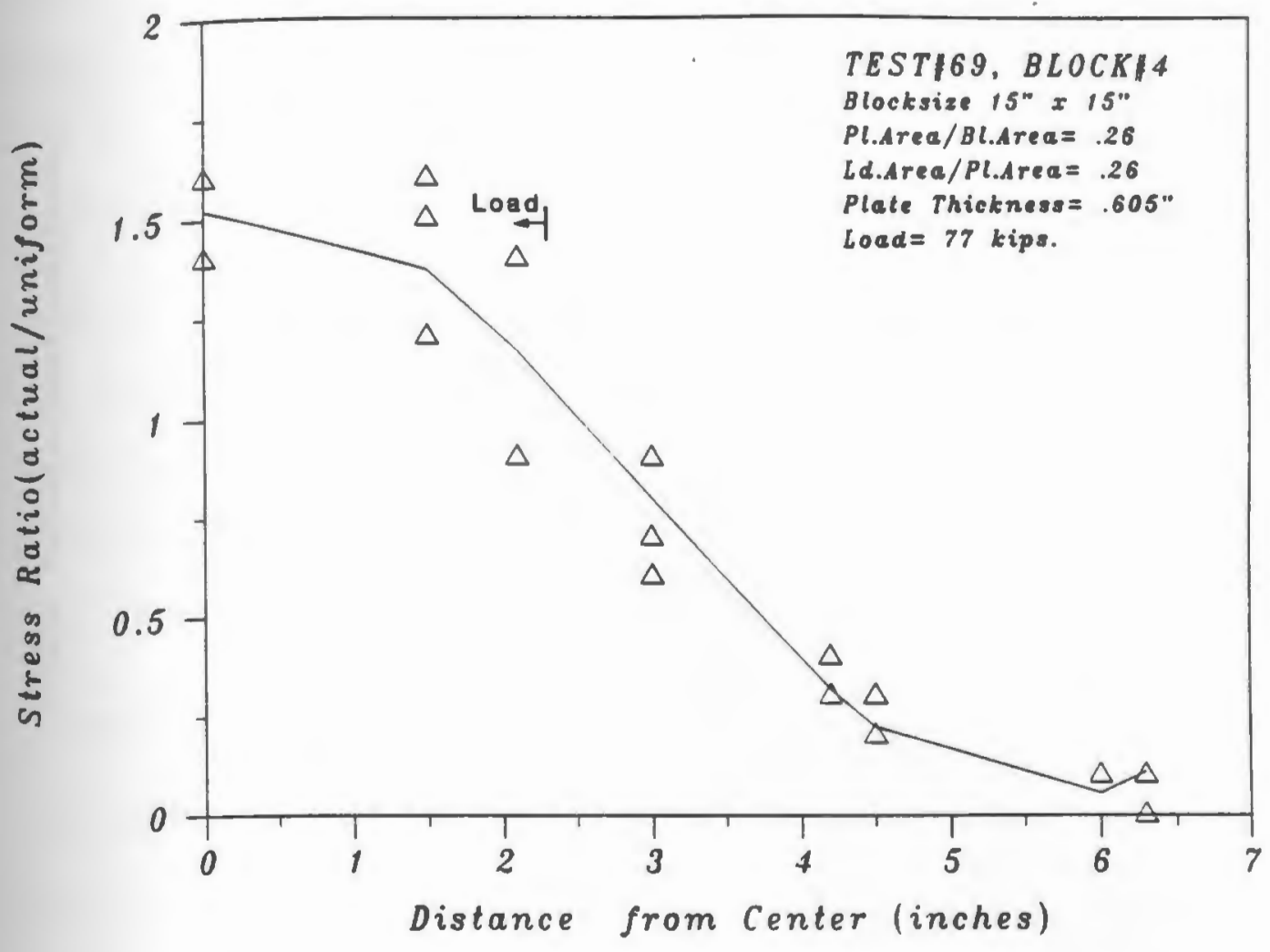

Fig.83: DISTRIBUTION OF STRESSES

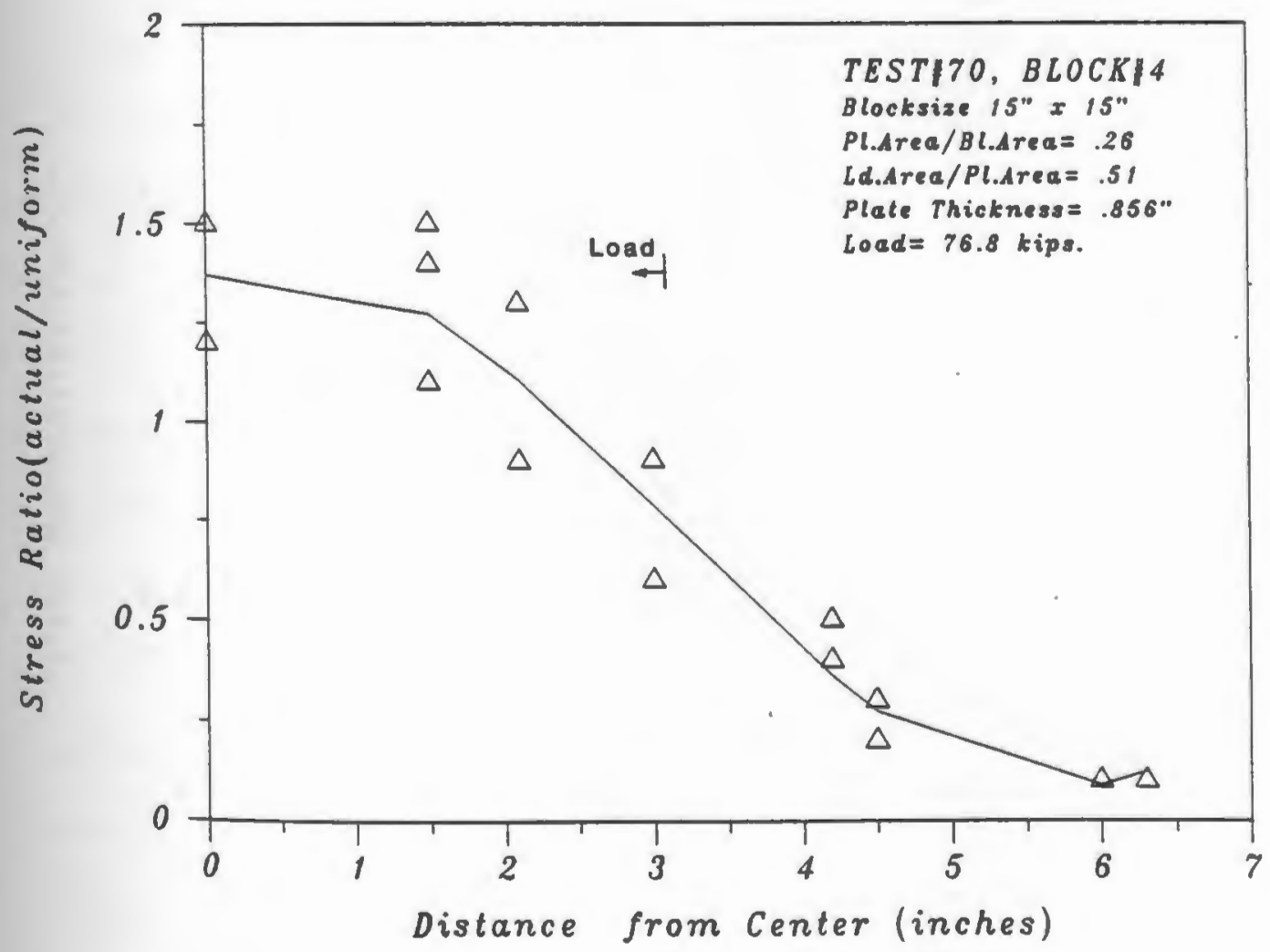

Fig.84: DISTRIBUTION OF STRESSES 


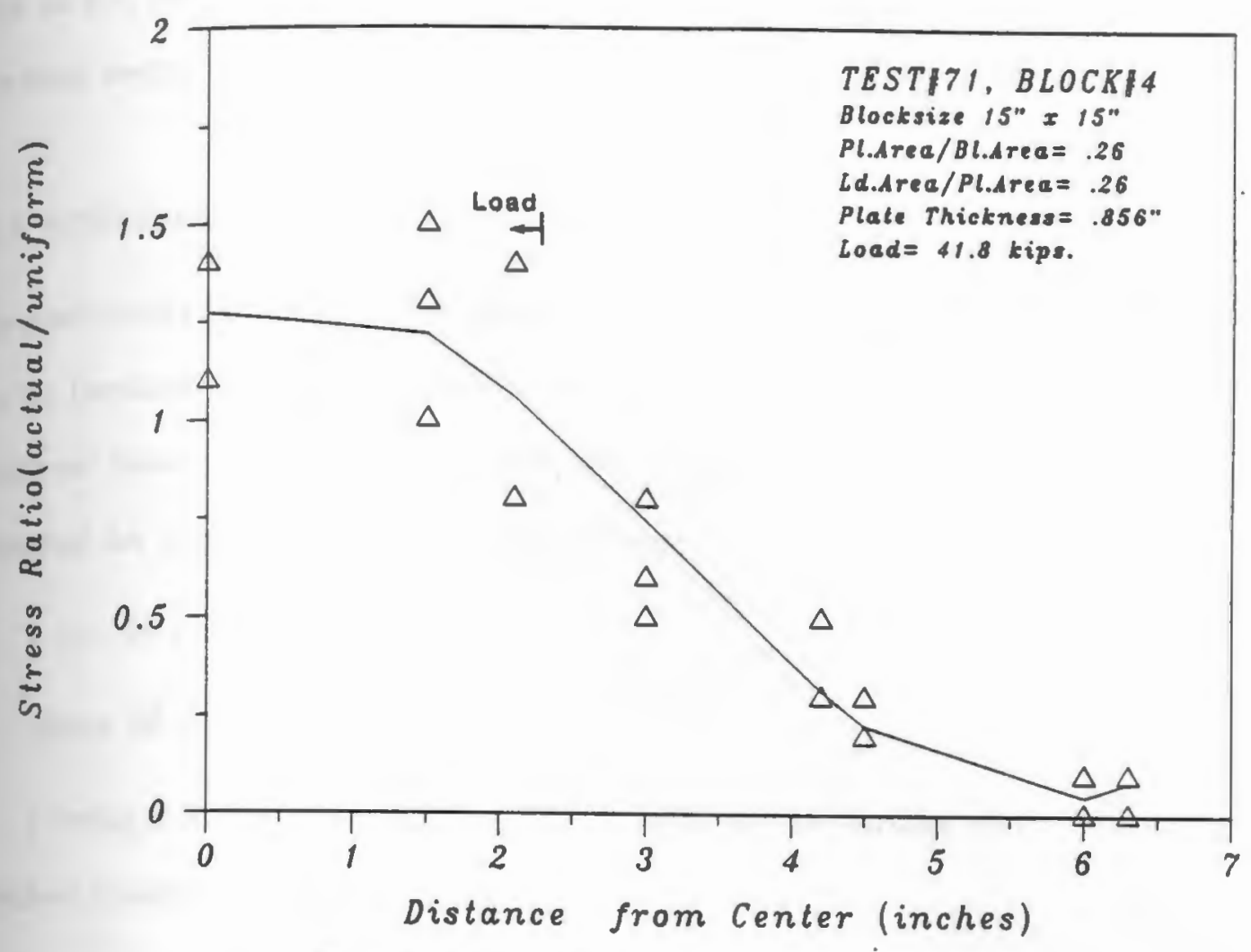

Fig.85: DISTRIBUTION OF STRESSES

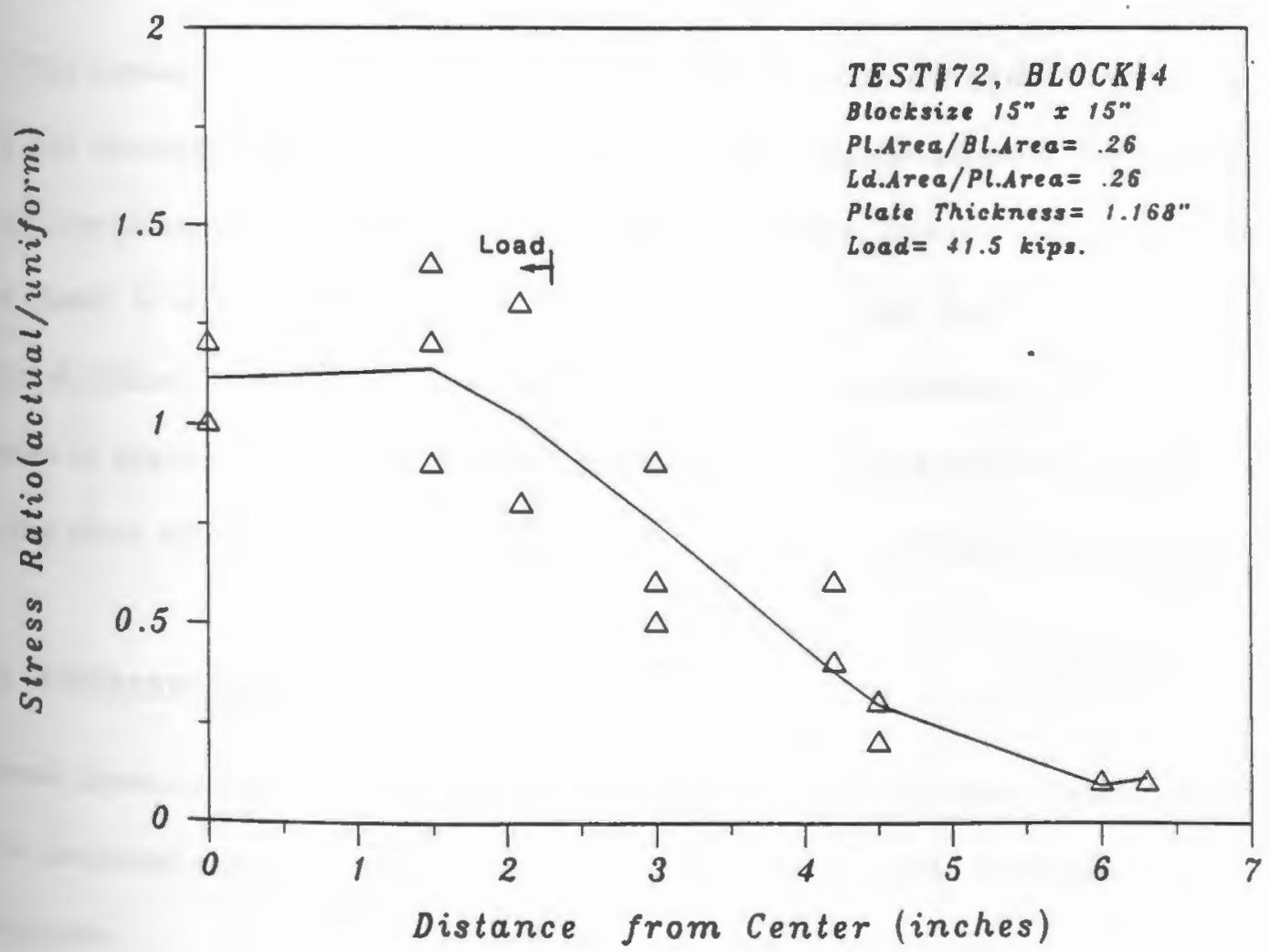

Fig.86: DISTRIBUTION OF STRESSES 
close to 3.5, and in most cases was between 1.0 and 3.5 at the center of the block. The load seems to be carried almost entirely under the loaded area.

\subsubsection{STRESSES IN BEARING PLATES:}

The measured stresses in bearing plates are given in Table 7. The expected stresses due to bending of the plate were calculated based on bending of the plate as a cantilever beam. It should be noted that the three dimensional effect has been neglected for computing the expected stresses.

$$
\sigma=-M \times c / I
$$

where $M=w \times l^{2} / 2$

$c$ being the distance from the neutral axis to the surface where the gage was attached (positive for top surface).

and $I=t^{3} / 12$ assuming unit width of the plate.

The stresses measured in the bearing plates were very low and little correlation with the theoretical could be found. In some cases tensile stresses were observed where compressive stresses were expected and vice versa, but in most cases stresses were closer to expected at very low loads and as the load increased the stresses either stabilized or reduced. Figs. 87 thru 92 show some representative plots for stresses in gages on the bearing plate. Perhaps this was due to the behavior of the bearing plate which was observed to lift at the edges during the ultimate load tests.

\subsubsection{STRESSES IN REINFORCING BAR:}

Stresses measured in the top horizontal reinforcing bar are given in Table 8. Several of the measured stresses are quite high indicating the possibility of localized cracking in concrete. 


\begin{tabular}{|c|c|c|c|c|c|c|}
\hline \multirow[b]{2}{*}{$\begin{array}{l}\text { Test } \\
\text { No. }\end{array}$} & \multirow{2}{*}{$\begin{array}{l}\text { Uniformly } \\
\text { distributed } \\
\text { stress(psi.) }\end{array}$} & \multirow{2}{*}{$\begin{array}{c}\text { Bearing } P l . \\
\text { thickness } \\
\text { (in.) }\end{array}$} & \multicolumn{2}{|c|}{ Struin gage } & \multicolumn{2}{|c|}{ Stress } \\
\hline & & & location & $\begin{array}{l}\text { overhang } \\
\text { (in.) }\end{array}$ & $\begin{array}{l}\text { measured } \\
\text { (psi.) }\end{array}$ & $\begin{array}{l}\text { expected } \\
\text { (psi.) }\end{array}$ \\
\hline 1 & 992.0 & 0.122 & $\operatorname{top}(\mathrm{d})$ & 1.75 & -2001.0 & - \\
\hline \multirow[t]{2}{*}{2} & \multirow[t]{2}{*}{846.1} & \multirow[t]{2}{*}{0.405} & top(c) & 0.8 & 638.0 & -9904.0 \\
\hline & & & bot(c) & 0.8 & -1392.0 & 9904.0 \\
\hline 3 & 907.3 & 0.476 & top(d) & 2.0 & 290.0 & - \\
\hline 4 & 887.3 & 0.837 & top(d) & 2.0 & broken & - \\
\hline \multirow[t]{3}{*}{5} & \multirow[t]{3}{*}{907.3} & \multirow[t]{3}{*}{0.837} & top(d) & 3.0 & 1624.0 & - \\
\hline & & & top(d) & 2.0 & 1044.0 & - \\
\hline & & & top $(c)$ & 0.8 & 2378.0 & -2486.6 \\
\hline \multirow[t]{6}{*}{6} & \multirow[t]{6}{*}{690.2} & \multirow[t]{6}{*}{0.837} & top (d) & 4.0 & broken & - \\
\hline & & & top (d) & 3.0 & 1798.0 & - \\
\hline & & & top(d) & 2.0 & 1247.0 & -11822.4 \\
\hline & & & top $(c)$ & 2.0 & 3770.0 & -11822.4 \\
\hline & & & top (c) & 0.8 & 2639.0 & -1891.6 \\
\hline & & & bot (c) & 2.0 & -3886.0 & 11822.4 \\
\hline \multirow[t]{3}{*}{7} & \multirow[t]{3}{*}{862.8} & \multirow[t]{3}{*}{1.203} & top(d) & 3.0 & 2697.0 & - \\
\hline & & & top $(c)$ & 0.8 & 3248.0 & -1144.7 \\
\hline & & & $\operatorname{bot}(c)$ & 0.8 & -1769.0 & 1144.7 \\
\hline \multirow[t]{4}{*}{8} & \multirow[t]{4}{*}{673.4} & \multirow[t]{4}{*}{1.203} & top (d) & 4.0 & 2610.0 & - \\
\hline & & & $\operatorname{top}(\mathrm{c})$ & 2.0 & 3248.0 & -5583.7 \\
\hline & & & top $(c)$ & 0.8 & 2552.0 & -893.4 \\
\hline & & & bot(c) & 0.8 & -1479.0 & 893.4 \\
\hline \multirow[t]{3}{*}{9} & \multirow[t]{3}{*}{674.3} & \multirow[t]{3}{*}{1.626} & $\operatorname{top}(\mathrm{d})$ & 4.0 & 1769.0 & -12242.0 \\
\hline & & & top (c) & 2.0 & 2320.0 & -3060.0 \\
\hline & & & bot (c) & 2.0 & -116.0 & 3060.0 \\
\hline 10 & 1369.4 & 0.123 & top(d) & 1.8 & 0.0 & - \\
\hline \multirow[t]{3}{*}{11} & \multirow[t]{3}{*}{1186.2} & \multirow[t]{3}{*}{0.315} & top (d) & 2.25 & 493.0 & - \\
\hline & & & top (c) & 0.6 & 1073.0 & -12911.0 \\
\hline & & & $\operatorname{bot}(c)$ & 0.6 & -493.0 & 12911.0 \\
\hline 12 & 656.8 & 0.685 & top(d) & 3.5 & 1740.0 & - \\
\hline & & & top (c) & 1.75 & 1624.0 & -12860.2 \\
\hline & & & bot(c) & 1.75 & 0.0 & 12860.2 \\
\hline 13 & 2020.4 & 0.123 & top(d) & 1.0 & 609.0 & - \\
\hline 14 & 1352.0 & 0.222 & top(d) & 1.7 & 1566.0 & - \\
\hline & & & top(c) & 0.45 & 1247.0 & -16665.5 \\
\hline & & & bot(c) & 0.45 & -1508.0 & 16665.5 \\
\hline 15 & 693.2 & 0.478 & top(d) & 2.2 & 435.0 & - \\
\hline & & & top(c) & 1.0 & -1972.0 & -9101.7 \\
\hline & & & $\operatorname{bot}(c)$ & 1.0 & 2059.0 & 9101.1 \\
\hline
\end{tabular}

"Expected based on bending of plate as a beam

Table 7: Stresses in bearing plates (working stress range tests) 


\begin{tabular}{|c|c|c|c|c|c|c|}
\hline \multirow[b]{2}{*}{$\begin{array}{l}\text { Test } \\
\text { No. }\end{array}$} & \multirow{2}{*}{$\begin{array}{l}\text { Uniformly } \\
\text { distributed } \\
\text { stress(psi.) }\end{array}$} & \multirow{2}{*}{$\begin{array}{c}\text { Bearing Pl. } \\
\text { thickness } \\
\text { (in.) } \\
\end{array}$} & \multicolumn{2}{|c|}{ Strain gage } & \multicolumn{2}{|c|}{ Stress } \\
\hline & & & location & $\begin{array}{c}\text { overhang } \\
\text { (in.) }\end{array}$ & $\begin{array}{c}\text { measured } \\
\text { (psi.) }\end{array}$ & $\begin{array}{l}\text { expected" } \\
\text { (psi.) }\end{array}$ \\
\hline 16 & 1004.3 & 0.122 & top(d) & 1.75 & -1827.0 & - \\
\hline 17 & 925.5 & 0.405 & $\begin{array}{l}\text { top(c) } \\
\text { bot (c) }\end{array}$ & $\begin{array}{l}0.8 \\
0.8\end{array}$ & $\begin{array}{r}841.0 \\
\text { broken }\end{array}$ & $\begin{array}{c}-10833.5 \\
10833.5\end{array}$ \\
\hline 18 & 882.6 & 0.476 & top (d) & 2.0 & 493.0 & - \\
\hline 19 & 924.4 & 0.837 & top (d) & 2.0 & 1044.0 & - \\
\hline 20 & 913.7 & 0.837 & $\begin{array}{l}\text { top(d) } \\
\text { top(d) } \\
\text { top(c) }\end{array}$ & $\begin{array}{l}3.0 \\
2.0 \\
0.8\end{array}$ & $\begin{array}{l}1740.0 \\
1943.0 \\
1218.0\end{array}$ & $\begin{array}{c}\overline{-} \\
-2504.1\end{array}$ \\
\hline 21 & 672.0 & 0.837 & $\begin{array}{l}\text { top(d) } \\
\text { top(d) } \\
\text { top(d) } \\
\text { top (c) } \\
\text { top(c) } \\
\text { bot(c) }\end{array}$ & $\begin{array}{l}4.0 \\
3.0 \\
2.0 \\
2.0 \\
0.8 \\
2.0\end{array}$ & $\begin{array}{c}\text { broken } \\
1885.0 \\
1798.0 \\
290.0 \\
1421.0 \\
-261.0\end{array}$ & $\begin{array}{c}- \\
- \\
-11510.6 \\
-11510.6 \\
-1841.7 \\
11510.6\end{array}$ \\
\hline 22 & 870.1 & 1.203 & $\begin{array}{l}\operatorname{top}(c) \\
\text { bot(c) }\end{array}$ & $\begin{array}{l}0.8 \\
0.8\end{array}$ & $\begin{array}{c}1015.0 \\
174.0\end{array}$ & $\begin{array}{c}-1154.4 \\
1154.4\end{array}$ \\
\hline 23 & 654.8 & 1.203 & $\begin{array}{l}\operatorname{top}(d) \\
\text { top (c) } \\
\text { top (c) } \\
\text { bot (c) }\end{array}$ & $\begin{array}{l}4.0 \\
2.0 \\
0.8 \\
0.8\end{array}$ & $\begin{array}{c}2088.0 \\
-464.0 \\
841.0 \\
-174.0 \\
\end{array}$ & $\begin{array}{c}- \\
-5429.5 \\
-868.7 \\
868.7 \\
\end{array}$ \\
\hline 24 & 699.6 & 1.626 & $\begin{array}{l}\text { top(d) } \\
\text { top(c) } \\
\text { bot (c) }\end{array}$ & $\begin{array}{l}4.0 \\
2.0 \\
2.0\end{array}$ & $\begin{array}{l}2204.0 \\
-899.0 \\
1218.0 \\
\end{array}$ & $\begin{array}{c}-12701.3 \\
-3175.3 \\
3175.3\end{array}$ \\
\hline 25 & 1436.9 & 0.123 & top (d) & 1.8 & 522.0 & - \\
\hline 26 & 1185.9 & 0.315 & top(d) & 2.25 & -232.0 & - \\
\hline 27 & 687.7 & 0.685 & $\begin{array}{l}\text { top(d) } \\
\text { top(c) }\end{array}$ & $\begin{array}{c}3.5 \\
1.75 \\
\end{array}$ & $\begin{array}{r}-1653.0 \\
-1015.0 \\
\end{array}$ & $\begin{array}{c}- \\
-13465.3 \\
\end{array}$ \\
\hline 28 & 2019.1 & 0.123 & top(d) & 1.0 & -1885.0 & $=$ \\
\hline 29 & 1341.0 & 0.222 & top (d) & 1.7 & -4060.0 & - \\
\hline & & & $\begin{array}{l}\text { top }(c) \\
\text { bot (c) }\end{array}$ & $\begin{array}{l}0.45 \\
0.45\end{array}$ & $\begin{array}{r}-4118.0 \\
4350.0 \\
\end{array}$ & $\begin{array}{c}-16529.8 \\
16529.8 \\
\end{array}$ \\
\hline 30 & 666.7 & 0.478 & $\begin{array}{l}\operatorname{top}(d) \\
\text { top(c) } \\
\text { bot(c) }\end{array}$ & $\begin{array}{l}2.2 \\
1.0 \\
1.0\end{array}$ & $\begin{array}{c}-116.0 \\
-4466.0 \\
-3915.0\end{array}$ & $\begin{array}{c}- \\
-8753.8 \\
8753.8 \\
\end{array}$ \\
\hline 31 & 1188.0 & 0.124 & top(d) & 2.25 & -14210.0 & - \\
\hline 32 & 789.3 & 0.500 & $\begin{array}{l}\text { top(d) } \\
\text { top (c) } \\
\text { bot(c) }\end{array}$ & $\begin{array}{l}3.5 \\
1.1 \\
1.1 \\
\end{array}$ & $\begin{array}{c}-19459.0 \\
\text { broken } \\
1102.0\end{array}$ & $\begin{array}{c}- \\
-11460.6 \\
11460.6\end{array}$ \\
\hline
\end{tabular}

*Expected based on bending of plate as a beam

Table 7(continved): Stresses in beuring plates (working stress range tests) 


\begin{tabular}{|c|c|c|c|c|c|c|}
\hline \multirow[b]{2}{*}{$\begin{array}{l}\text { Test } \\
\text { No. }\end{array}$} & \multirow{2}{*}{$\begin{array}{l}\text { Uniformly } \\
\text { distributed } \\
\text { stress(psi.) }\end{array}$} & \multirow{2}{*}{$\begin{array}{c}\text { Bearing } P l . \\
\text { thickness } \\
\text { (in.) }\end{array}$} & \multicolumn{2}{|c|}{ Strain gage } & \multicolumn{2}{|c|}{ Stress } \\
\hline & & & Tocation & $\begin{array}{l}\text { overhang } \\
\text { (in.) }\end{array}$ & $\begin{array}{c}\text { measured } \\
\text { (psi.) }\end{array}$ & $\begin{array}{l}\text { expected }{ }^{*} \\
\text { (psi.) }\end{array}$ \\
\hline \multirow[t]{3}{*}{33} & \multirow[t]{3}{*}{590.3} & \multirow[t]{3}{*}{1.050} & top(d) & 5.0 & -17255.0 & - \\
\hline & & & top (c) & 2.5 & -8381.0 & -10039.1 \\
\hline & & & $\operatorname{bot}(c)$ & 2.5 & broken & 10039.1 \\
\hline 34 & 1242.0 & 0.122 & top(d) & 1.75 & 1972.0 & - \\
\hline \multirow[t]{3}{*}{35} & \multirow[t]{3}{*}{936.8} & \multirow[t]{3}{*}{0.405} & top(d) & 2.7 & -10962.0 & - \\
\hline & & & top $(c)$ & 0.8 & -1131.0 & -10965.7 \\
\hline & & & $\operatorname{bot}(c)$ & 0.8 & -29.0 & 10965.7 \\
\hline 36 & 1205.6 & 0.476 & top(d) & 2.0 & -11194.0 & - \\
\hline 37 & 1200.9 & 0.837 & top(d) & 2.0 & -9251.0 & - \\
\hline \multirow[t]{3}{*}{38} & \multirow[t]{3}{*}{938.6} & \multirow[t]{3}{*}{0.837} & top(d) & 3.0 & -7598.0 & - \\
\hline & & & top(d) & 2.0 & 1943.0 & -16077.0 \\
\hline & & & $\operatorname{top}(c)$ & 0.8 & 2813.0 & -2572.4 \\
\hline \multirow[t]{6}{*}{39} & \multirow[t]{6}{*}{677.0} & \multirow[t]{6}{*}{0.837} & top(d) & 4.0 & -7337.0 & - \\
\hline & & & top(d) & 3.0 & -4176.0 & - \\
\hline & & & top(d) & 2.0 & -2465.0 & -11596.3 \\
\hline & & & top(c) & 2.0 & -3074.0 & -11596.3 \\
\hline & & & top $(c)$ & 0.8 & 4089.0 & -1855.4 \\
\hline & & & bot(c) & 2.0 & 3364.0 & 11596.3 \\
\hline 40 & 939.4 & 1.203 & top(c) & 0.8 & 3219.0 & -1246.3 \\
\hline \multirow[t]{5}{*}{$\overline{41}$} & \multirow[t]{5}{*}{670.4} & \multirow[t]{5}{*}{1.203} & $\operatorname{top}(d)$ & 4.0 & broken & - \\
\hline & & & top(d) & 3.0 & -5365.0 & -12507.4 \\
\hline & & & top (c) & 2.0 & broken & -5558.8 \\
\hline & & & top(c) & 0.8 & 3625.0 & -889.4 \\
\hline & & & bot(c) & 0.8 & 1102.0 & 889.4 \\
\hline \multirow[t]{3}{*}{42} & \multirow[t]{3}{*}{672.7} & \multirow[t]{3}{*}{1.626} & top(d) & 4.0 & -7946.0 & - \\
\hline & & & top(c) & 2.0 & -1305.0 & -3049.5 \\
\hline & & & bot (c) & 2.0 & 725.0 & 3049.5 \\
\hline 43 & 1814.1 & 0.123 & top (d) & 1.2 & broken & - \\
\hline \multirow[t]{2}{*}{44} & \multirow[t]{2}{*}{1317.5} & \multirow[t]{2}{*}{0.280} & top(d) & 1.9 & 2088.0 & - \\
\hline & & & top (c) & 0.5 & 29.0 & -12603.6 \\
\hline 45 & 1755.1 & 0.368 & top(d) & 1.25 & -232.0 & - \\
\hline 46 & 1730.4 & 0.605 & top(d) & 1.4 & -2871.0 & - \\
\hline 47 & 1314.8 & 0.605 & top(d) & 2.0 & -899.0 & - \\
\hline & & & top(d) & 1.4 & 145.0 & - \\
\hline & & & top $(c)$ & 1.1 & broken & -13039.3 \\
\hline 48 & 712.8 & 0.605 & top(d) & 3.0 & -7482.0 & - \\
\hline & & & top(d) & 2.0 & broken & - \\
\hline & & & top(d) & 1.4 & 174.0 & -11450.8 \\
\hline
\end{tabular}

"Expected based on bending of plate as a beam

Table 7(continued): Stresses in bearing plates (working stress range tests) 


\begin{tabular}{|c|c|c|c|c|c|c|}
\hline \multirow[b]{2}{*}{$\begin{array}{l}\text { Test } \\
\text { No. }\end{array}$} & \multirow{2}{*}{$\begin{array}{l}\text { Uniformly } \\
\text { distributed } \\
\text { stress(psi.) }\end{array}$} & \multirow{2}{*}{$\begin{array}{c}\text { Bearing Pl. } \\
\text { thickness } \\
\text { (in.) }\end{array}$} & \multicolumn{2}{|c|}{ Strain gage } & \multicolumn{2}{|c|}{ Stress } \\
\hline & & & location & $\begin{array}{c}\text { overhang } \\
\text { (in.) }\end{array}$ & $\begin{array}{c}\text { measured } \\
\text { (psi.) }\end{array}$ & $\begin{array}{l}\text { expected }{ }^{*} \\
\text { (psi.) }\end{array}$ \\
\hline 48 & 712.8 & 0.605 & $\begin{array}{l}\text { top }(c) \\
\text { top }(c)\end{array}$ & $\begin{array}{l}1.1 \\
0.6\end{array}$ & $\begin{array}{l}-1276.0 \\
\text { broken }\end{array}$ & $\begin{array}{l}-7069.1 \\
-2103.2\end{array}$ \\
\hline 49 & 1315.7 & 0.856 & $\begin{array}{l}\text { top(d) } \\
\text { top(c) }\end{array}$ & $\begin{array}{l}2.0 \\
0.6\end{array}$ & $\begin{array}{c}-3741.0 \\
4350.0\end{array}$ & $\begin{array}{c}- \\
-1939.3\end{array}$ \\
\hline 50 & 697.4 & 0.856 & $\begin{array}{l}\text { top(d) } \\
\text { top(d) } \\
\text { top(c) } \\
\text { top(c) }\end{array}$ & $\begin{array}{l}2.9 \\
2.0 \\
1.5 \\
0.6\end{array}$ & $\begin{array}{c}-9077.0 \\
-3248.0 \\
-1566.0 \\
3799.0\end{array}$ & $\begin{array}{c}- \\
-11421.3 \\
-6424.5 \\
-1027.9\end{array}$ \\
\hline 51 & 702.4 & 1.168 & $\begin{array}{l}\text { top(d) } \\
\text { top (c) }\end{array}$ & $\begin{array}{l}2.8 \\
1.5\end{array}$ & $\begin{array}{l}-6844.0 \\
-1247.0\end{array}$ & $\begin{array}{c}-12109.8 \\
-3475.4\end{array}$ \\
\hline 52 & 1189.5 & $0 . \overline{124}$ & top(d) & 2.25 & -2262.0 & - \\
\hline$\overline{53}$ & 789.0 & 0.500 & $\begin{array}{l}\operatorname{top}(d) \\
\text { top(c) } \\
\text { bot(c) }\end{array}$ & $\begin{array}{l}3.5 \\
1.1 \\
1.1\end{array}$ & $\begin{array}{c}-1798.0 \\
-522.0 \\
1102.0\end{array}$ & $\begin{array}{c}- \\
-11456.3 \\
11456.3\end{array}$ \\
\hline 54 & 589.0 & 1.050 & $\begin{array}{l}\text { top(d) } \\
\text { top(c) } \\
\text { bot (c) }\end{array}$ & $\begin{array}{l}5.0 \\
2.5 \\
2.5 \\
\end{array}$ & $\begin{array}{c}928.0 \\
-1450.0 \\
1247.0\end{array}$ & $\begin{array}{c}- \\
-10017.0 \\
10017.0\end{array}$ \\
\hline 55 & 1245.0 & 0.122 & top(d) & 1.75 & -145.0 & - \\
\hline 56 & 939.0 & 0.405 & $\begin{array}{l}\text { top(d) } \\
\text { top(c) } \\
\text { bot(c) }\end{array}$ & $\begin{array}{l}2.7 \\
0.8 \\
0.8\end{array}$ & $\begin{array}{l}-841.0 \\
-609.0 \\
\text { broken }\end{array}$ & $\begin{array}{c}- \\
-10991.5 \\
10991.5\end{array}$ \\
\hline 57 & 1206.6 & 0.476 & top(d) & 2.0 & -174.0 & - \\
\hline 58 & 1202.4 & 0.837 & top(d) & 2.0 & -174.0 & - \\
\hline 59 & 937.6 & 0.837 & $\begin{array}{l}\operatorname{top}(\mathrm{d}) \\
\text { top(d) } \\
\text { top(c) }\end{array}$ & $\begin{array}{l}3.0 \\
2.0 \\
0.8\end{array}$ & $\begin{array}{c}406.0 \\
725.0 \\
1450.0\end{array}$ & $\begin{array}{c}- \\
-16060.0 \\
-2569.6\end{array}$ \\
\hline 60 & 672.0 & 0.837 & $\begin{array}{l}\text { top(d) } \\
\text { top(d) } \\
\text { top(d) } \\
\text { top(c) } \\
\text { top(c) } \\
\text { bot(c) }\end{array}$ & $\begin{array}{l}4.0 \\
3.0 \\
2.0 \\
2.0 \\
0.8 \\
2.0\end{array}$ & $\begin{array}{c}1102.0 \\
638.0 \\
435.0 \\
609.0 \\
1740.0 \\
-1160.0 \\
\end{array}$ & $\begin{array}{c}- \\
- \\
-11510.6 \\
-11510.6 \\
-1841.7 \\
11510.6 \\
\end{array}$ \\
\hline 61 & 942.0 & 1.203 & $\begin{array}{l}\operatorname{top}(d) \\
\text { top }(c)\end{array}$ & $\begin{array}{l}2.7 \\
0.8 \\
\end{array}$ & $\begin{array}{c}957.0 \\
1276.0 \\
\end{array}$ & $\begin{array}{c}-14235.4 \\
-1249.7 \\
\end{array}$ \\
\hline 62 & 679.2 & 1.203 & $\begin{array}{l}\text { top(d) } \\
\text { top(d) } \\
\text { top(c) } \\
\text { top(c) }\end{array}$ & $\begin{array}{l}4.0 \\
3.0 \\
2.0 \\
0.8\end{array}$ & $\begin{array}{c}348.0 \\
725.0 \\
-1943.0 \\
1102.0\end{array}$ & $\begin{array}{c}- \\
-12671.6 \\
-5631.8 \\
-901.1\end{array}$ \\
\hline
\end{tabular}

Expected based on bending of plate as a beam

Thble 7(continued): Stresses in bearing plates (working stress range tests) 


\begin{tabular}{|c|c|c|c|c|c|c|}
\hline \multirow[b]{2}{*}{$\begin{array}{l}\text { Test } \\
\text { No. }\end{array}$} & \multirow{2}{*}{$\begin{array}{l}\text { Uniformly } \\
\text { distributed } \\
\text { stress(psi.) }\end{array}$} & \multirow{2}{*}{$\begin{array}{c}\text { Bearing Pl. } \\
\text { thickness } \\
\text { (in.) }\end{array}$} & \multicolumn{2}{|c|}{ Strain gage } & \multicolumn{2}{|c|}{ Stress } \\
\hline & & & location & $\begin{array}{c}\text { overhang } \\
\text { (in.) }\end{array}$ & $\begin{array}{c}\text { measured } \\
\text { (psi.) }\end{array}$ & $\begin{array}{l}\text { expected } \\
\text { (psi.) }\end{array}$ \\
\hline \multirow[t]{3}{*}{63} & \multirow[t]{3}{*}{672.0} & \multirow[t]{3}{*}{1.626} & top(d) & 4.0 & 464.0 & -12185.3 \\
\hline & & & top $(c)$ & 2.0 & -435.0 & -3046.3 \\
\hline & & & bot(c) & 2.0 & 522.0 & 3046.3 \\
\hline 64 & 1810.0 & 0.123 & top(d) & 1.2 & -348.0 & - \\
\hline 65 & 1312.0 & 0.280 & top(d) & 1.9 & 118.0 & - \\
\hline 66 & 1756.8 & 0.368 & top(d) & 1.25 & 638.0 & - \\
\hline 67 & 1730.0 & 0.605 & $\operatorname{top}(d)$ & 1.4 & 1334.0 & - \\
\hline \multirow[t]{3}{*}{68} & \multirow[t]{3}{*}{1309.0} & \multirow[t]{3}{*}{0.605} & top(d) & 2.0 & 1276.0 & - \\
\hline & & & top(d) & 1.4 & 899.0 & - \\
\hline & & & top (c) & 1.1 & broken & -12981.8 \\
\hline \multirow[t]{5}{*}{69} & \multirow[t]{5}{*}{707.1} & \multirow[t]{5}{*}{0.605} & top(d) & 3.0 & -551.0 & - \\
\hline & & & top(d) & 2.0 & 1044.0 & - \\
\hline & & & top(d) & 1.4 & 580.0 & -11359.2 \\
\hline & & & $\operatorname{top}(c)$ & 1.1 & -377.0 & -7012.6 \\
\hline & & & top (c) & 0.6 & broken & -2086.4 \\
\hline \multirow[t]{2}{*}{70} & \multirow[t]{2}{*}{1310.0} & \multirow[t]{2}{*}{0.856} & top(d) & 2.0 & 870.0 & - \\
\hline & & & top (c) & 0.6 & 2958.0 & -1930.8 \\
\hline \multirow[t]{4}{*}{71} & \multirow[t]{4}{*}{713.0} & \multirow[t]{4}{*}{0.856} & top(d) & 2.9 & -1769.0 & - \\
\hline & & & top(d) & 2.0 & 609.0 & -11676.8 \\
\hline & & & top (c) & 1.5 & -638.0 & -6568.2 \\
\hline & & & top (c) & 0.6 & 2409.0 & -1050.9 \\
\hline \multirow[t]{2}{*}{72} & \multirow[t]{2}{*}{705.0} & \multirow[t]{2}{*}{1.168} & top(d) & 2.8 & -812.0 & -12154.6 \\
\hline & & & top (c) & 1.5 & -145.0 & -3488.2 \\
\hline
\end{tabular}

"Expected based on bending of plate as a beam

Table 7(continued): Stresses in bearing plates (working stress range tests). 


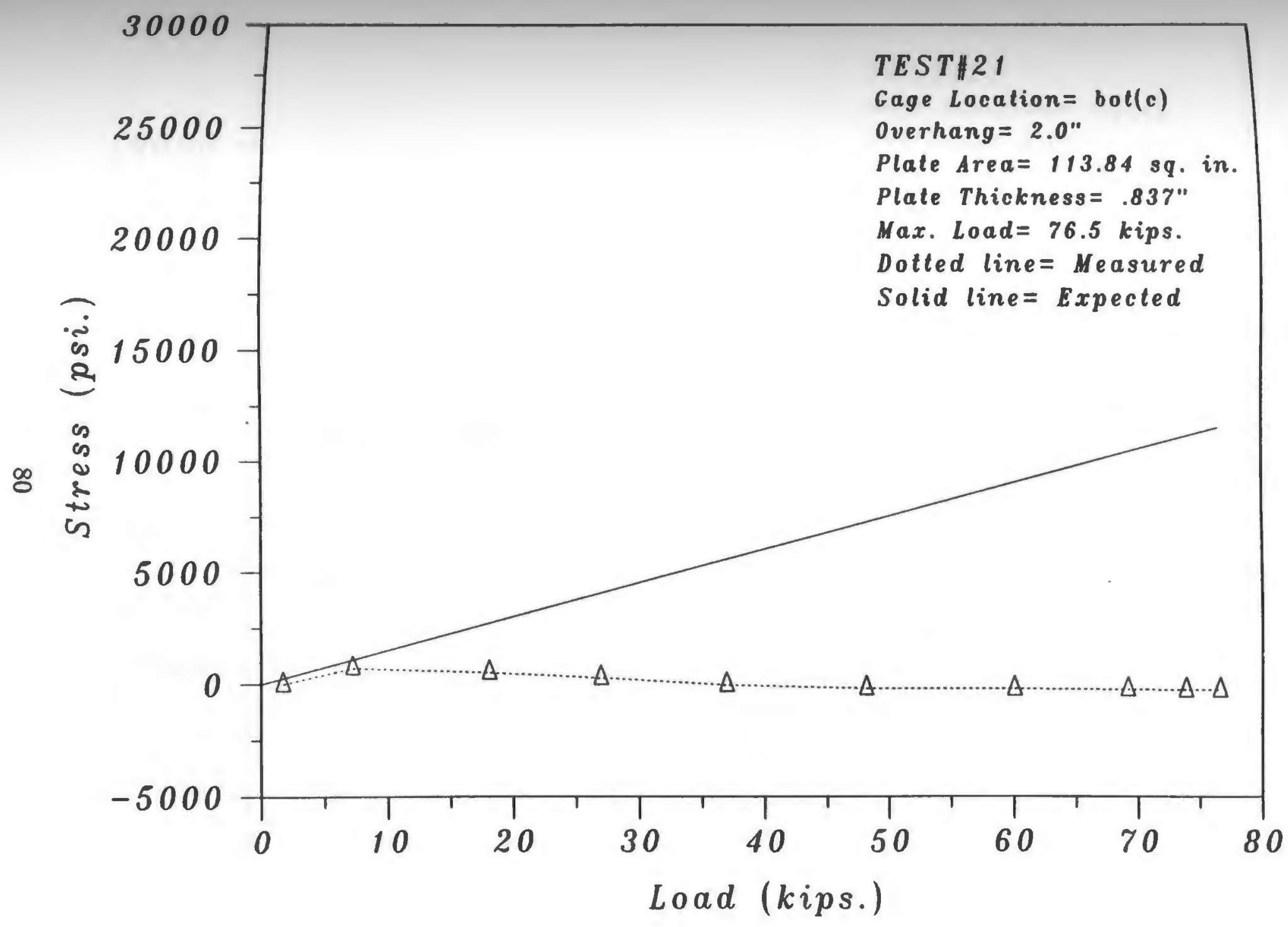

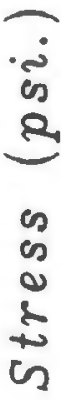

Fig.87: STRESSES IN BEARING PLATE 


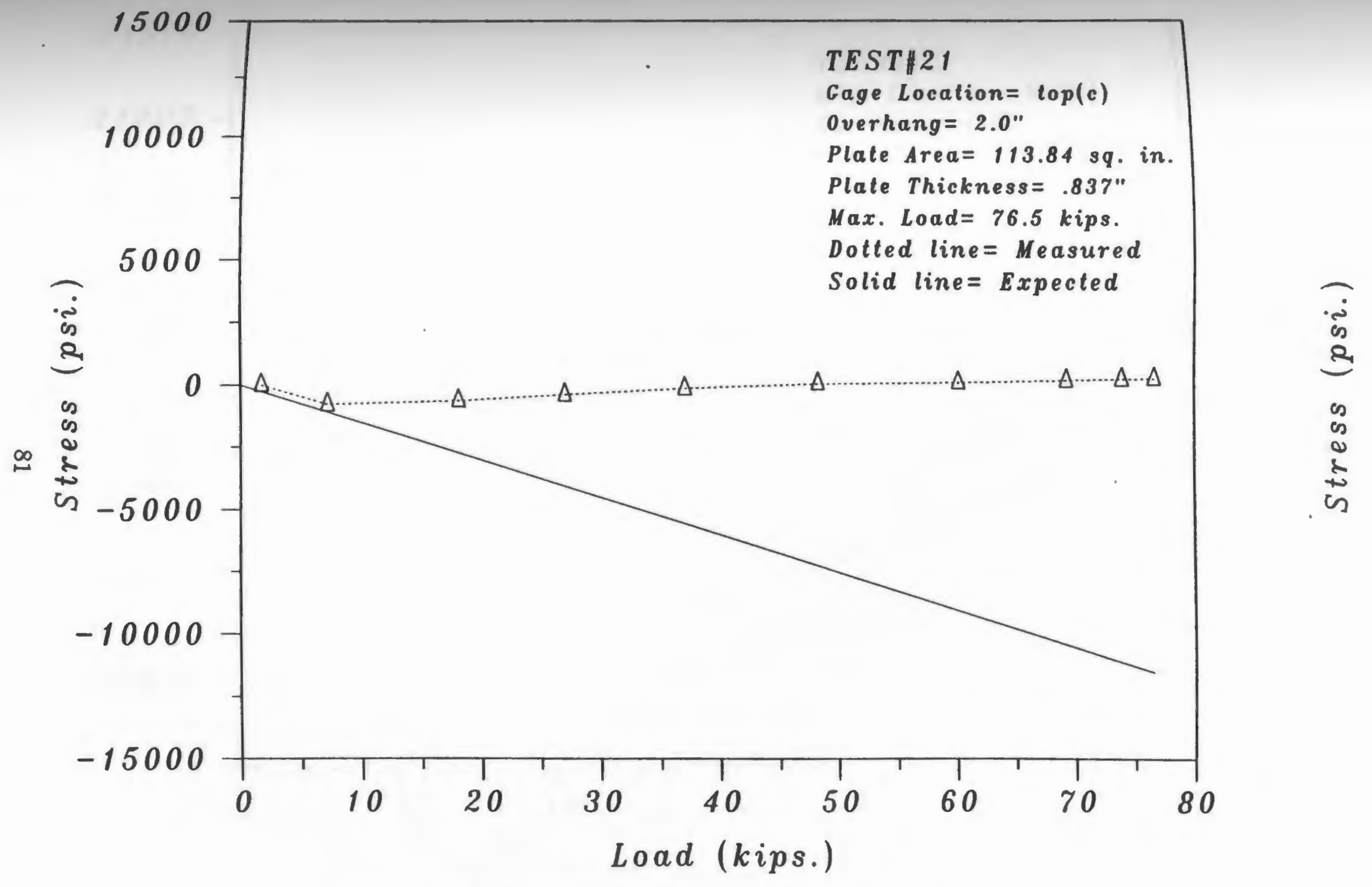

Fig.88: STRESSES IN BEARING PLATE 


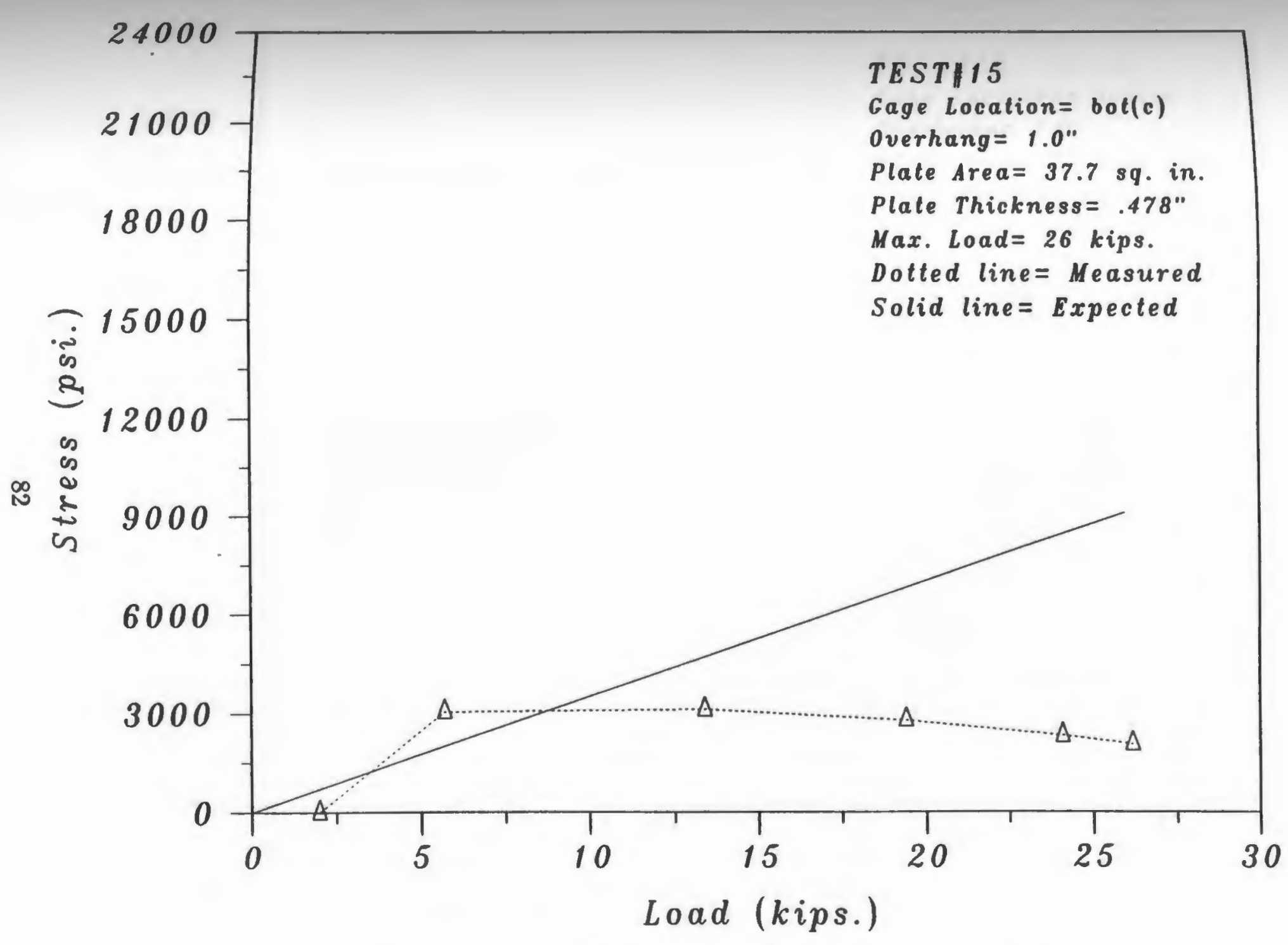

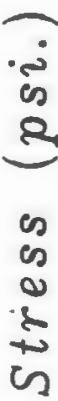

Fig.89: STRESSES IN BEARING PLATE 


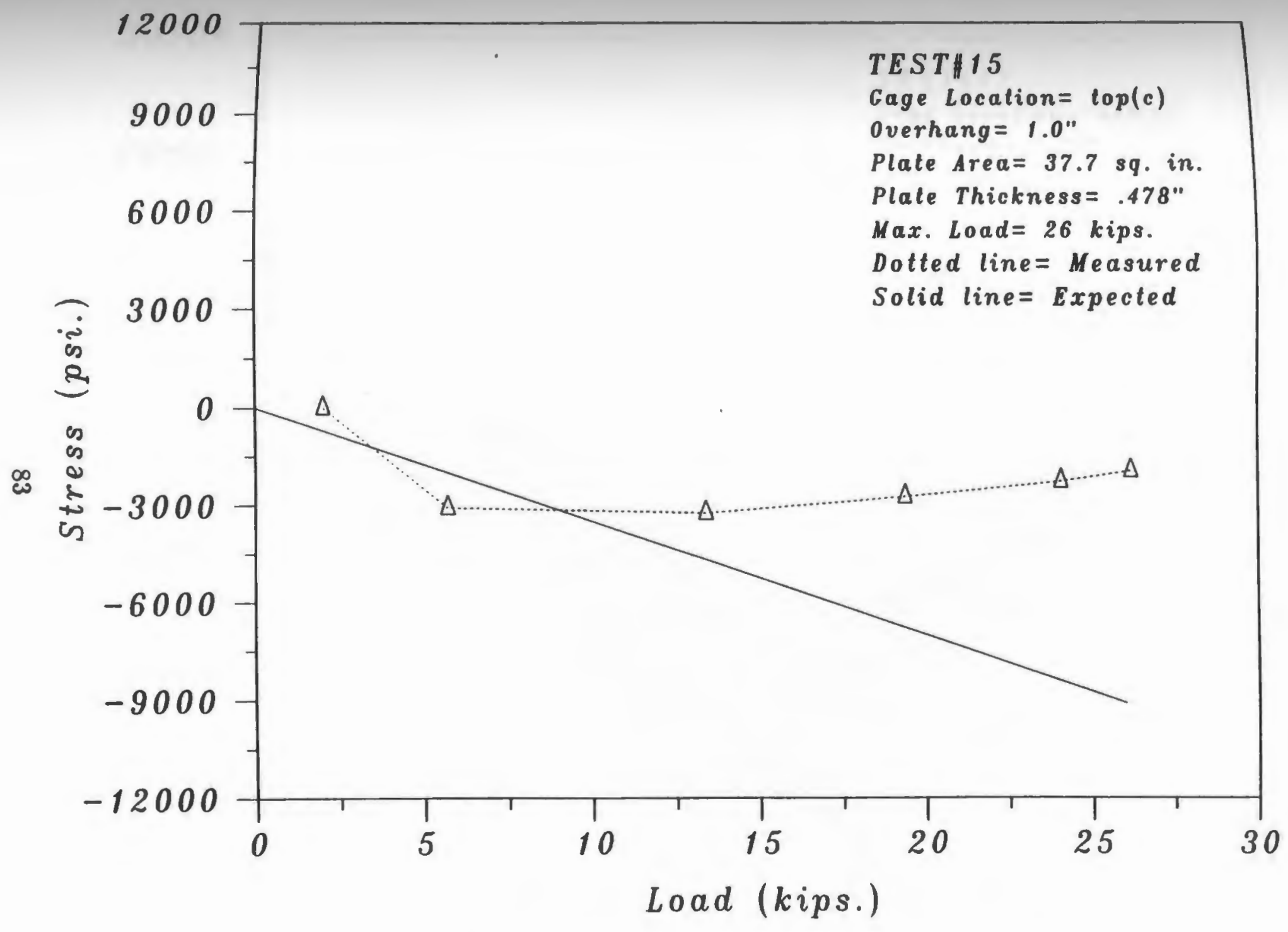

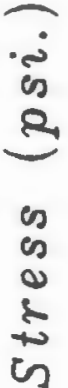

Fig.90: STRESSES IN BEARING PLATE 


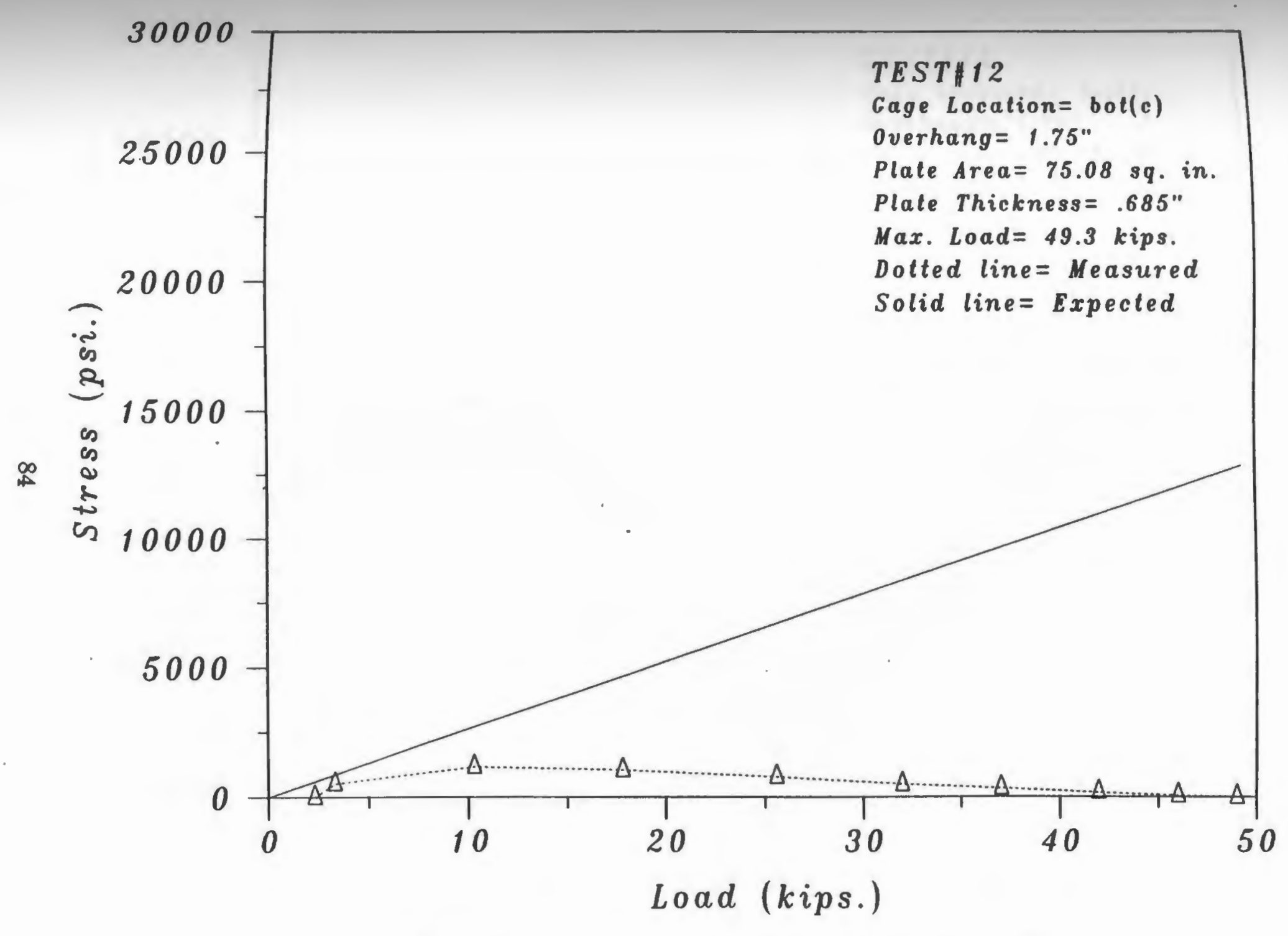

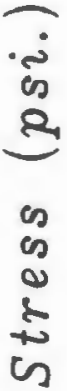

Fig.91: STRESSES IN BEARING PLATE 


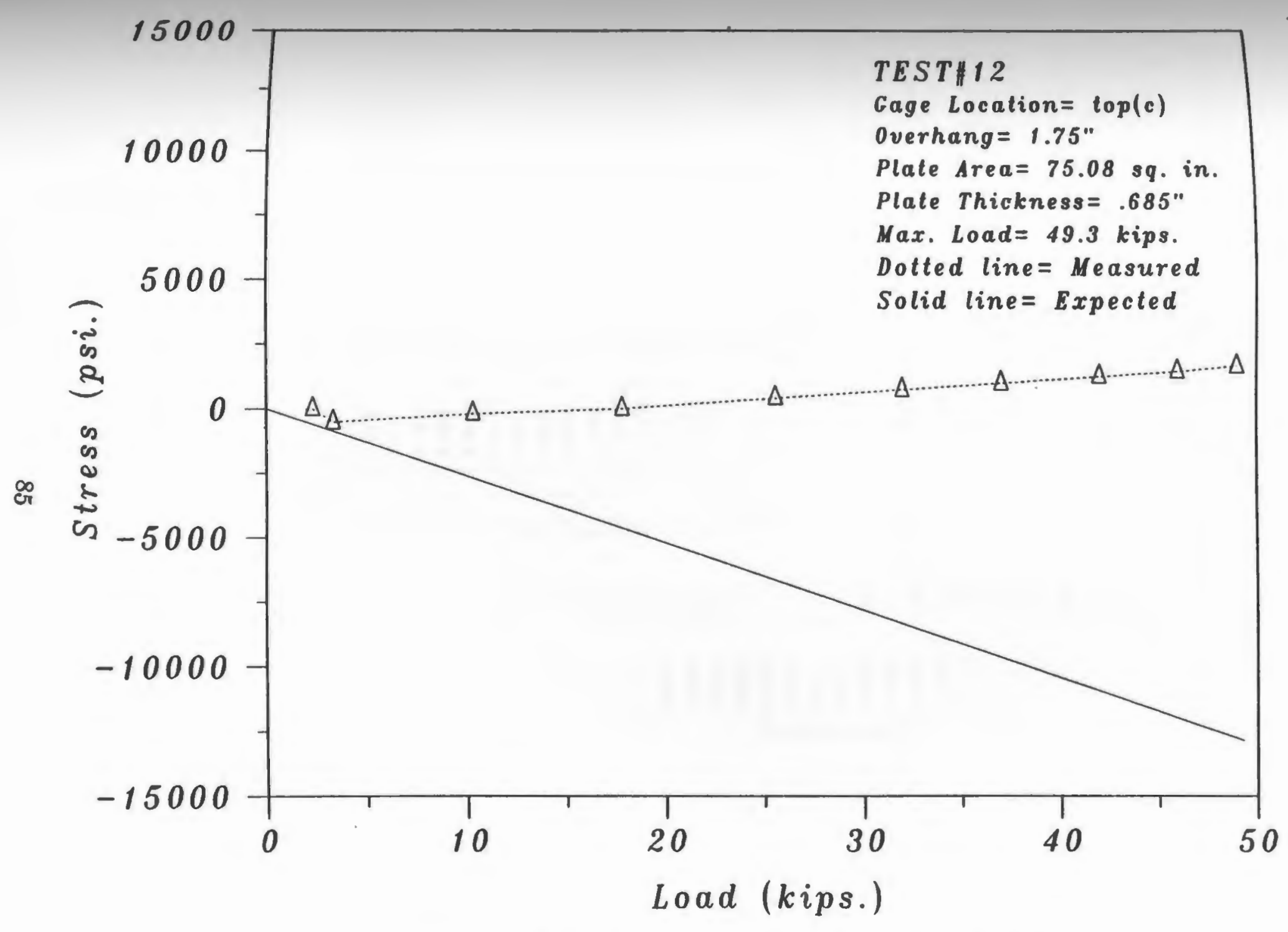




\begin{tabular}{|c|c|c|c|c|c|}
\hline $\begin{array}{l}\text { Test } \\
\text { No. }\end{array}$ & $\begin{array}{c}\text { Lood } \\
\text { (kips.) }\end{array}$ & $\begin{array}{l}\text { Stress } \\
\text { (psi.) }\end{array}$ & $\begin{array}{l}\text { Test } \\
\text { No. }\end{array}$ & $\begin{array}{c}\text { Lood } \\
\text { (kips.) }\end{array}$ & $\begin{array}{l}\text { Stress } \\
\text { (psi.) }\end{array}$ \\
\hline 1 & 109.5 & 2001.0 & $\overline{737}$ & 136.7 & 5104.0 \\
\hline 2 & 96.5 & 1827.0 & 38 & 106.9 & 5742.0 \\
\hline 3 & 103.1 & 2987.0 & 39 & 77.1 & 4408.0 \\
\hline 4 & 101.0 & 1827.0 & 40 & 106.9 & 3915.0 \\
\hline 5 & 103.3 & 1914.0 & 41 & 76.3 & 2871.0 \\
\hline 6 & 78.6 & 1711.0 & 42 & 76.6 & 1508.0 \\
\hline 7 & 98.2 & 2320.0 & 43 & 102.2 & 8091.0 \\
\hline 8 & 76.7 & 1653.0 & 44 & 76.9 & 5829.0 \\
\hline 9 & 76.8 & 1276.0 & 45 & 101.9 & 7511.0 \\
\hline 10 & 98.8 & 2291.0 & 46 & 101.9 & 7337.0 \\
\hline 11 & 89.0 & 1943.0 & 47 & 77.4 & 5626.0 \\
\hline 12 & 49.3 & 1305.0 & 48 & 42.0 & 3248.0 \\
\hline 13 & 72.9 & 1566.0 & 49 & 77.1 & 5075.0 \\
\hline 14 & 51.6 & 1073.0 & 50 & 40.9 & 2639.0 \\
\hline 15 & 26.1 & 522.0 & 51 & 41.4 & 2262.0 \\
\hline 16 & 110.8 & 3132.0 & 52 & 200.9 & 5046.0 \\
\hline 17 & 105.6 & 2871.0 & 53 & 136.9 & 2813.0 \\
\hline 18 & 100.3 & 3218.0 & 54 & 101.9 & 1914.0 \\
\hline 19 & 105.2 & 3132.0 & 55 & 137.4 & 2262.0 \\
\hline 20 & 104.0 & 2697.0 & 56 & 107.1 & 1856.0 \\
\hline 21 & 76.5 & 1769.0 & 57 & 137.1 & 2320.0 \\
\hline 22 & 99.1 & 2929.0 & 58 & 136.9 & 2204.0 \\
\hline 23 & 74.5 & 1914.0 & 59 & 106.8 & 1653.0 \\
\hline 24 & 79.7 & 1740.0 & 60 & 76.5 & 1102.0 \\
\hline 25 & 103.7 & 2871.0 & 61 & 107.3 & 1711.0 \\
\hline 26 & 89.0 & 2610.0 & 62 & 77.3 & 1305.0 \\
\hline 27 & 51.7 & 2668.0 & 63 & 76.5 & 1508.0 \\
\hline 28 & 72.9 & 1972.0 & 64 & 102.0 & 1595.0 \\
\hline 29 & 51.2 & 1189.0 & 65 & 76.6 & 1218.0 \\
\hline 30 & 25.1 & 464.0 & 66 & 102.0 & 1682.0 \\
\hline 31 & 200.7 & 6322.0 & 67 & 101.8 & 1624.0 \\
\hline 32 & 137.0 & 5916.0 & 68 & 77.1 & 1102.0 \\
\hline 33 & 102.1 & 4089.0 & 69 & 41.6 & 667.0 \\
\hline 34 & 137.1 & 7743.0 & 70 & 76.8 & 1073.0 \\
\hline 35 & 106.8 & 7279.0 & 71 & 41.8 & 725.0 \\
\hline 36 & 137.0 & 6322.0 & 72 & 41.5 & 580.0 \\
\hline
\end{tabular}

Table 8: Stress in top horizontal rebar (working stress tests) 


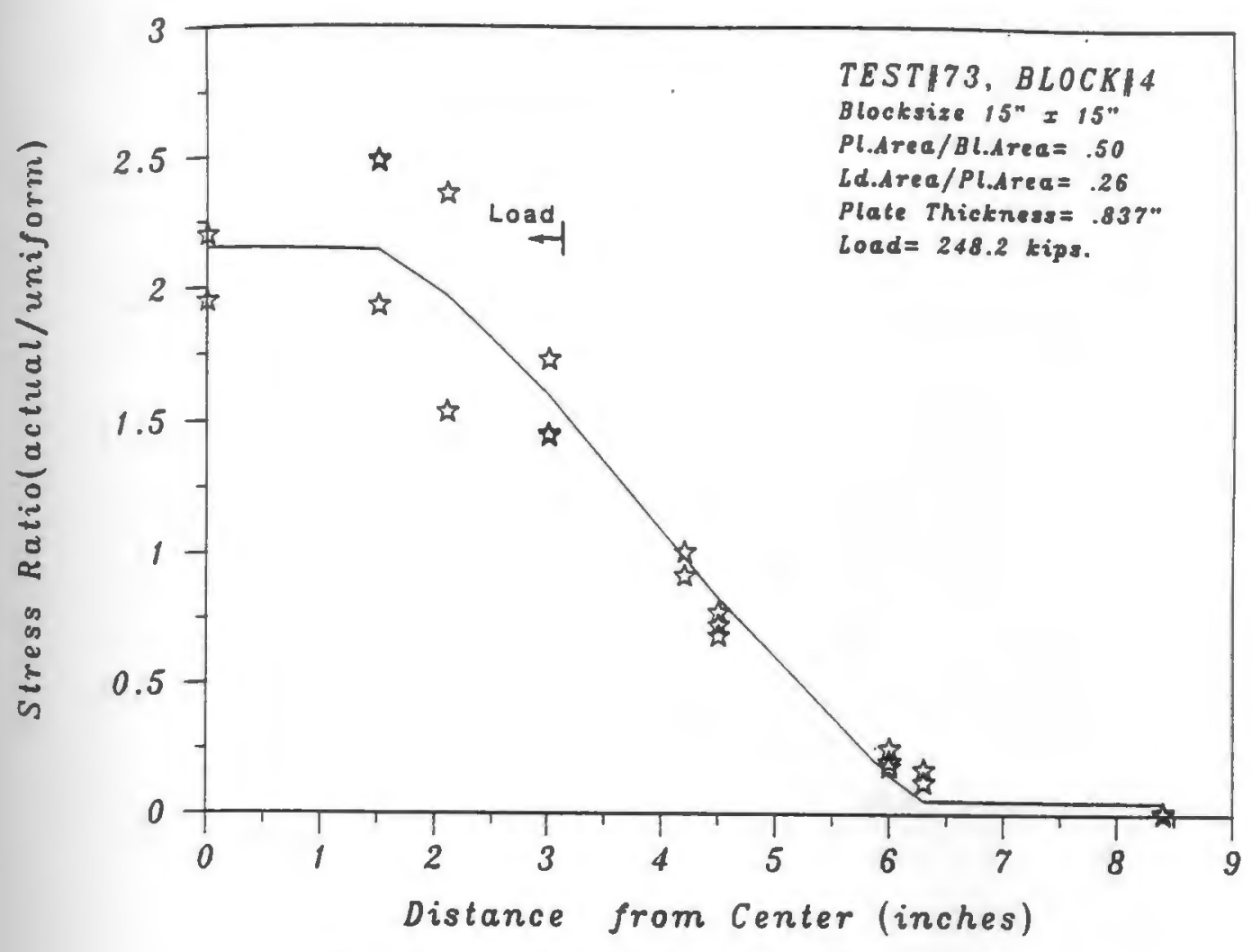

TESTI73, BLOCK $/ 4$

Blocksize 15" 1 15"

Pl.Area/Bl.Area $=.50$

Cd.Area/Pl.Area $=.26$

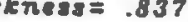

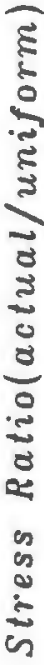

Fig.93: DISTRIBUTION OF STRESSES

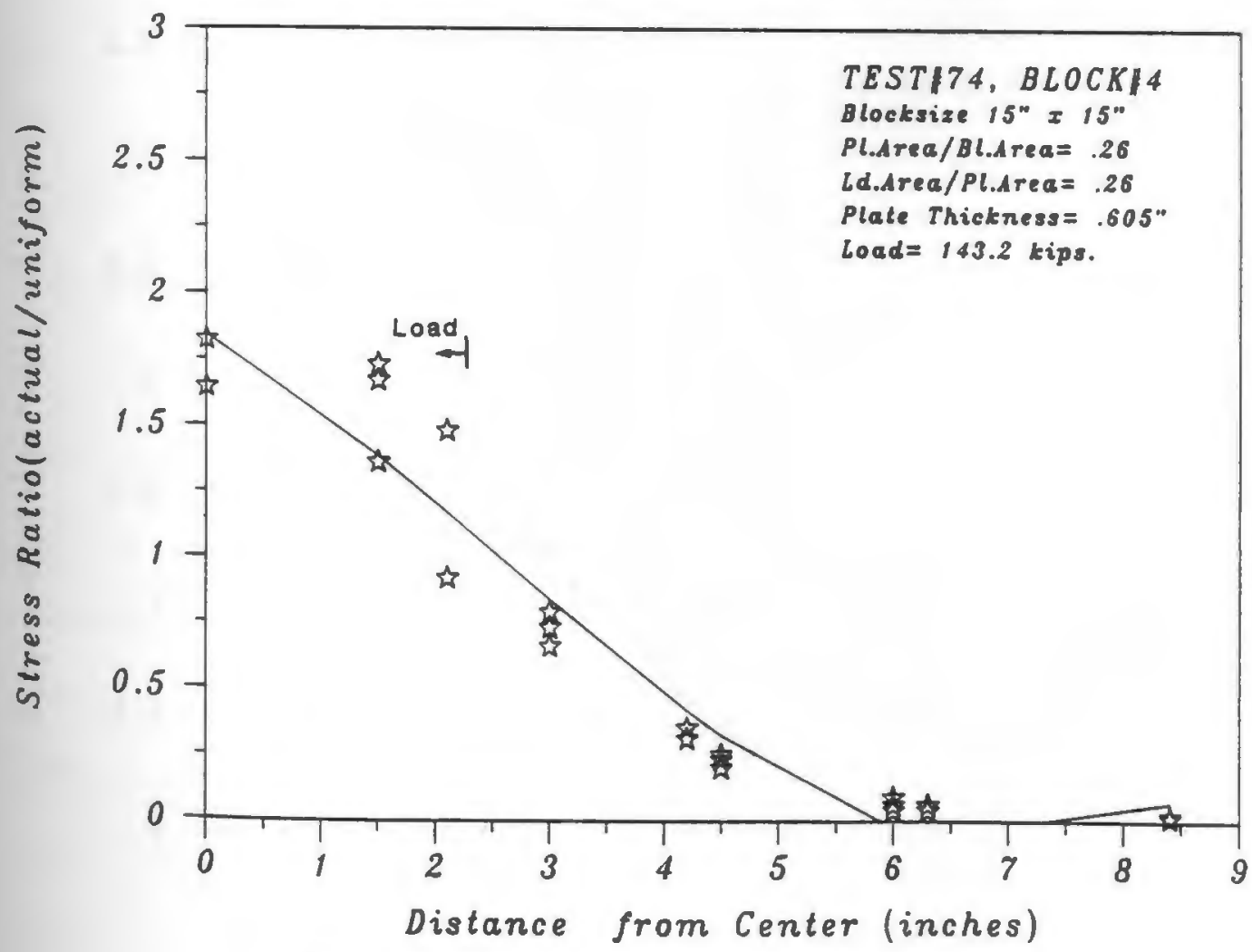

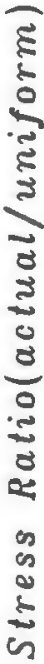

Fig.94: DISTRIBUTION OF STRESSES 


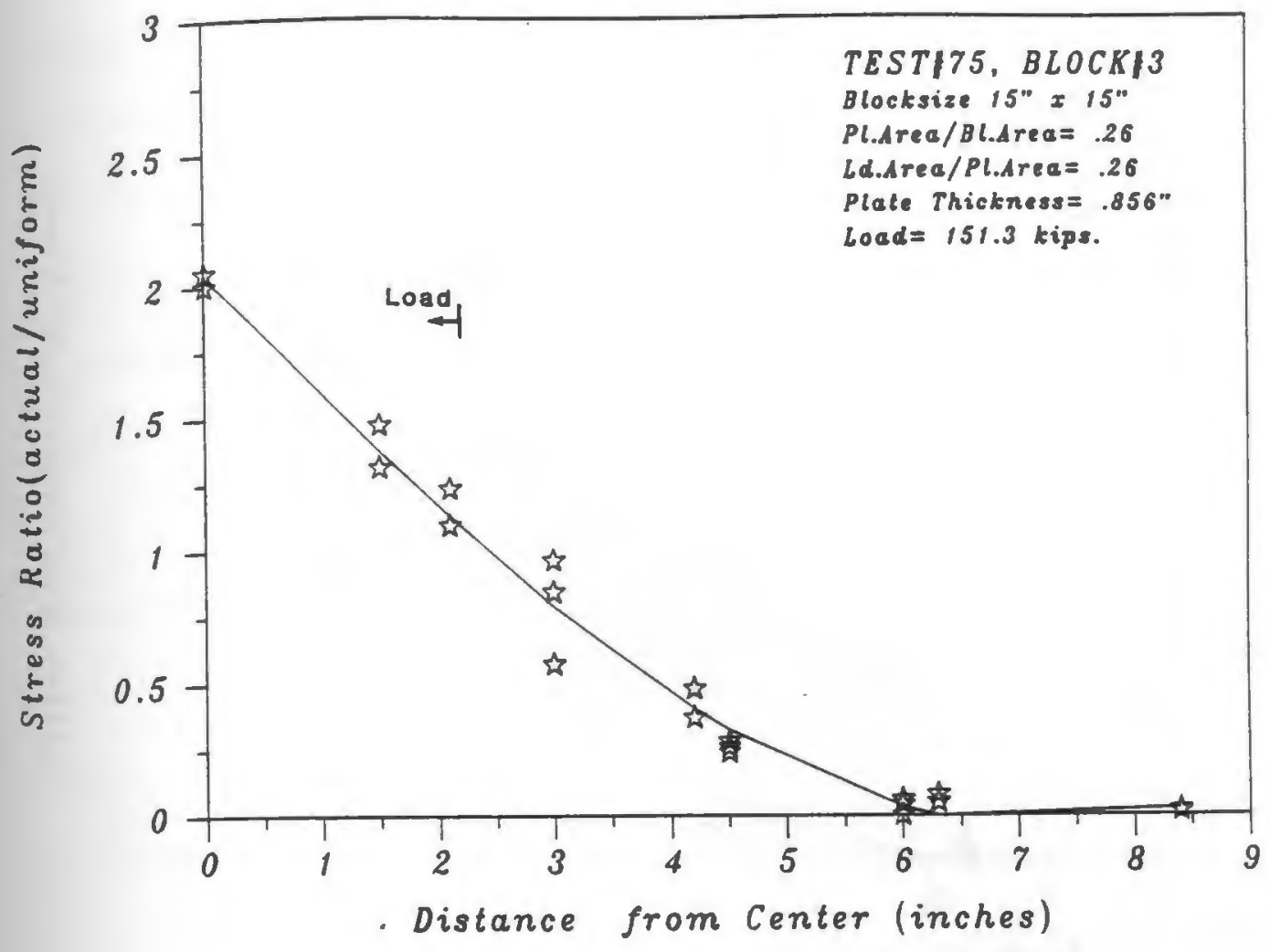

है

Fig.95: DISTRIBUTION OF STRESSES

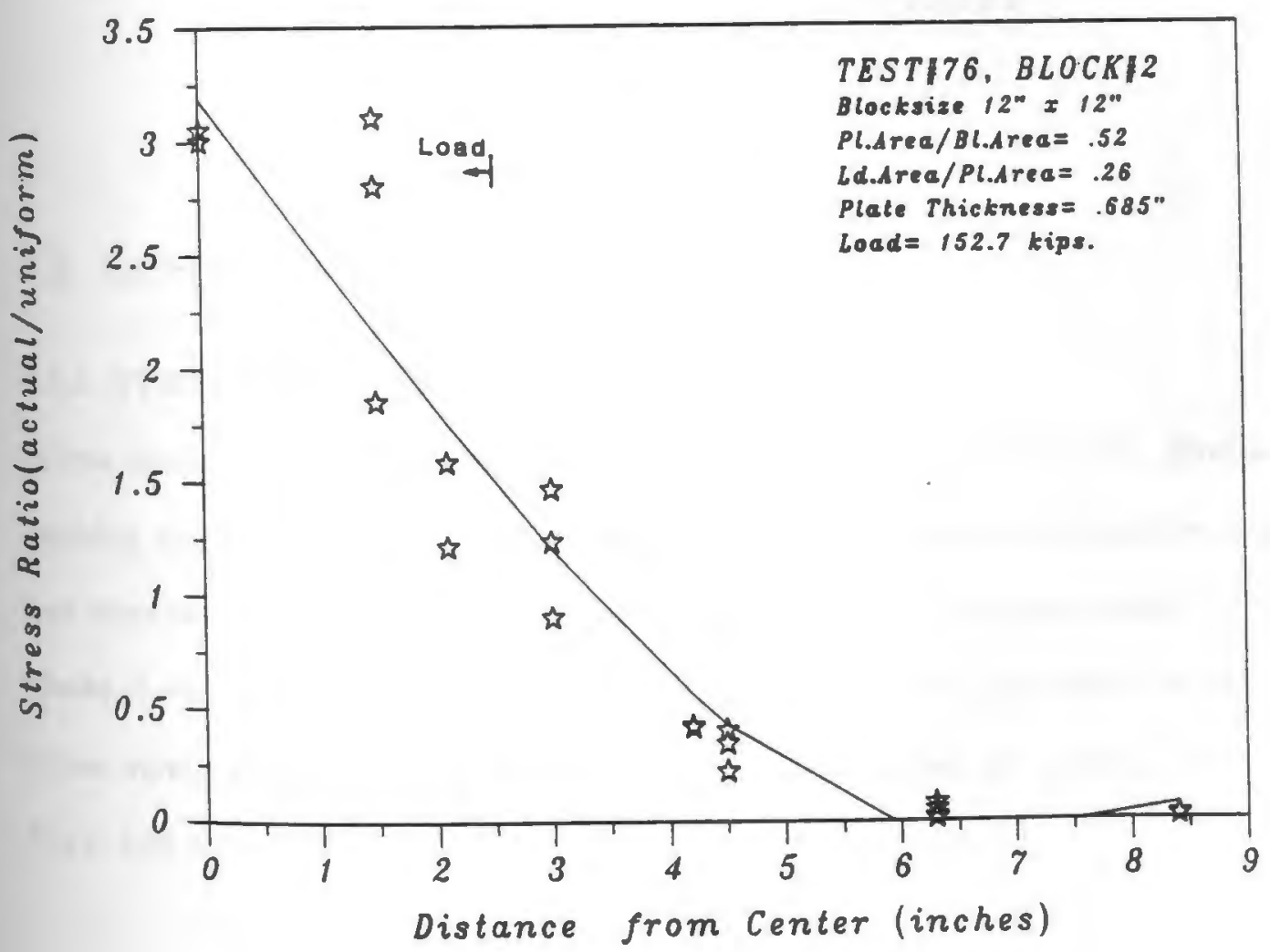

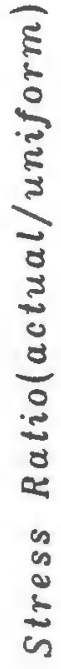

Fig.96: DISTRIBUTION OF STRESSES 


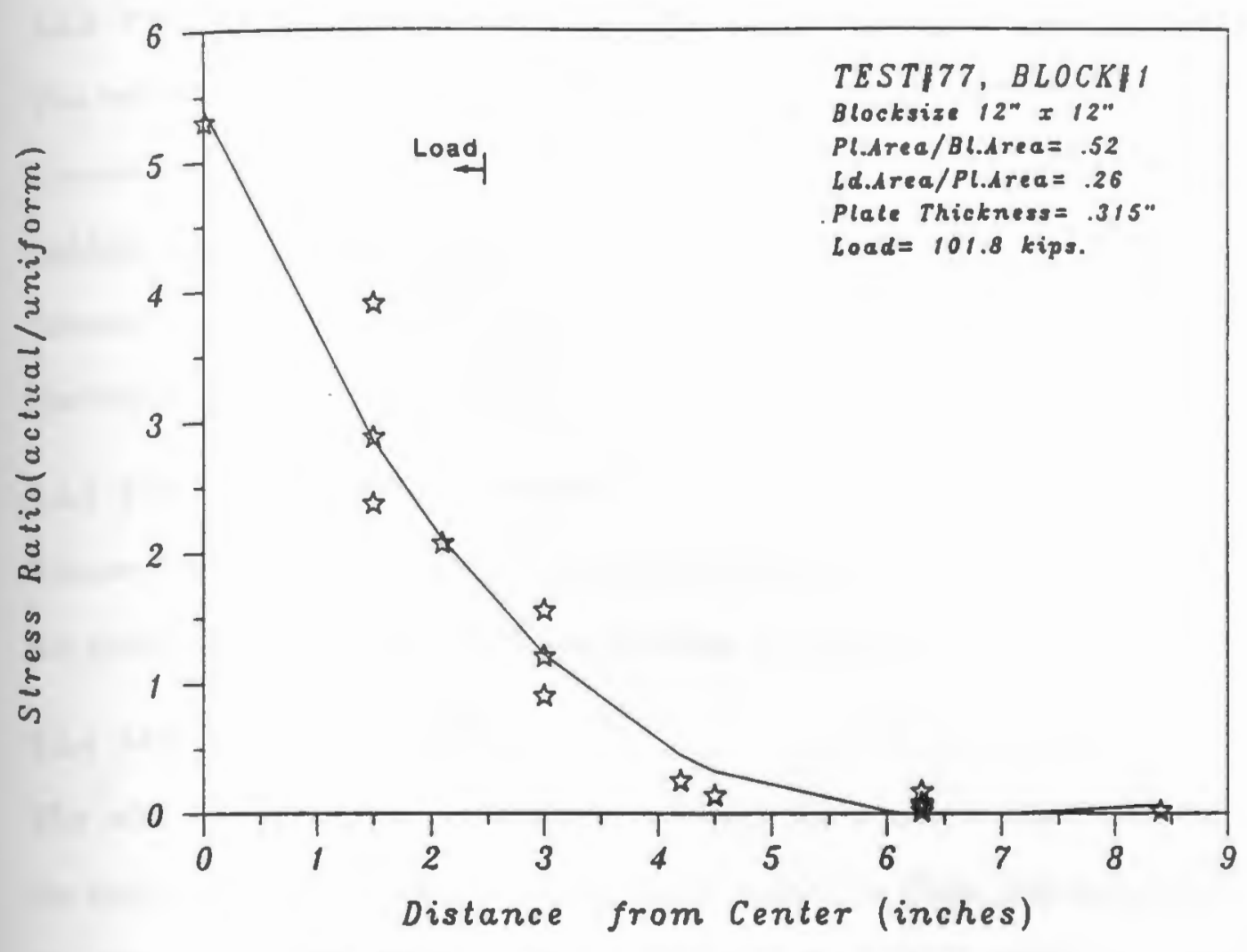

TESTI77, BLOCKI1

Blocksize $12^{\prime \prime} \times 12 "$

Pl.Area/Bl.Area $=.52$

Ld.drea/Pl.Area $=.26$

Plate Thickness $=.315^{\circ}$

load $=101.8$ kips.

Fig.97: DISTRIBUTION OF STRESSES

\subsection{ULTIMATE LOAD TESTS:}

\subsubsection{STRESSES IN CONCRETE:}

Stress distribution in the concrete can be seen in Figs. 93 thru 97. Similar to the working stress range tests, high stress concentration were seen near the center and less stresses away from the loaded area. The strains measured inside the concrete blocks is shown in Figs. 98 thru 101. The stress distribution based on the uniaxial stress strain diagram (Fig. 8) after the yielding started at center can be seen in Figs. 102 thru 105. 


\subsubsection{STRESSES IN BEARING PLATES:}

The behavior of the bearing plates was similar to the working stress range tests and stresses observed were very low as compared to expected. In many locations where yielding was expected, very low stresses were observed. Table 9 lists the plate stresses at ultimate loads, which in most cases are quite different than expected theoretical streses.

\subsubsection{STRESSES IN REINFORCING BAR:}

Stresses measured in the top horizontal rebar are given in Table 10. The stresses are quite high, which indicate local cracking of concrete.

\subsubsection{SLIP MEASUREMENT:}

The relative horizontal displacement between the concrete block and the edge of the steel bearing plate was measured and is plotted in Figs. 106 thru 109. The load at which the slip was measured is evident from the figures while loading as well as unloading. The permanent slip can also be seen in the plots.

\subsubsection{LIFT MEASUREMENT:}

As mentioned earlier, test 74 (first ultima te load test) resulted in a considerable permanent deformation of the steel plate. For the rest three ultimate load tests, i.e. 75 thru 77, the vertical displacement at the corner of the plate was measured at different load levels and can be seen in Figs. 110 thru 112. The permanent deformation can also be seen. 


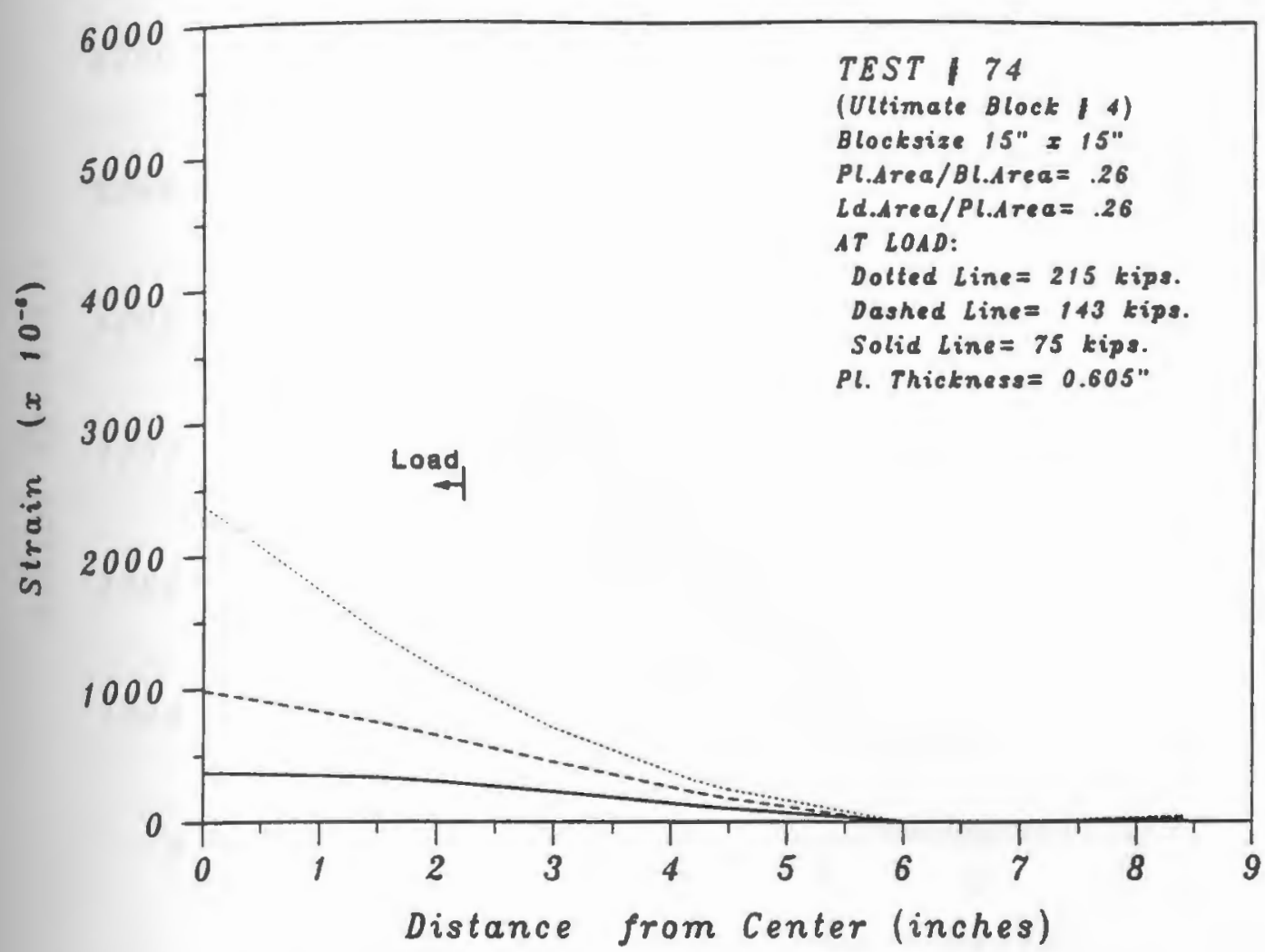

8
8
8
8
8
5
5

Fig.98: INTERNAL STRAIN DISTRIBUTION

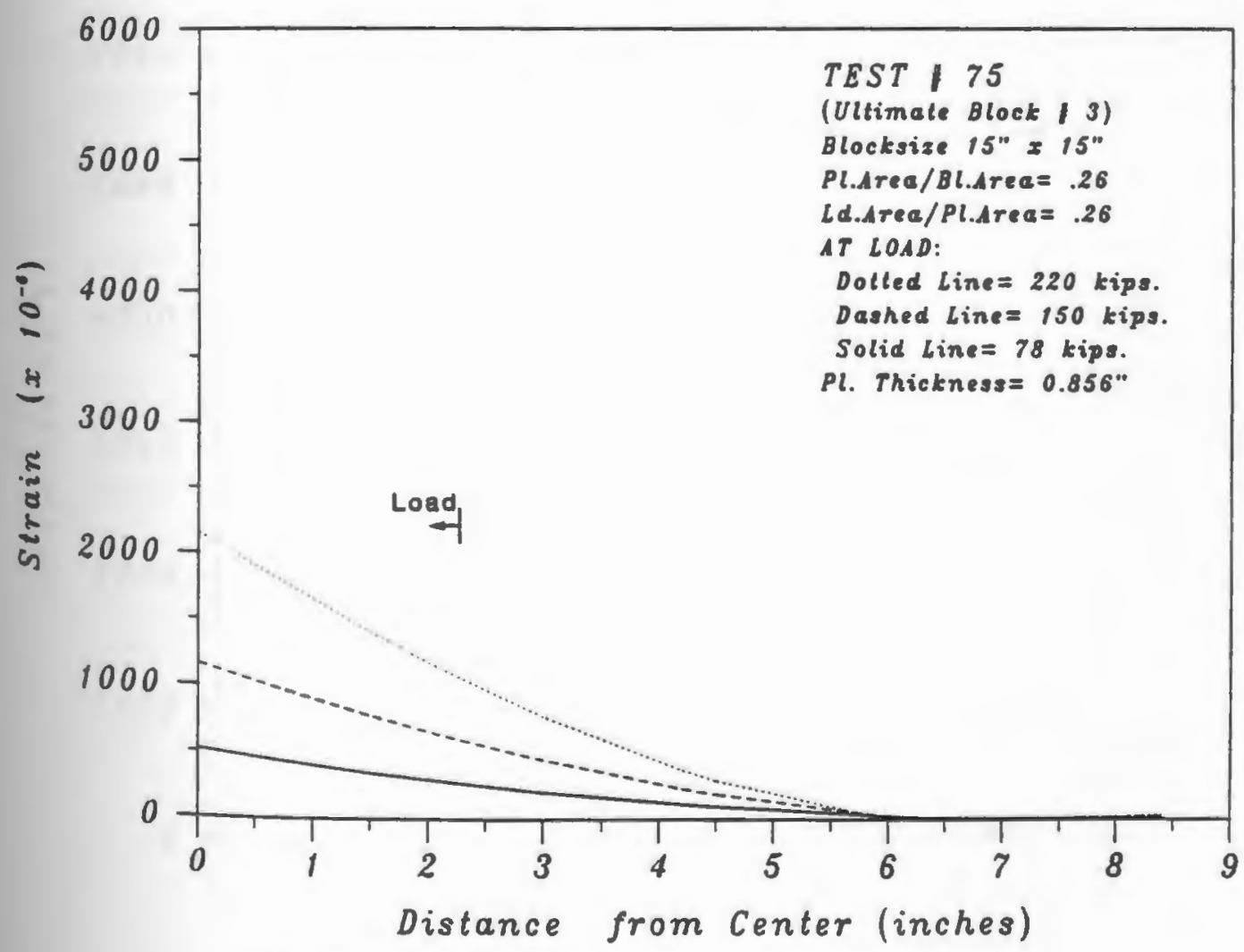

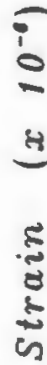

Fig.99: INTERNAL STRAIN DISTRIBUTION 


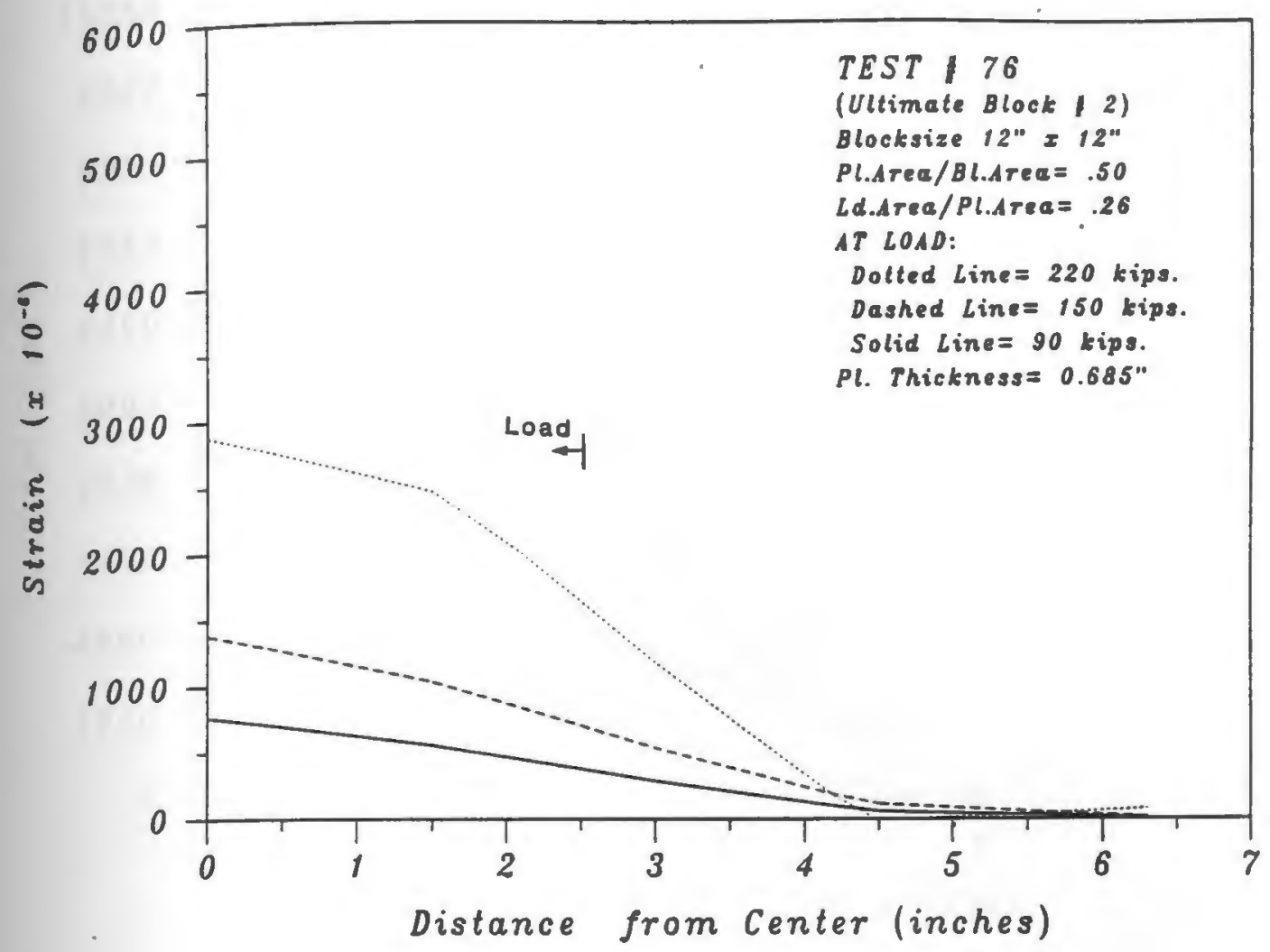

0
0
0
0
0
0
0
0

Fig.100: INTERNAL STRAIN DISTRIBUTION

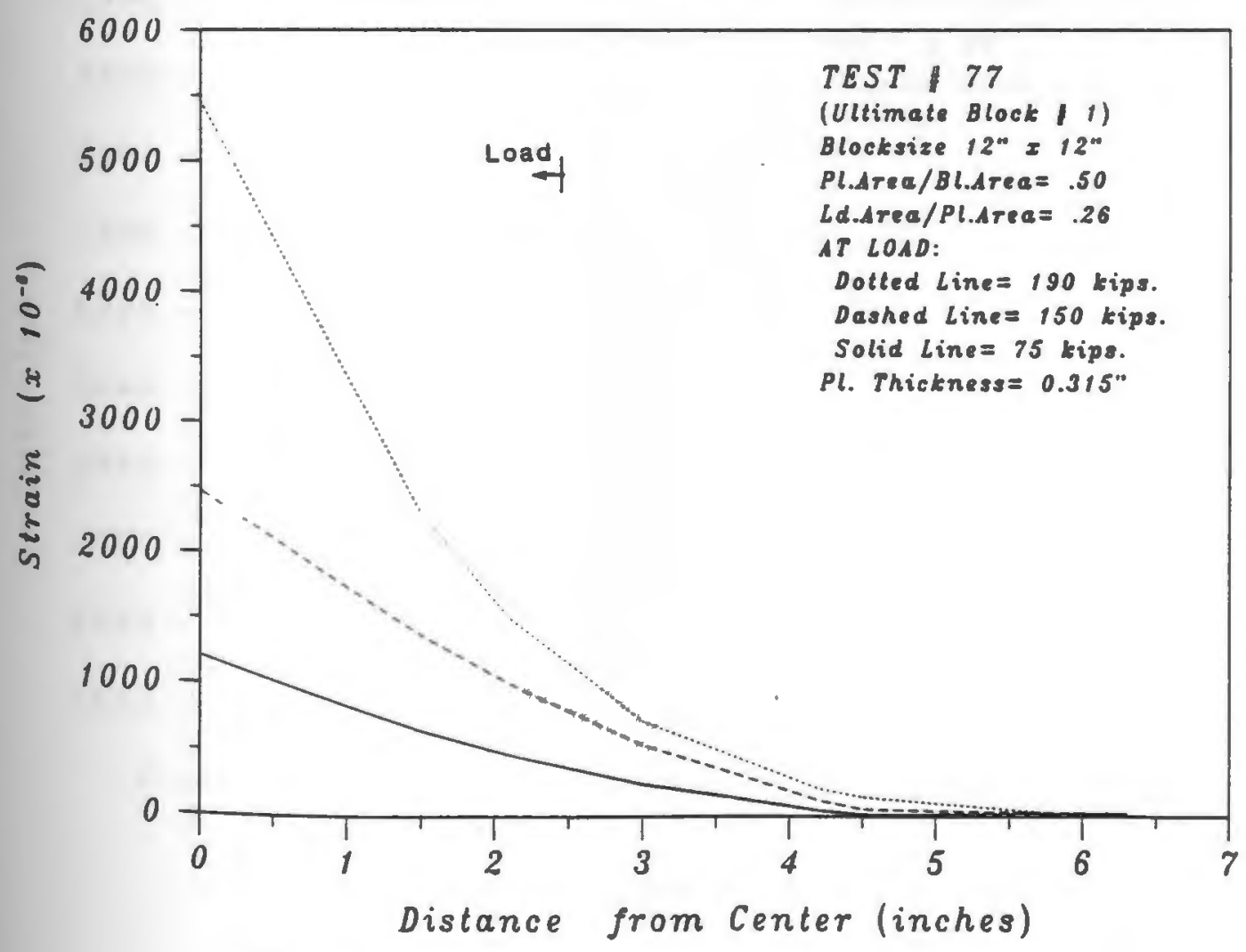

Fig.101: INTERNAL STRAIN DISTRIBUTION 


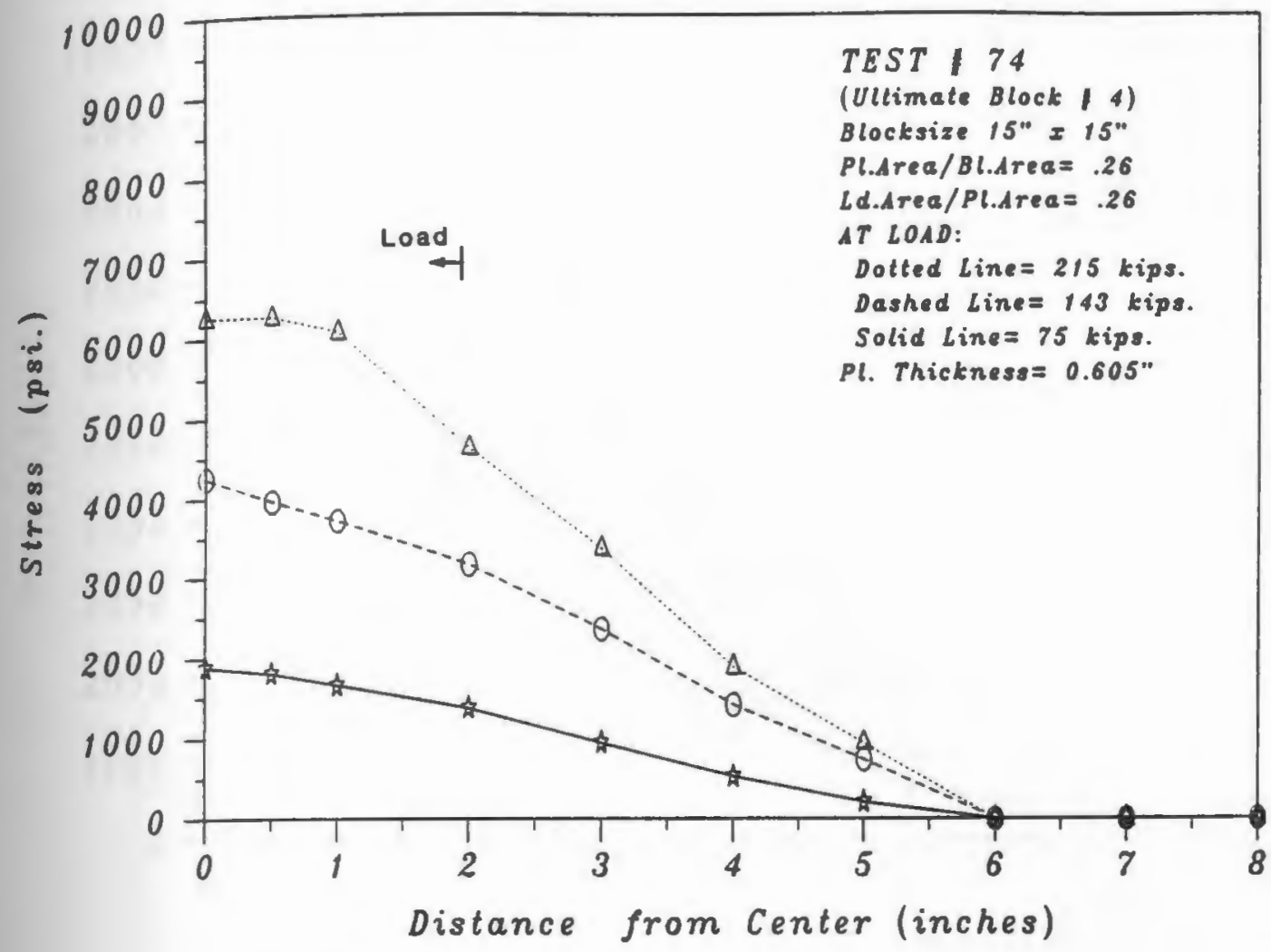

3
8
0
5
0
5
5

Fig.102:INTERNAL STRESS DISTRIBUTION

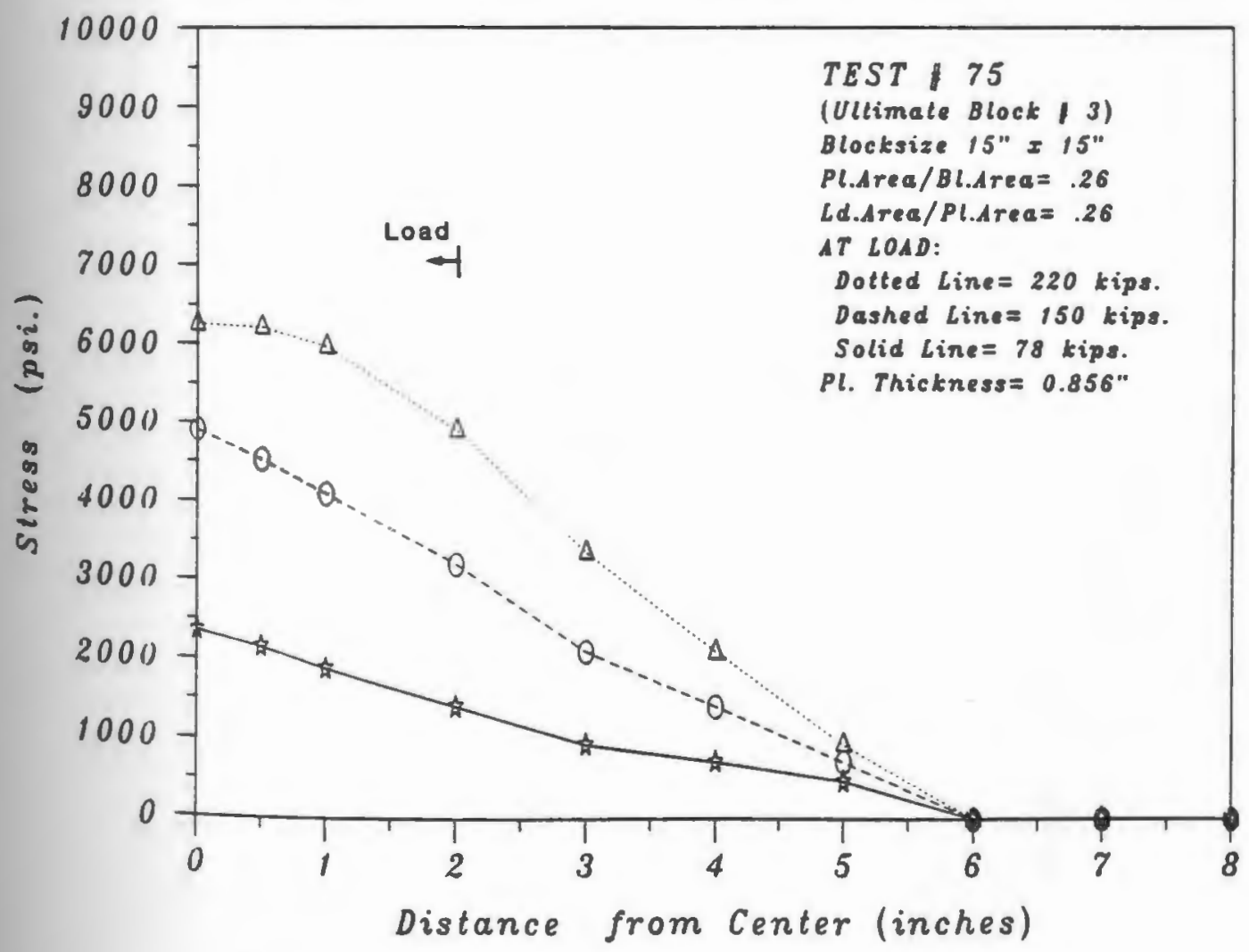

Fig.103: INTERNAL STRESS DISTRIBUTION 


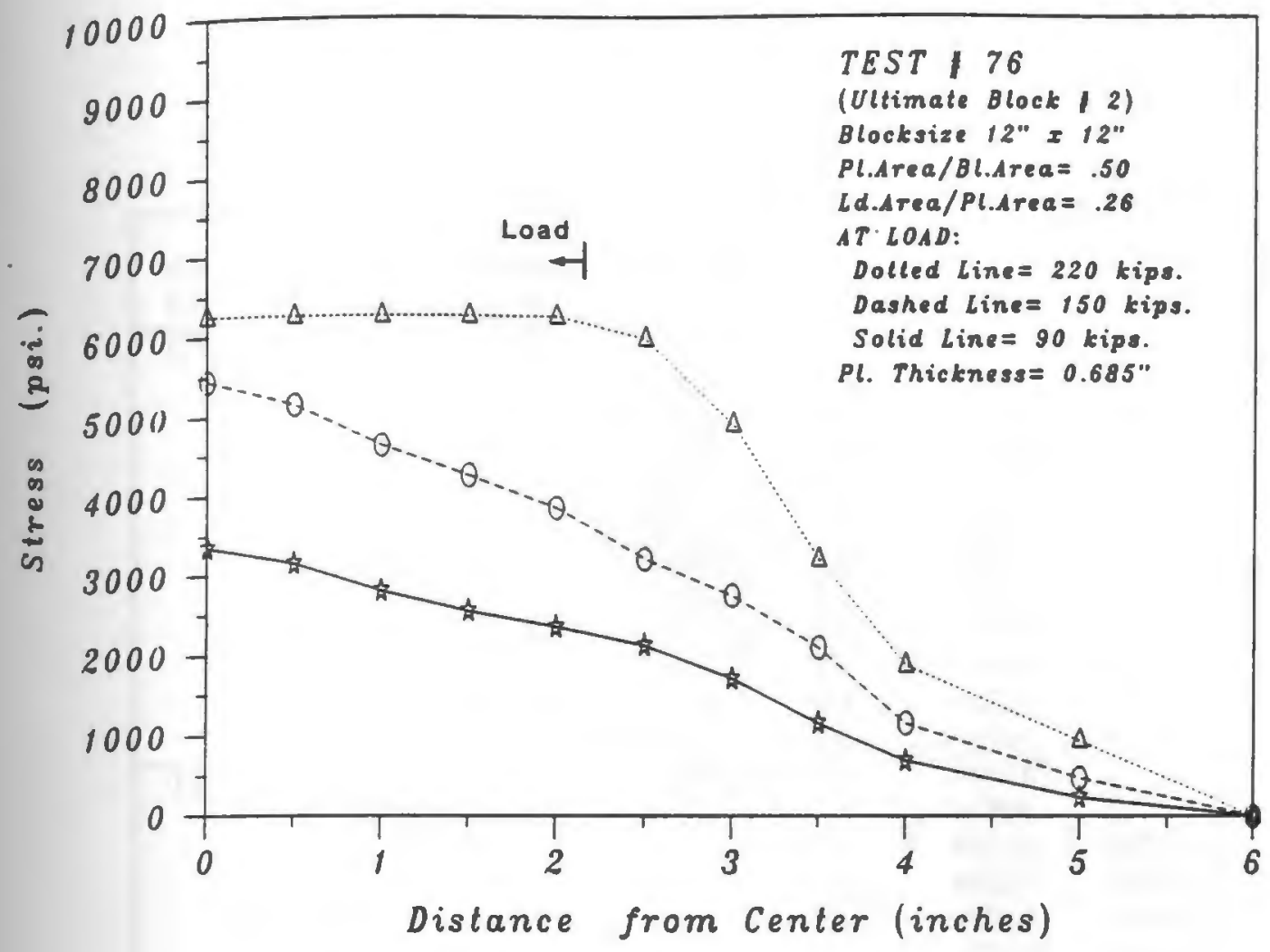

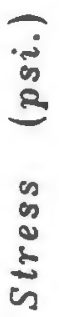

Fig.104: INTERNAL STRESS DISTRIBUTION

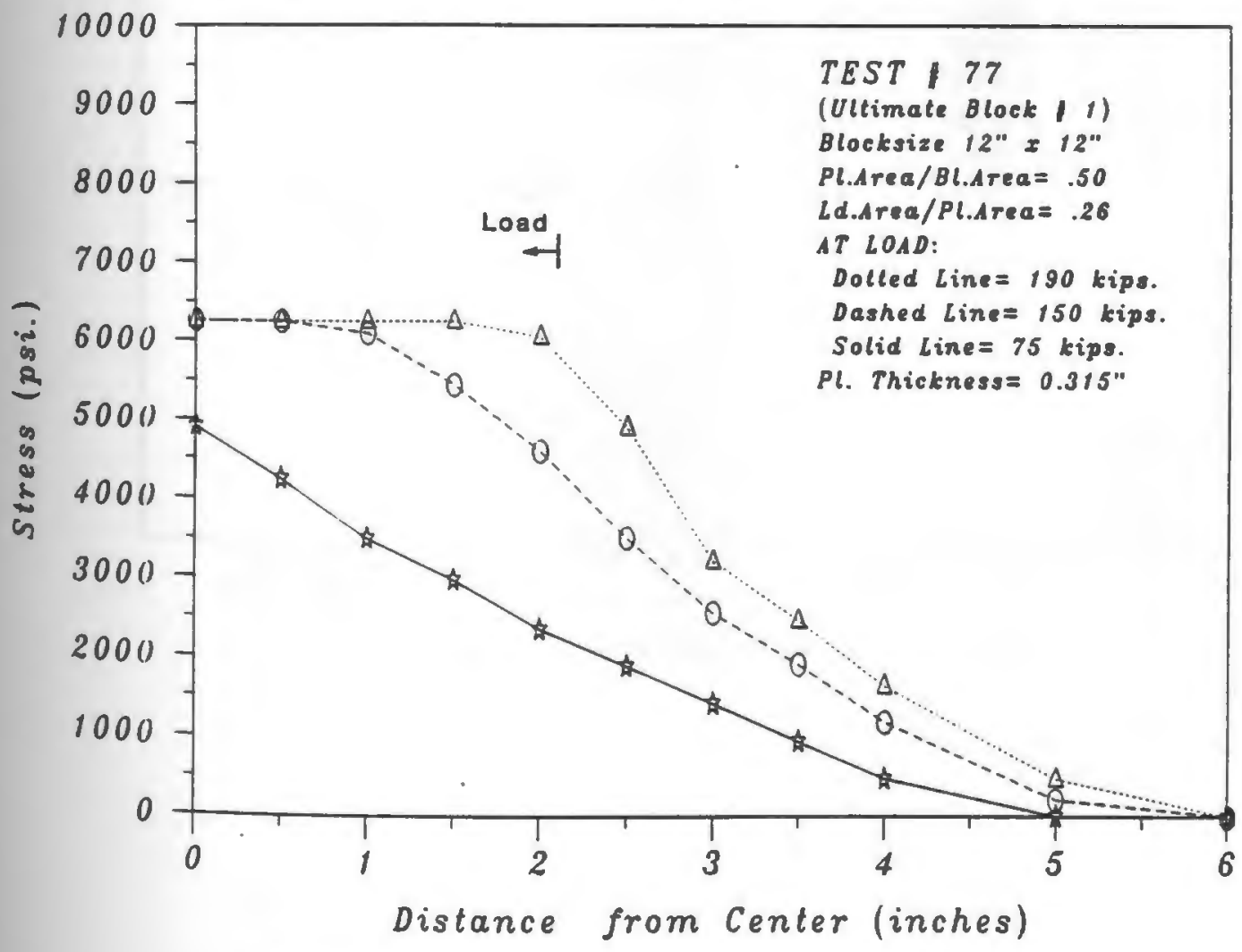

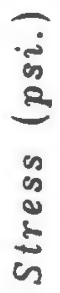

Fig.105: INTERNAL STRESS DISTRIBUTION 


\begin{tabular}{|c|c|c|c|c|c|c|}
\hline \multirow[b]{2}{*}{$\begin{array}{l}\text { Test } \\
\text { No. }\end{array}$} & \multirow{2}{*}{$\begin{array}{l}\text { Uniformly } \\
\text { distributed } \\
\text { stress(psi.) }\end{array}$} & \multirow{2}{*}{$\begin{array}{c}\text { Bearing } P l . \\
\text { thichness } \\
\text { (in.) }\end{array}$} & \multicolumn{2}{|c|}{ Strain gage } & \multicolumn{2}{|c|}{ Stress } \\
\hline & & & lacation & $\begin{array}{l}\text { overhang } \\
\text { (in.) }\end{array}$ & $\begin{array}{c}\text { mensured } \\
\text { (psi.) }\end{array}$ & $\begin{array}{l}\text { expected }^{+} \\
\text {(psi.) }\end{array}$ \\
\hline \multirow[t]{12}{*}{$73^{\prime \prime}$} & 1433.0 & \multirow[t]{12}{*}{0.837} & top(d) & 4.0 & 2552.0 & - \\
\hline & & & $\operatorname{top}(d)$ & 3.0 & 2523.0 & - \\
\hline & & & top(d) & 2.0 & 1682.0 & -24545.5 \\
\hline & & & top (c) & 2.0 & broken & -24545.5 \\
\hline & & & top (c) & 0.8 & 5336.0 & -3927.3 \\
\hline & & & bot(c) & 2.0 & broken & 24545.5 \\
\hline & 2180.0 & & top(d) & 4.0 & 4089.0 & - \\
\hline & & & top (d) & 3.0 & 6264.0 & - \\
\hline & & & top(d) & 2.0 & 3973.0 & -yicld \\
\hline & & & top(c) & 2.0 & broken & -yield \\
\hline & & & top(c) & 0.8 & 8001.0 & -5974.6 \\
\hline & & & bot(c) & 2.0 & broken & yield \\
\hline \multirow[t]{12}{*}{74} & 1869.6 & \multirow[t]{12}{*}{0.605} & $\operatorname{top}(d)$ & 3.0 & 3422.0 & - \\
\hline & & & top(d) & 2.0 & broken & - \\
\hline & & & top (d) & 1.4 & 4524.0 & -26821.0 \\
\hline & & & top (c) & 1.1 & 4437.0 & -16558.0 \\
\hline & & & top (c) & 0.6 & 8671.0 & -4926.3 \\
\hline & & & bot(c) & 1.1 & -3741.0 & 16558.0 \\
\hline & 2430.5 & & top(d) & 3.0 & 17313.0 & - \\
\hline & & & top (d) & 2.0 & broken & - \\
\hline & & & top(d) & 1.4 & 7424.0 & -yield \\
\hline & & & top $(c)$ & 1.1 & 25897.0 & -24104.0 \\
\hline & & & top (c) & 0.6 & 14906.0 & -7171.0 \\
\hline & & & bot(c) & 1.1 & -15950.0 & 24104.0 \\
\hline \multirow[t]{10}{*}{75} & 1744.5 & \multirow[t]{10}{*}{0.856} & top(d) & 2.9 & -1133.0 & - \\
\hline & & & top(d) & 2.0 & -1768.0 & - \\
\hline & & & $\operatorname{top}(c)$ & 1.5 & -3219.0 & -16070.4 \\
\hline & & & top $(c)$ & 0.6 & 6728.0 & -2571.3 \\
\hline & & & bot (c) & 1.5 & broken & 16070.4 \\
\hline & 2582.0 & & top(d) & 2.9 & -8468.0 & - \\
\hline & & & top(d) & 2.0 & 1160.0 & - \\
\hline & & & top(c) & 1.5 & 174.0 & -23785.5 \\
\hline & & & top $(c)$ & 0.6 & 8787.0 & -3805.7 \\
\hline & & & bot(c) & 1.5 & broken & 23785.5 \\
\hline
\end{tabular}

Bloct did not fail at 250 kips. (maximum capacity of the pressure transducer)

+ Expected based on bending of plate as a beam.

Table 9: Stresses in bearing plates (Ultimate load tests) 


\begin{tabular}{|c|c|c|c|c|c|c|}
\hline \multirow[b]{2}{*}{$\begin{array}{l}\text { Test } \\
\text { No. }\end{array}$} & \multirow{2}{*}{$\begin{array}{l}\text { Uniformly } \\
\text { distributed } \\
\text { stress(psi.) }\end{array}$} & \multirow{2}{*}{$\begin{array}{c}\text { Bearing Pl. } \\
\text { thickness } \\
\text { (in.) }\end{array}$} & \multicolumn{2}{|c|}{ Strain gage } & \multicolumn{2}{|c|}{ Stress } \\
\hline & & & location & $\begin{array}{l}\text { overhang } \\
\text { (in.). }\end{array}$ & $\begin{array}{l}\text { measured } \\
\text { (psi.) }\end{array}$ & $\begin{array}{l}\text { expected } \\
\text { (psi.) }\end{array}$ \\
\hline \multirow[t]{4}{*}{76} & 1472.0 & \multirow[t]{4}{*}{0.685} & top (d) & 3.5 & -1914.0 & - \\
\hline & & & $\operatorname{top}(c)$ & 1.75 & -319.0 & -28822.0 \\
\hline & 2033.2 & & top(d) & 3.5 & -2668.0 & - \\
\hline & & & top $(c)$ & 1.75 & 899.0 & -yield \\
\hline \multirow[t]{10}{*}{77} & 1009.5 & \multirow[t]{10}{*}{0.315} & top(d) & 3.5 & 6554.0 & - \\
\hline & & & top (d) & 2.25 & 2523.0 & - \\
\hline & & & top (c) & 1.75 & 11107.0 & - yield \\
\hline & & & top(c) & 0.6 & 3770.0 & -10987.8 \\
\hline & & & bot(c) & 1.75 & -13340.0 & yield \\
\hline & 1356.4 & & top(d) & 3.5 & 8555.0 & - \\
\hline & & & top (d) & 2.25 & 3770.0 & - \\
\hline & & & top (c) & 1.75 & 15196.0 & -yield \\
\hline & & & top (c) & 0.6 & 5278.0 & -14763.5 \\
\hline & & & bot (c) & 1.75 & -18995.0 & yield \\
\hline
\end{tabular}

+ Expected stress based on bending of plate as a beam.

Table 9(continued): Stresses in bearing plates (Ultimate load tests)

\begin{tabular}{||c|c|c|c|c|c||}
\hline \hline $\begin{array}{c}\text { Test } \\
\text { No. }\end{array}$ & $\begin{array}{c}\text { Load } \\
\text { (kips.) }\end{array}$ & $\begin{array}{c}\text { Stress } \\
\text { (psi.) }\end{array}$ & $\begin{array}{c}\text { Lond } \\
\text { (kips.) }\end{array}$ & $\begin{array}{c}\text { Stress } \\
\text { (psi.) }\end{array}$ \\
\hline \hline 73 & 163.1 & 3103.0 & & 248.2 & 6757.0 \\
\hline 74 & 98.3 & 1943.0 & & 143.2 & 2813.0 \\
\hline 75 & 102.2 & 6467.0 & & 151.3 & 10904.0 \\
\hline 76 & 110.5 & 2407.0 & & 152.7 & 7076.0 \\
\hline 77 & 75.8 & 986.0 & & 101.8 & 1421.0 \\
\hline
\end{tabular}

Table 10: Stress in top horizontal rebar (ultimate load tests) 


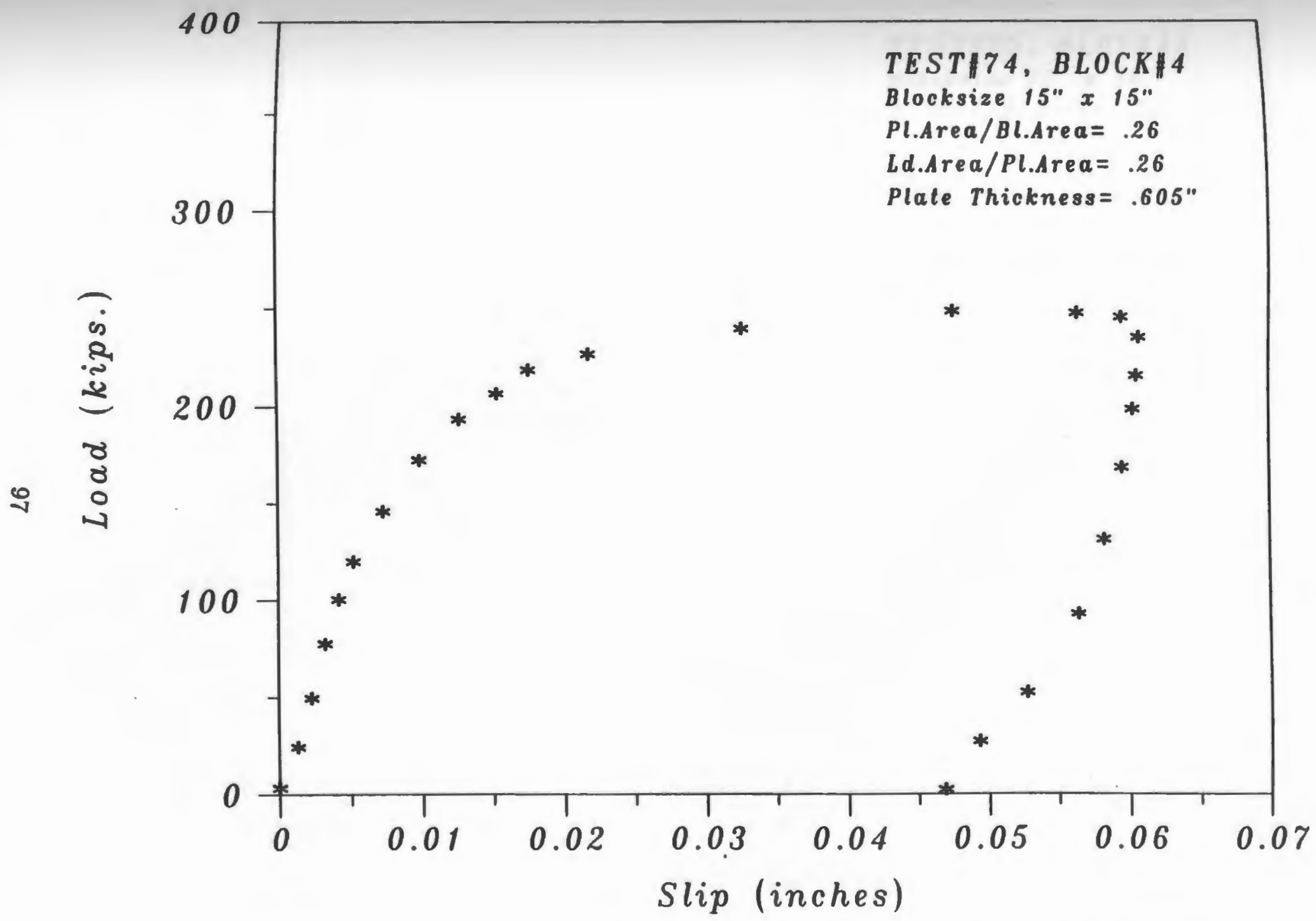

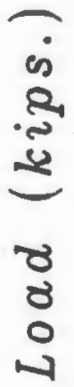

Fig.106: SLIP OF PLATE EDGE RELATIVE TO CONCRETE 


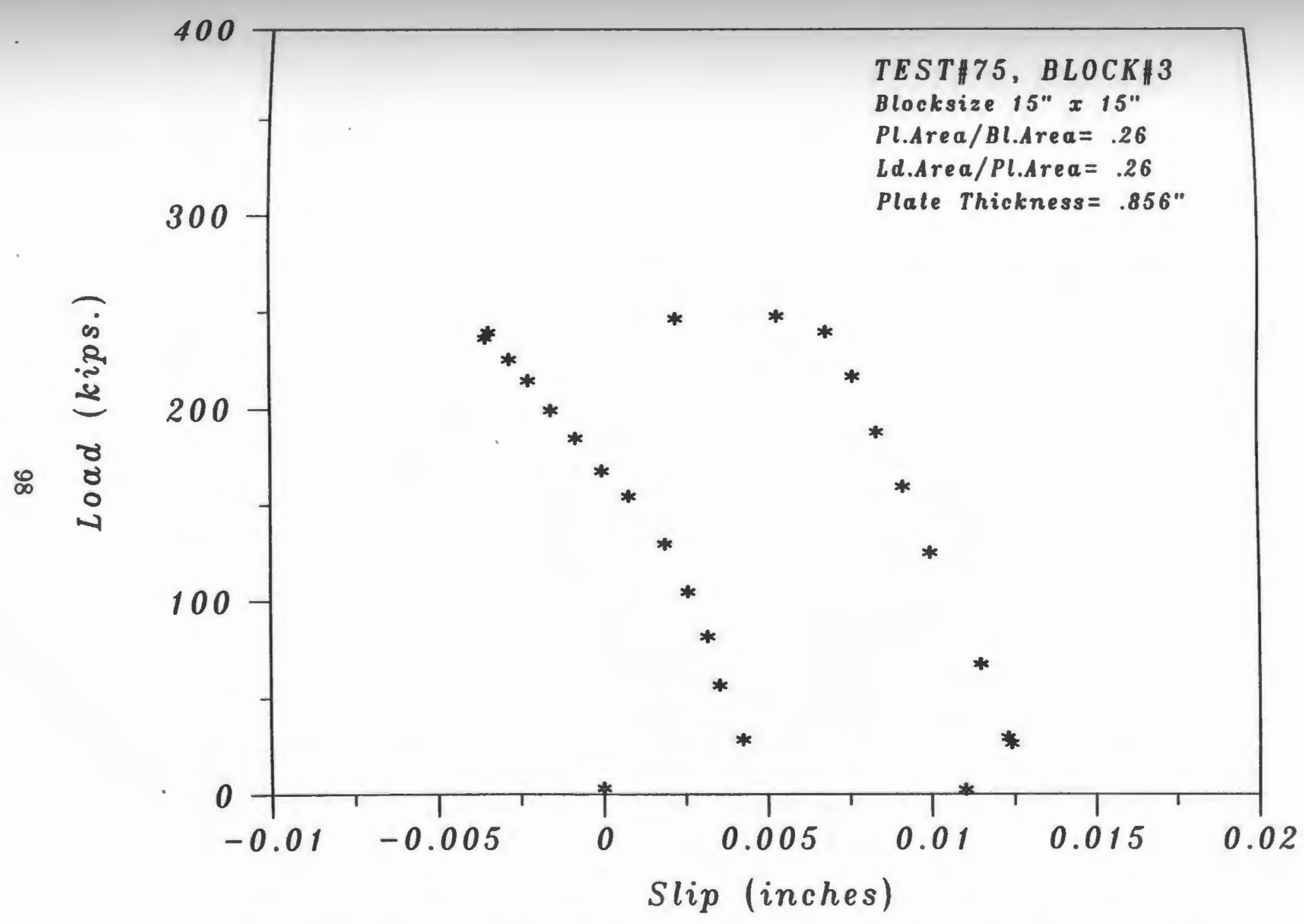

0
0
0
3
3
7
0
0
0

Fig.107: SLIP OF PLATE EDGE RELATIVE TO CONCRETE 


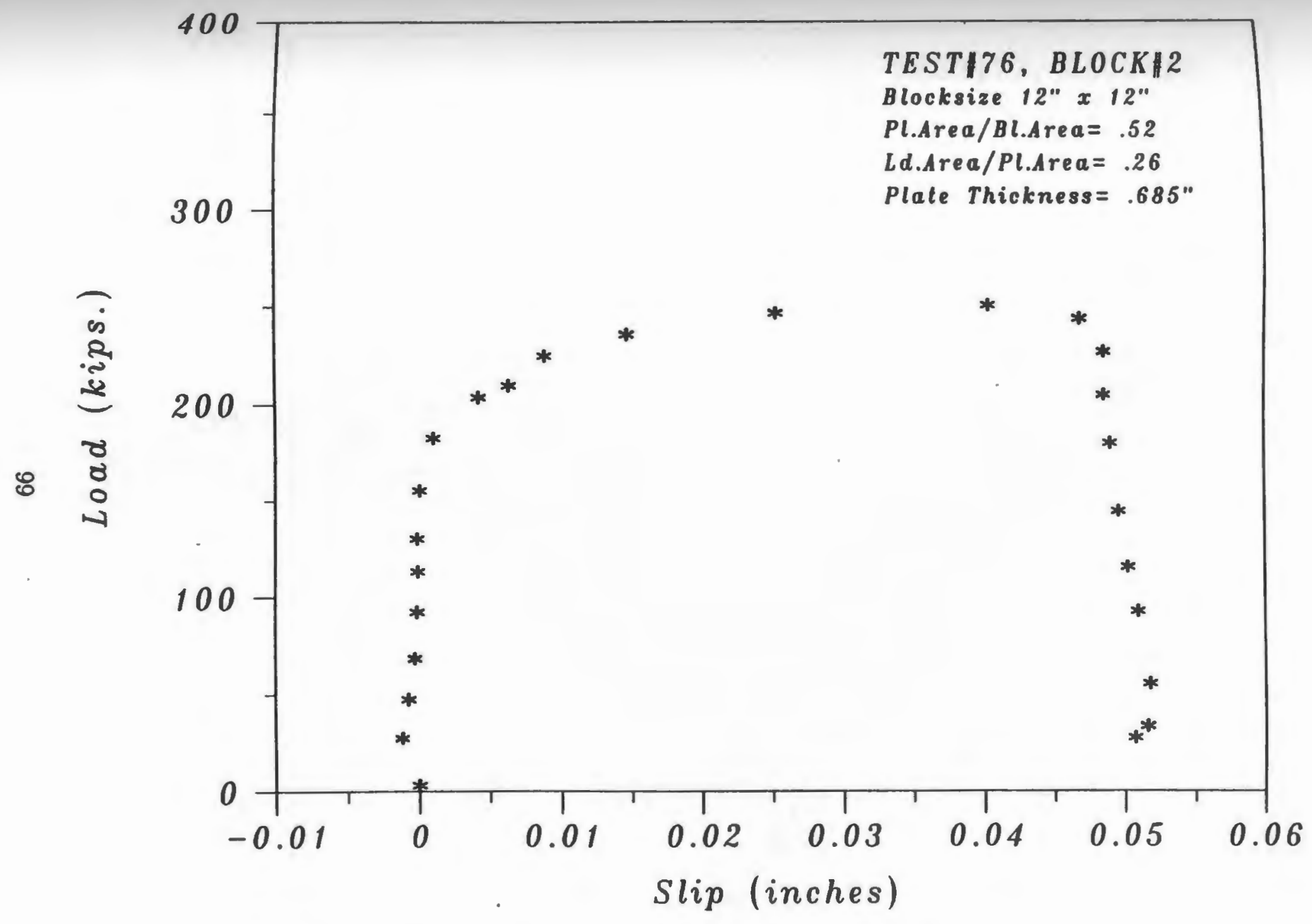

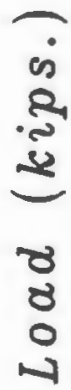

Fig.108: SLIP OF PLATE EDGE RELATIVE TO CONCRETE 


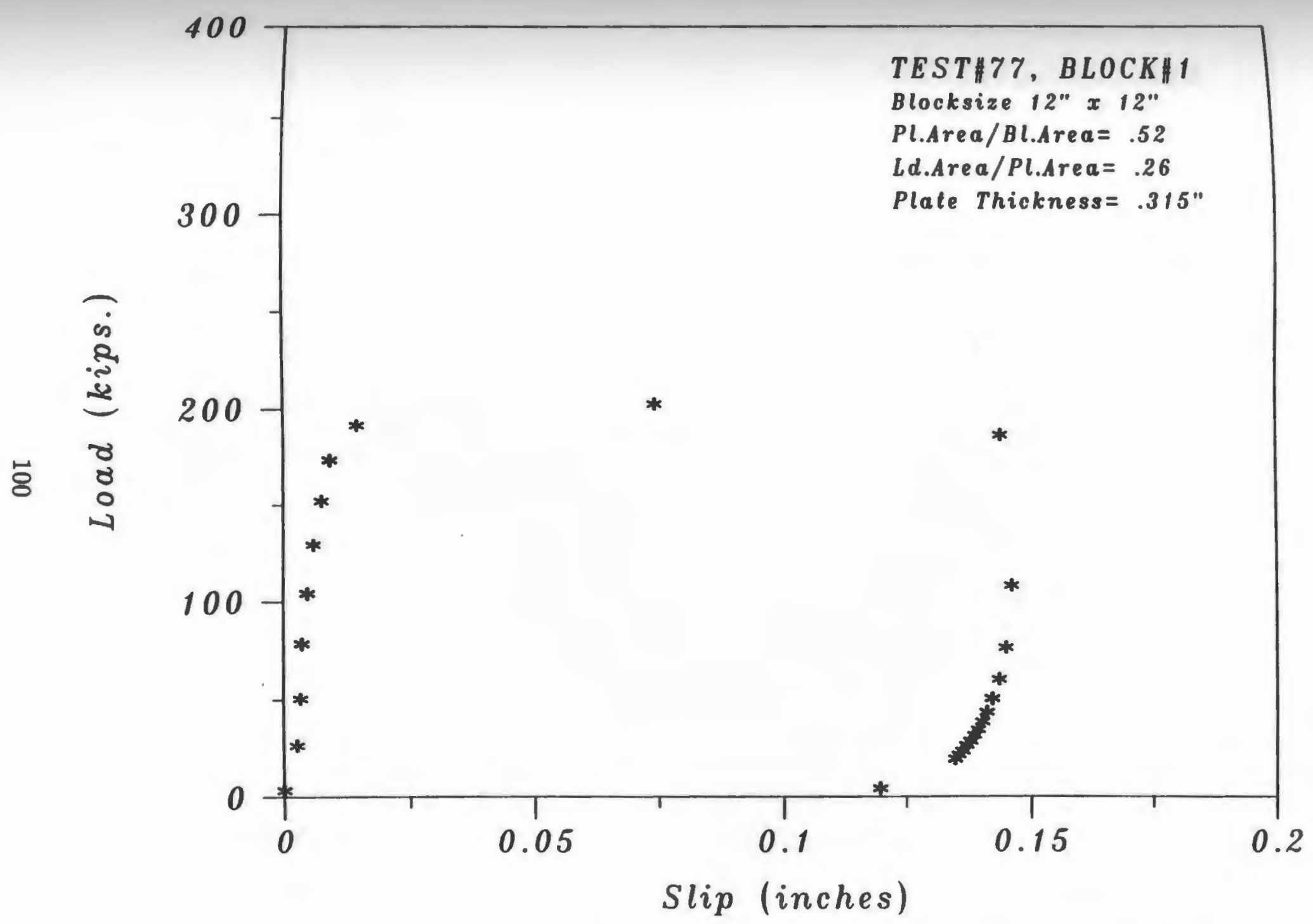

20
2
3
3
0
0
0
0

Fig.109: SLIP OF PLATE EDGE RELATIVE TO CONCRETE 


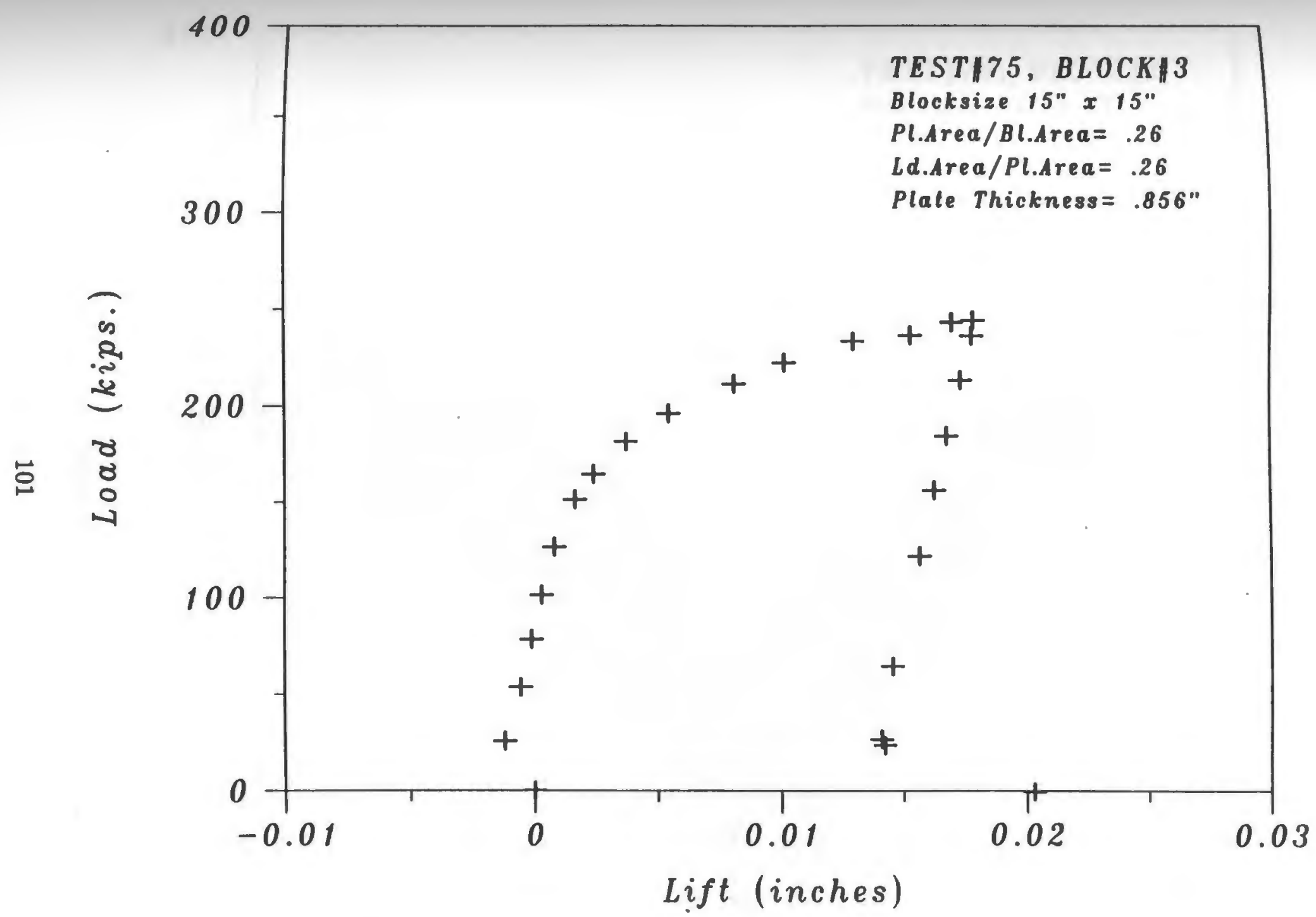

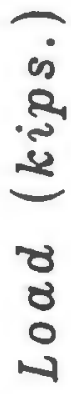

Fig.110: LIFT OF PLATE CORNER RELATIVE TO CONCRETE 


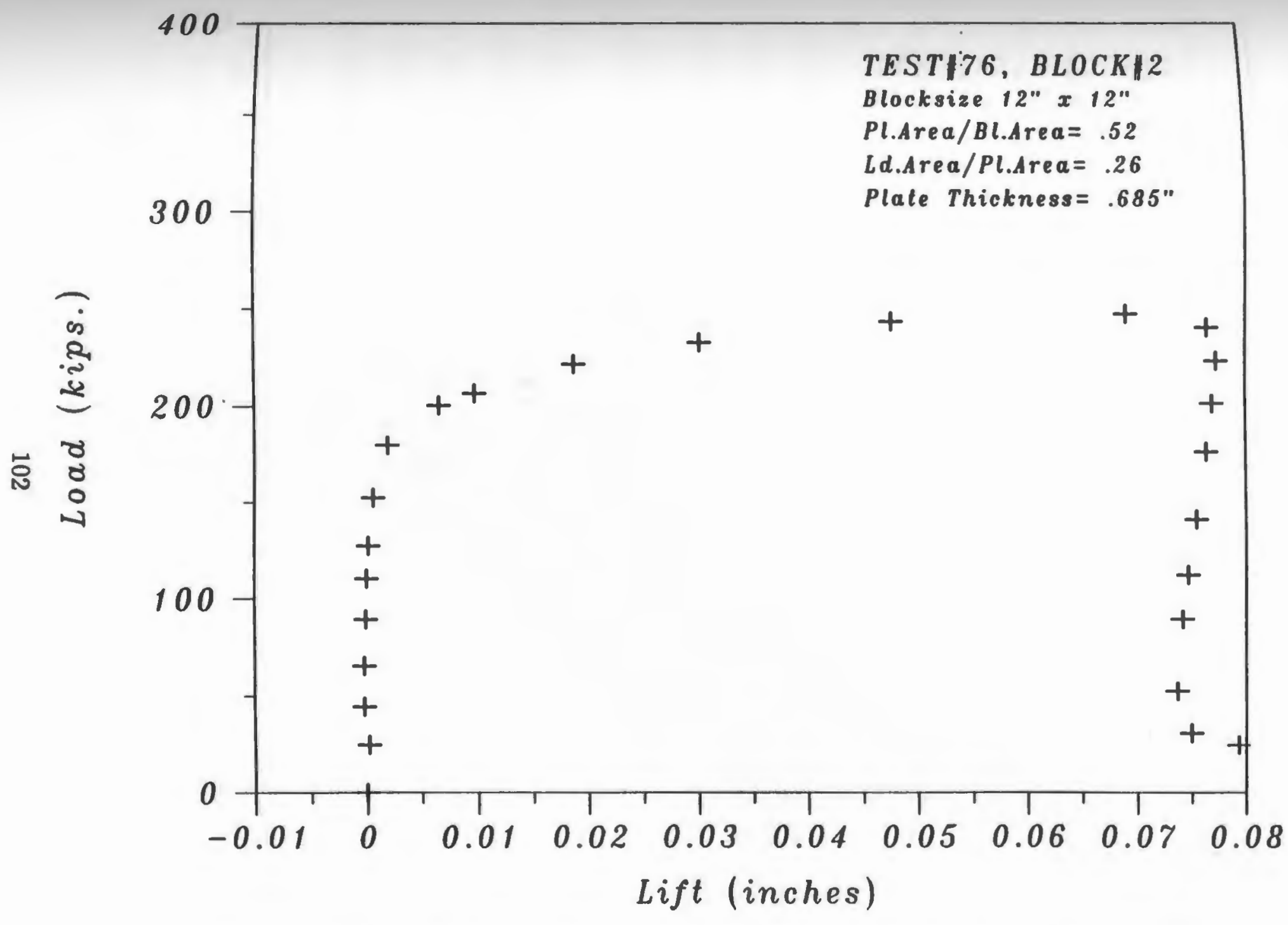

के
3
3
0
0
0
0

Fig.111: LIFT OF PLATE CORNER RELATIVE TO CONCRETE 


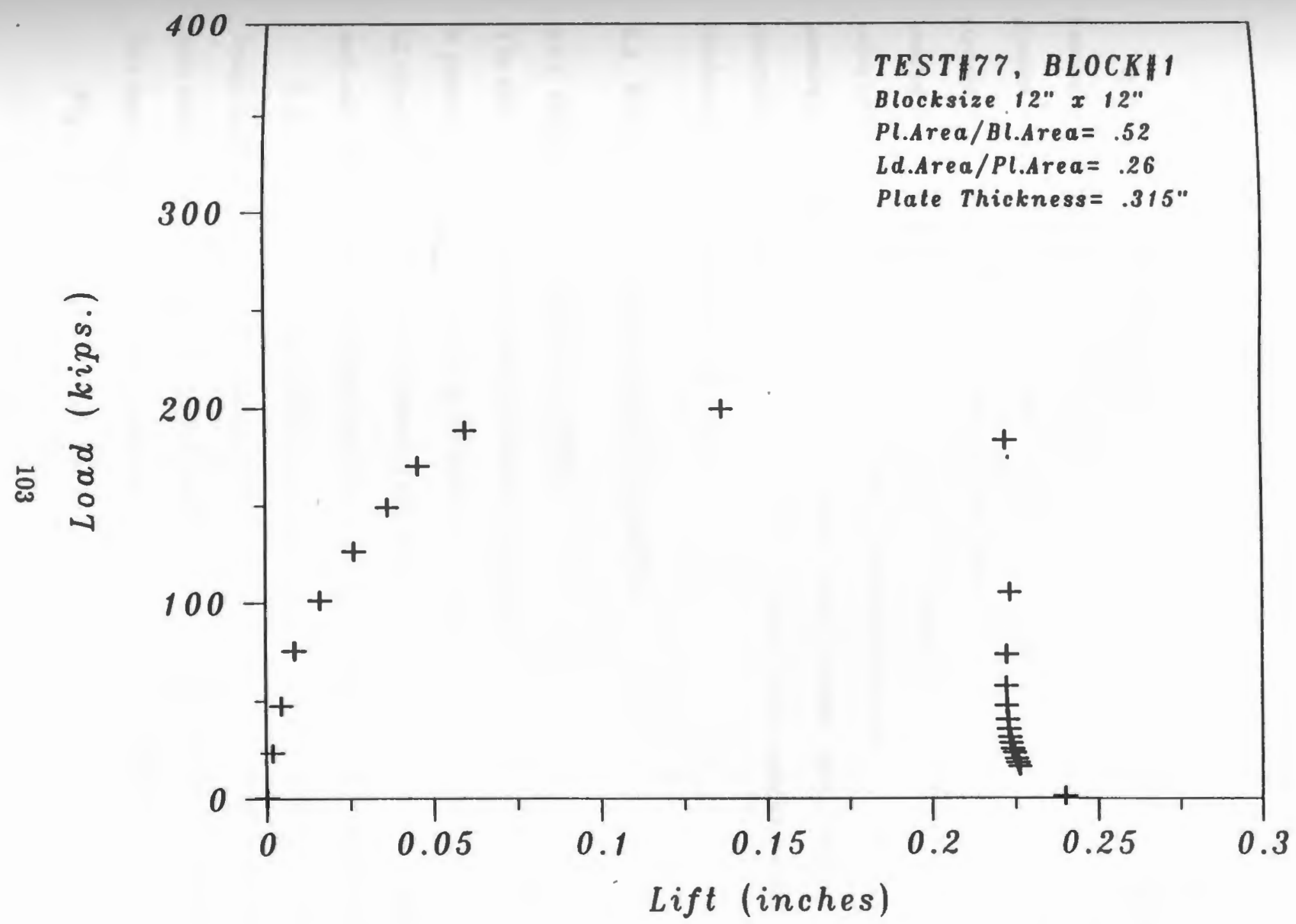

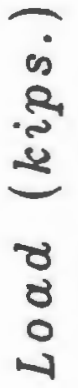

Fig.112: LIFT OF PLATE CORNER RELATIVE TO CONCRETE 


\section{CHAPTER 4}

\section{DISCUSSION OF RESULTS}

It is very clear from the test results that the stress distribution beneath the bearing plate is not uniform but rather is parabolic in nature. In most cases, the stresses occuring close to the center, are almost two to three times the expected stresses based on the expected uniform distribution. The stresses occuring in the bearing plate are quite lower than expected. The results indicate that the load is being carried on to the concrete substructure with little bending in the plate. The bearing plate edges lift up from the concrete due to localized high strains in the concrete and steel beneath the loaded area. The effects of the various parameters involved in the study are described below.

\subsection{WORKING STRESS RANGE TESTS:}

\subsubsection{EFFECT OF PLATE THICKNESS:}

The effect of plate thickness can be observed in Figs. 113 thru 130 . The stress ratio is plotted varying with distance from the center for different plate thicknesses, while all other parameters remain the same. The distribution of stresses can be compared and seen that for almost all cases maximum stresses decrease as thickness increases.

It is evident that there is negligible effect of plate thickness on the stress distribution for higher load area to plate area ratios, whereas for lower load area to plate area ratios the stress ratio decreased quite a bit for higher thicknesses. However, this decrease in stress is evident only close to the center and under the loaded area.

Figs. 131, 132, and 133 show the effect of thickness on the maximum stress 


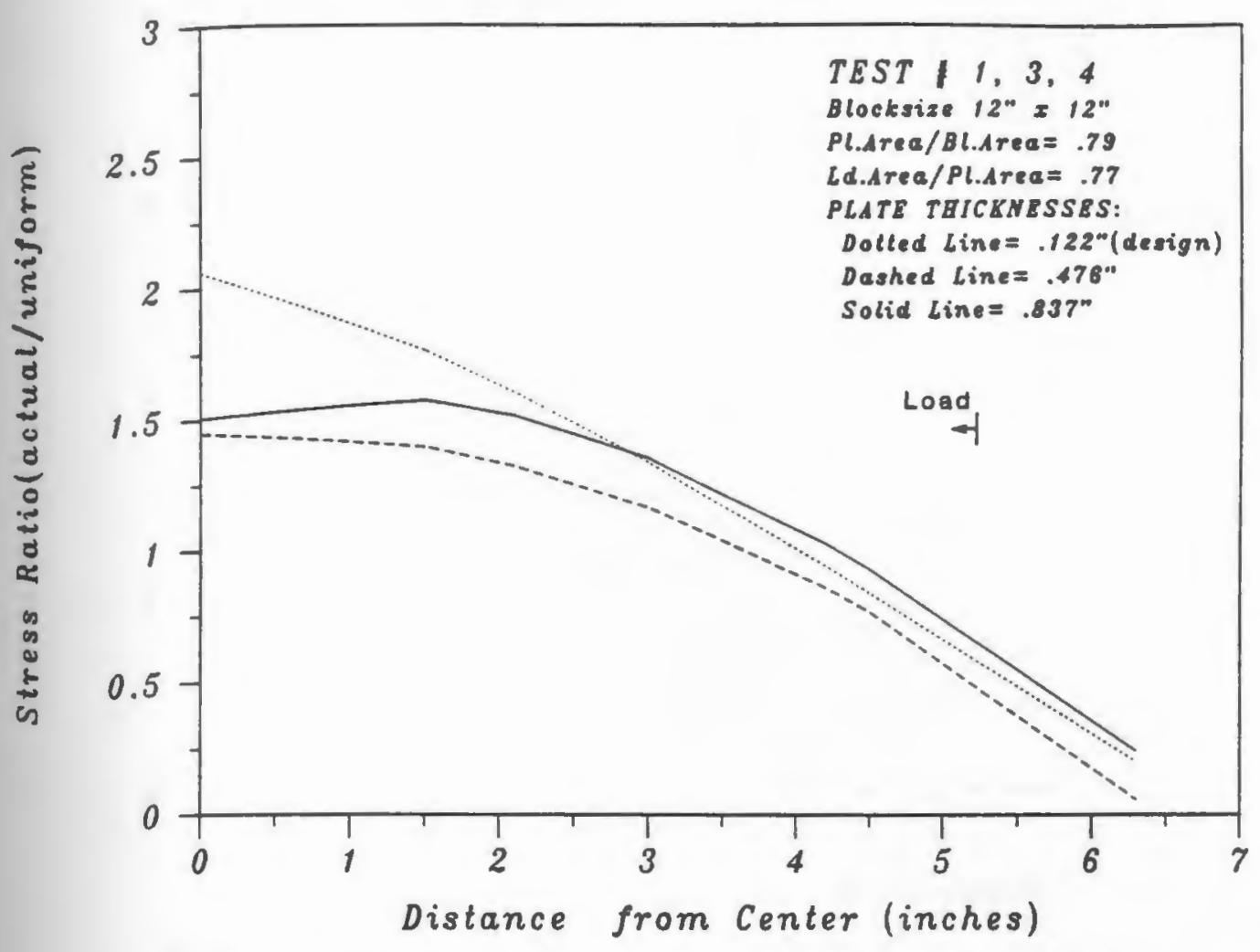

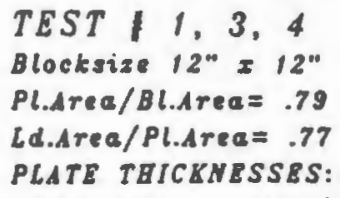

Dotted Line $=.122^{\circ 1}$ (design)

Dashed Line $=.476^{\circ}$

Solid Line $=.837^{\circ}$

Fig.113: EFFECT OF PLATE THICKNESS (Block 1)

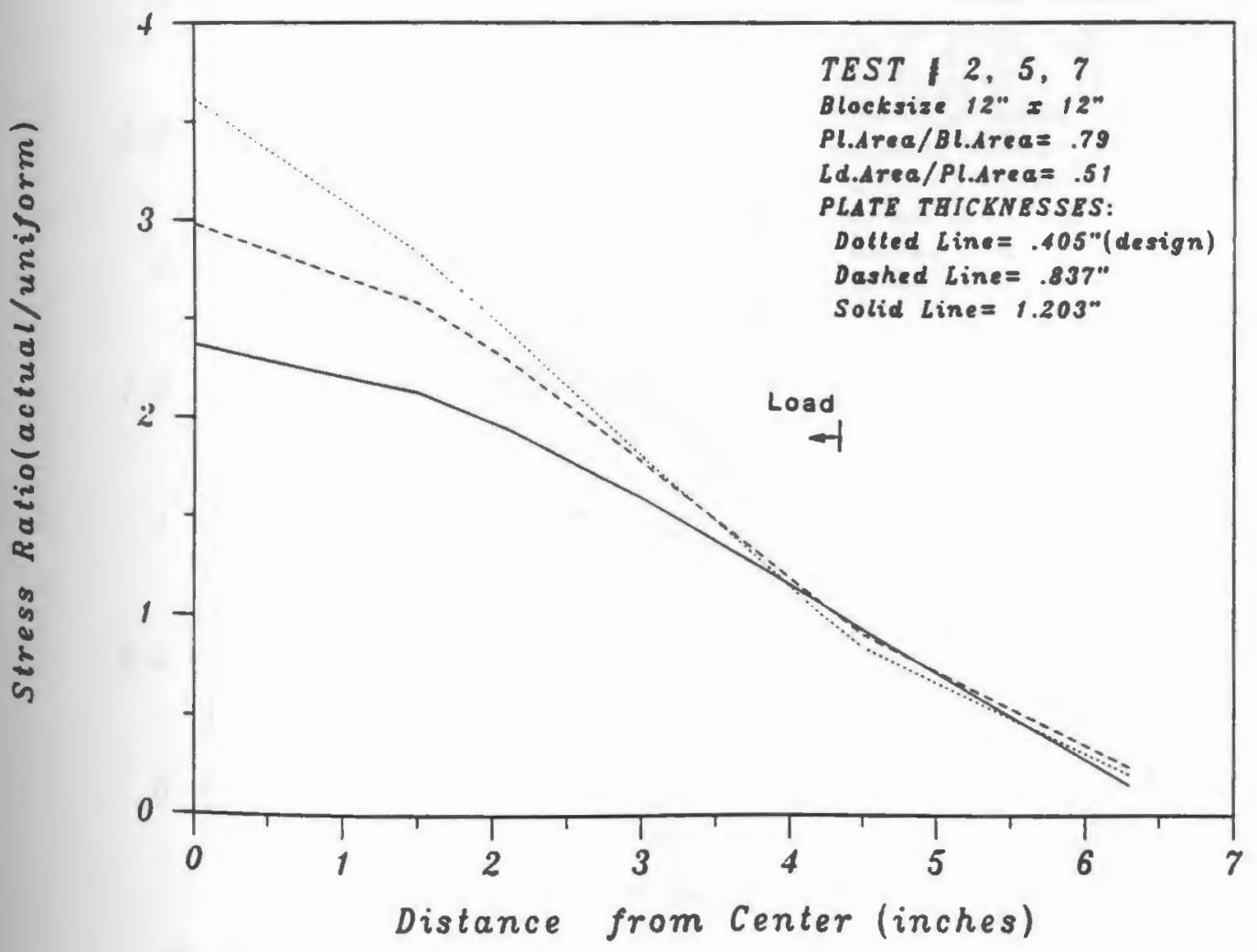

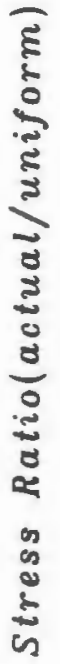

Fig.114: EFFECT OF PLATE THICKNESS (Block t) 


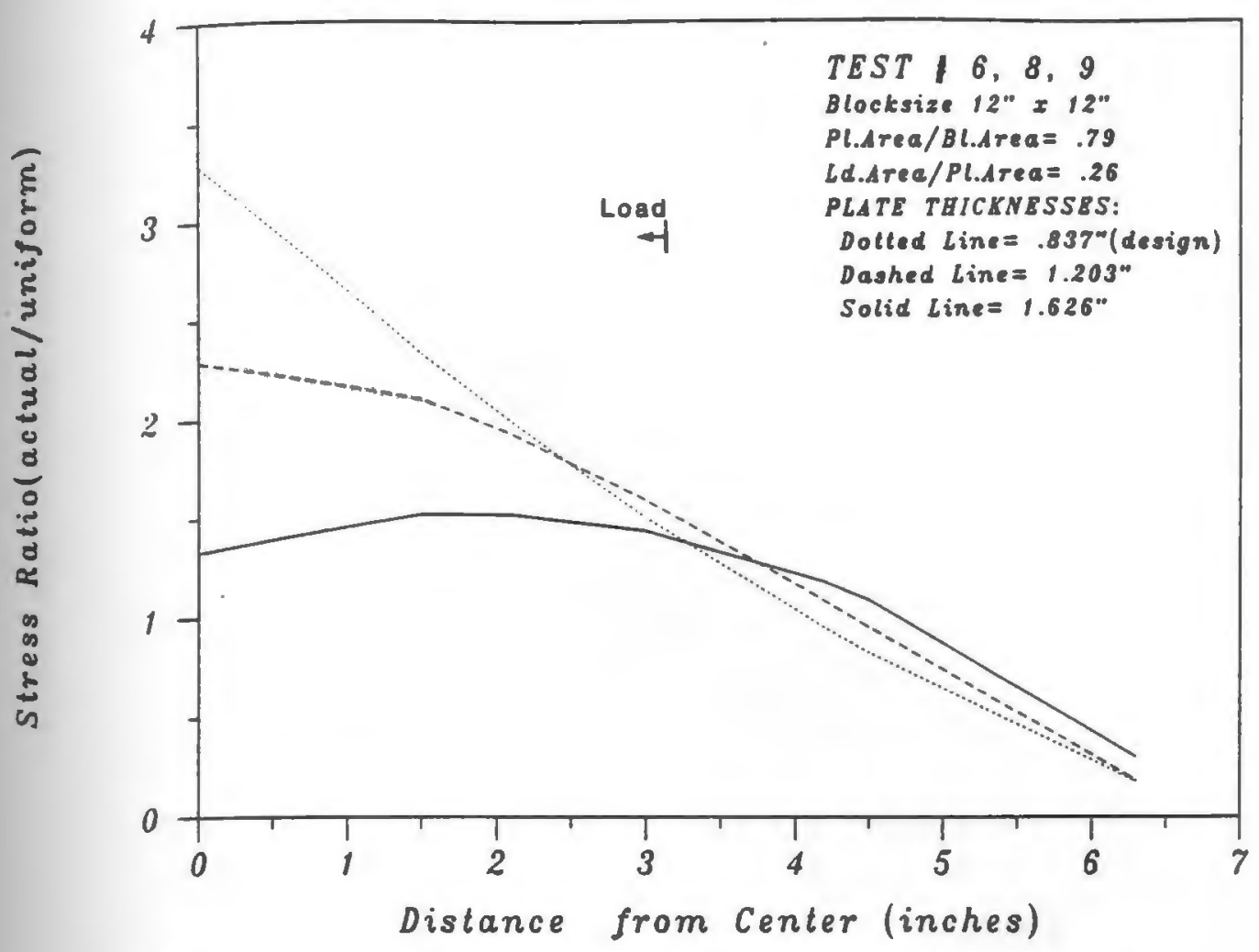

है

Fig.115: EFFECT OF PLATE THICKNESS (Block 1)

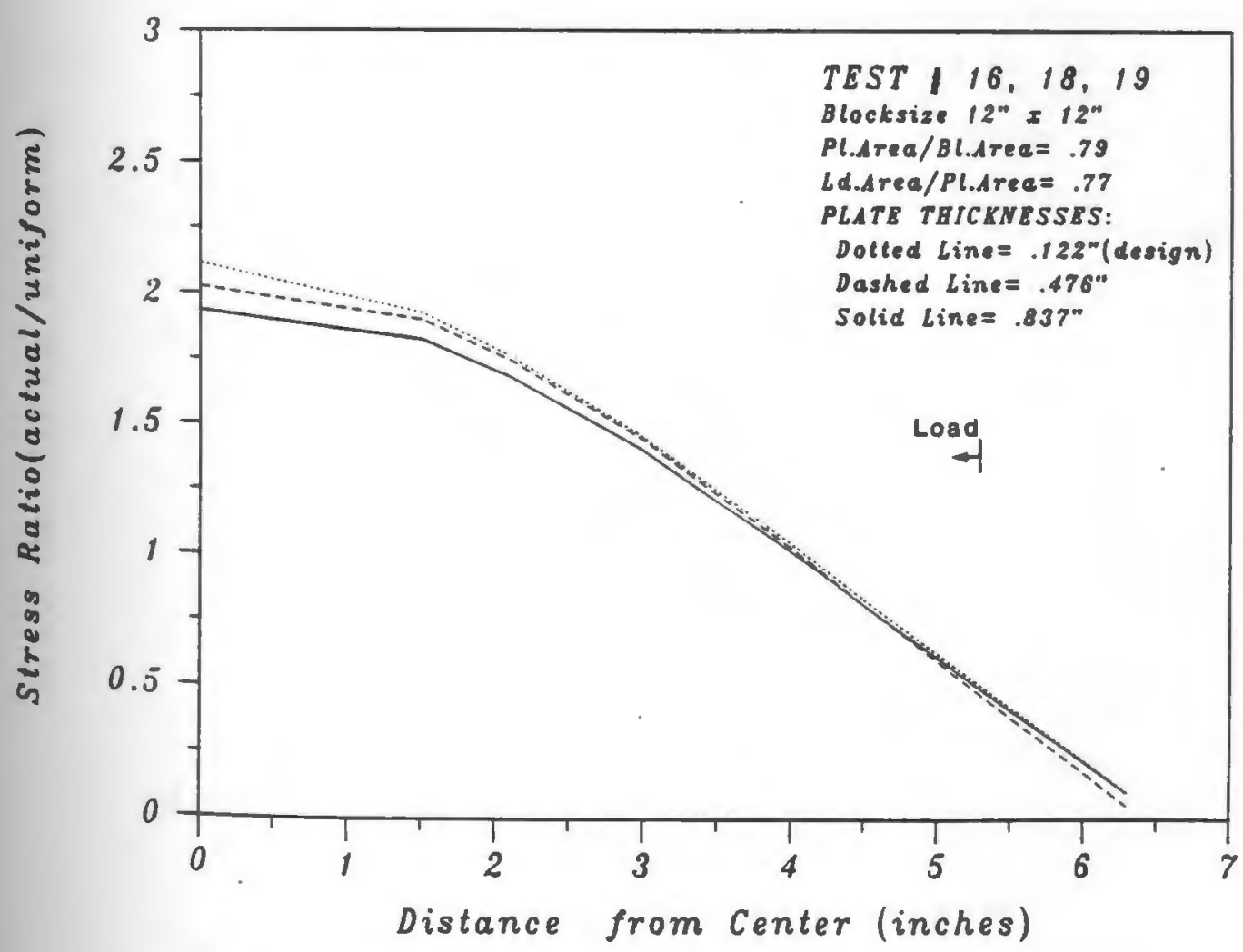

है

Fig.116: EFFECT OF PLATE THICKNESS (Block 2) 


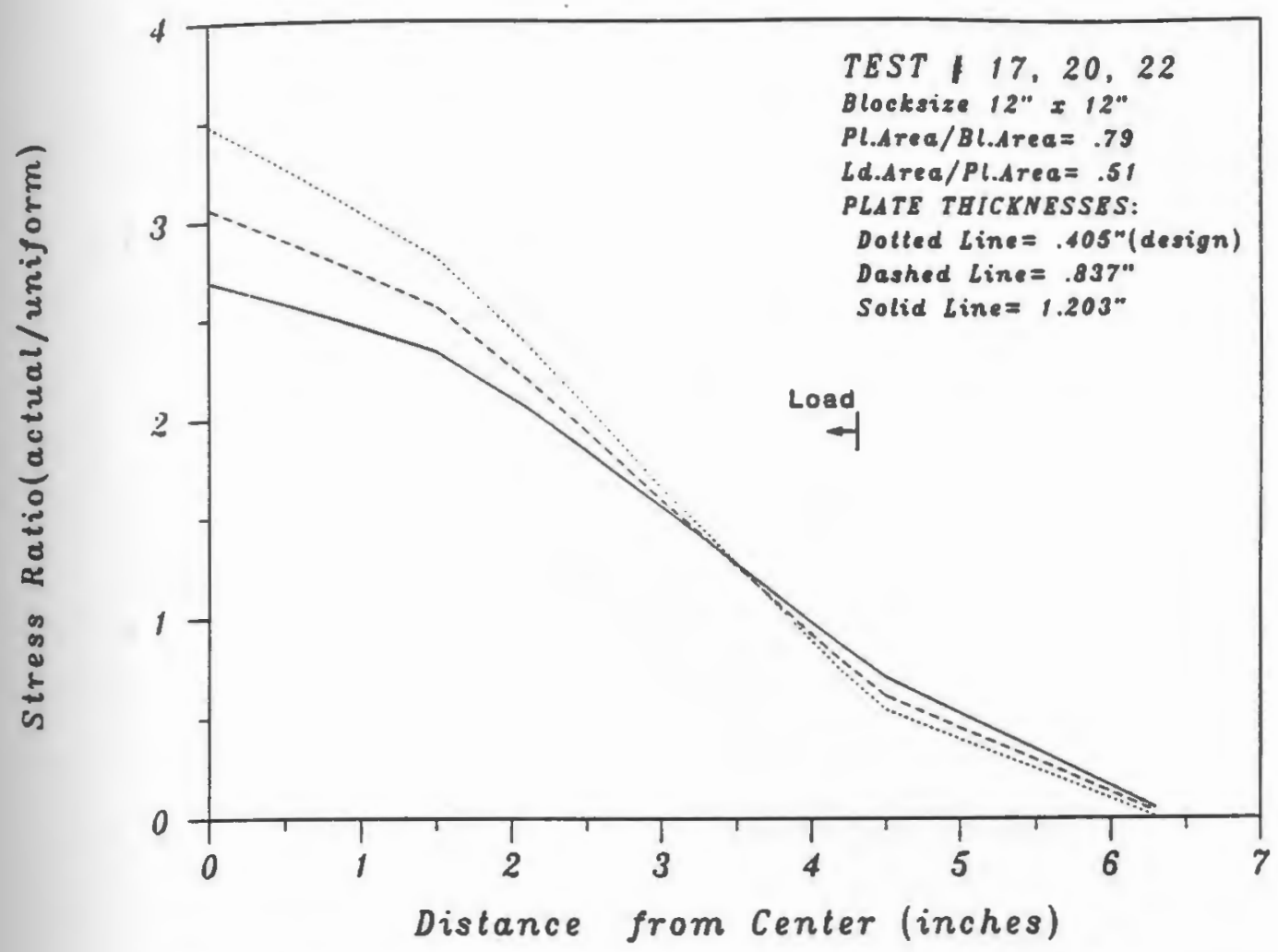

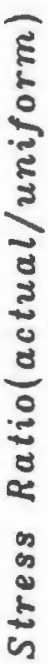

Fig.117: EFFECT OF PLATE THICKNESS (Block 2)

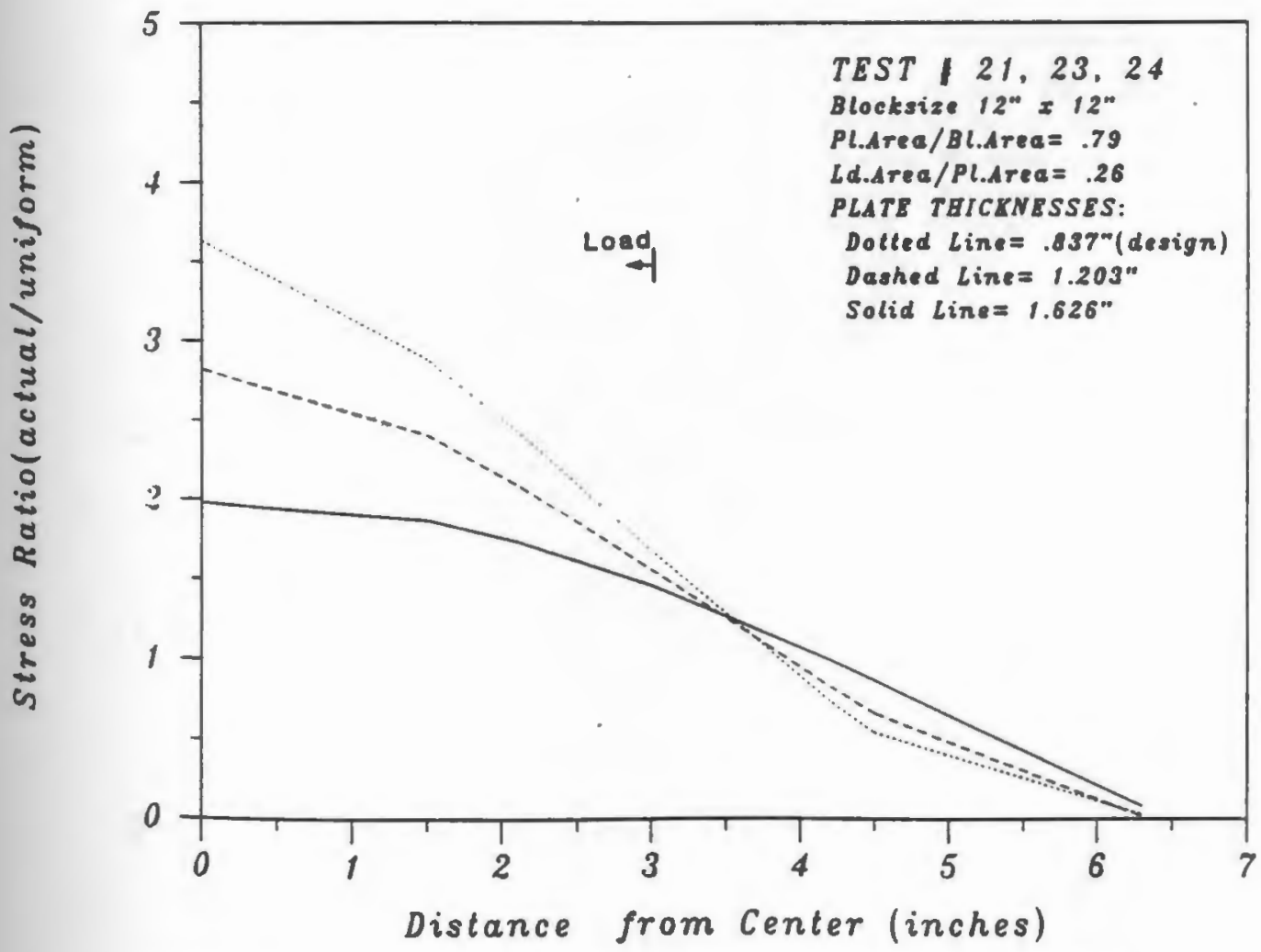

है

Fig.118: EFFECT OF PLATE THICKNESS (Block 2) 107 


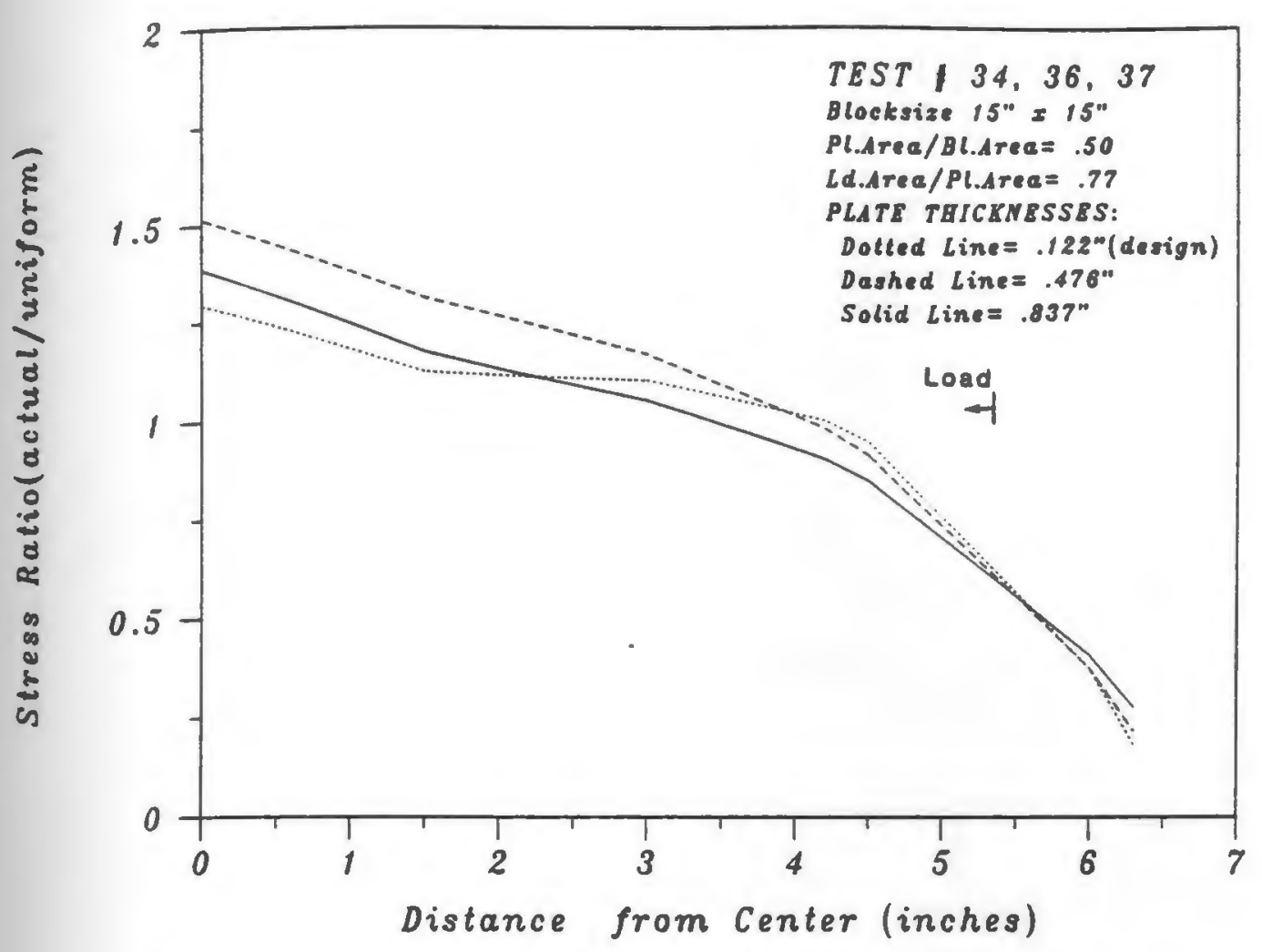

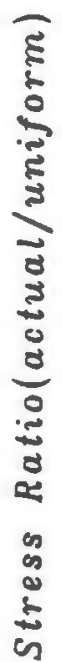

Fig.119: EFFECT OF PLATE THICKNESS (Block 3)

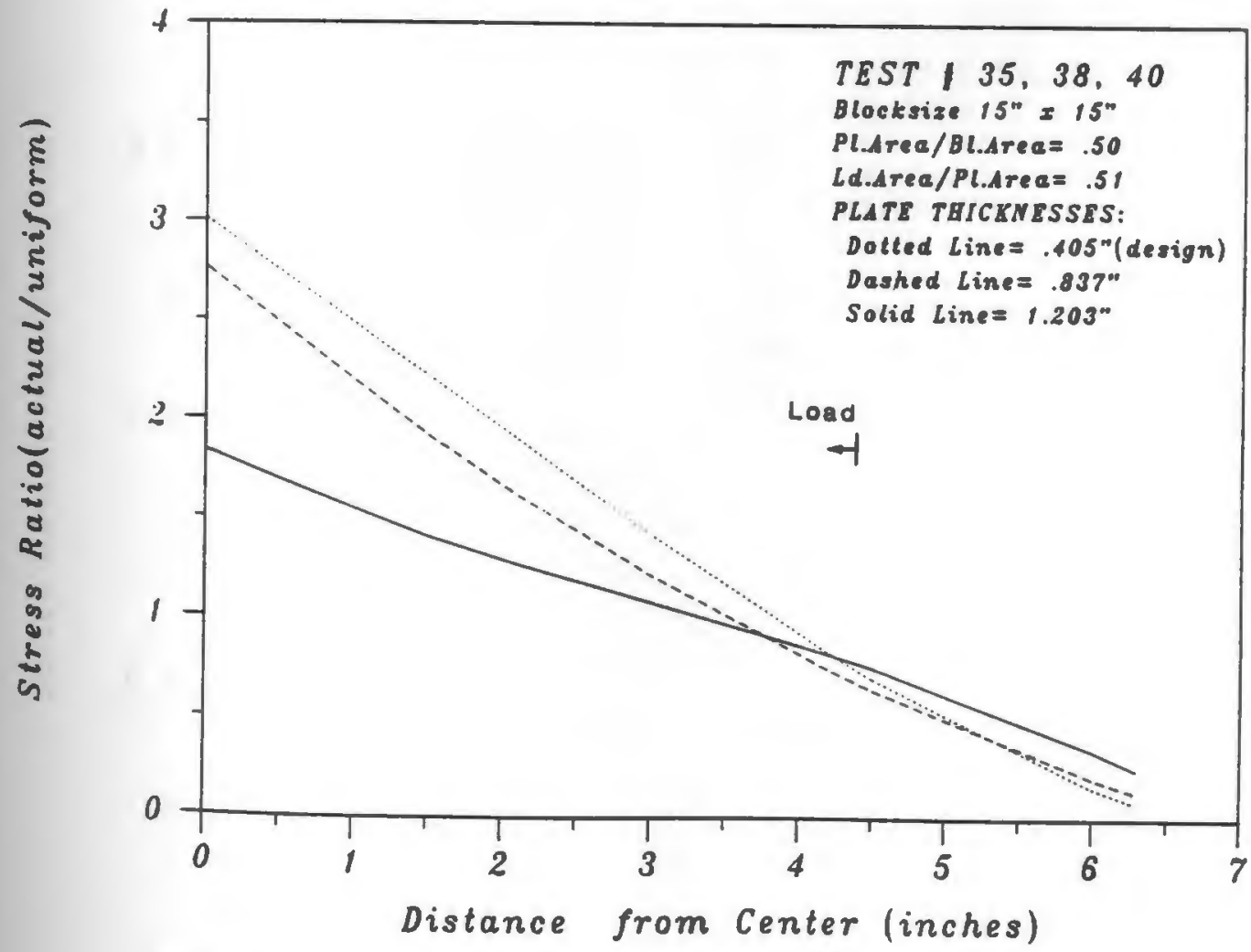

0
5
0
0
0
0
0
5
0
0
0
0
0
0
0
0
0
0
0
0
0

Fig.120: EFFECT OF PLATE THICKNESS (Block 3) 108 


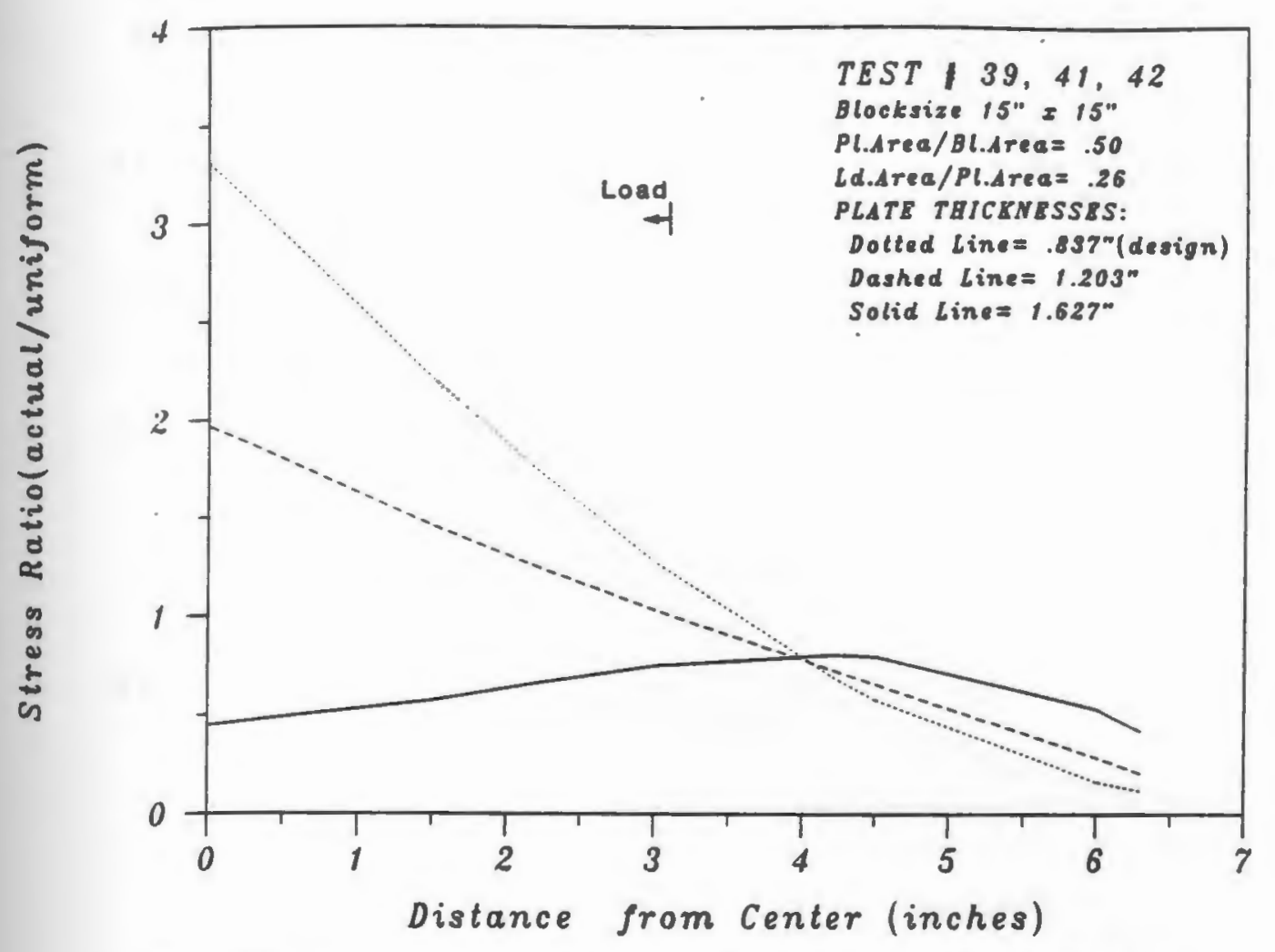

है

Fig.121: EFFECT OF PLATE THICKNESS (Block 3)

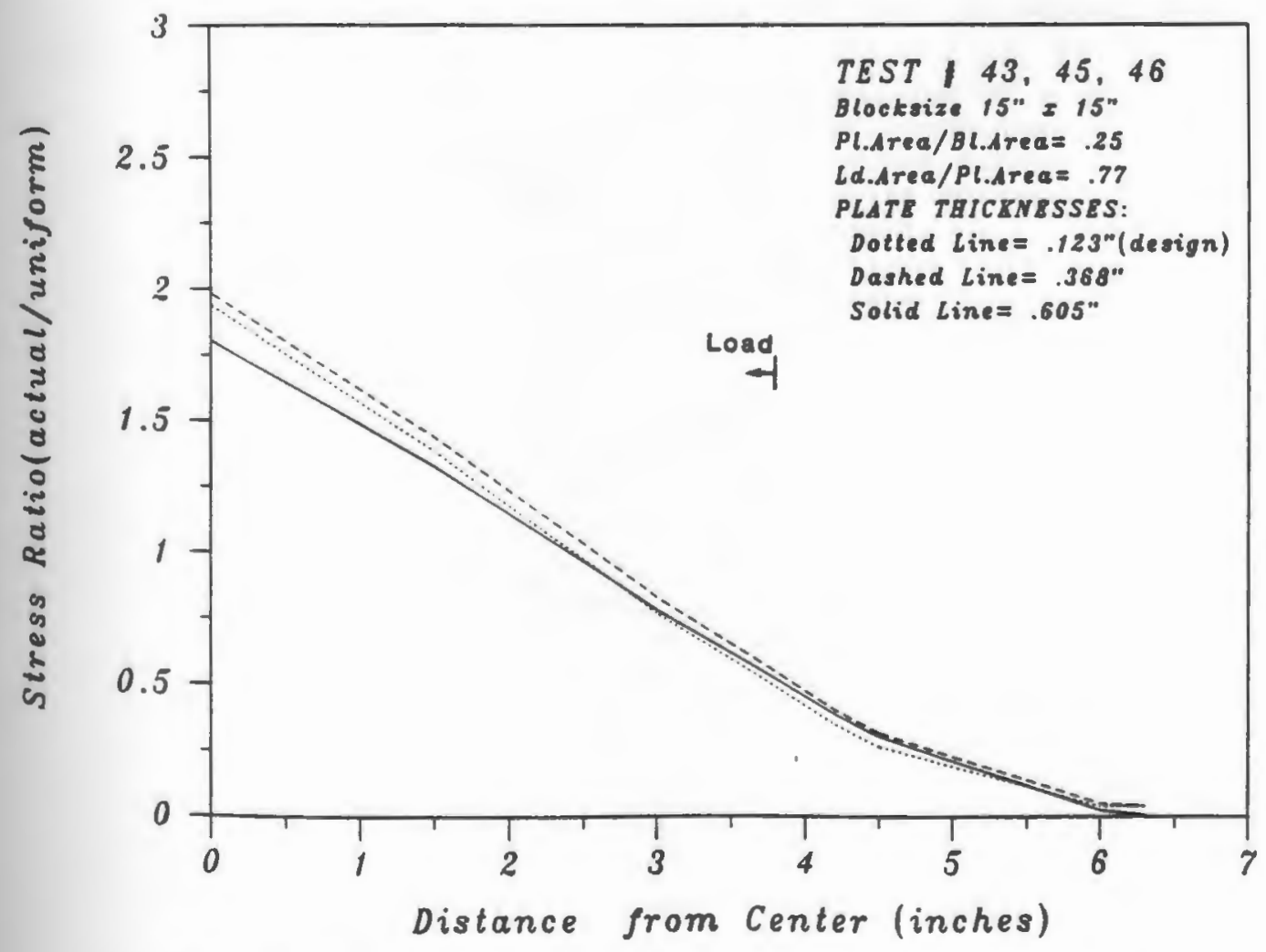

है

Fig.122: EFFECT OF PLATE THICKNESS (Block 3) 


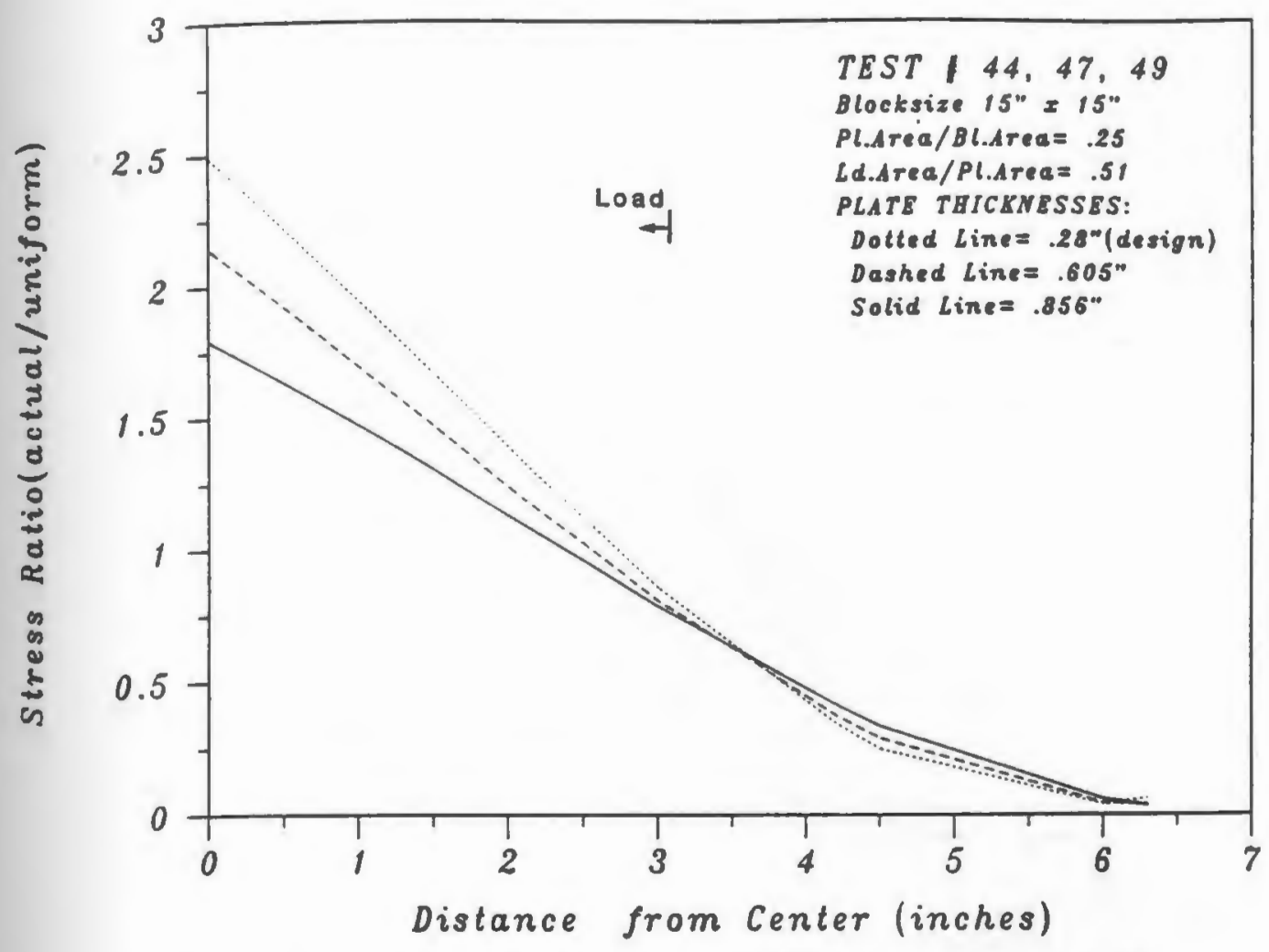

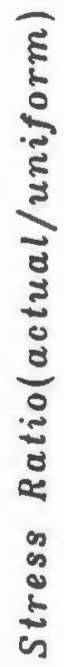

Fig.123: EFFECT OF PLATE THICKNESS (Block 3)

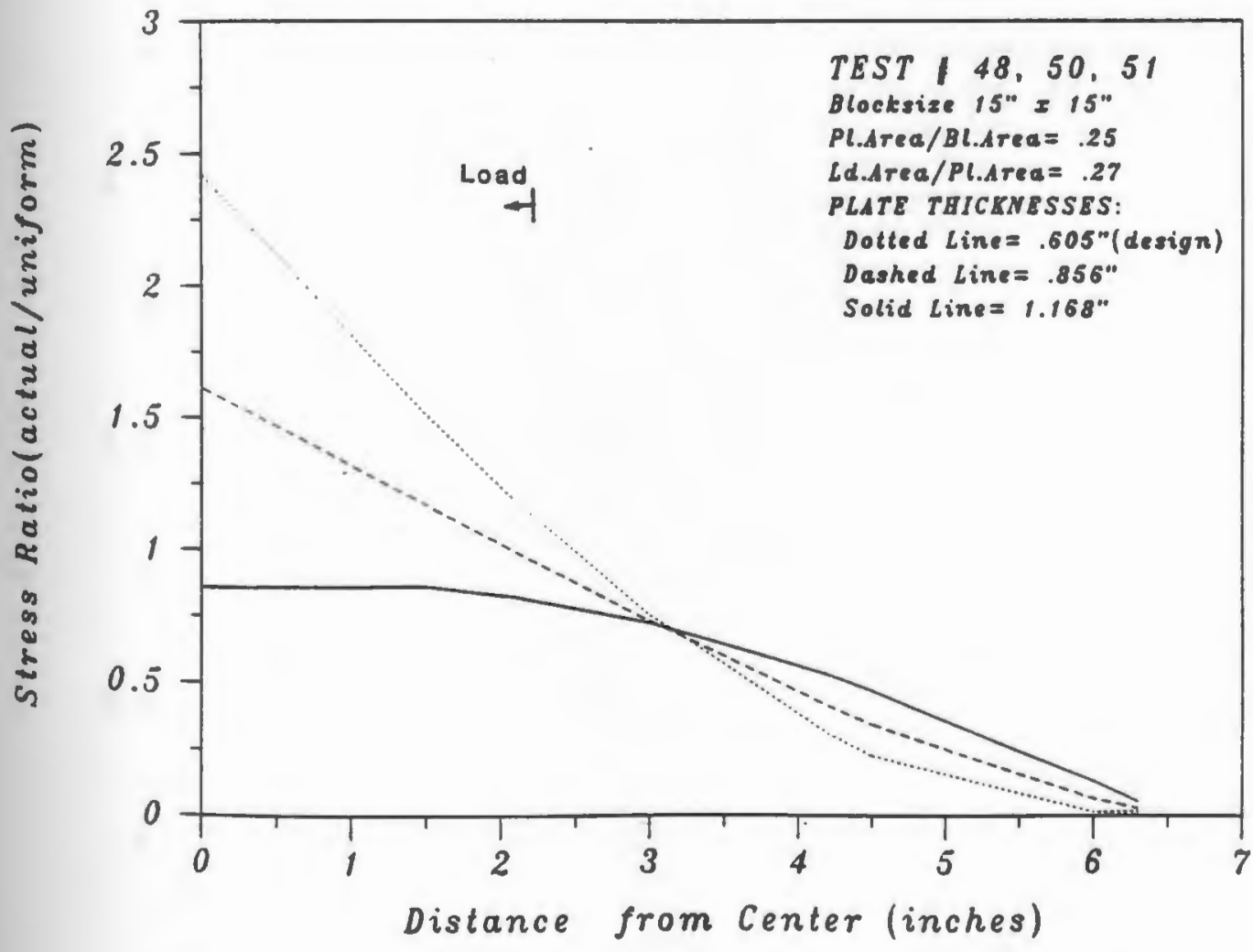

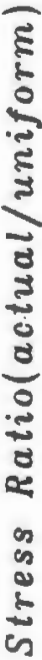

Fig.124: EFFECT OF PLATE THICKNESS (Block 3) 


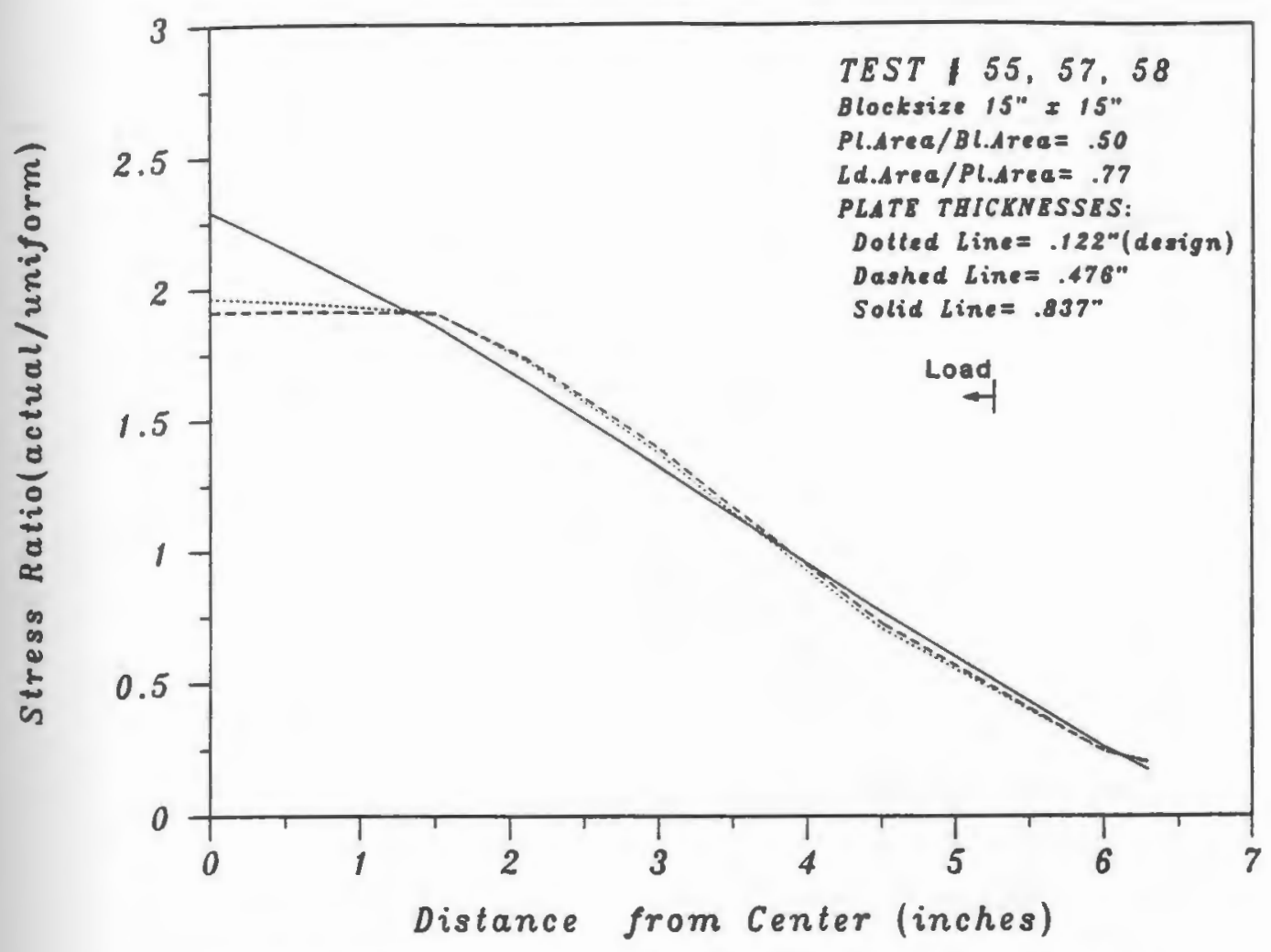

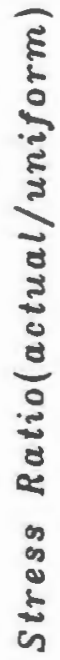

Fig.125: EFFECT OF PLATE THICKNESS (Block \#4)

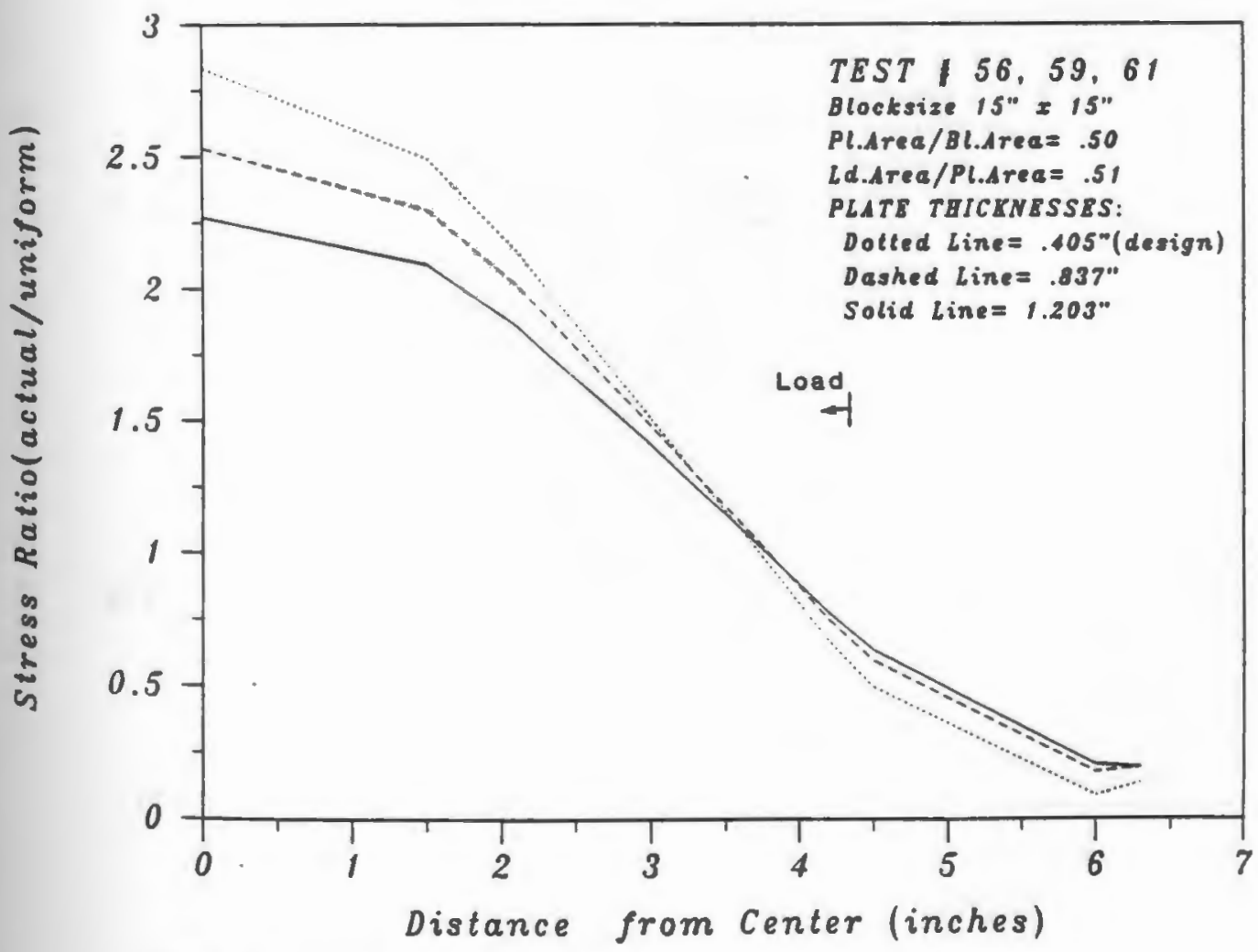

है

Fig.126: EFFECT OF PLATE THICKNESS (Block 4) 


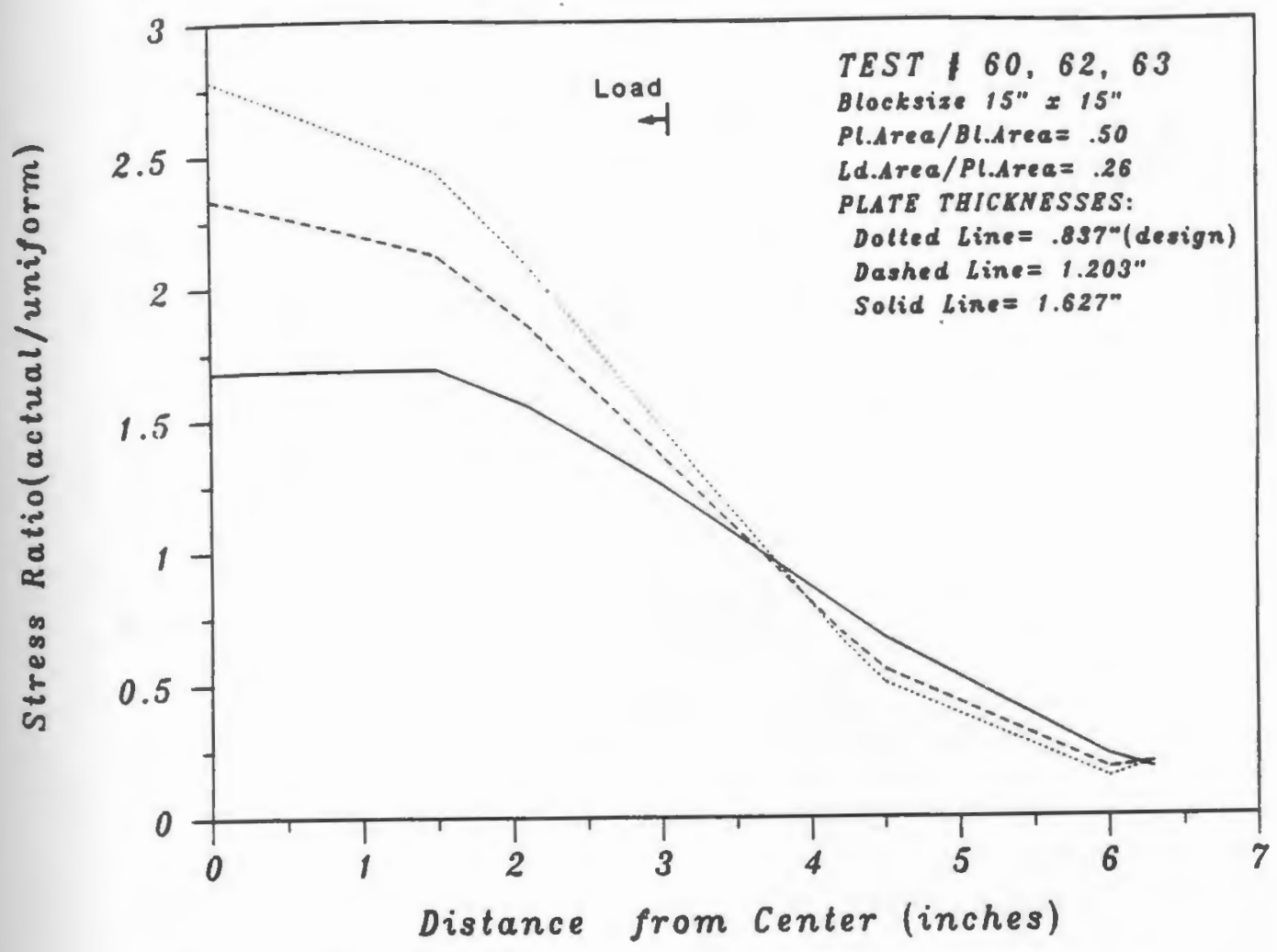

है

Fig.127: EFFECT OF PLATE THICKNESS (Block 4)

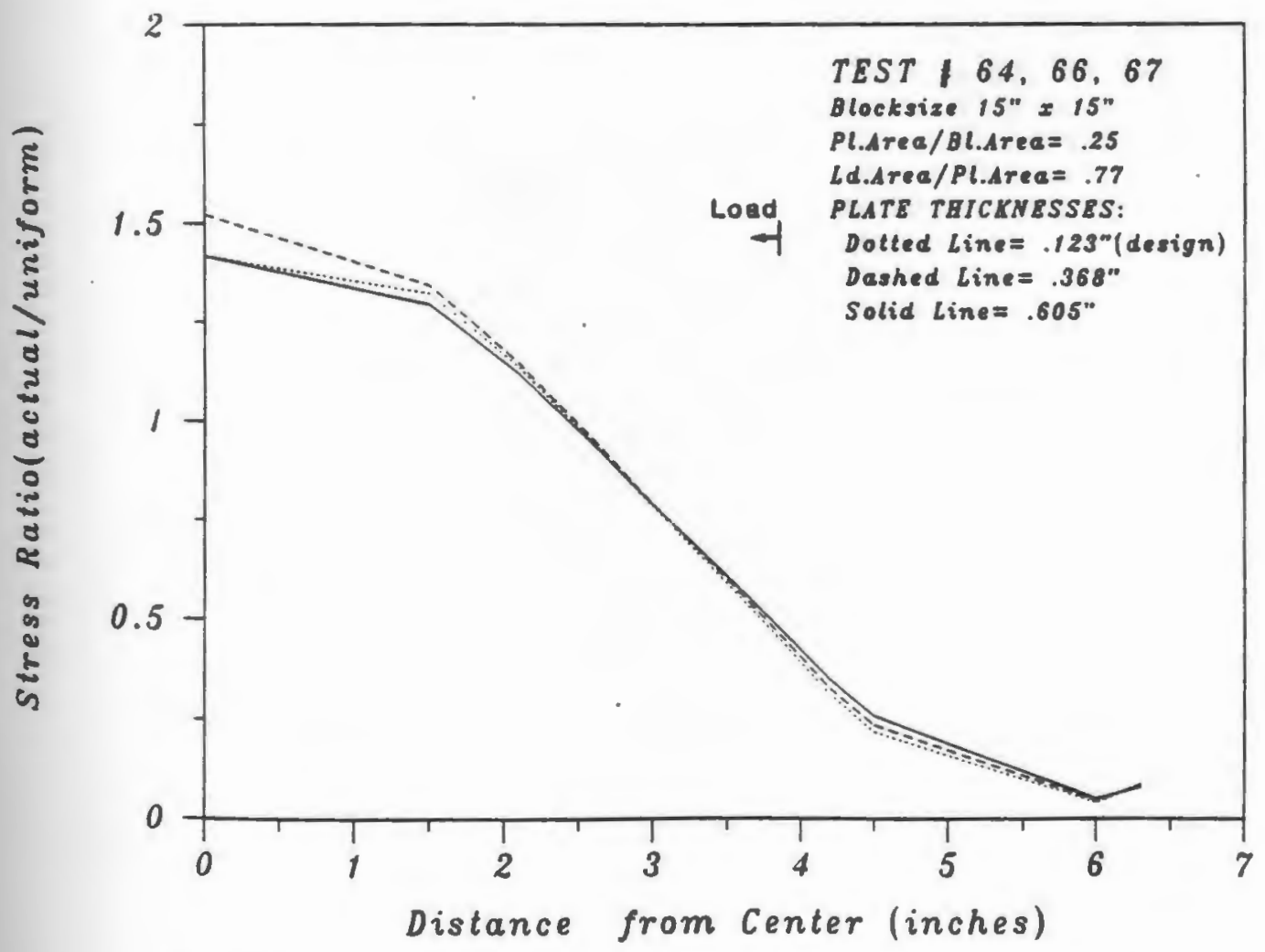

Fig.128: EFFECT OF PLATE THICKNESS (Block 4) 


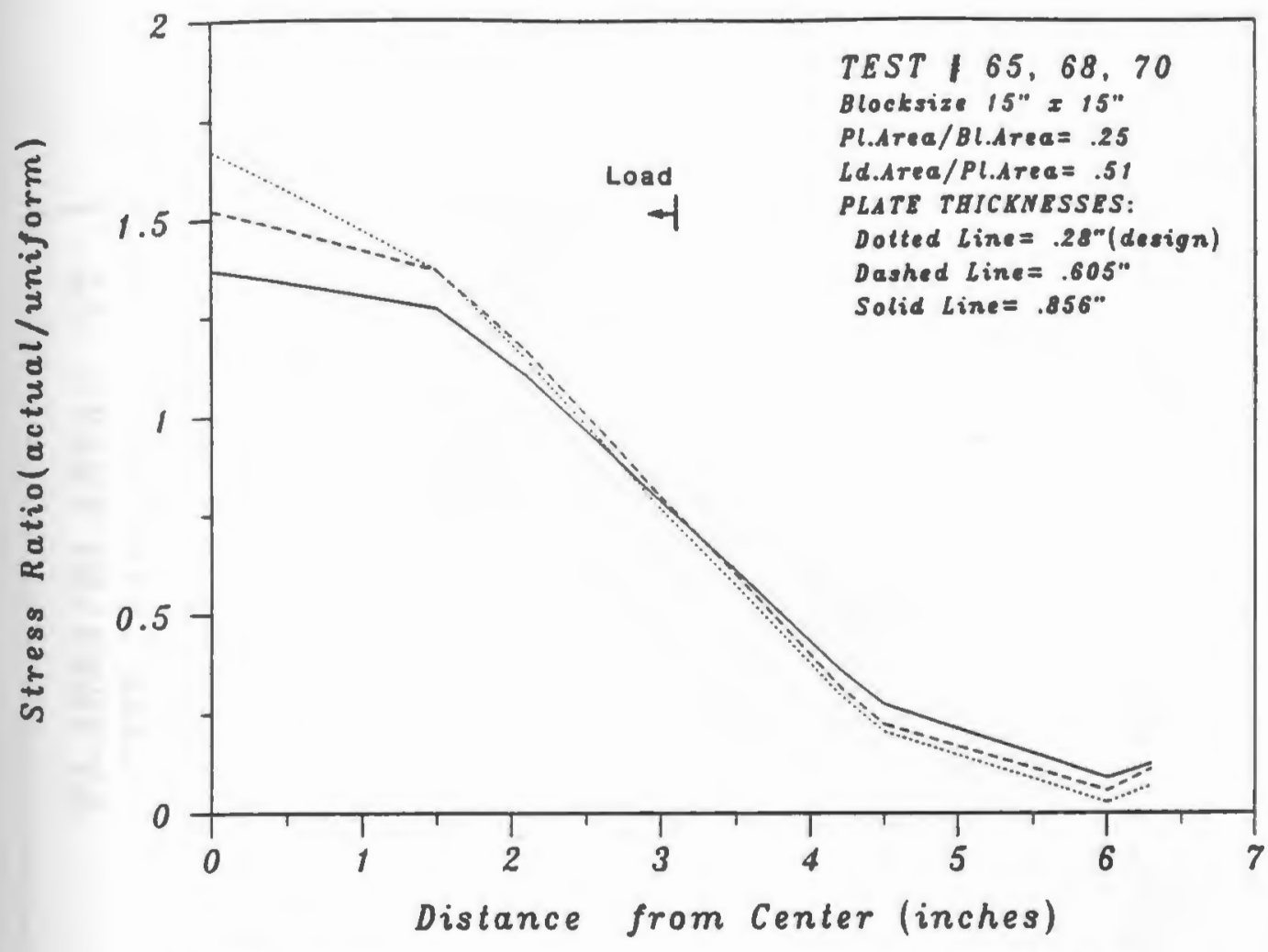

TEST 65, 68, 70

Blocksize 15" $x 15^{\prime \prime}$

Pl.Area/Bl.Area $=.25$

Dotted Line $=.28^{\prime \prime}$ (design)

Dashed Line $=.605^{\circ}$

Solid Line $=.856^{\circ}$

Fig.129: EFFECT OF PLATE THICKNESS (Block 4)

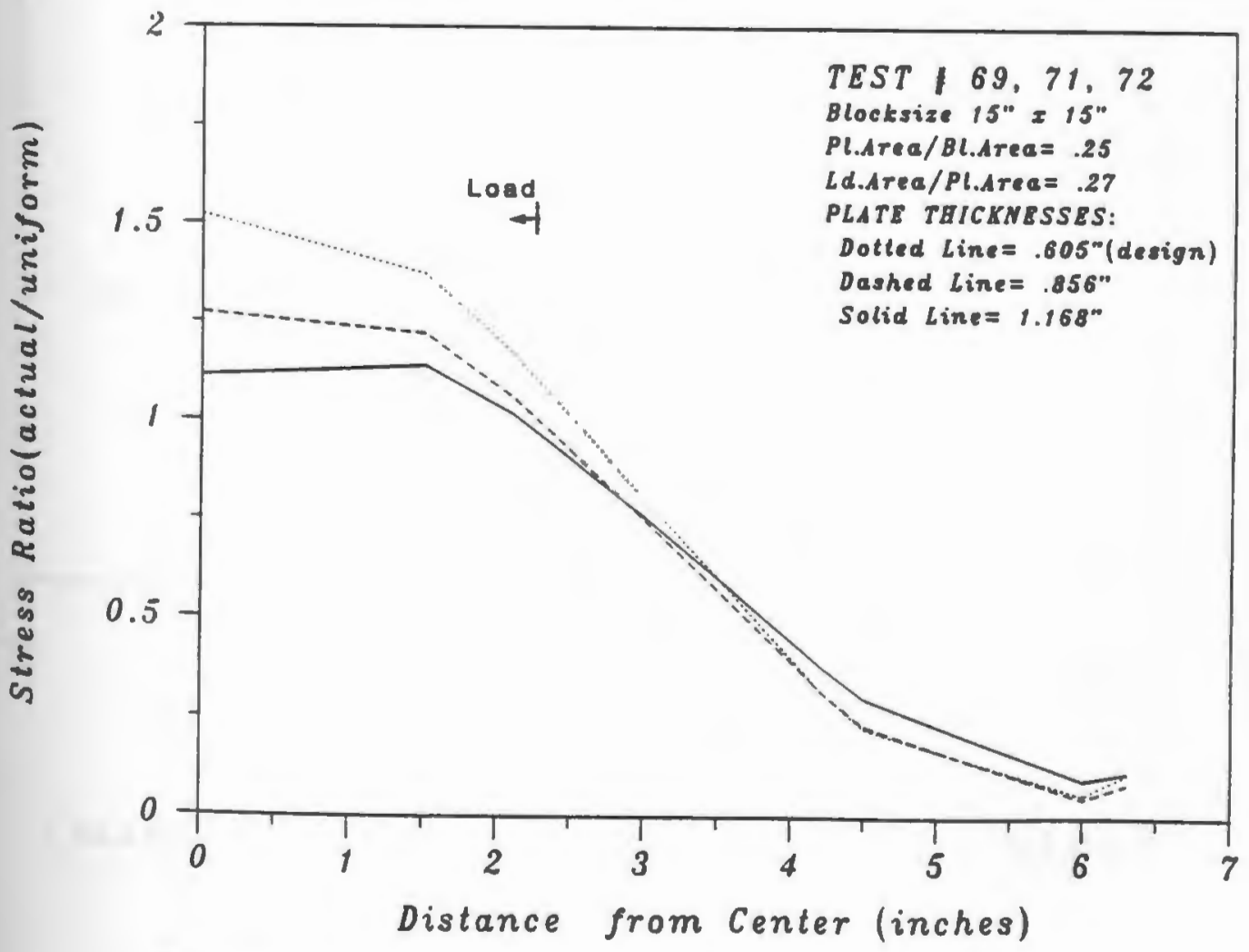

है

Fig.130: EFFECT OF PLATE THICKNESS (Block 4) 


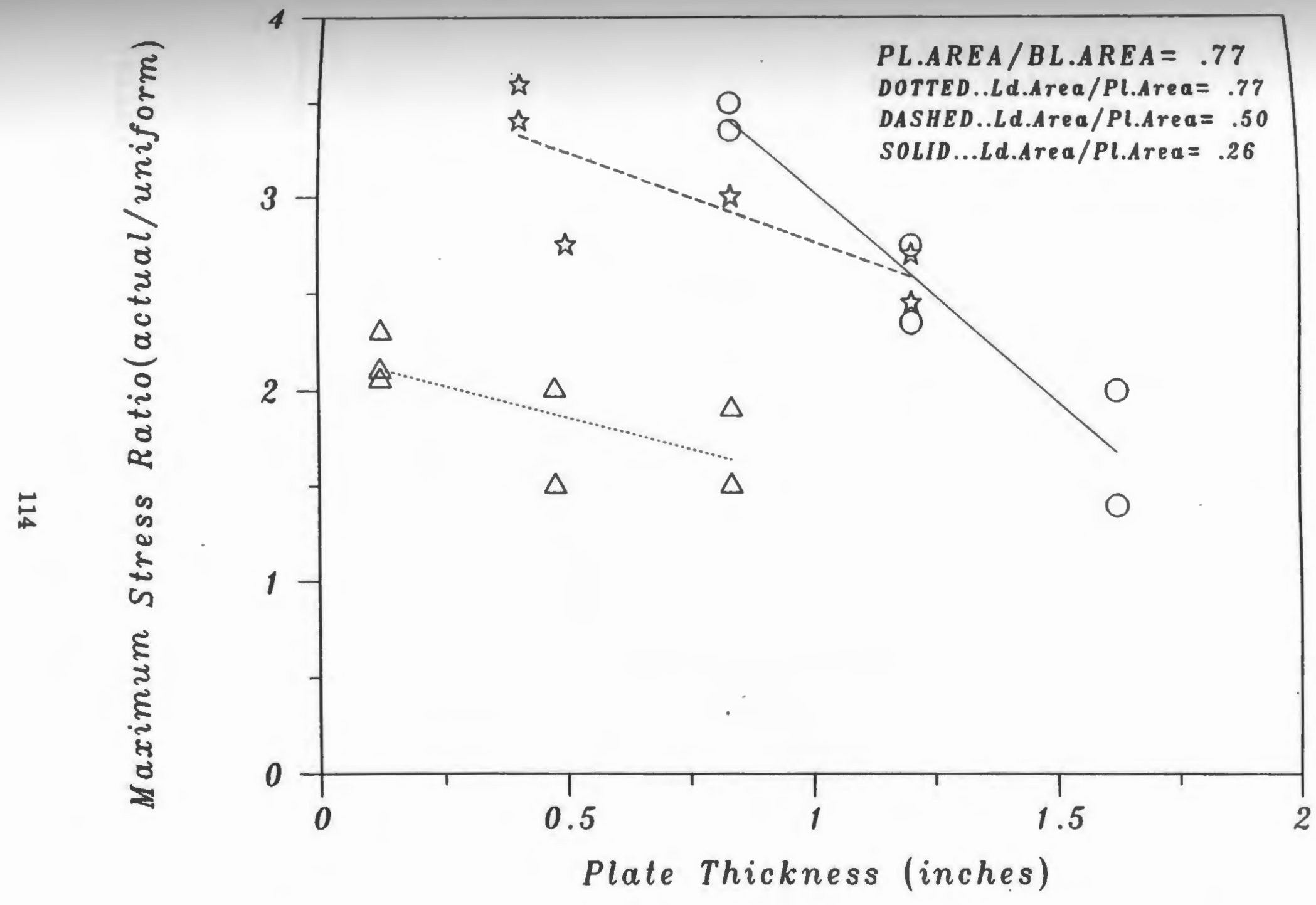

Fig.131: EFFECT OF PLATE THICKNESS AND LD.AREA/PL.AREA 


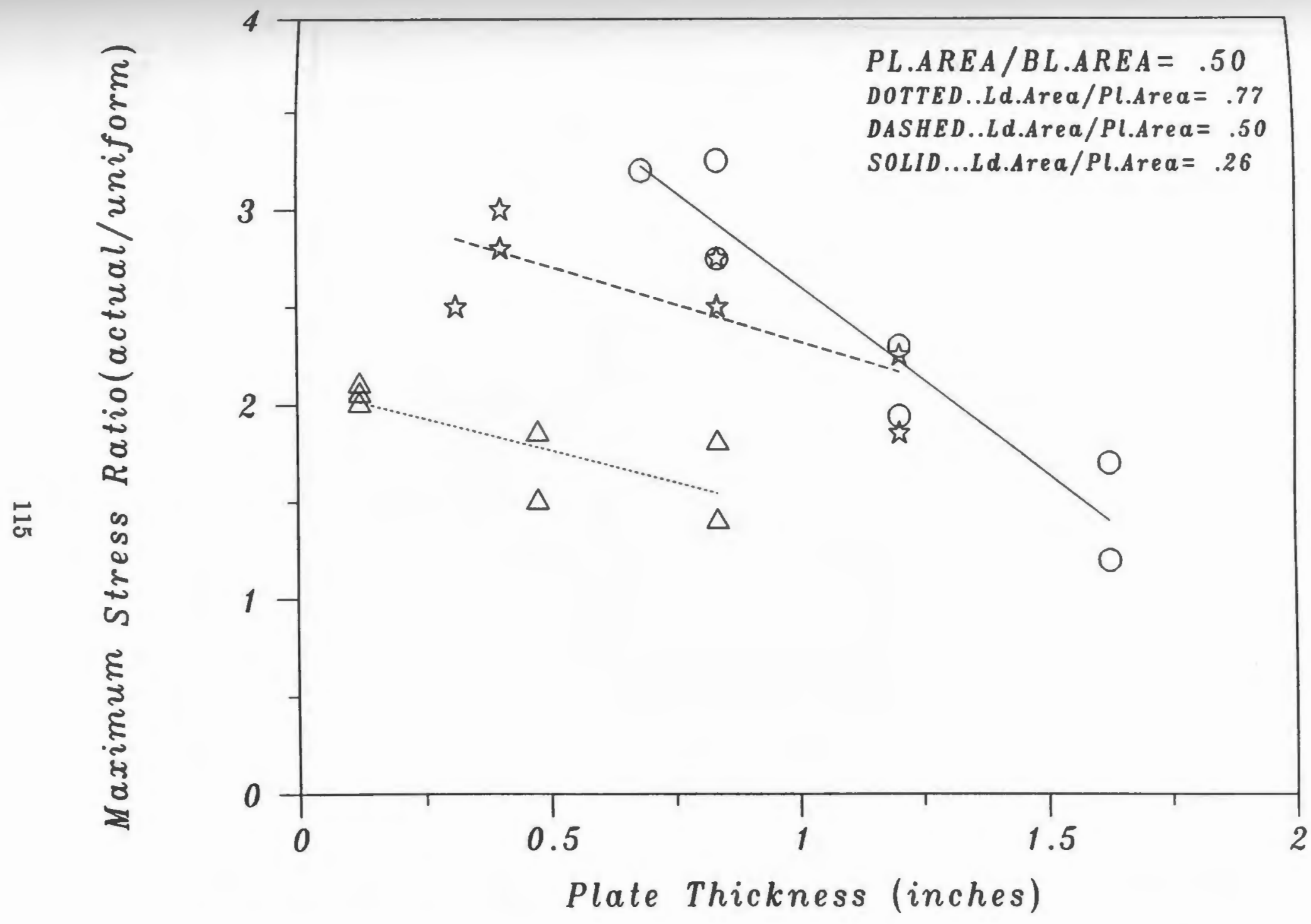

Fig.132: EFFECT OF PLATE THICKNESS AND LD.AREA/PL.AREA 


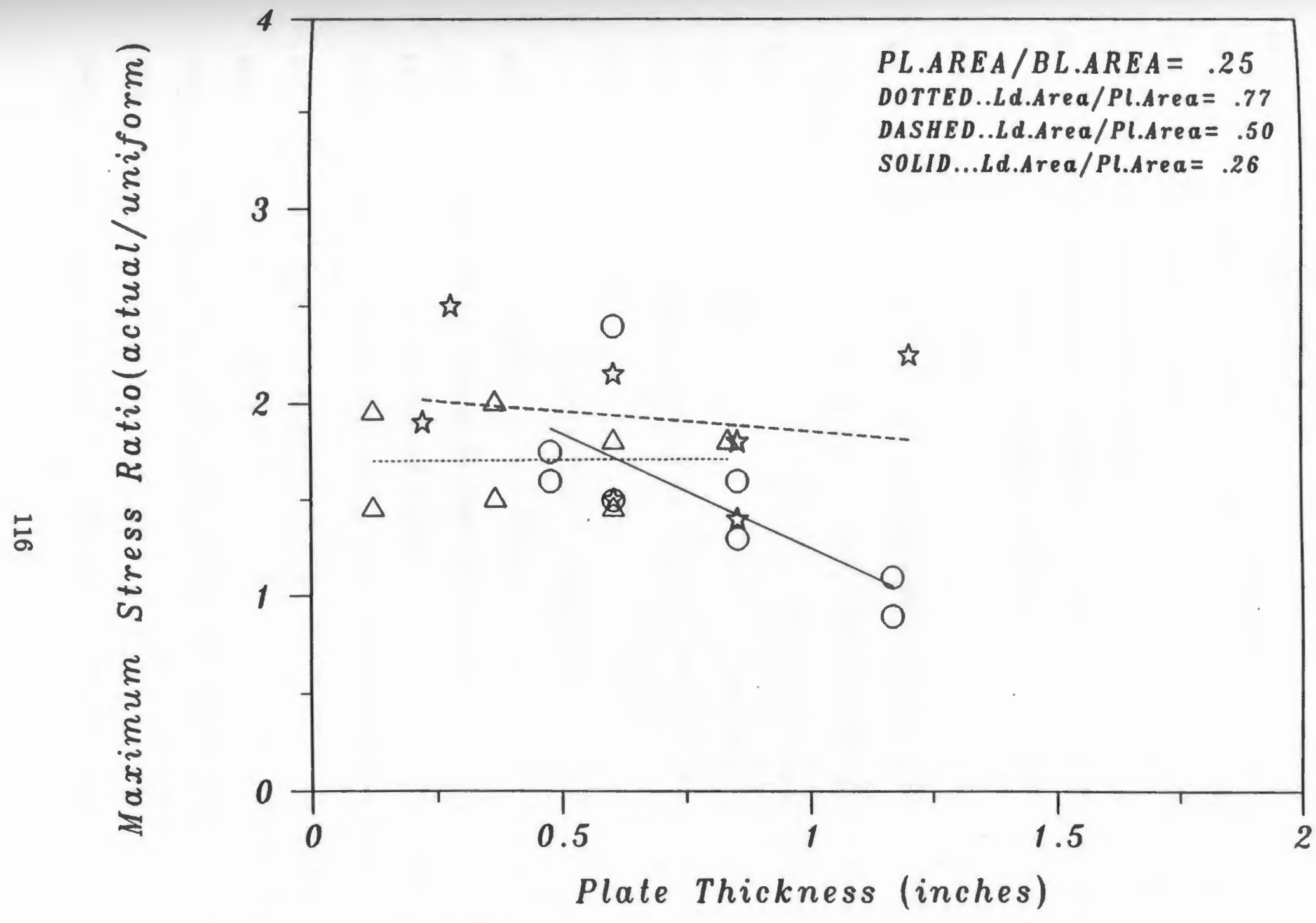

Fig.133: EFFECT OF PLATE THICKNESS AND LD.AREA/PL.AREA 
ratio for plate area to block area ratios of $0.77,0.50$ and 0.25 respectively. It can be seen that even for the tests in which very thick bearing plates were used, the maximum stress ratio is much higher than 1.0. However, the decrease in the maximum stress ratios with the thickness for a particular load area to plate area ratio is seen to be linear in nature for plate area to block area ratios of 0.77 and 0.50 . No trend could be determined for plate area to block area ratio of 0.25 .

From these figures we also see that for the same thickness bearing plate, and for plate area to block area ratios of 0.77 and 0.50 , we get higher stress ratios as the load area to plate area ratio goes down. For plate area to block area ratio of 0.26 no trend could be observed.

\subsubsection{EFE ECT OF PLATE AREA TO BLOCK A REA RATIO AND LOADED}

\section{AREA TO PLATE AREA RATIOS FOR DESIGN THICKNESSES:}

Lower plate area to block area ratios resulted in much lower stress ratios whereas higher plate area to block area ratios resulted in much higher stress ratios not just in the center of the block but away from the center as well. This can be observed in Figs. 134 thru 145.

Figs. 146, 147 and 148 show that for load area to plate area ratios of 0.25 and 0.5 as the plate area to block area ratio increases, the maximum stress ratios increase considerably (i.e. the stress distribution tends to be more non uniform), but for load area to plate area ratio of 0.75 they do not vary much and are quite low. This indicates that a higher load area to plate area ratio leads to a more uniform distribution as compared to a lower load area to plate area ratio. Also from the same figures it can be observed that as the load area to plate area ratio increases, the maximum stress ratio goes down considerably for plate area to block a rea ratios of 0.77 and 0.5 , but for plate area to block area ratio of 0.25 the maximum stress ratios did not show much variation with increase in load area to plate area ratio. 


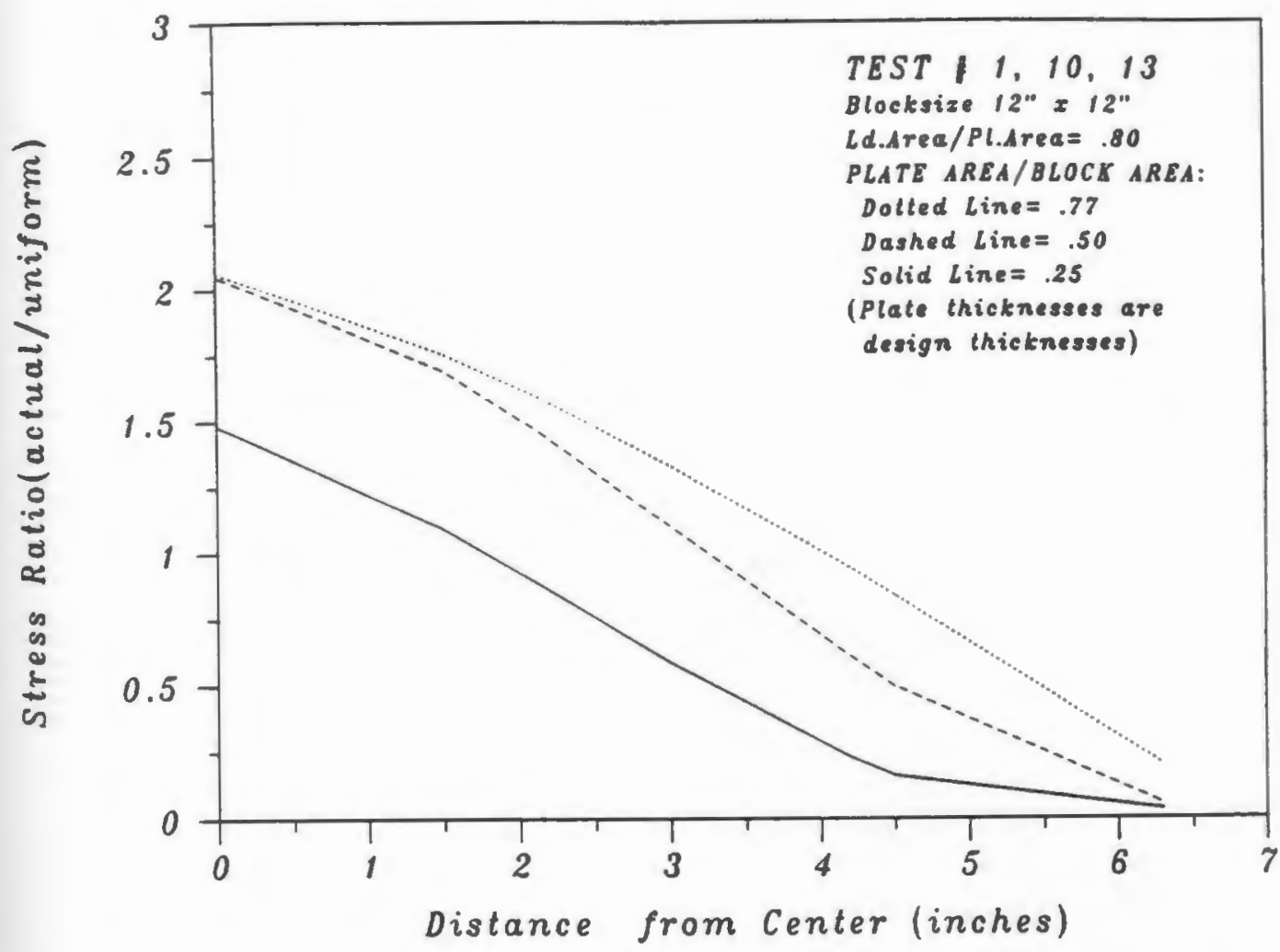

TEST | 1, 10,13

Blocksize $12^{\prime \prime} \times 12^{\prime \prime}$

Ld.Area/Pl.Area $=.80$

PLATE AREA/BLOCX AREA:

Dotted line $=.77$

Deshed Line $=.50$

Plate thicknesses are

Fig.134: EFFECT OF PLATE AREA/BLOCK AREA (Block 1)

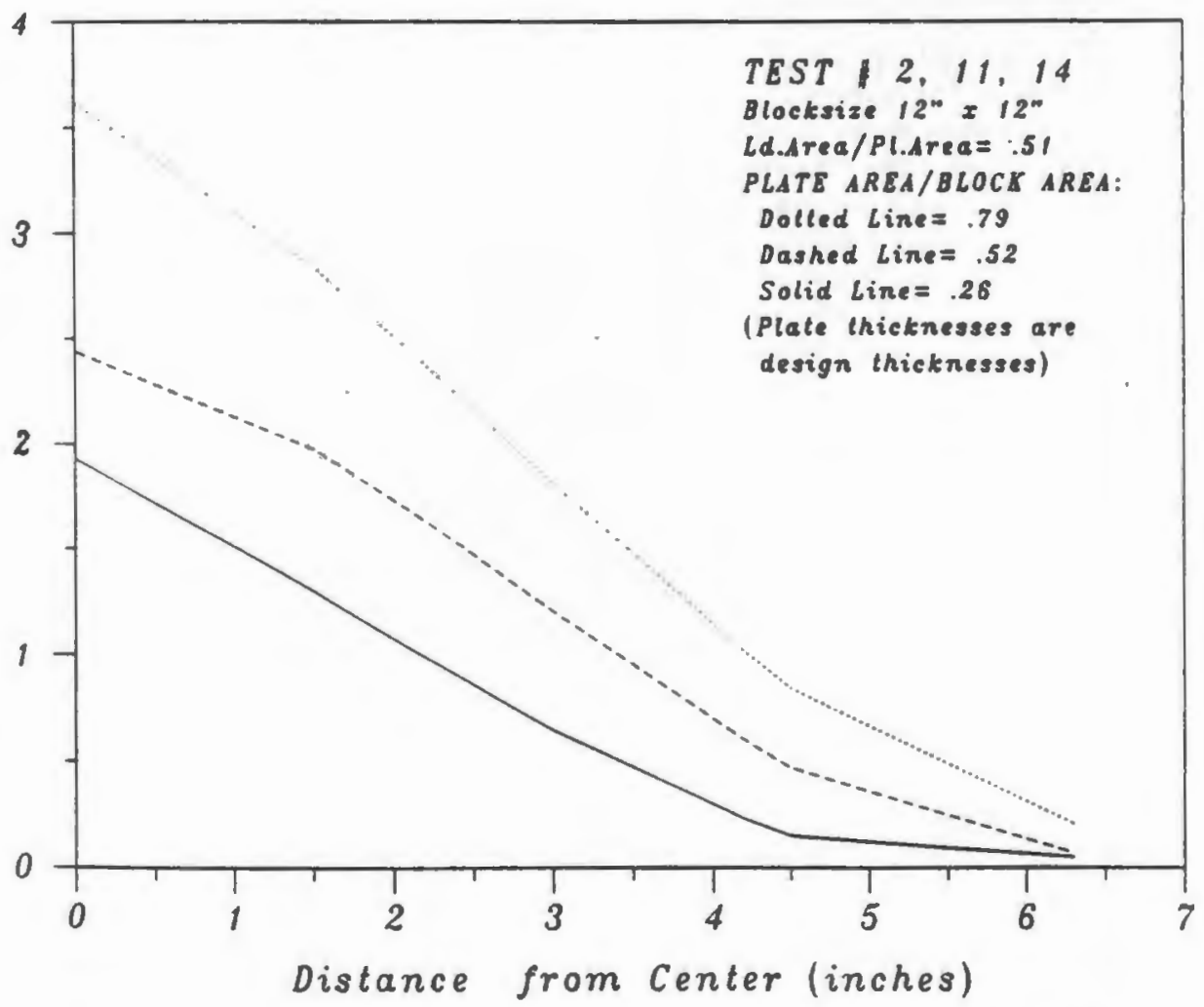

Fig.135: EFFECT OF PLATE AREA/BLOCK AREA (Block \#1) 


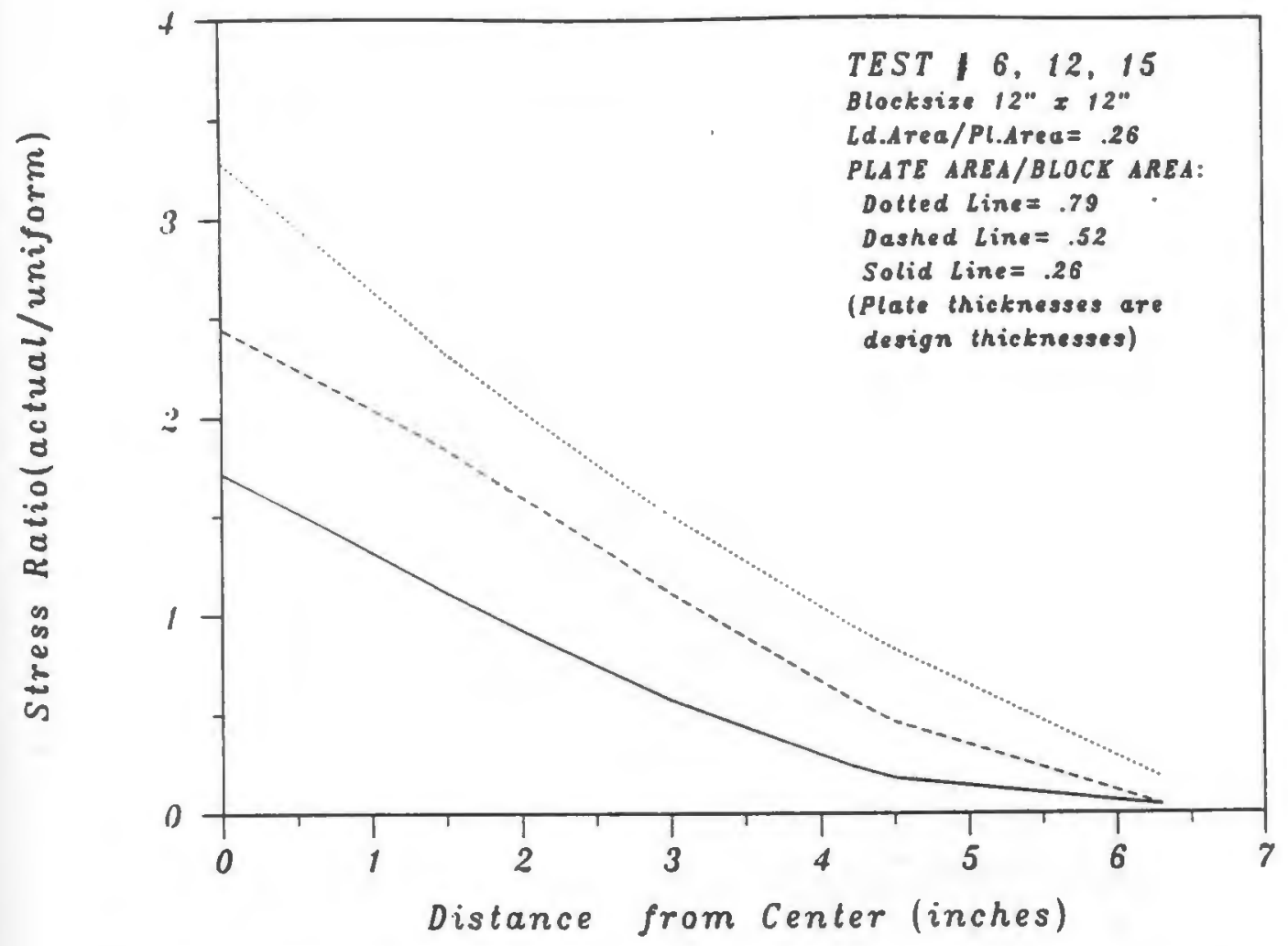

TEST $6,12,15$

Blocksize $12^{\prime \prime} \times 12^{n}$

Ld.Area/Pl.ATea $=.26$

PLATE AREA/BLOCK AREA:

Dotted Line $=.79$

line $=.52$

$=.26$

Plate (hicknesses ar

Fig.136: EFFECT OF PLATE AREA/BLOCK AREA (Block \#1)

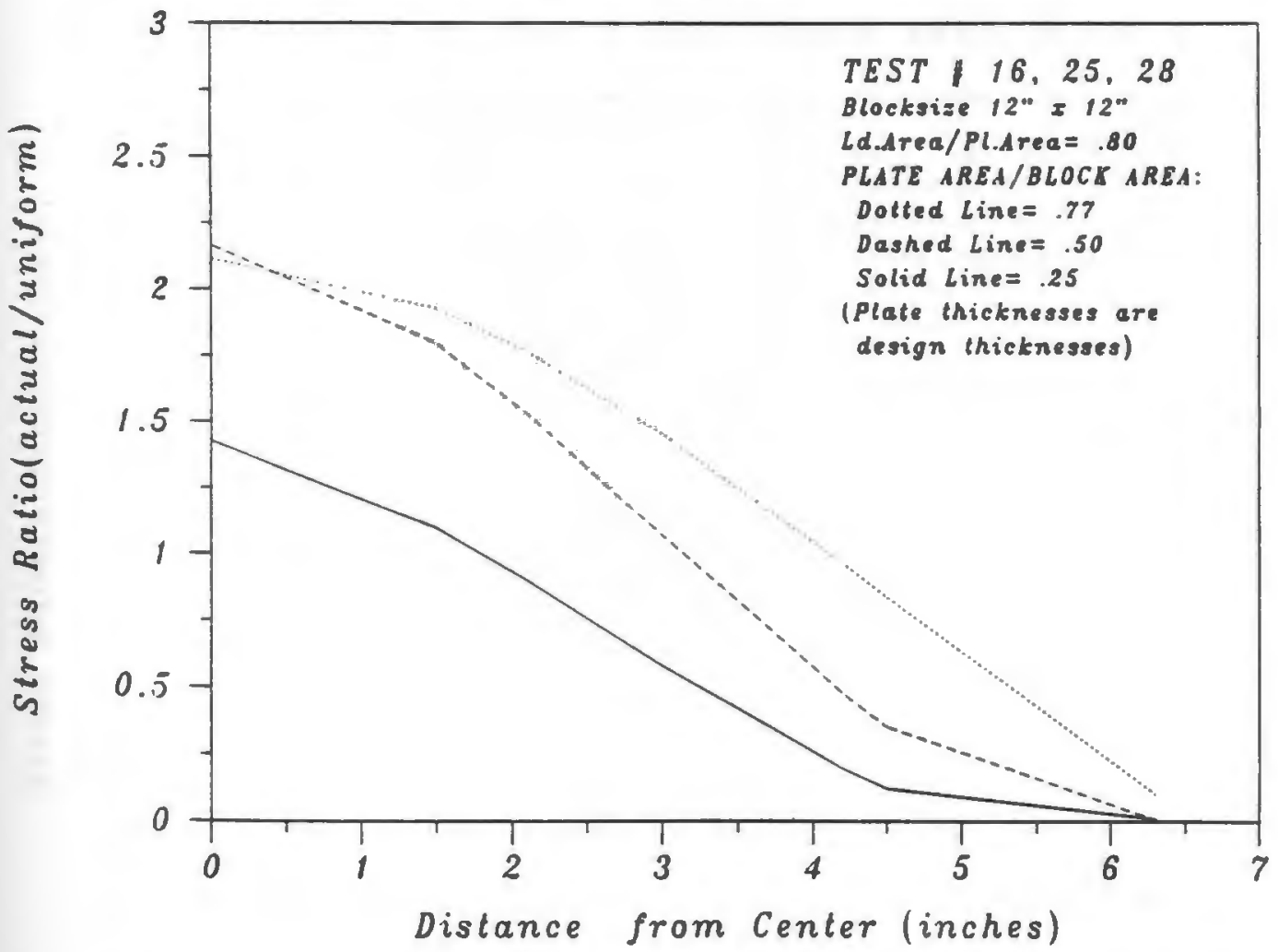

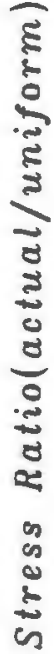

Fig.137: EFFECT OF PLATE AREA/BLOCK AREd (Block\#2) 


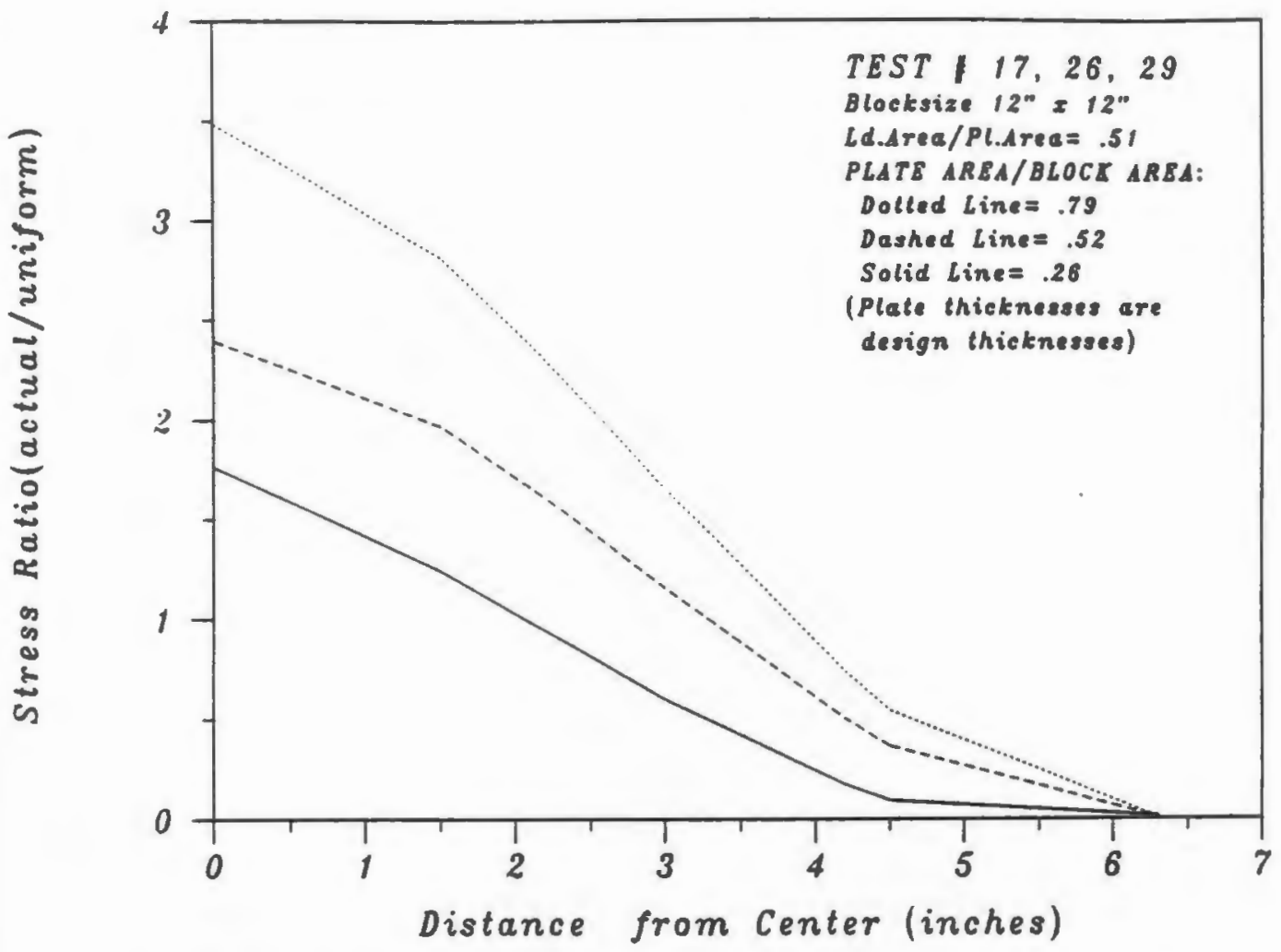

$T E S T \mid 17,26,29$

$12 \times 12$

d.Area/Pl.Aree $=.51$

LATE AREA/BLOCK AREA:

Dolled Line $=.79$

Dashed line $=.52$

Slate thicknesses are

2

Fig.138: EFFECT OF PLATE AREA/BLOCK AREA (Block 2)

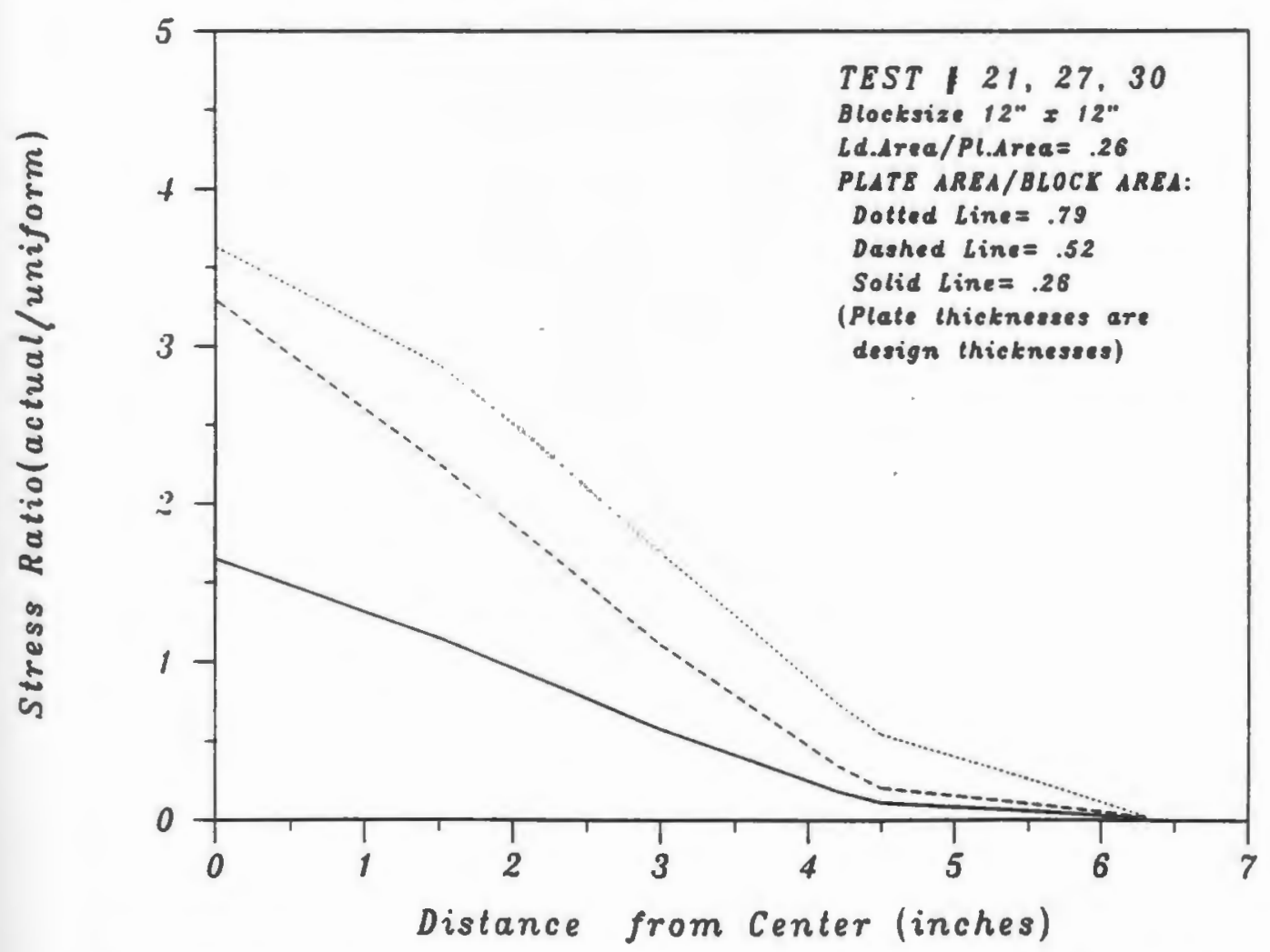

है

Fig.139: EFFECT OF PLATE AREA/BLOCK AREA (Block 2) 


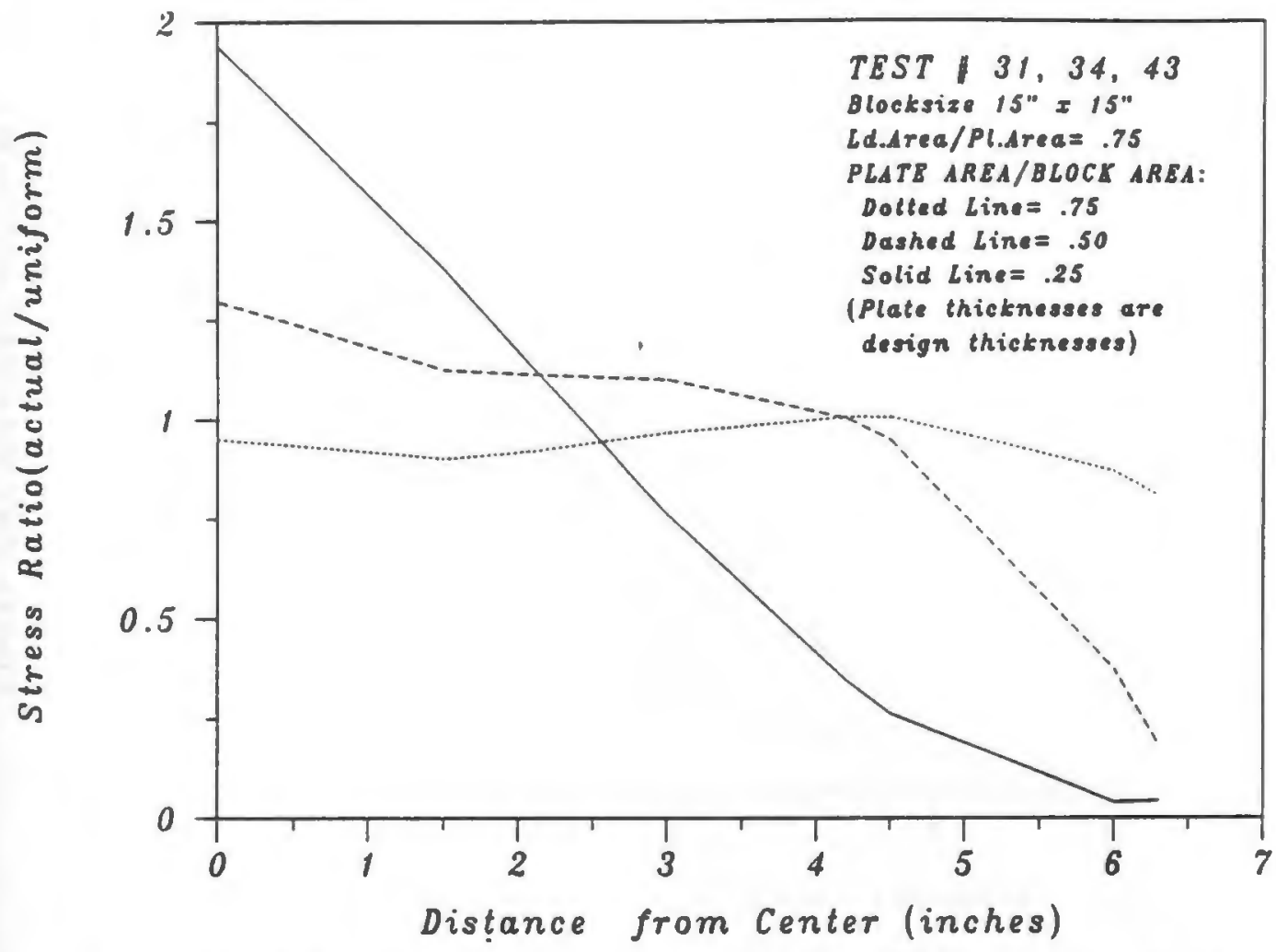

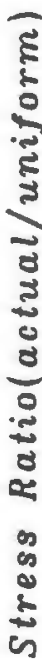

Fig.140: EFFECT OF PLATE AREA/BLOCK AREA (Block 3)

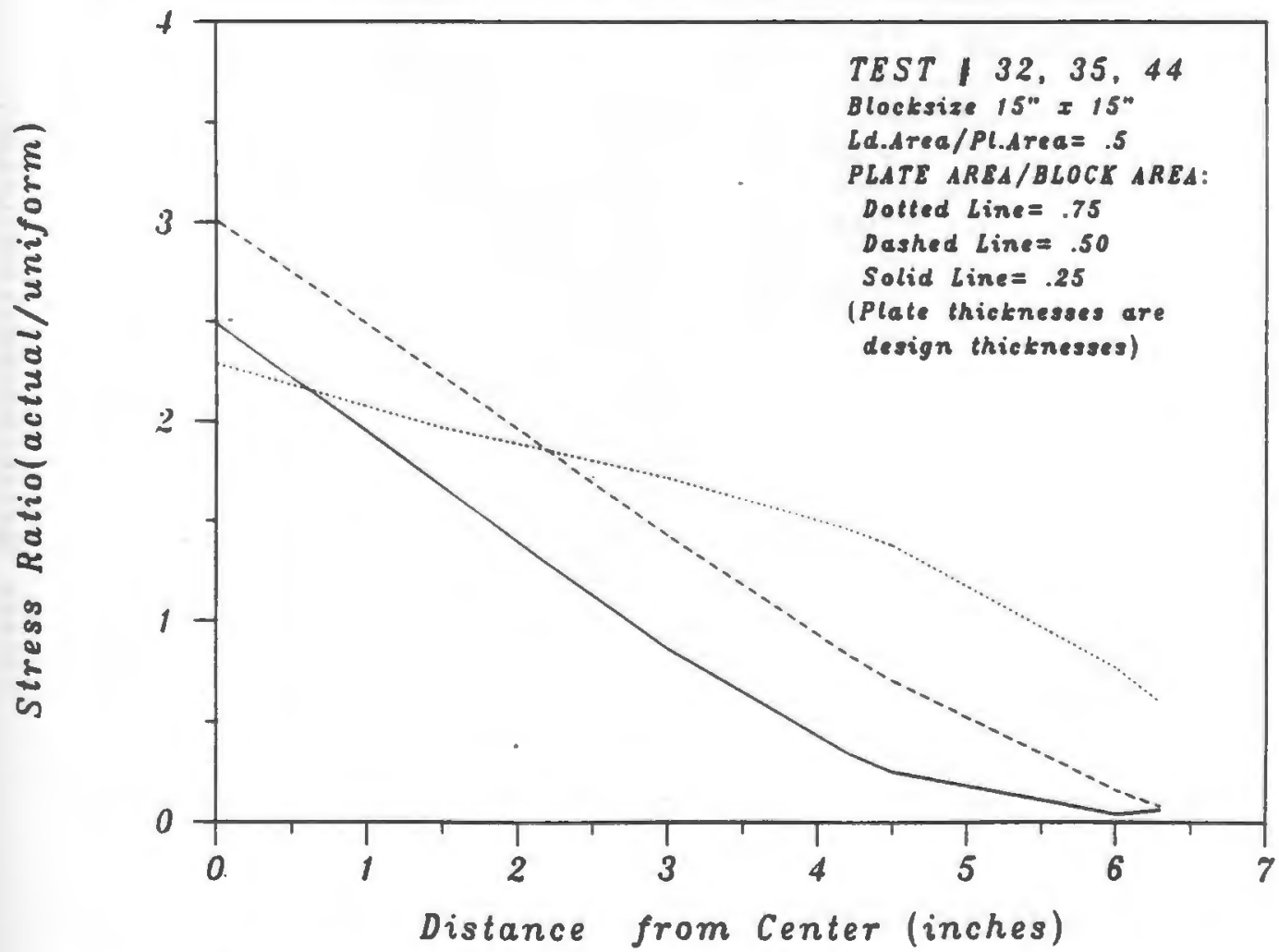

Fig.141: EFFECT OF PLATE AREA/BLOCK AREA (Block 3) 
है

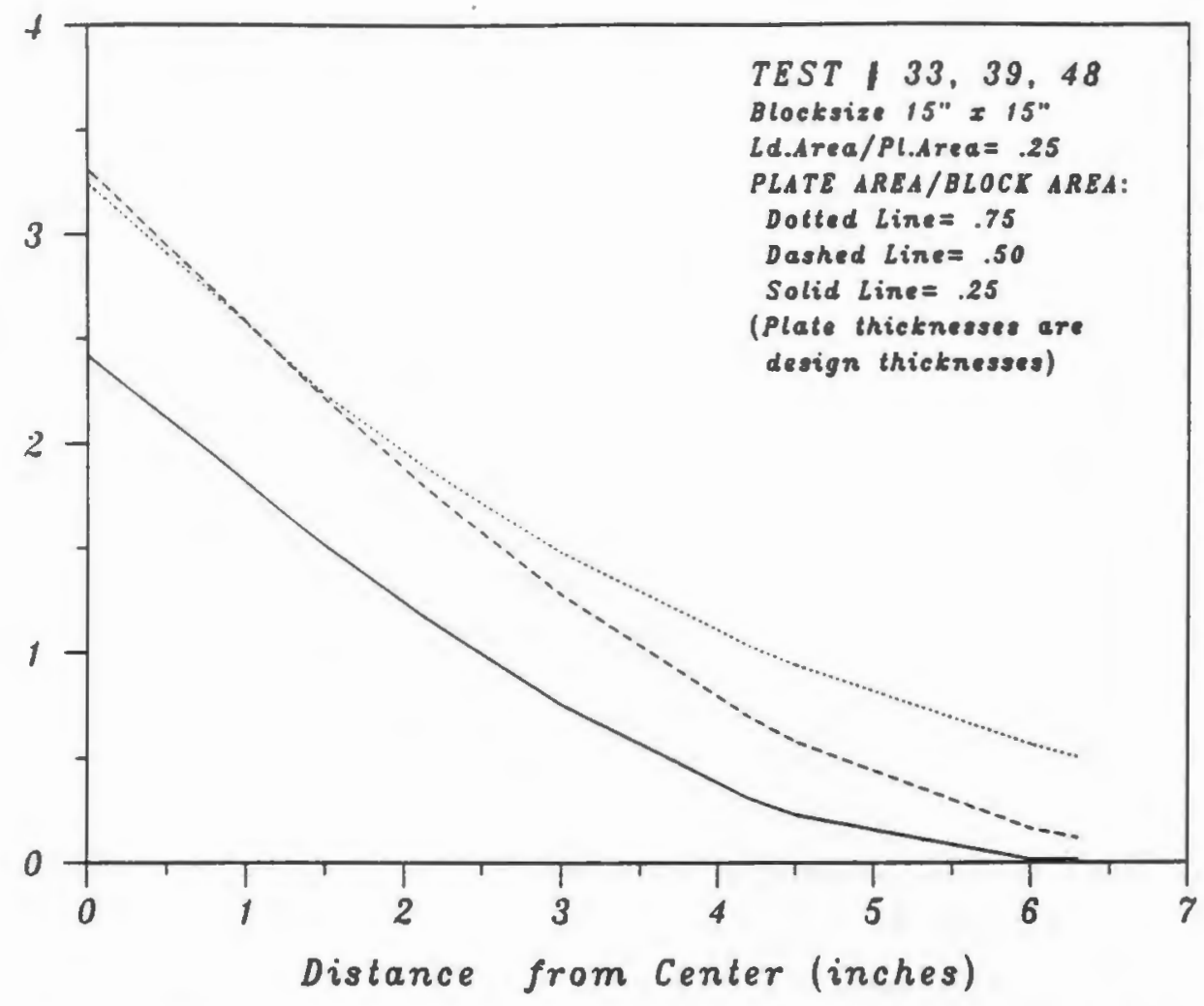

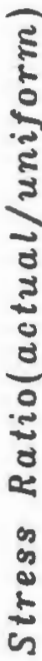

Fig.142: EFFECT OF PLATE AREA/BLOCK AREA (Block \#)

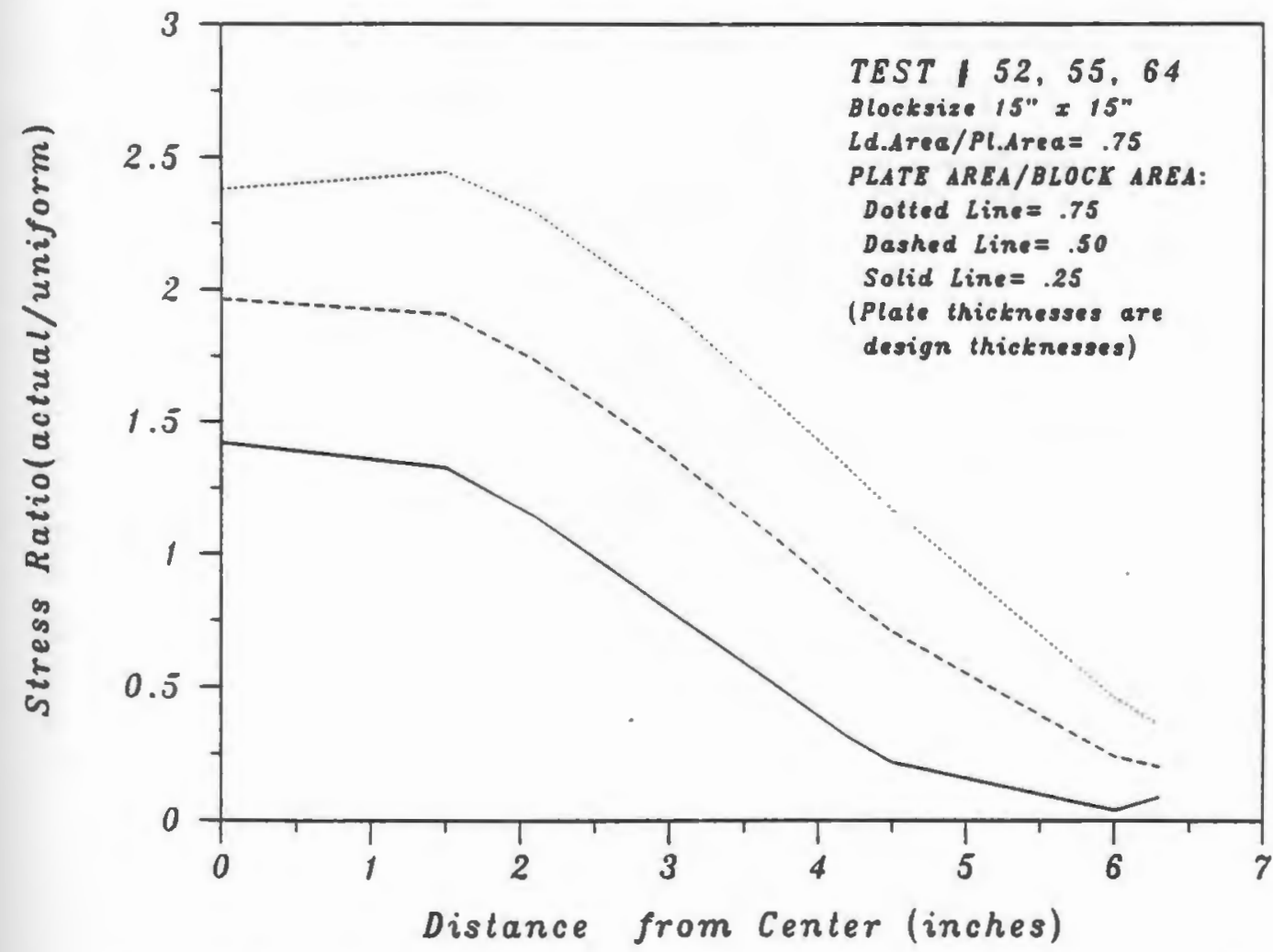

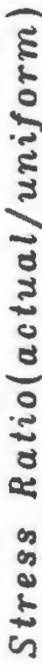

Fig.143: EFFECT OF PLATE AREA/BLOCK AREA (Block 4) 


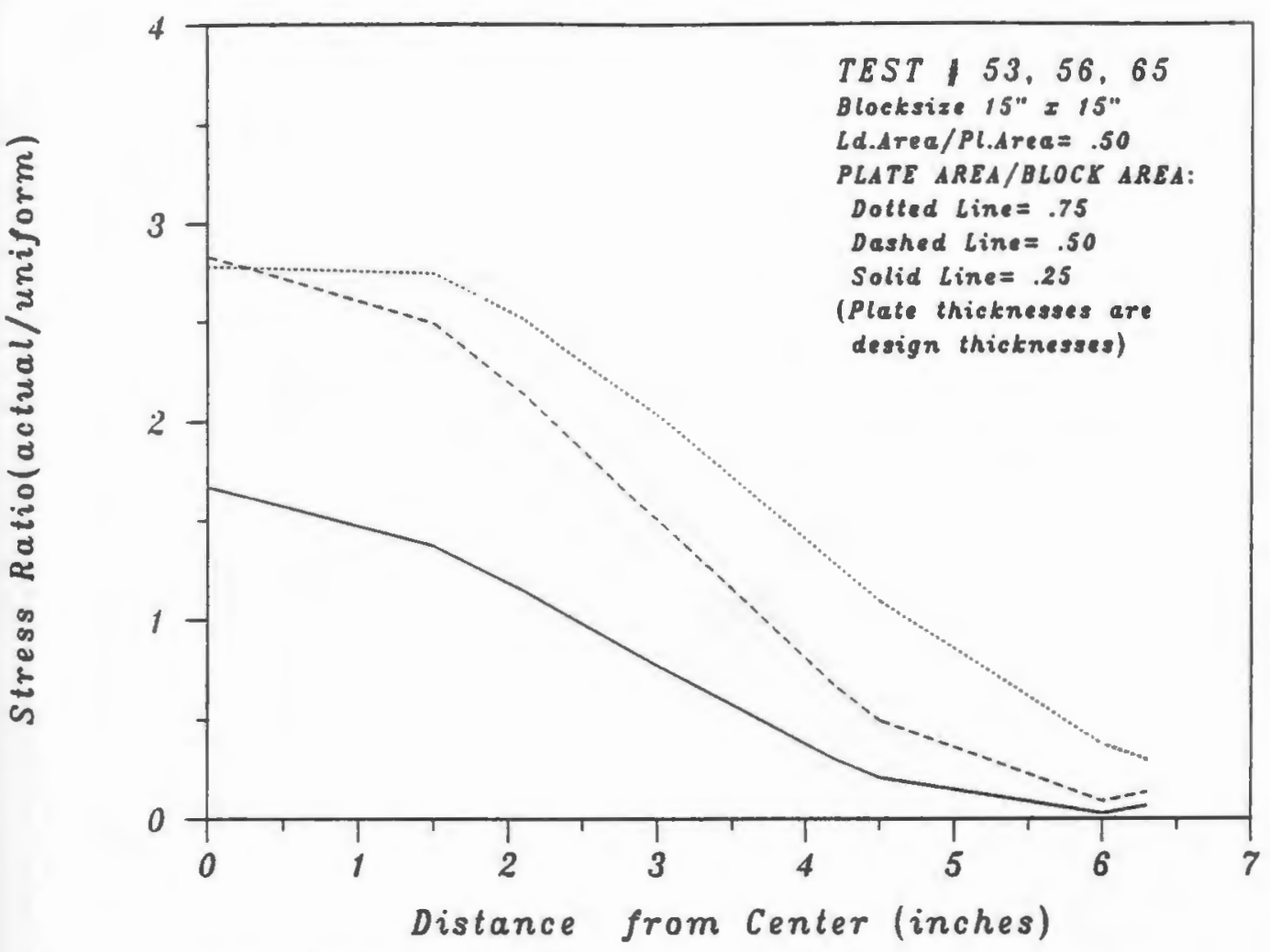

Fig.144: EFFECT OF PLATE AREA/BLOCK AREA (Block 4)

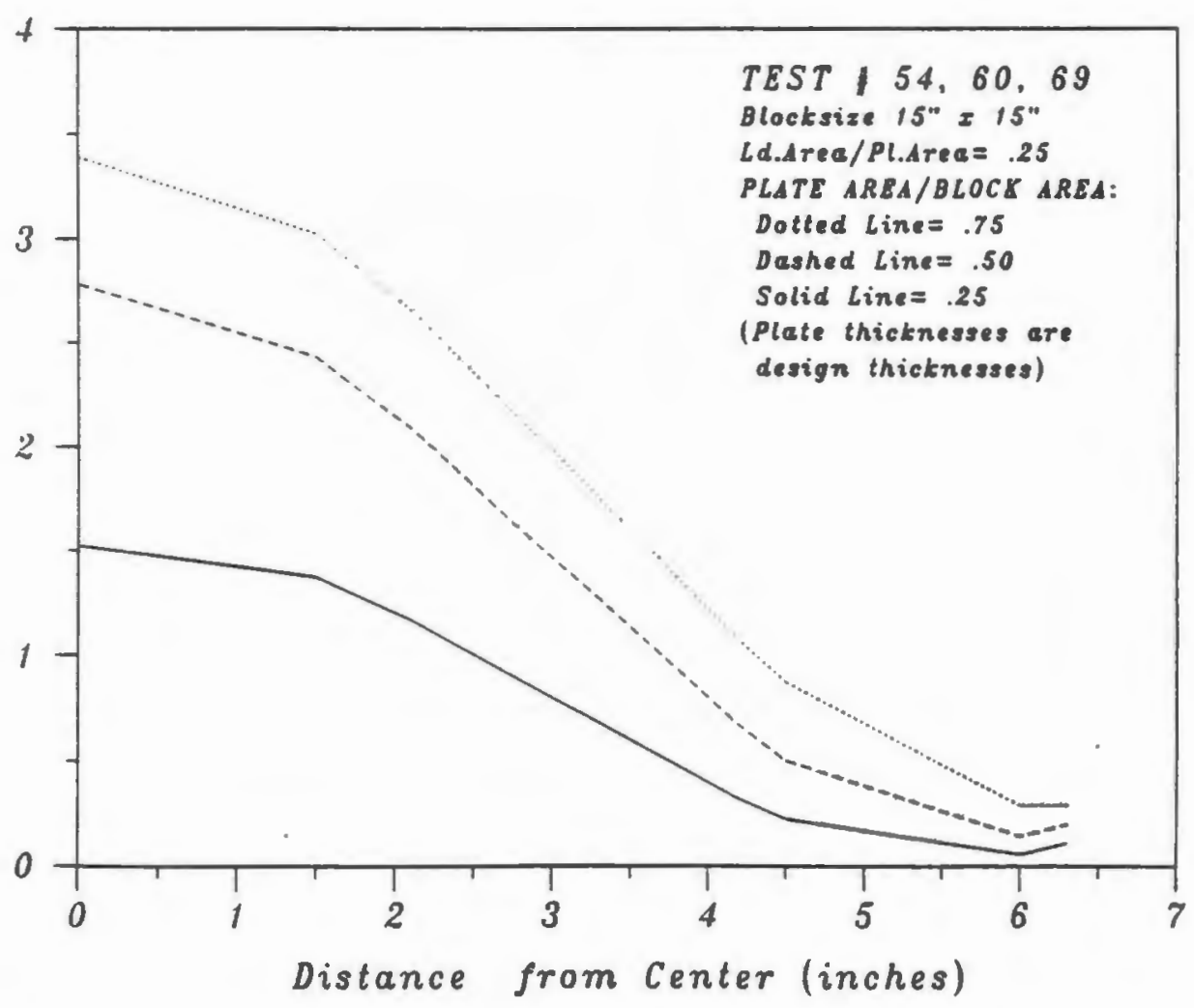

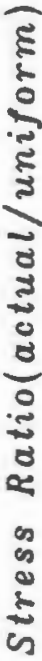

Fig.145: EFFECT OF PLATE AREA/BLOCK AREA (Block 4) 


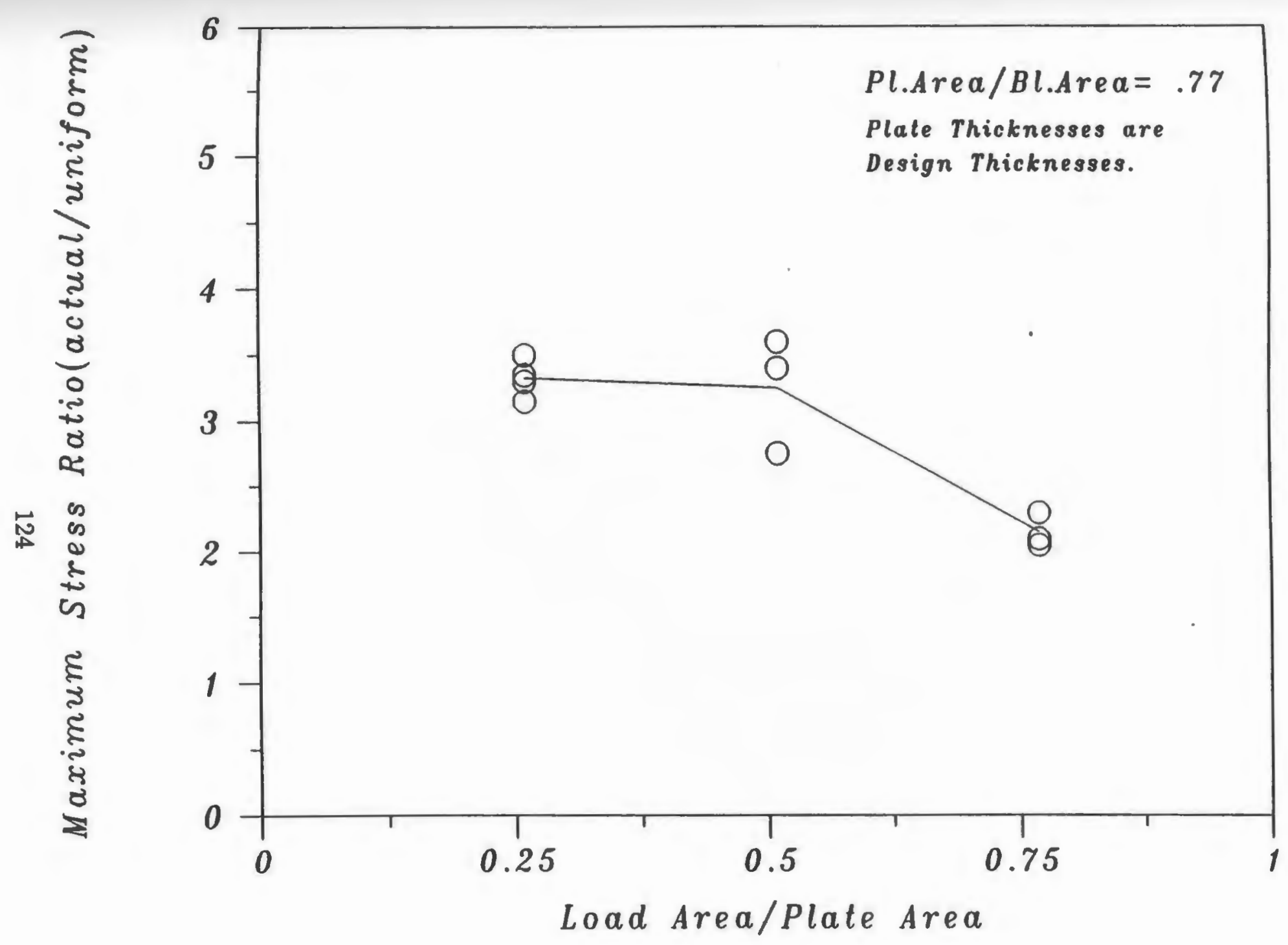

Fig.146: EFFECT OF LD.AREA/PL.AREA 


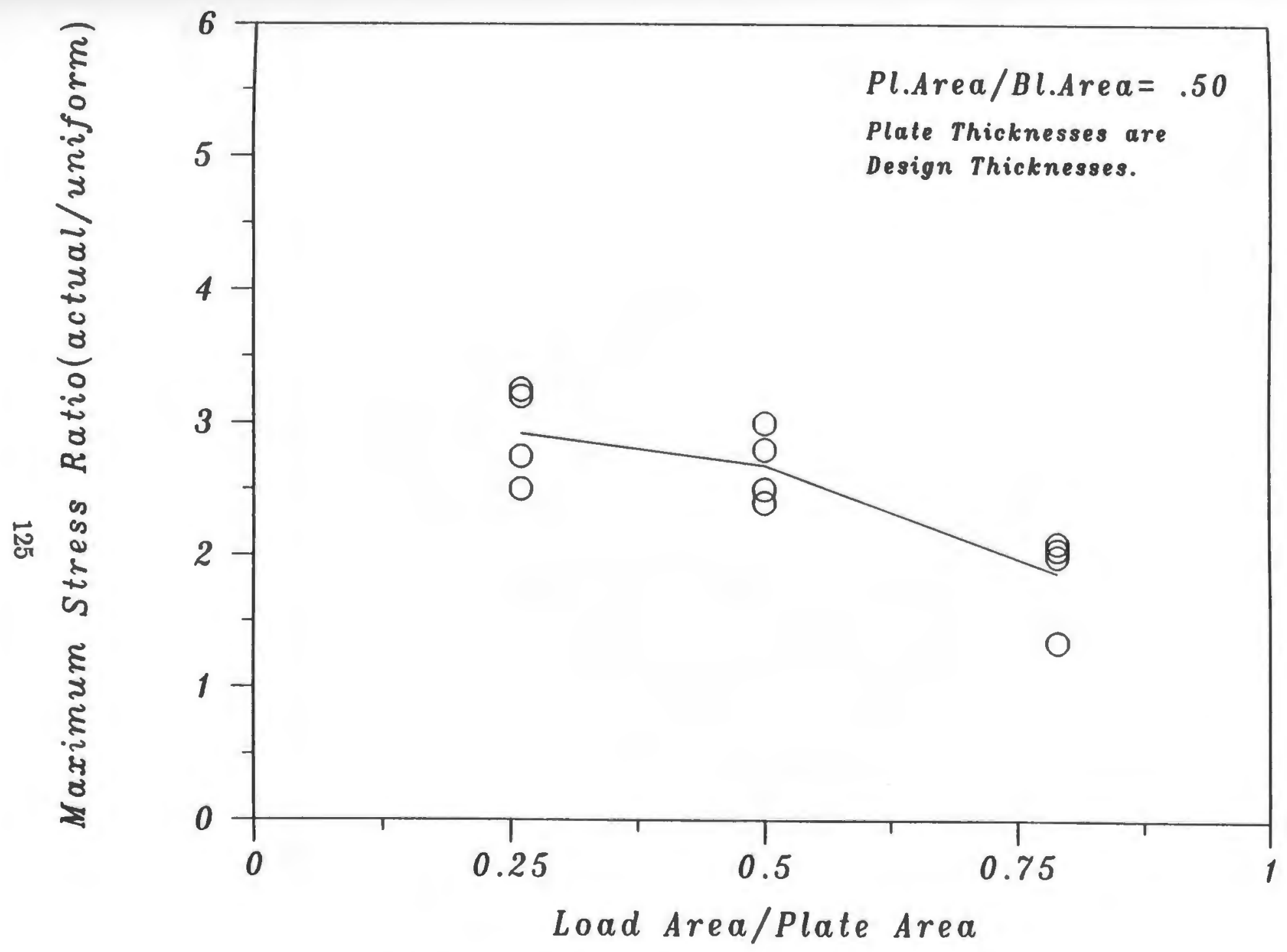

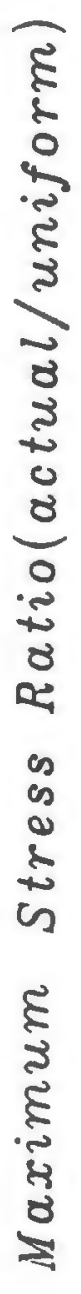

Fig.147: EFFECT OF LD.AREA/PL.AREA 


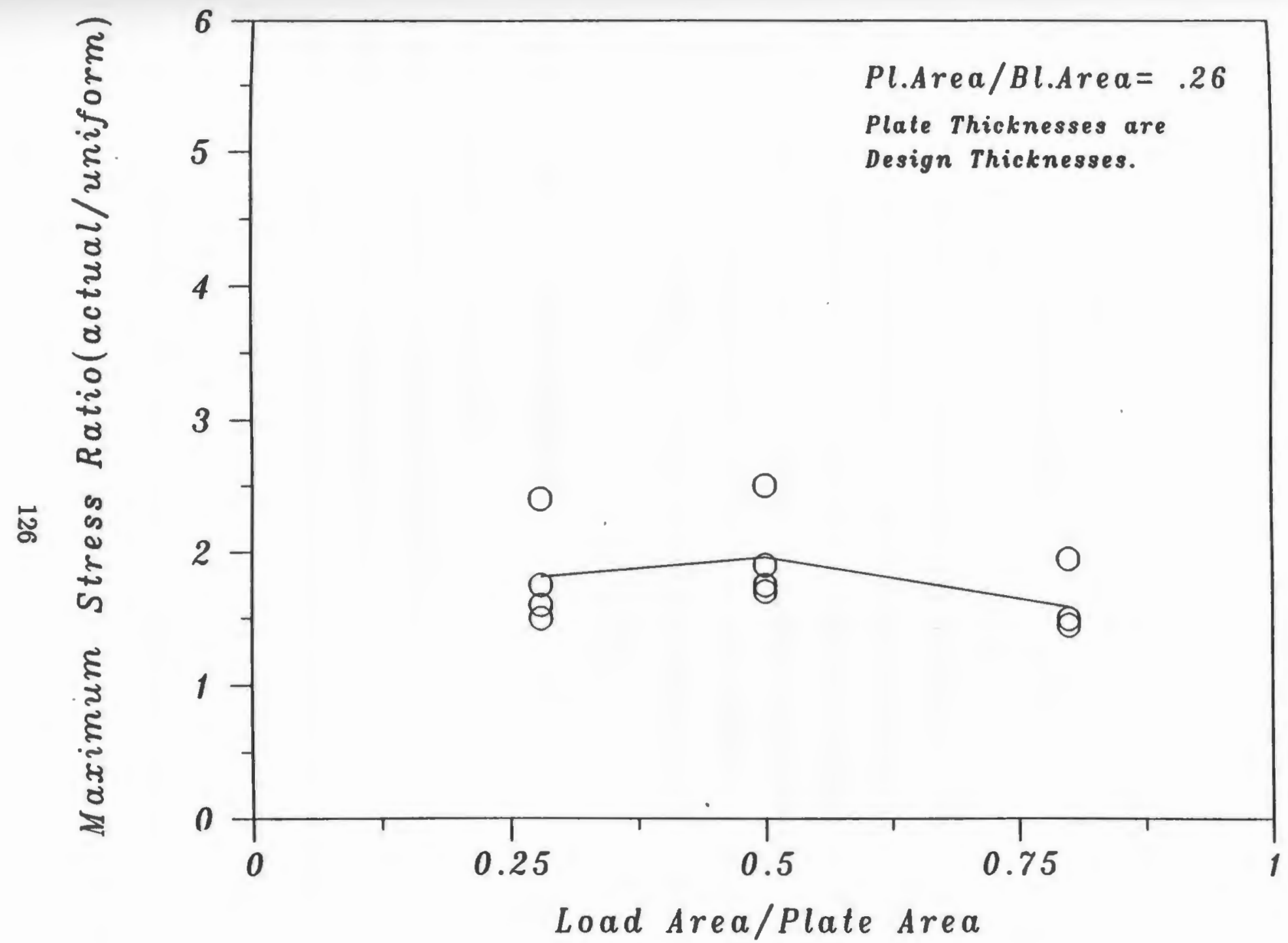

ह

Fig.148: EFFECT OF LD.AREA/PL.AREA 


\subsubsection{EFFET OF OVERHANG OF BEARING PLATE FOR DESIGN THICKNESS:}

The portion of the bearing plate extending beyond the loaded area perpendicular to the edge of the plate has been defined as the overhang of the bearing plate.

Tests with bearing plates having larger overhangs resulted in higher stress ratios. This indicates that the overhang of the plate does not serve its purpose of distribution of the load to the concrete substructure.

Figs. 149, 150 and 151 show the effect of overhang on the maximum stress ratio for plate area to block area ratios of $0.77,0.50$ and 0.26 respectively. It is clear that large overhangs resulted in larger stress ratios, i.e. greater non uniformity in the distribution of stresses.

Results indicate that for plate area to block area ratios of 0.77 and 0.50 , the maximum stress ratio increased with the increase in overhang for upto about 1 inch and above this increase in the maximum stress ratio was not significant. For plate area to block area ratio of 0.25 , no effect of overhang could be observed.

Figs. 87 thru 92 show the stresses in the bearing plates to be much lower than expected, thereby indicating that negligible lateral transfer of stresses by the bearing plate.

\subsection{ULTIMATE LOAD TESTS:}

\subsubsection{STRESSES IN CONCRETE:}

Figs. 102 thru 105 show the distribution of stresses which were determined using the stress-strain curve obtained from uniaxial compression test (Fig.8). The maximum ultimate stress being 6250 psi. Yielding first starts at the center and then spreads out under the whole loaded area, whereas the stresses away from the loaded area are increased only slightly.

The 12 in. blocks show lateral distribution of stress at lower loads than the 15 in. blocks. Also it should be noted that the loaded area used on 15 in. blocks was 


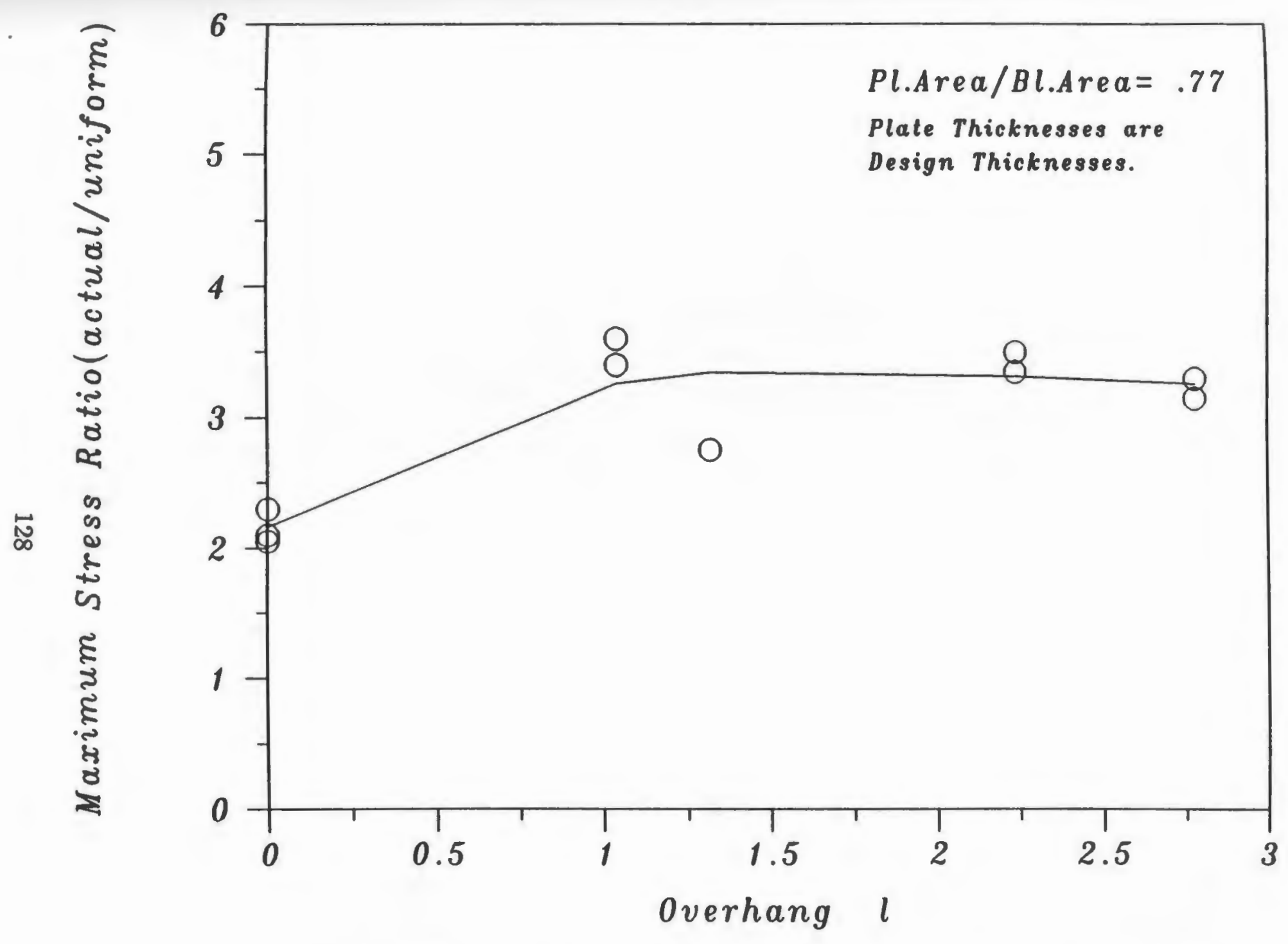

है

Fig.149: EFFECT OF OVERHANG OF BEARING PLATE 


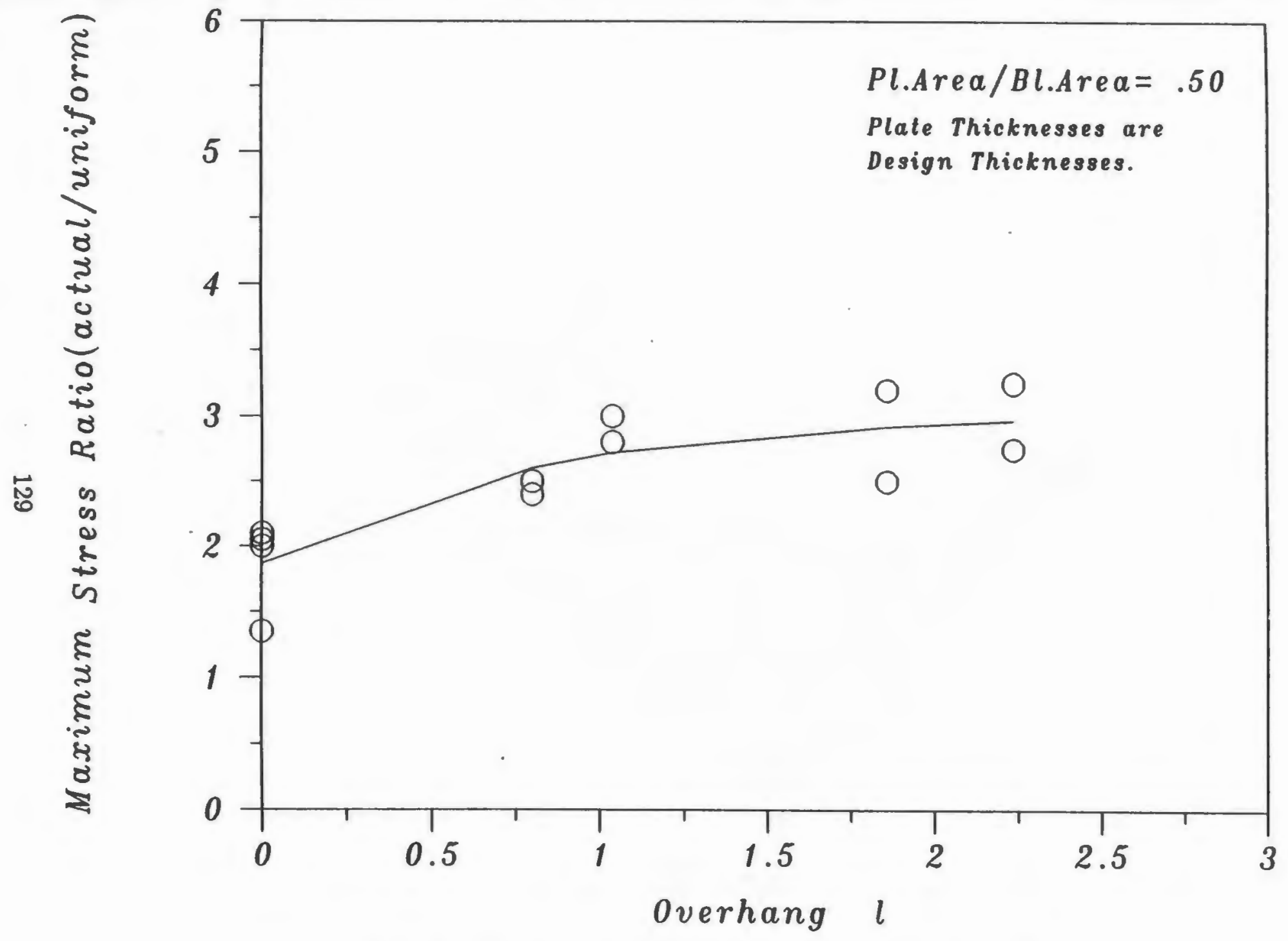

है

Fig.150: EFFECT OF OVERHANG OF BEARING PLATE 


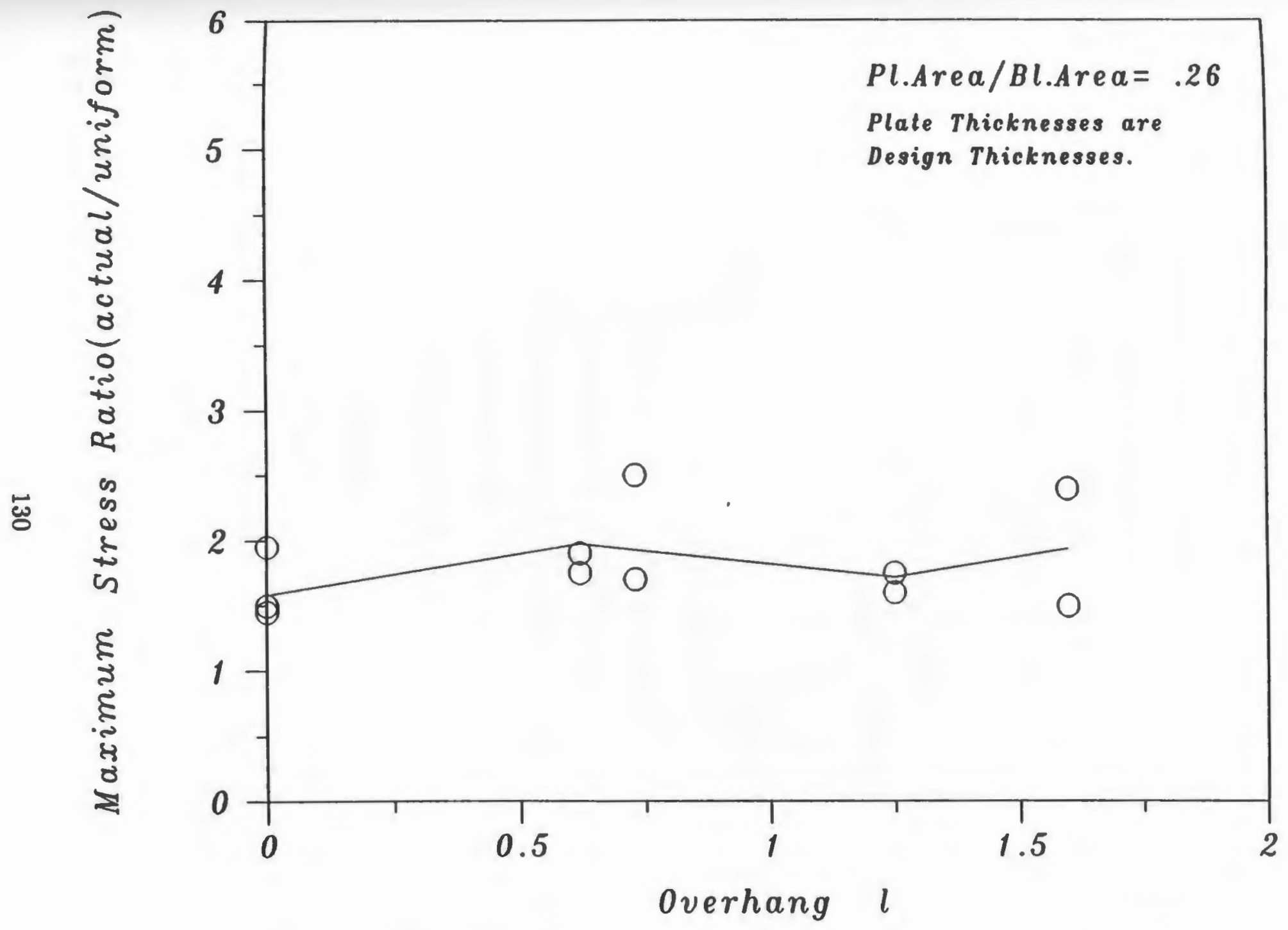

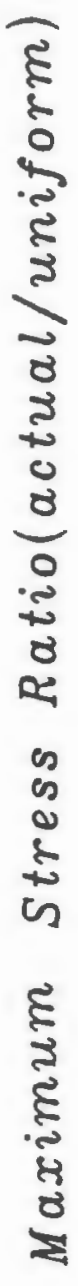

Fig.151: EFFECT OF OVERHANG OF BEARING PLATE 
lower than the loaded area used on the 12 in. blocks.

The ultimate maximum loads carried by the blocks $1,2,3$ and 4 were 200 kips., 250 kips., greater than 250 kips.(block did not fail completely) and 247 kips. respectively.

The only variable during the ultimate load tests on the $12 \mathrm{in.}$ blocks was the thickness of the bearing plate. The plate thickness used for ultimate load test on block 1 was 0.315 in. (< design) and on block 2 it was 0.605 in. (design). The difference in thickness is significant, it can be seen that even at 75 kips. block 1 had higher stresses than block 2 at 90 kips., and at 150 kips block 1 showed localized yielding whereas block 2 did not.

The initial and final cracking patterns for the 12 in. blocks (blocks 1 and 2) can be seen in Figs. 152 and 153. The cracks initiated at the top and as the load was increased, they propagated to the bottom of the block.

The plate thicknesses used for test on block 3 was 0.856 in. (>design) and for block 4 was 0.605 in. (design). Comparing Figs. 103 and 102 not much variation in stress distribution can be observed between the two blocks. The stresses occuring in the two blocks are almost the same for the same loads.

The initial and final cracking patterns for the $15 \mathrm{in.} \mathrm{blocks} \mathrm{(blocks} 3$ and 4 ) can be seen in Fig. 153. The cracks initiated at the top and as the load was increased, they propagated to the bottom of the block.

\subsubsection{STRESSES IN BEARING PLATE:}

Similar to the working stress range tests, the stresses were lower than expected Representative plots of which have been shown in Figs. 87 thru 92 . The stresses at various loads are shown in Table 9 . Some gages showed tension where compression was expected and vice versa, which indicates that the bending of the bearing plate is not as a cantilever but is rather more complex in nature. The lifting of the plate 
edges confirms this fact.

\subsubsection{SLIP OF PLATE EDGE RELATIVE TO CONCRETE:}

The relative lateral motion of the plate and concrete has been called the slip. The slip of the plate edge is due to greater lateral strain in concrete than steel. It can be seen in Figs. 106, 108 and 109 that the slip increases linearly until close to the failure load and then increases rapidly. Some permanent slip is evident after failure and unloading. The permanent slip is due to permanent cracks formed in the concrete.

\subsubsection{LIFT OF PLATE CORNER REL ATIVE TO CONCRETE:}

The lift measurements can be seen in Figs. 110 thru 112. It has been observed that the bearing plate does not distribute the load uniformly to the concrete but most of the load is carried by the portion beneath the loaded area. Concrete strains increase beneath the loaded area considerably whereas strains are low in the portion of the concrete away from the loaded area. This forces the bearing plate to have loacalized high strains at the edge of the loaded area because of the deformed concrete surface, and forces the bearing plate to deform at the end of the loaded area. Therefore the edges of the bearing plates lift up due to this deformation behavior. After unloading, the measurements show some value of lift which indicates permanent deformation in the bearing plate.

\subsection{RECOMMENDATIONS:}

From the test results it is clear that the actual bending stresses in the bearing plate are lower than expected for most of the cases. Table 11 summarises the stress ratios occuring beneath the bearing plate (for the tests conducted with design plate thicknesses) at the end of the loaded area (row $A$ ) and at the edge of the bearing plate (row $B$ ). 
As concluded earlier, for achieving a uniform distribution, an extremely thick bearing plate would be required, but this would not be economical.

The bearing plates can be designed based on the experimental results using the following steps:

1. Assuming the loaded area is known, compute load area to plate area ratio. In case plate area is not known, it would be preferable to choose plate area such that this ratio is close to 0.75 .

2. Compute plate area to block area ratio. In case block area is not known, it would be preferable to choose a block area such that this ratio is close to 0.25 .

3. Compute the uniformly distributed working stress, using the assumption that the stress is uniformly distributed beneath the plate.

4. Using the last column in Table 11, pick up the maximum stress ratios at the end of loaded area (row A) and at the edge of the bearing plate (row B) for the respective load area to plate area ratio and plate area to block area ratio.

5. Multiplying these values to the stress computed in 3, get actual stresses beneath the plate at the end of the loaded area and at the edge of the plate.

6. Assume a linear variation of stress in between and design the plate based on this distribution.

It can be seen that without affecting the stress distribution, the thickness of the bearing plates can be reduced for most of the cases. 


\begin{tabular}{|c|c|c|c|c|c|c|c|}
\hline \multicolumn{3}{|c|}{ Ratio of } & \multicolumn{5}{|c|}{ Stress Ratios } \\
\hline $\begin{array}{c}\text { Plate Area } \\
\text { to } \\
\text { Block Area }\end{array}$ & $\begin{array}{c}\text { Load Area } \\
\text { to } \\
\text { Plate Area }\end{array}$ & & $\begin{array}{l}\text { Block } 1 \\
(12 \text { in. })\end{array}$ & $\begin{array}{l}\text { Block } 2 \\
(12 \text { in. })\end{array}$ & $\begin{array}{l}\text { Block } 3 \\
(15 \text { in. })\end{array}$ & $\begin{array}{l}\text { Block } 4 \\
\text { (15 in.) }\end{array}$ & $\begin{array}{c}\text { Maximum } \\
\text { value }\end{array}$ \\
\hline \multirow[t]{6}{*}{0.75} & \multirow[t]{2}{*}{0.25} & $\bar{A}$ & 1.4 & 1.5 & 1.0 & 1.2 & 1.5 \\
\hline & & $\bar{B}$ & 0.5 & 0.5 & 0.5 & $\overline{0.4}$ & $\overline{0.5}$ \\
\hline & \multirow[t]{2}{*}{0.50} & $\bar{A}$ & 0.9 & 0.7 & 1.0 & $\overline{0.8}$ & 1.0 \\
\hline & & $\bar{B}$ & $0 . \overline{6}$ & 0.5 & 0.6 & 0.5 & 0.6 \\
\hline & \multirow[t]{2}{*}{0.75} & $A$ & $0 . \overline{6}$ & 0.5 & 0.6 & 0.5 & 0.6 \\
\hline & & $\bar{B}$ & 0.6 & 0.5 & 0.6 & 0.5 & 0.6 \\
\hline \multirow[t]{6}{*}{0.50} & \multirow[t]{2}{*}{0.25} & $A$ & 1.25 & 1.4 & 1.1 & 1.5 & 1.5 \\
\hline & & $\bar{B}$ & 0.6 & 0.5 & 0.5 & 0.5 & 0.6 \\
\hline & \multirow[t]{2}{*}{0.50} & $\bar{A}$ & $\overline{0.9}$ & 0.8 & 0.7 & 0.7 & 0.9 \\
\hline & & $\bar{B}$ & 0.6 & 0.5 & 0.5 & 0.4 & 0.6 \\
\hline & \multirow[t]{2}{*}{$0 . \overline{75}$} & $\bar{A}$ & 0.6 & 0.5 & 0.6 & 0.5 & $0 . \overline{6}$ \\
\hline & & $\bar{B}$ & $\overline{0.6}$ & 0.5 & 0.6 & 0.5 & 0.6 \\
\hline \multirow[t]{6}{*}{0.25} & \multirow[t]{2}{*}{0.25} & $A$ & $1 . \overline{0}$ & 1.0 & 1.0 & 1.0 & 1.0 \\
\hline & & $\bar{B}$ & $\overline{0 . \overline{6}}$ & $\overline{0.5}$ & 0.5 & 0.5 & 0.6 \\
\hline & \multirow[t]{2}{*}{0.50} & $A$ & 0.75 & 0.75 & 0.75 & 0.75 & 0.75 \\
\hline & & $\bar{B}$ & 0.6 & 0.6 & 0.5 & 0.5 & 0.6 \\
\hline & \multirow[t]{2}{*}{0.75} & $\bar{A}$ & 0.5 & 0.6 & 0.5 & 0.5 & 0.6 \\
\hline & & $\bar{B}$ & 0.5 & $0 . \overline{6}$ & 0.5 & 0.5 & 0.6 \\
\hline
\end{tabular}

Table 11: Stress ratios at end of Loaded Area and at Plate edge.

\begin{tabular}{||c|c|c|c|c|c||}
\hline \hline $\begin{array}{c}\text { Block } \\
\text { No. }\end{array}$ & $\begin{array}{c}\text { Bearing Plate } \\
\text { Thickness } \\
\text { (in.) }\end{array}$ & $\begin{array}{c}\text { Area } \\
\text { (sq.in.) }\end{array}$ & $\begin{array}{c}\text { Maximum } \\
\text { Load } \\
\text { (kips.) }\end{array}$ & $\begin{array}{c}\text { Working stress } \\
\text { Design Load } \\
\text { (kips.) }\end{array}$ & $\begin{array}{c}\text { Factor } \\
\text { of } \\
\text { Safety }\end{array}$ \\
\hline \hline 1 & 0.315 (<design) & 75.04 & 200.0 & 140.7 & 1.42 \\
\hline 2 & 0.685 (=design) & 75.08 & 250.0 & 140.7 & 1.77 \\
\hline 3 & 0.856 (>design) & 58.60 & $>250.0$ & 109.9 & $>2.27$ \\
\hline 4 & 0.605 (=design) & 58.9 & 247.0 & 110.4 & 2.23 \\
\hline
\end{tabular}

Table 12: Factor of safety against failure from Ultimate load Tests. 


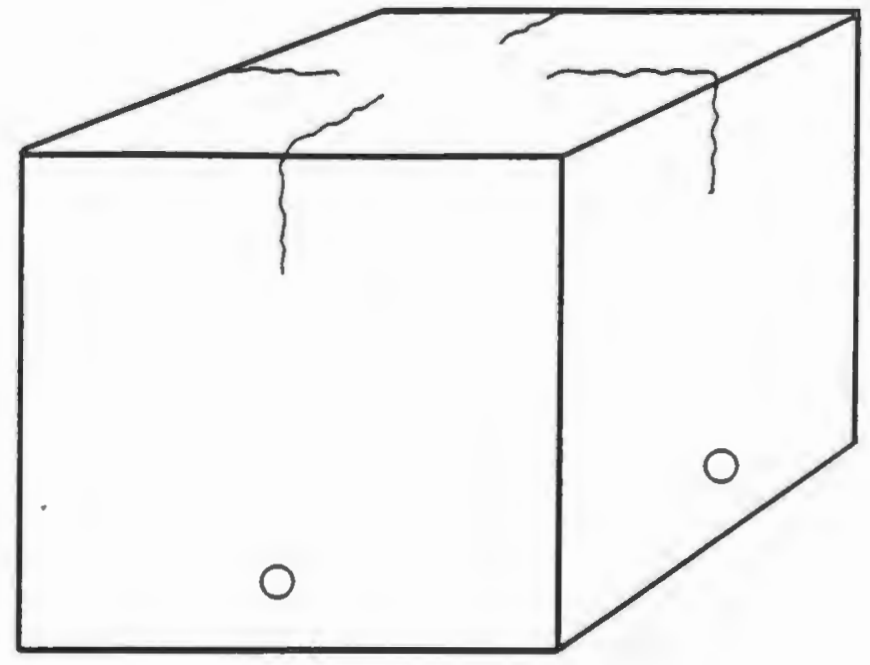

Fig.152(a): Initlal crocking pottern for block 1

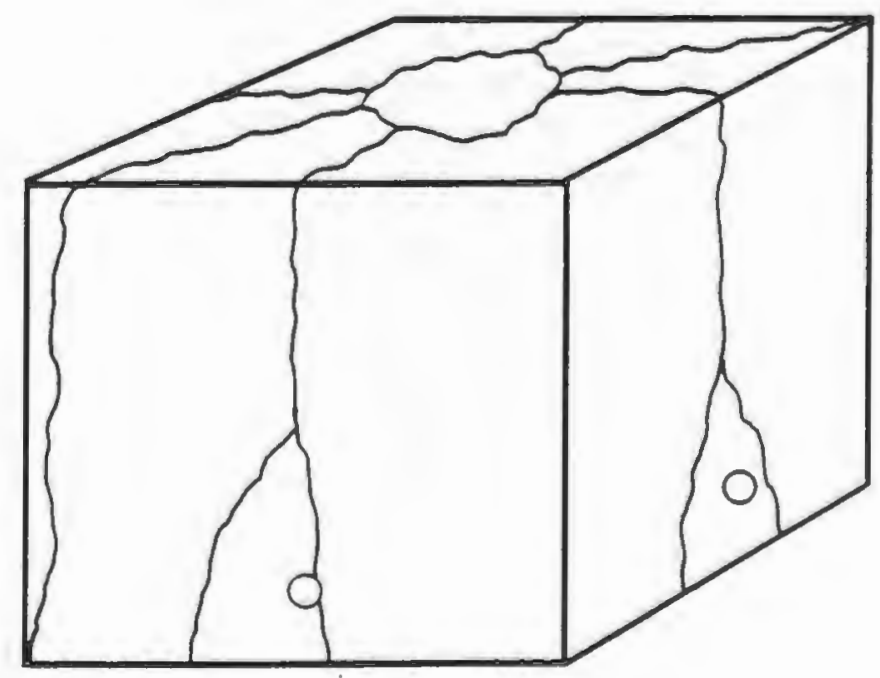

Fig.152(b): Final cracking pottern for block 1 


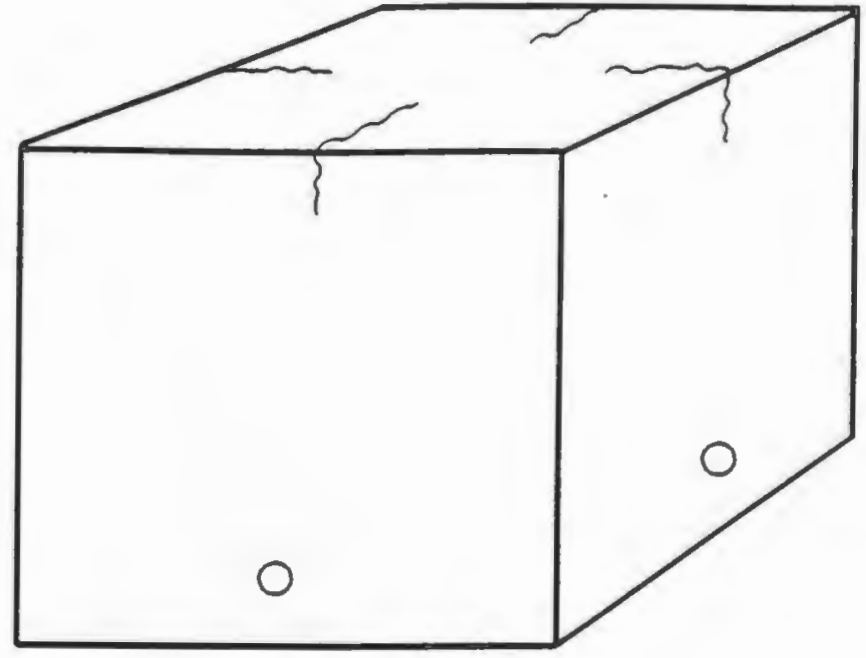

Fig.153(a): In 1 t la crocking pattern for blocks $2.3 \& 4$

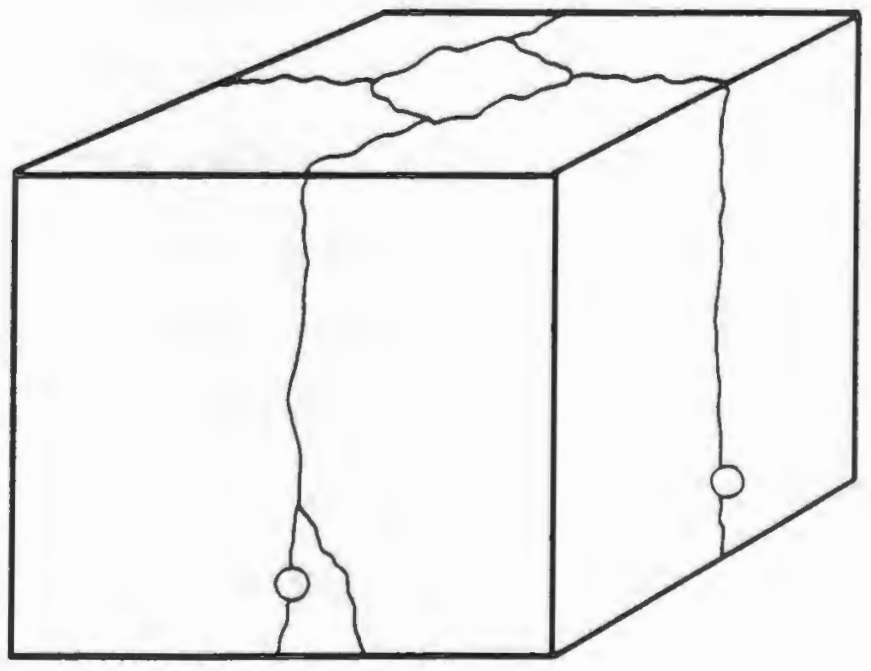

Fig.153(b): Finol crocking pottern for blocks $2.3 \& 4$ 


\section{FINITE ELEMENT ANALYSIS}

A finite element model of the bearing system was developed by McEwen et

al [10] for the purpose of comparing the analytical results to the experimental results. The model was developed for the 12 inch concrete block and for the purpose of comparison test number 12 and test number 76 were selected as the working stress and ultimate load tests. It should be realized that for the finite element analysis, various assumptions are involved for the material properties and behavior of concrete, therefore the finite element analysis results may not be exactly the same as the results from the experiments.

\subsection{FINITE ELEMENT MODEL:}

Test numbers 12 and 76 consisted of bearing plate size $8.66 " \times 8.66 " \times 0.685$ ". The finite element model is shown in Fig. 154. A total of 408 nodes and 72 elements were used for the purpose of analysis. The elements used for the concrete blocks consisted of both eight node linear displacement bricks and variable node bricks.

ABAQUS [3], a non-linear finite element code was used to solve the problem. The loading being symmetric about the vertical axis, only one quarter of the system was analysed using appropriate boundary conditions at the two planes of symmetry.

The concrete stress strain behavior was taken from the cylinder tests at 28 days, shown in Fig. 8.

The nominal reinforcement present in the concrete blocks was modelled as a layer of steel of constant thickness based on the area of the rebar divided by its 


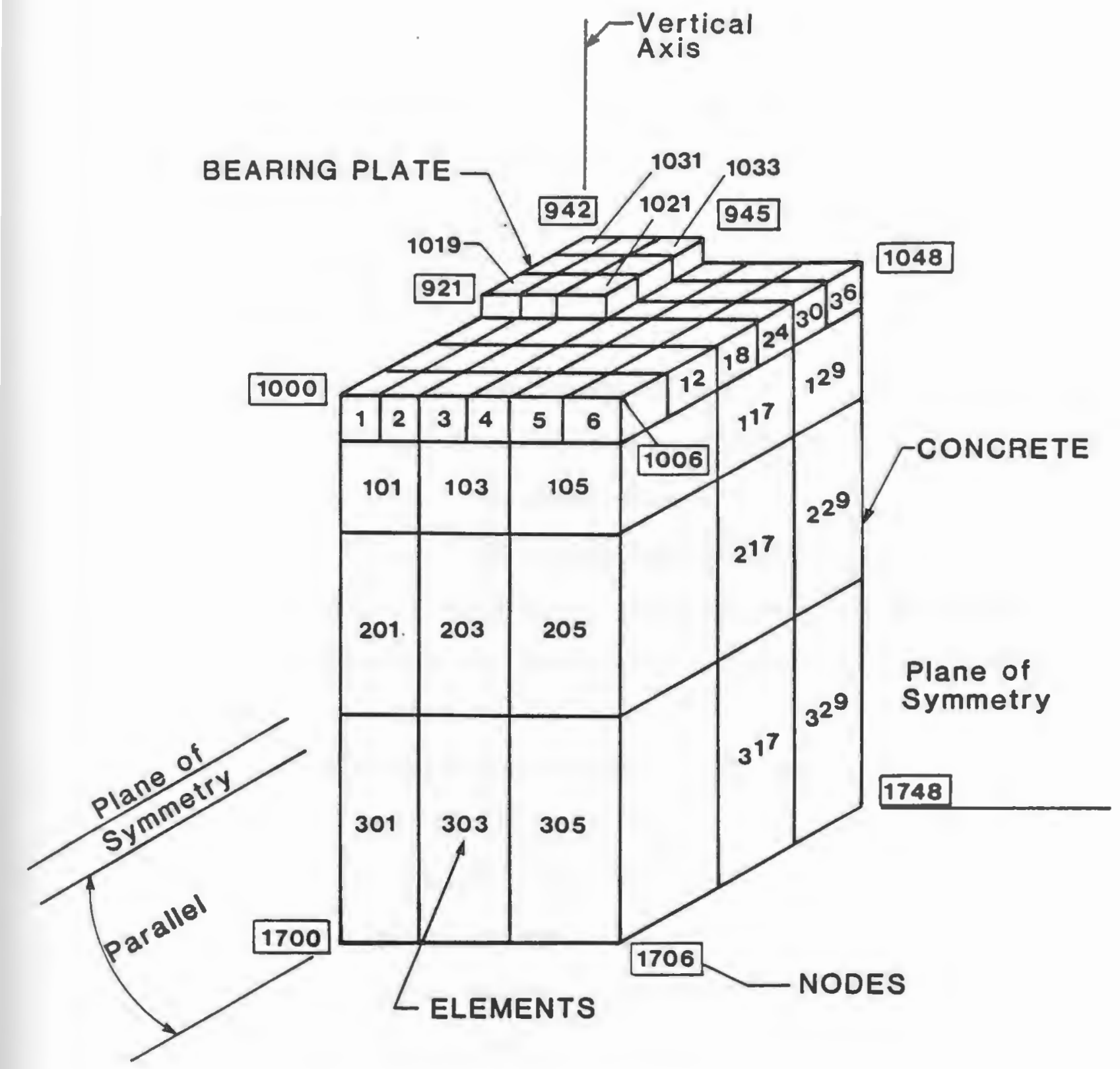

Fig.154: FINITE ELEMENT MESH 
spacing.

\subsubsection{APPLIED LOADS:}

To compare the working stress test results, the bearing system was analysed for an applied uniform stress of 2220 psi. applied over the circular area of 19.17 sq. in. For the ultimate load test the stress was increased from zero to failure.

\subsection{COMPARISON OF EXPERIMENTAL AND FINITE ELEMENT}

\section{RESULTS:}

The vertical stresses resulting in the concrete block at the level of the strain gages is shown in Fig. 155. The stresses observed in concrete were in the elastic range and the stress distribution is close to axisymmetric.

The comparison for the vertical stresses can be seen in Fig. 156. The experimental results are the least squares fit of the data as shown in Fig. 26, and it can be seen from both the analytical and experimental results that the stress distribution is non uniform.

The stresses measured in the steel plates at the applied stress of 2220 psi. (49.3 kips. load) over the loaded area, at the top surface of the steel plate were $1.62 \mathrm{ksi}$. , and $1.74 \mathrm{ksi}$. in tension. These are quite low as compared to the design stresses and are opposite in sign. From the finite element analysis we get stresses of approximately $1.18 \mathrm{ksi}$ in compression at the same location.

Fig. 157 shows a comparison of the strains measured near failure (load 220 kips.) with those resulting from the finite element analysis. The strains measured are higher than the analytical results probably due to extensive cracking of the concrete.

Fig. 158 shows the load-displacement curve for the concrete block determined by the finite element analysis. The displacements are vertical displacements at the 
$-1368$

$-1192$

$-457$

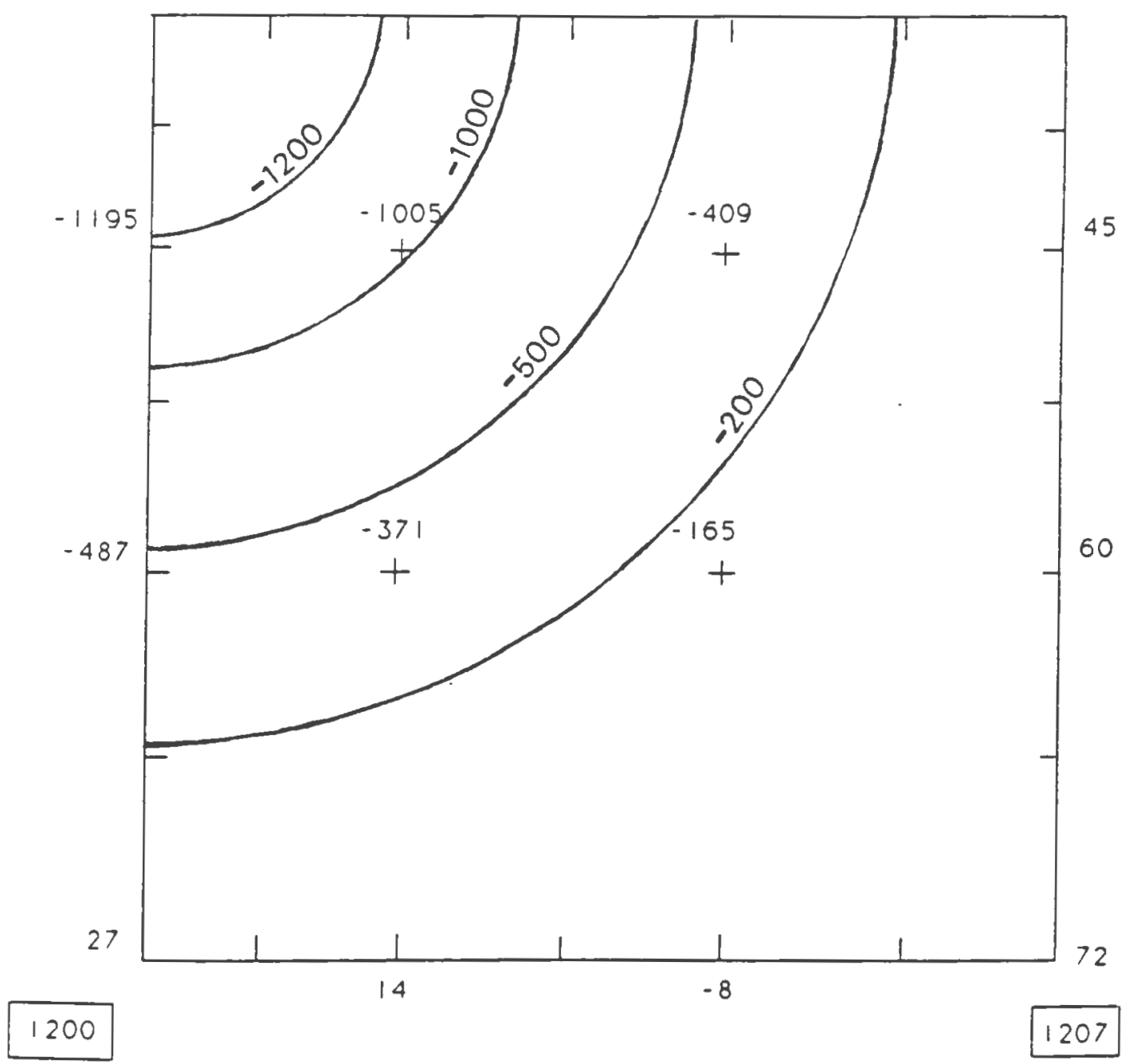

$\operatorname{lood} \cdot 2220$ PSI

Fig.155: VERTICAL STRESSES( $p$ S I) IN CONCRETE AT STRAIN GAGES LEVEL 


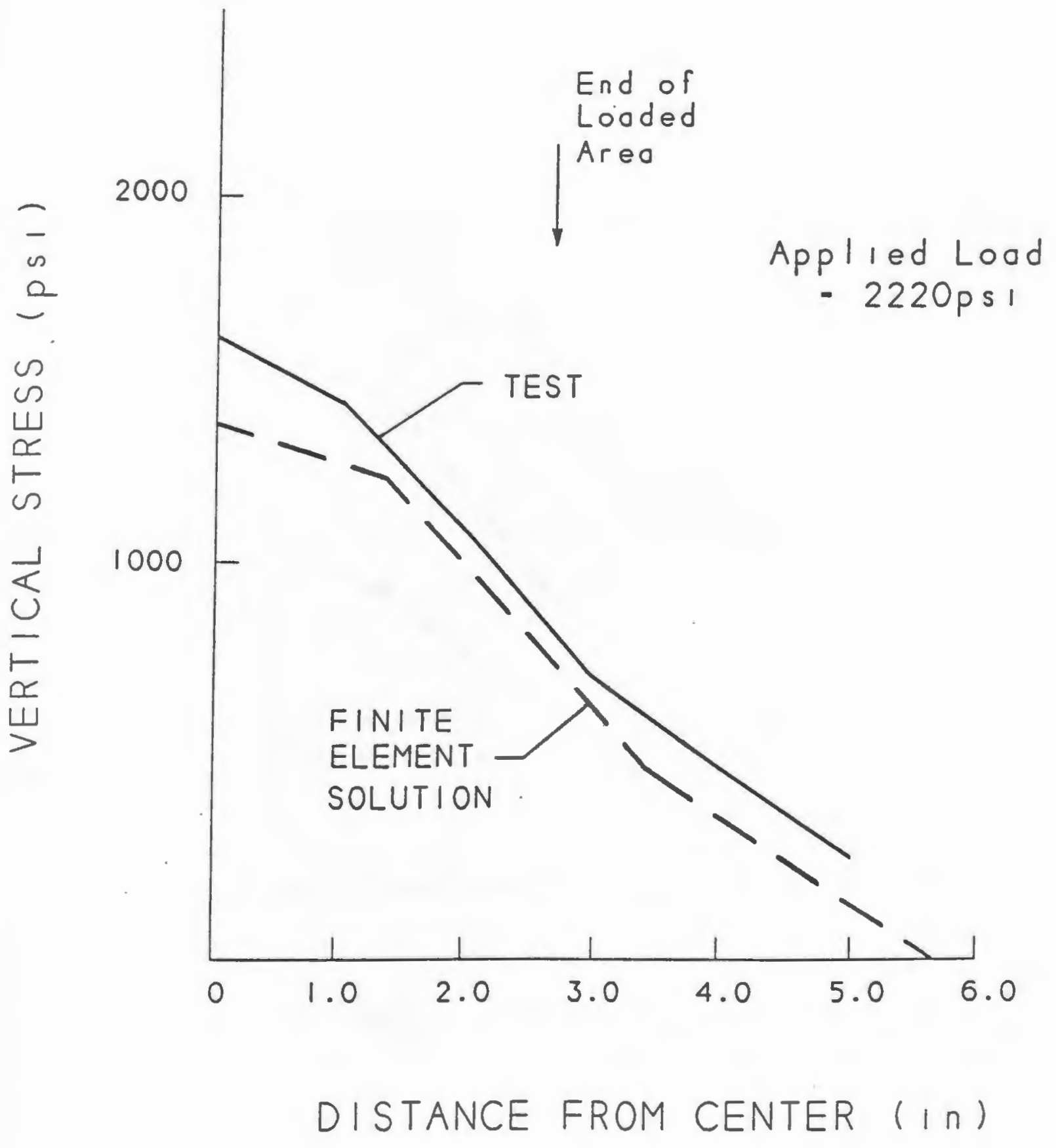

Fig.156: VARIATION OF CONCRETE STRESSES 


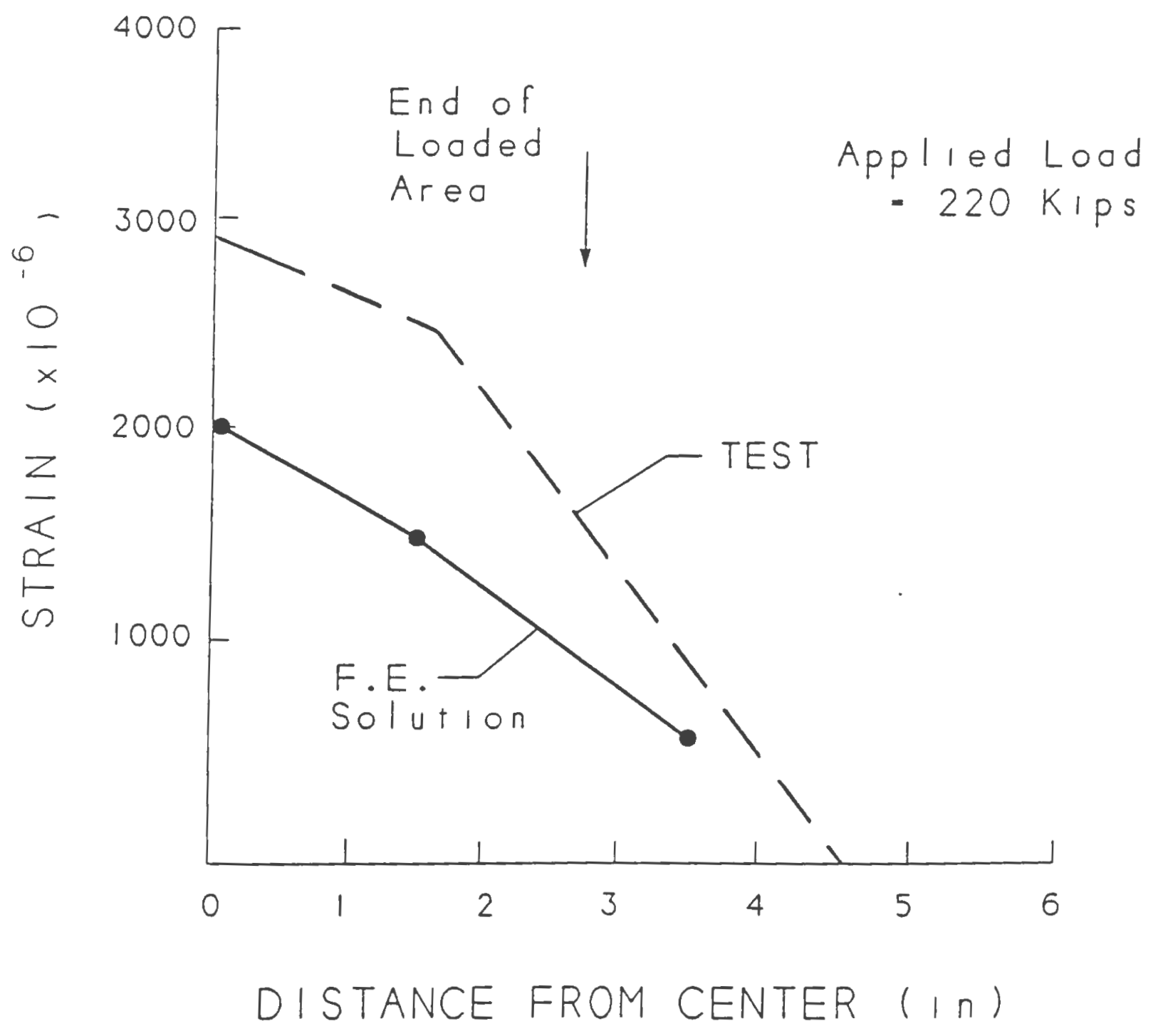

Fig.157: STRAIN DISTRIBUTION AT FAILURE 


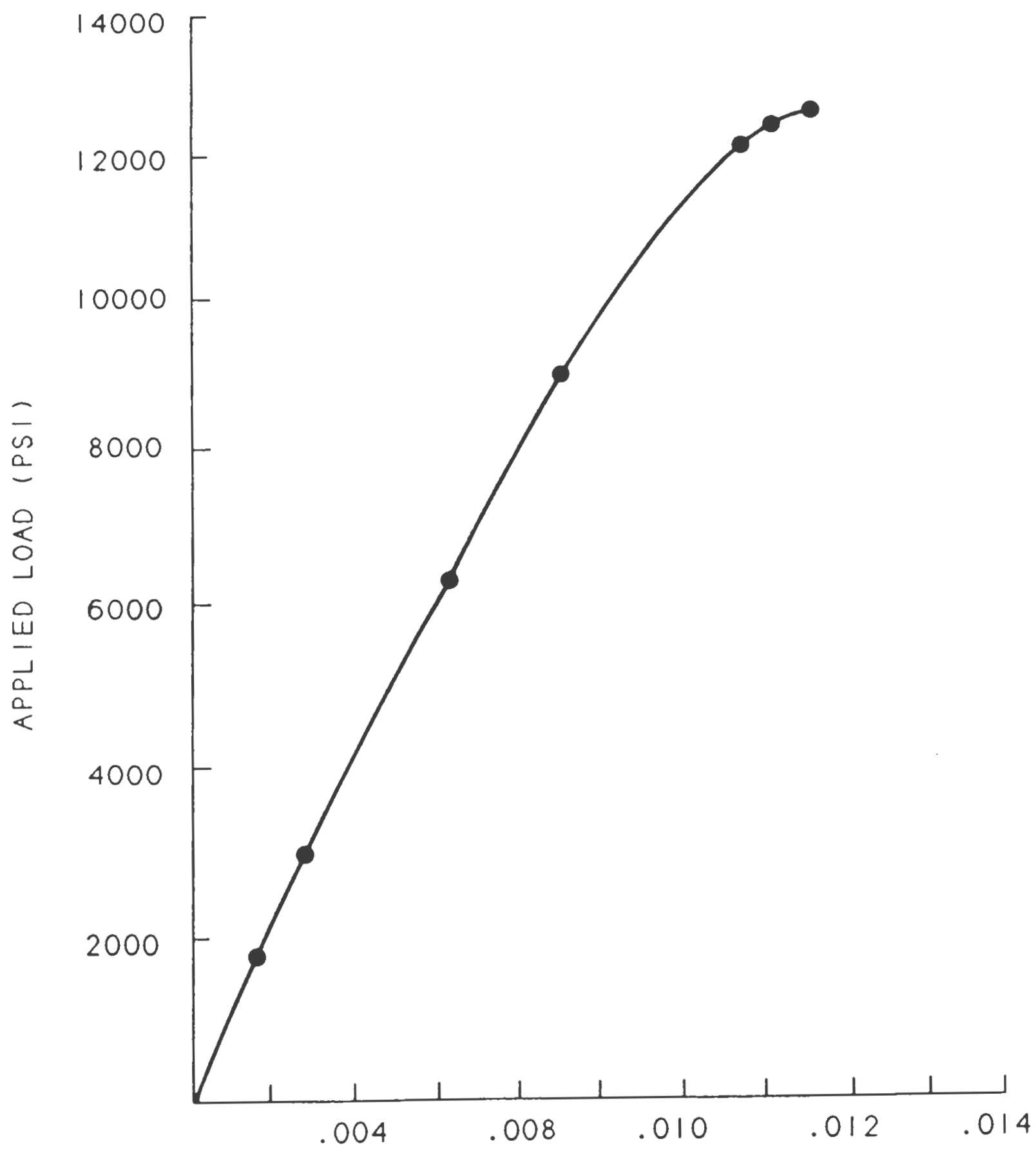

Fig.158: VERT I CAL DISPLACEMENT AT CENTERL INE (INCHES) 
center of the block. The ultimate load from the figure can be seen to be $10000 \mathrm{psi}$. (221 kips.). The actual ultimate load applied for failure was 250 kips. It can be seen from the load displacement curve that it is linear upto 8000 psi. whereas the cylinder stress-strain curve (Fig. 8) shows linearity upto 3000 psi. and an ultimate stress of only 6400 psi. 


\section{CHAPTER 6}

\section{SUMMARY AND CONCLUSIONS}

A parametric study on the behavior of the masonry bearing plates has been performed. The results show that the stress distribution beneath the bearing plate is not at all uniform but is parabolic, with stresses almost two to three times the expected stresses occuring close to the center. The analytical solution [11] using a two dimensional model also gives a parabolic distribution for a similar case. The measured stresses in the bearing plates are quite lower than expected. All this is due to the fact that stresses in both steel and concrete are highly localized and lateral transfer of stresses takes place by little bending of the bearing plate.

The finite element analysis results show a good agreement with the experimental results for the stresses measured in concrete for the working stress and also for the ultimate load the system can carry. However, the stresses in the bearing plate differed greatly from the values expected based on the design assumptions, and were quite erratic.

For high load area to plate area ratios, effect of plate thickness was negligible. This is because of the small overhang of the plate, therefore not much bending of the plate is involved. However, for small load area to plate area ratios, some decrease in stresses could be observed. It is important to note that, even for a very thick bearing plate, a uniform distribution could not be achieved, which means that an extremely thick plate would be required for achieving a stress distribution close to uniform. 
From the test results it is clear that the actual bending stresses in the bearing plate are lower than expected for most of the cases. Table 11 summarises the stress ratios occuring beneath the bearing plate (for the tests conducted with design plate thicknesses) at the end of the loaded area (row $A$ ) and at the edge of the bearing plate (row $B$ ).

As concluded earlier, for achieving a uniform distribution, an extremely thick bearing plate would be required, but this would not be economical.

The recommendations for the design of the bearing plate have been made and summarized in section 4.3 , and it can be seen that without affecting the stress distribution, the thickness of the bearing plates can be reduced for most of the cases.

The load carrying capacities of the concrete blocks based on working stress design (i.e. $0.3 f_{c}^{\prime} \times$ Bearing Plate Area) have been shown in Table 12. The factor of safety is computed based on the maximum load carried by each system. Looking at these factor of safety values against failure, it is worth noting that the factor of safety against failure increases considerably with increase in the size of the concrete substructure. However, since there were only two different sized blocks, it is difficult to conclude the exact relationship between the ultimate load carrying capacity and the size of the concrete substructure.

The expected factor of safety from the current design assumptions is 3.33 (i.e. Ultimate Stress $f_{c}^{\prime} /$ Allowable Stress $0.3 f_{c}^{\prime}$ ). The factor of safety obtained from the ultimate load tests conducted in the laboratory are quite low, because of high stresses at the centerline in concrete.

Section 1.5.26.(3) of the Standard specifications for Highway Bridges [1] recommends that the allowable bearing stress on concrete be taken as $0.3 f_{c}^{\prime}$ and that the allowable bearing stress on the loaded area may be increased by $\sqrt{A_{2} / A_{1}}$, but 
not more than 2 , when the area of the concrete substructure $A_{2}$ is wider on all sides of the loaded area $A_{1}$. This is not advisable for small concrete substructures, because the factor of safety would go down further.

A series of ultimate load tests may be required with different sized blocks to determine the effect of the size of the concrete substructure on the ultimate stress carrying capacity of the bearing system. 


\section{REFERENCES}

1."Standard Specifications for Highway Bridges", Twelfth edition (Adopted by the American Association of State Highw ay and Transportation Officials).

2."Manual of Steel Construction", American Institution of Steel Construction, Inc., eighth edition.

3. "ABAQUS User Manual-Version 4.6", Hibitt, Karlsson, and Sorenson, Inc., May 1988.

4. McEwen, E.E., and Saxena, A.,"Behavior of Masonry Plates in Bridge Bearing Systems: Analytical Study", Technical Report for RIDOT, 1985, Re port No. FHWA$R I-R D-85-01$

5. Chen, W.F.,"Plasticity in Reinforced Concrete", McGraw-Hill, 1982.

6. Chen, A.C.T., and Chen, W.F., "Constitutive relations for Concrete", ASCE, J. Engr. Mech. Div., Vol 101, 1975, pp.465-481.

7. "Standard Specifications for Road and Bridge Constructions", State of Rhode Island \& Providence Plantations, Dept. of Transportation, Div. of Public Works.

8. Saxena, A., and McEwen, E., "Behavior of Masonry Bearing Plates",Second World Congress on Joints and Bearings, Amerionn Concrete Institute, August, 1986.

9. "Practical Strain Gage Measurements", Hewlett Packard Company, Applioation Note 290-1.

10. McEwen, E. and Agrawal, V., "Behavior of Masonry Plates in Bridge Bearing Systems", Technical Report for Rhode Island Department of Transportation (under preparation).

11. Sadd, M., "An Introduction to Elasticity Theory", Class Notes, pp 9-18. 
APPENDIX A 


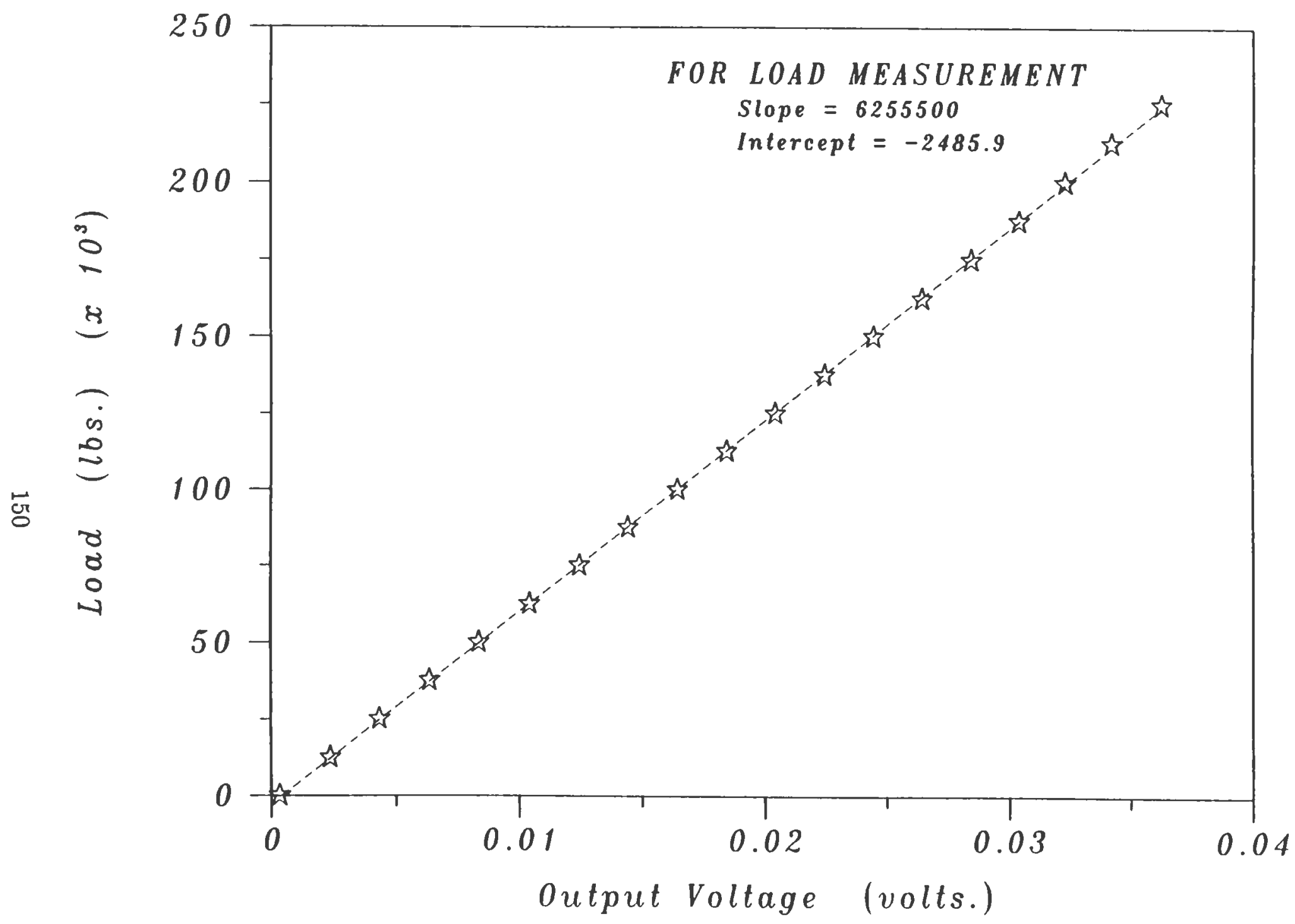

30
0
8
8
0
0
0
8
0
0
0

Fig.159: CALIBRATION CURVE, PRESSURE TRANSDUCER 


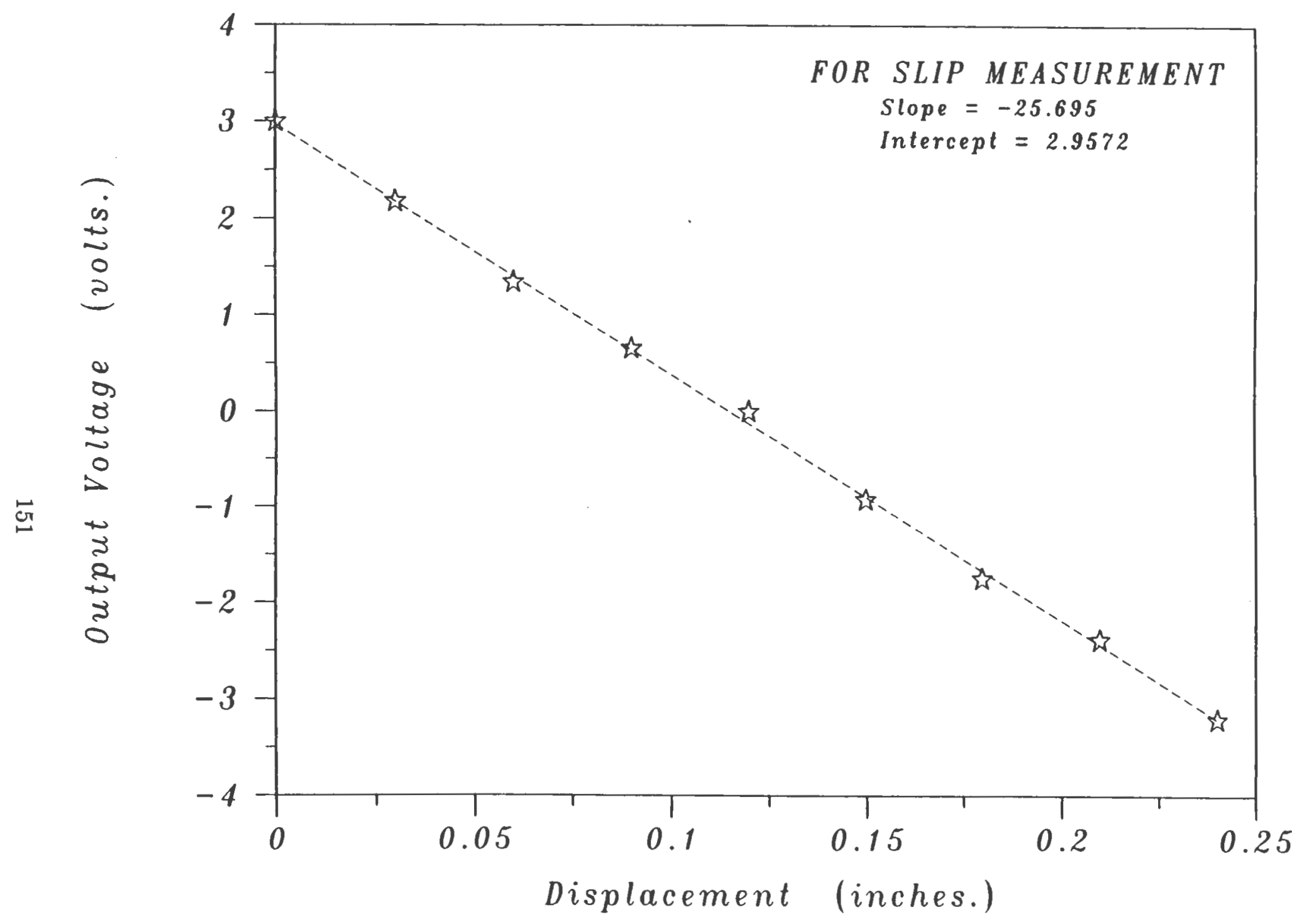

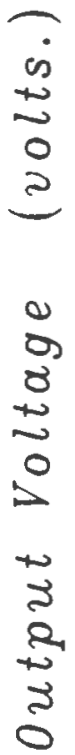

Fig.160: CALIBRATION CURVE, DISPLACEMENT TRANSDUCER \# 1 


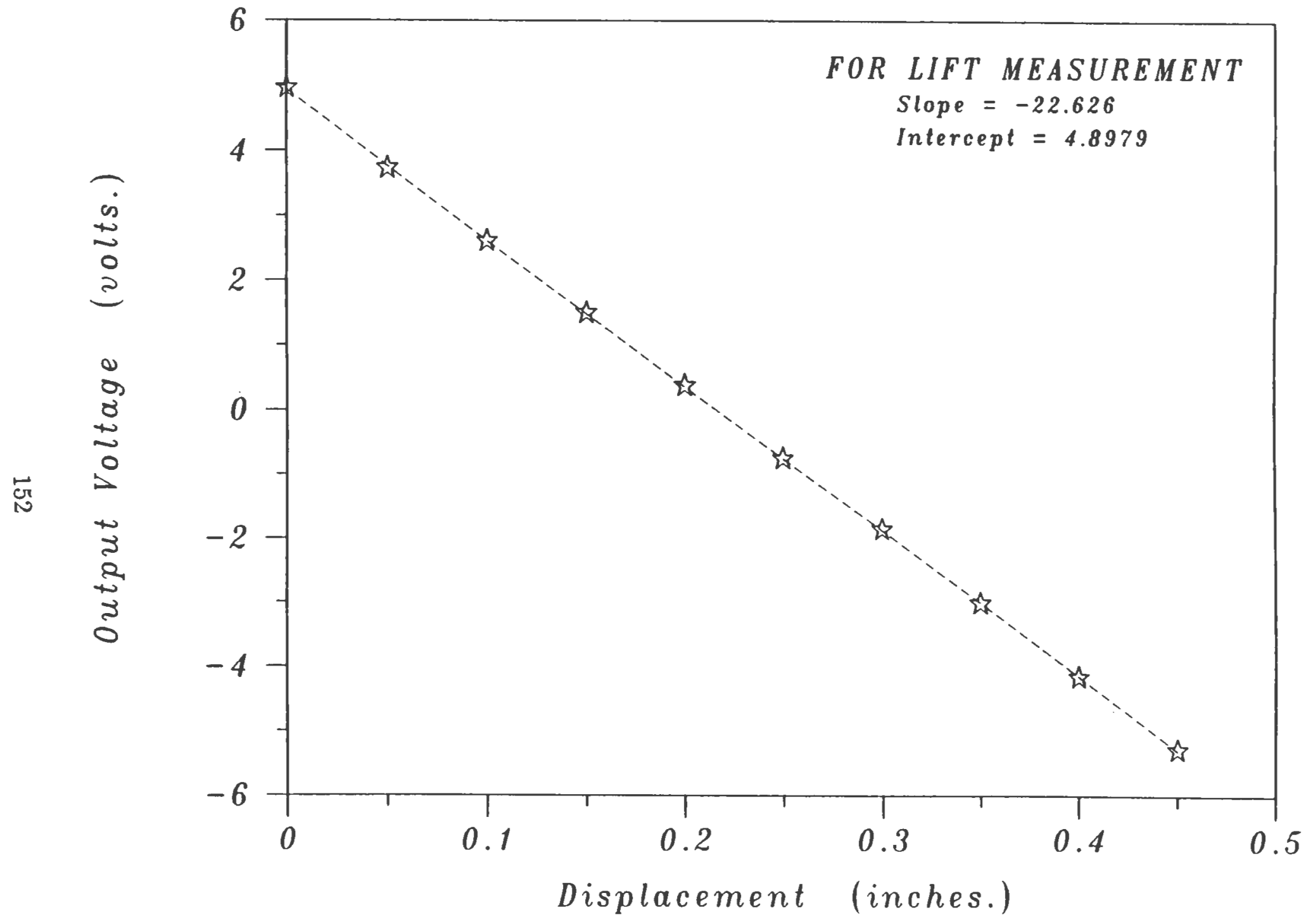

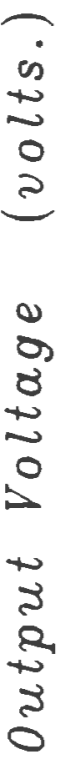

Fig.161: CALIBRATION CURVE, DISPLACEMENT TRANSDUCER\#Z 
APPENDIX B 


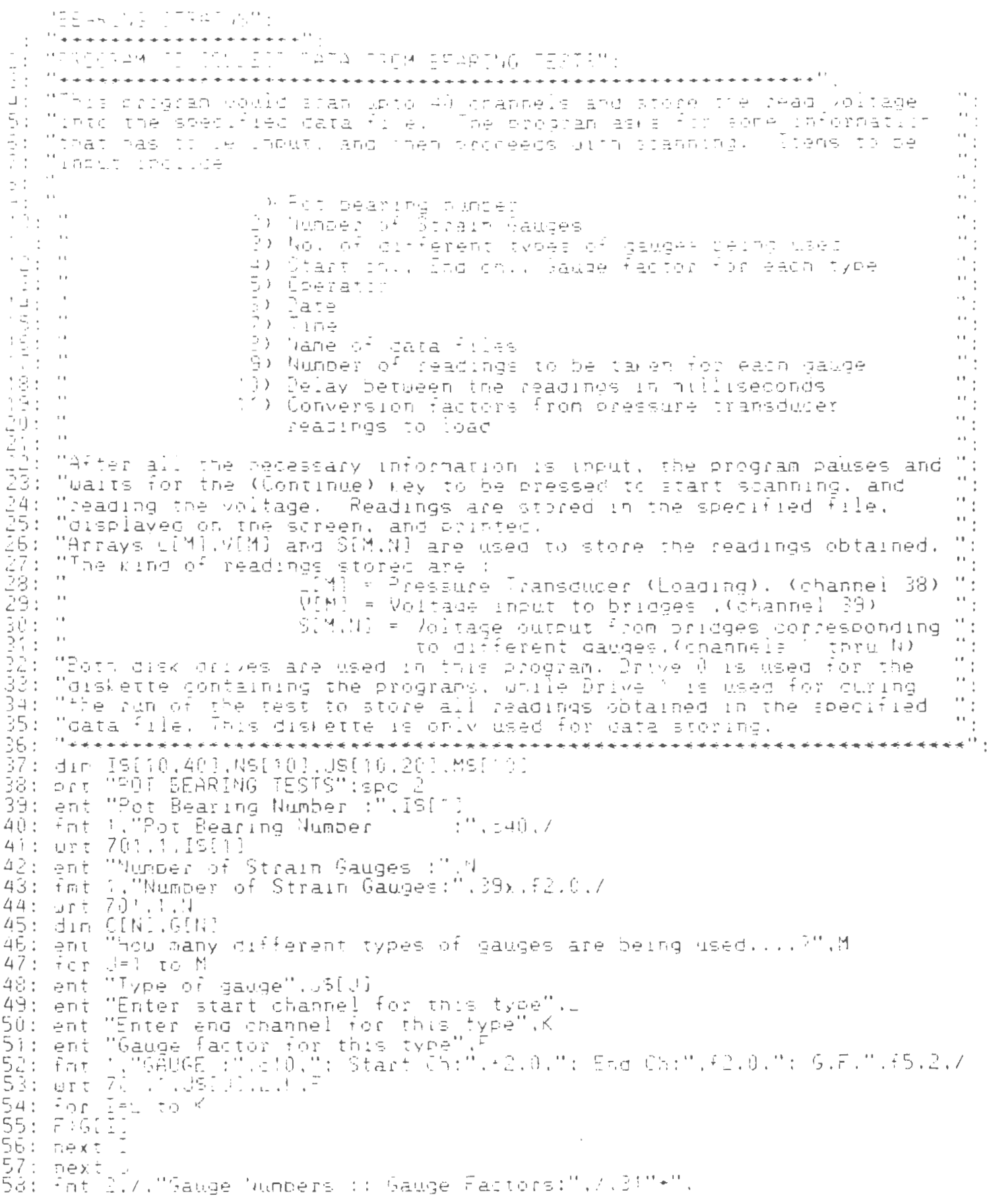




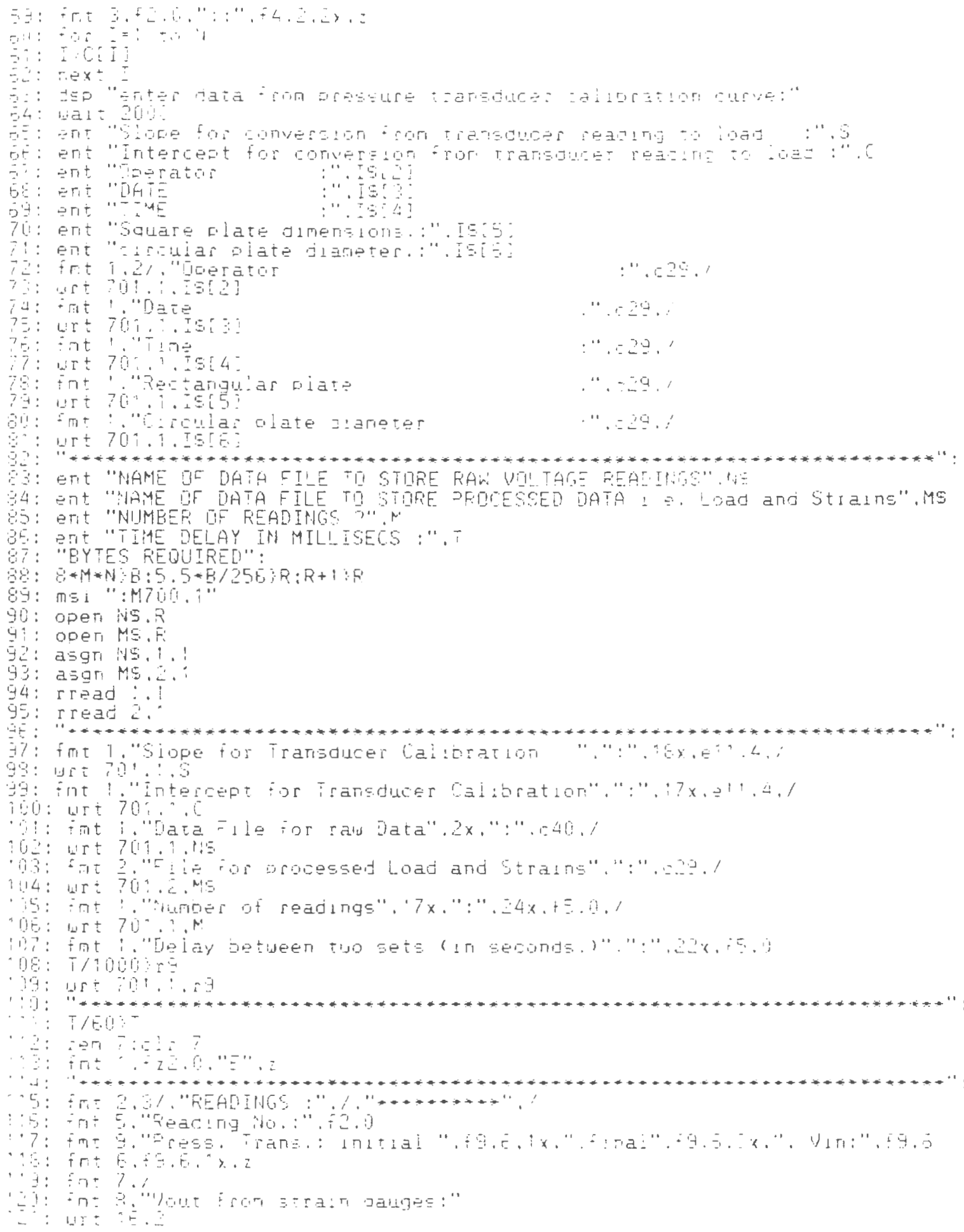




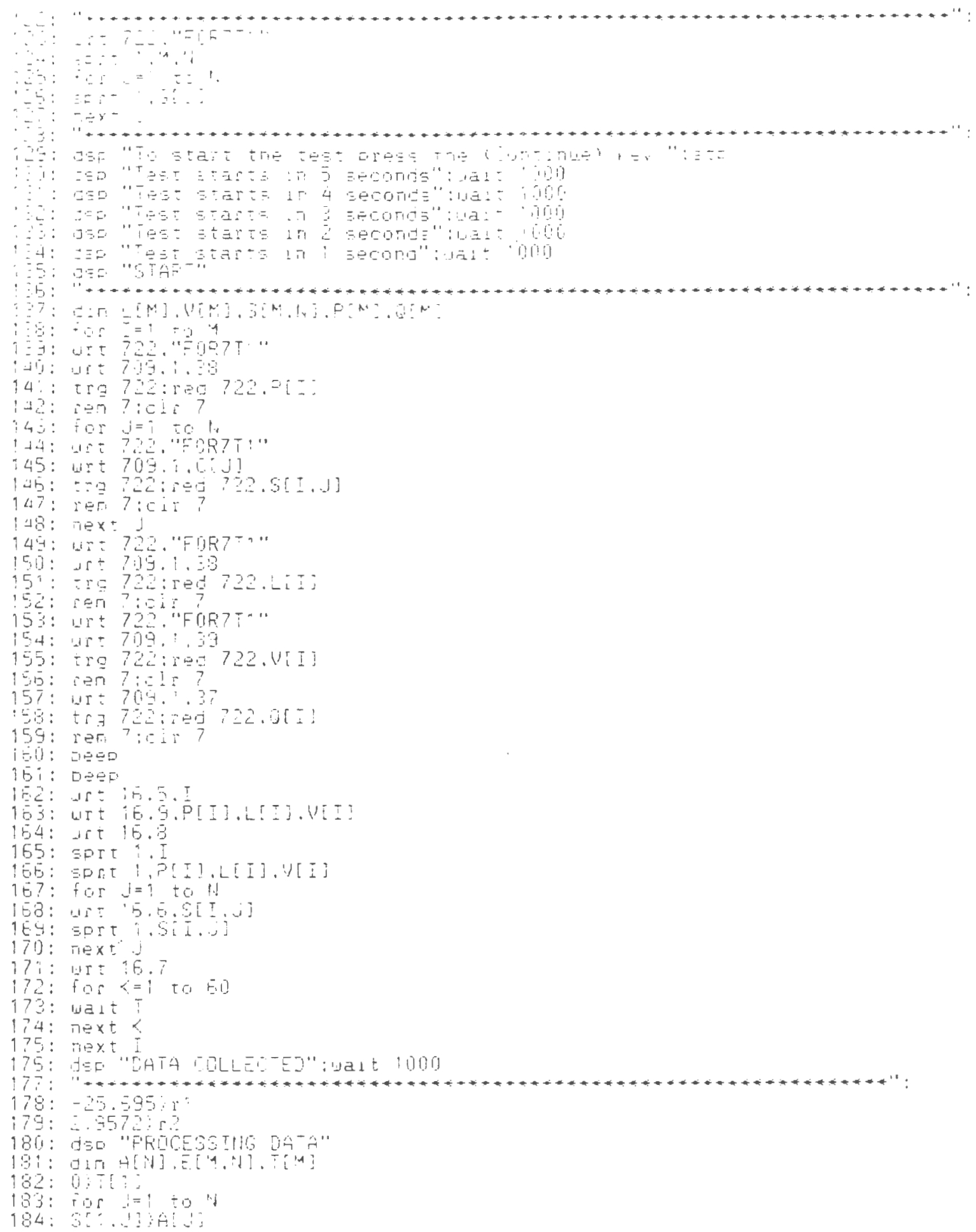




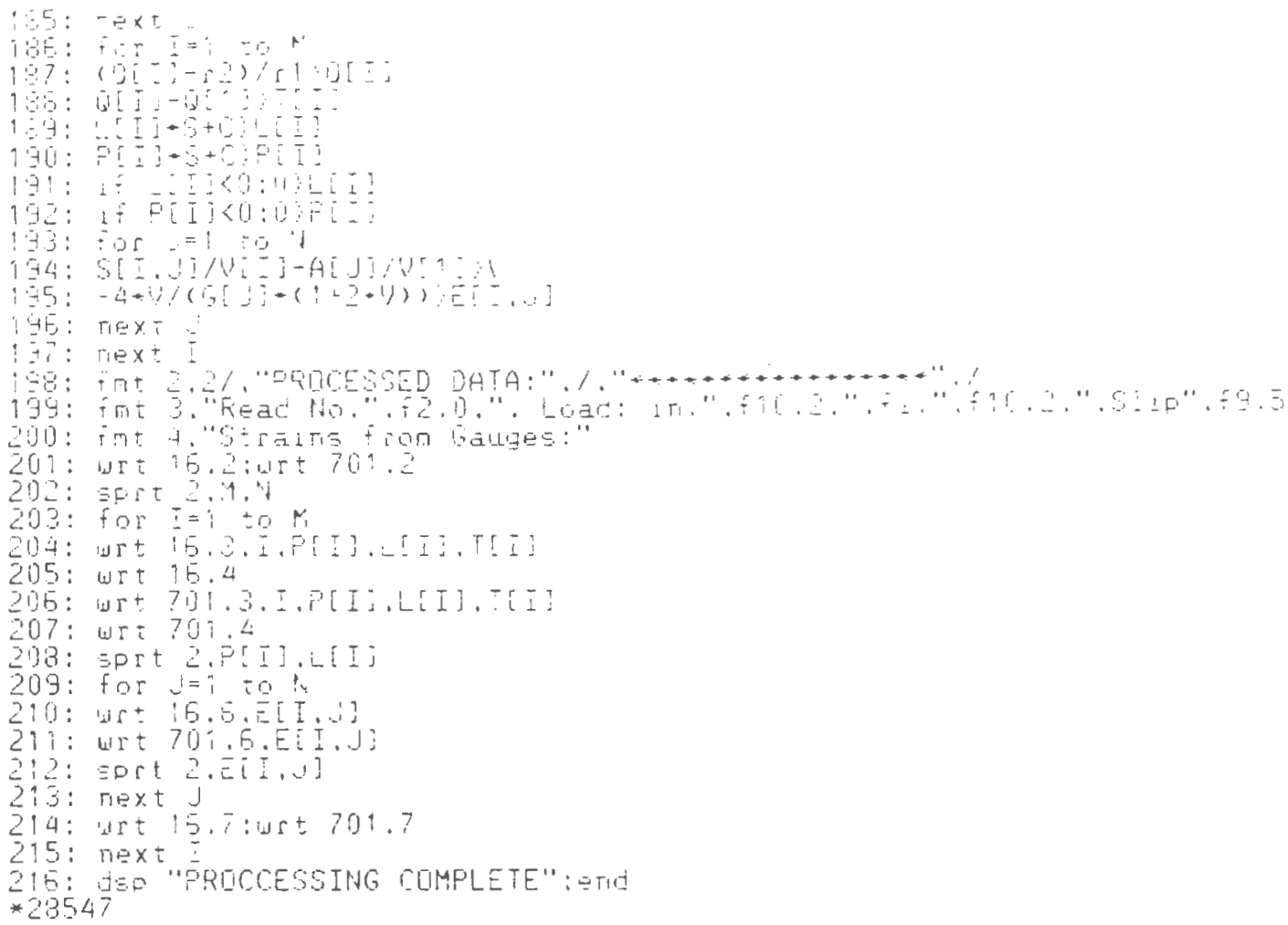




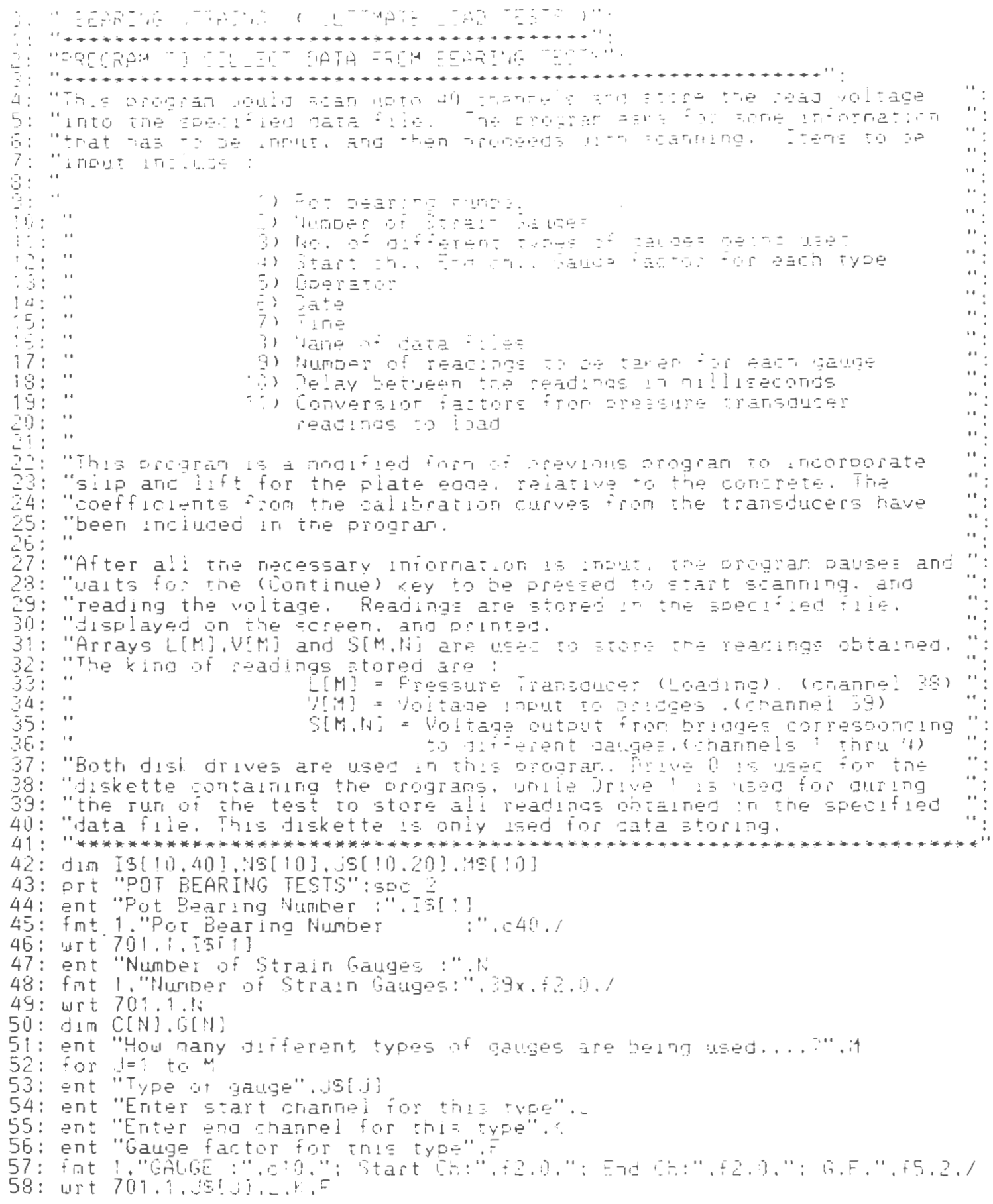




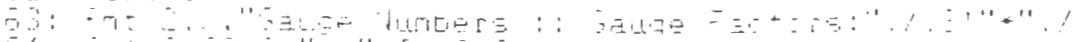

$54: \div$

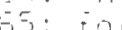
,

F,

Si: -

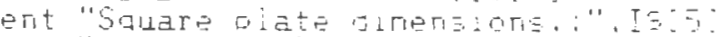

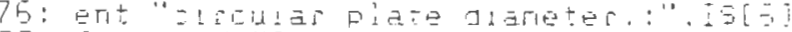

77: fnt 1.2/."loterats

79: art $79 i$, is?

79: fot ifore

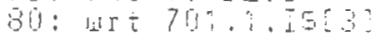

$31:+7 t:$ " ine

82: wrt $70 ;. j .45 j$

83: fat i "Rectarigular olate

84: idt 701.1 .

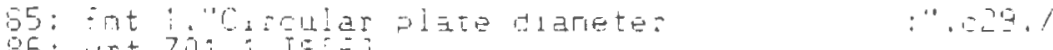

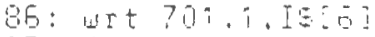

37

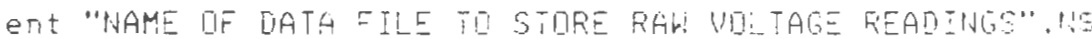

90: ent "NUMEER DF FEADTRES ?" STR

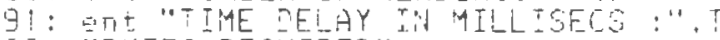

G2: "EYTES REGUIRER":

93: $\quad 3-4-N: 3: 5.5+B / 256: P: R+1: R$

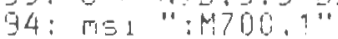

75: gFen: : 15,8

G5: opst: ME.R

$\exists 7:$ asgn $15, i$

9 : asgn $M S .2$

$33:$ r 5 :

$100:$ r reac 2

i ij

$702:$

tis 5100

int $101,1,0$

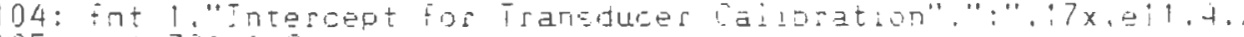

105: wrt 701.1 .8

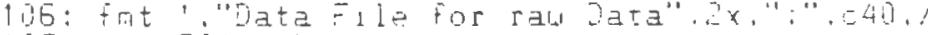

$107:$ wet 707 .

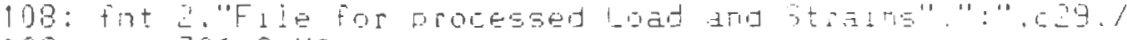

109: wri $709.2 . \mathrm{Ms}$

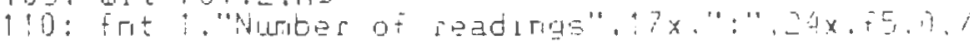

$111:$ art 701, M

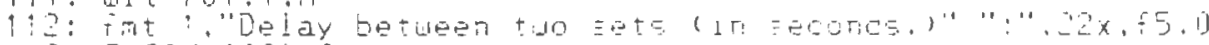

i 3: $\overline{1}+50 / 1000: 5$

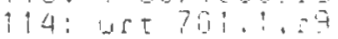

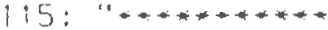

$110: \operatorname{sen} 7: \operatorname{lol} ?$

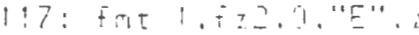

i 18: " $\cdots+\ldots+\infty+\infty+\infty+\infty$

119: $5 \mathrm{~m} t \mathrm{2} 3 /$ "READEH6\%

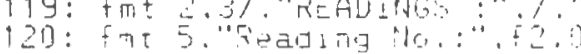

121: fnt 


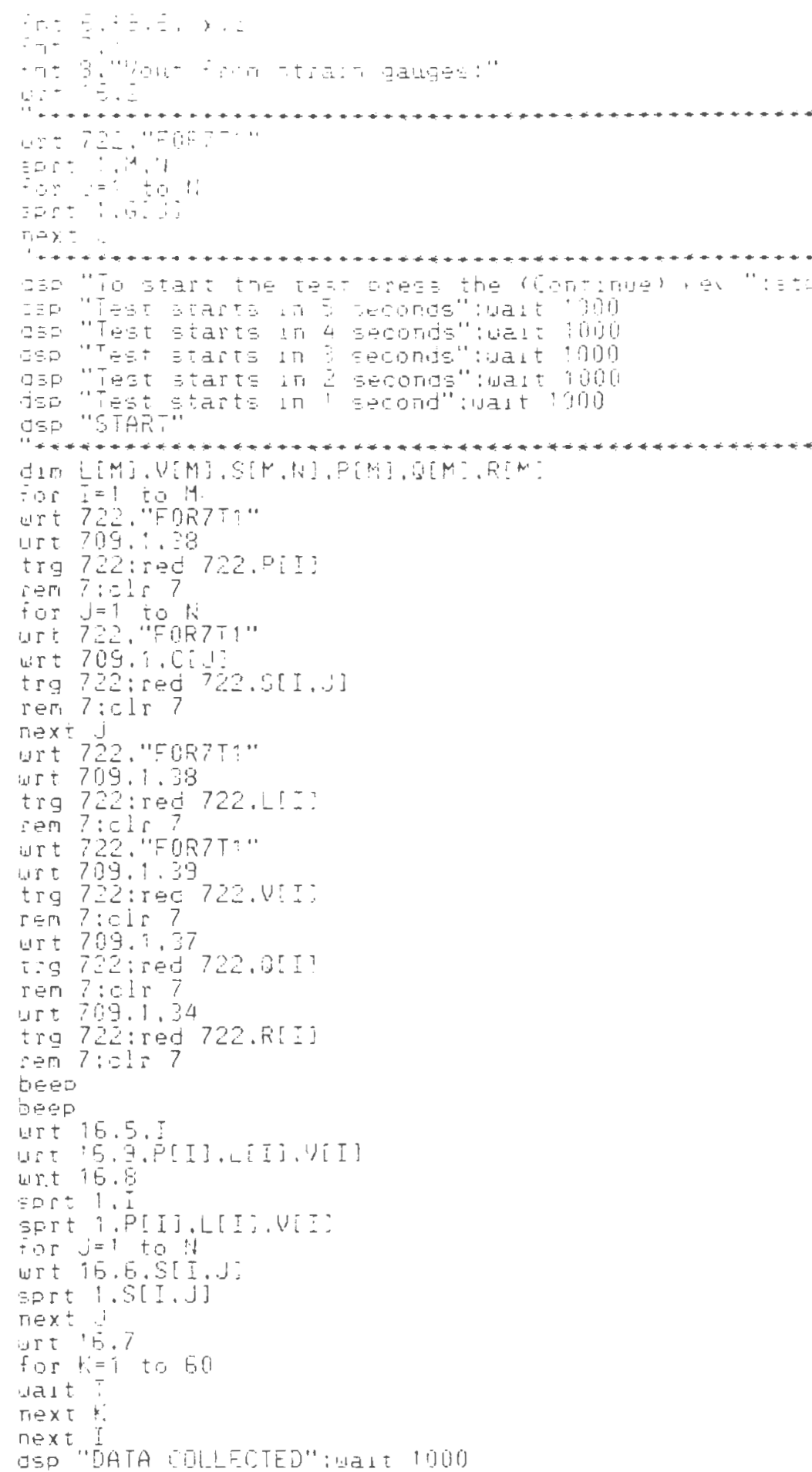




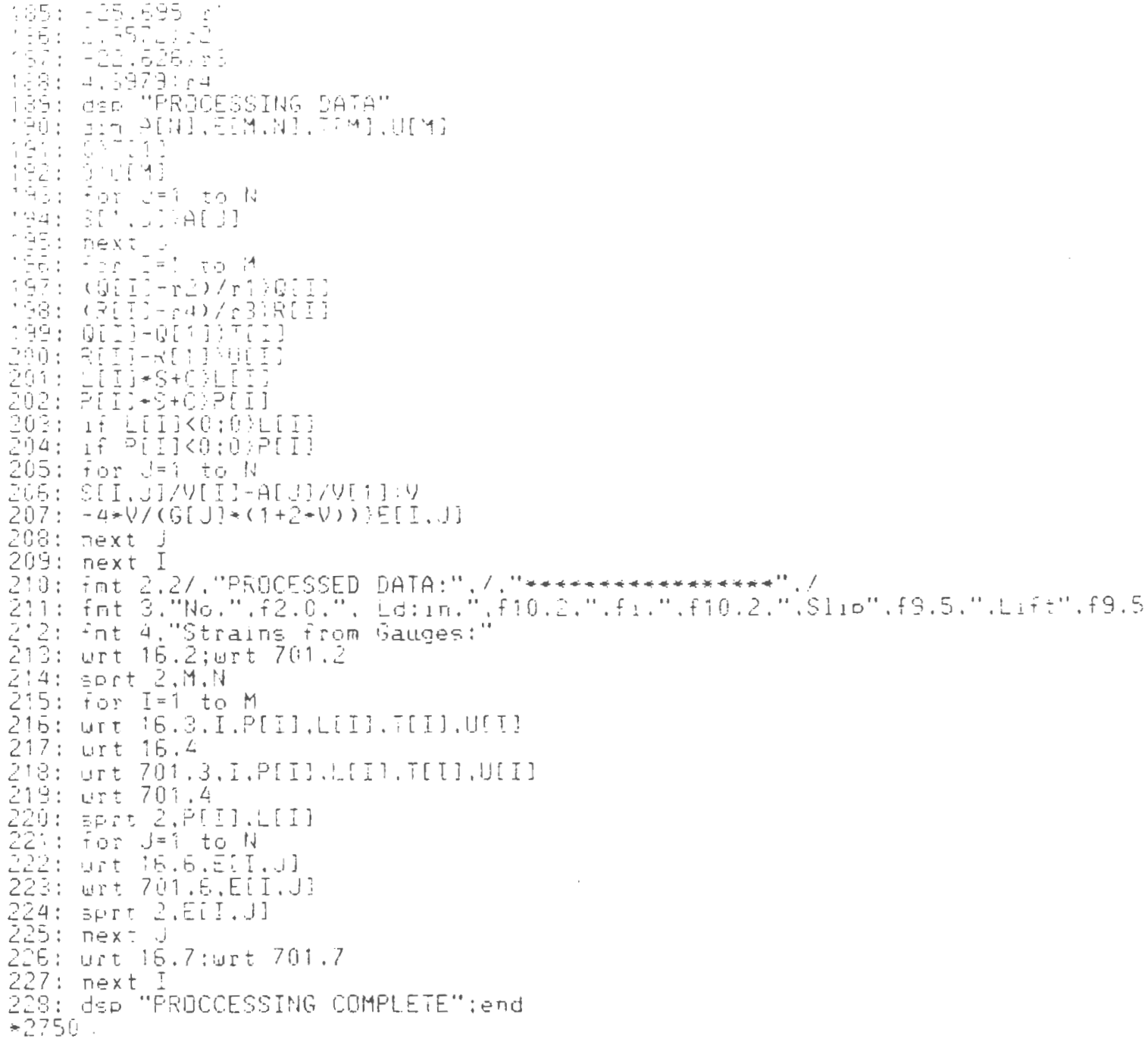




\section{BIBLIOGRAPHY}

"ABAQUS User Manual-Version 4.6", Hibitt, Karlsson, and Sorenson, Inc., May 1988.

Chen, A.C.T., and Chen, W.F., "Constitutive relations for Concrete",ASCE, J. Engr. Mech. Div., Vol 101, 1975, pp.465-481.

Chen, W.F.,"Plasticity in Reinforced Concrete", McGraw-Hill, 1982.

"Manual of Steel Construction", American Institution of Steel Construction, Inc., eighth edition.

McEwen, E. and Agrawal, V.,"Behavior of Masonry Plates in Bridge Bearing Systems", Technical Report for Rhode Island Department of Transportation (under preparation).

McEwen, E.E., and Saxena, A.,"Behavior of Masonry Plates in Bridge Bearing Systems: Analytical Study",Technical Report for RIDOT, 1985, Report No. FHWA-RI-RD$85-01$

"Practical Strain Gage Measurements", Hewlett Packard Company, Application Note 290-1.

Sadd, M.,"An Introduction to Elasticity Theory", Class Notes, pp 9-18.

Saxena, A., and McEwen, E.,"Behavior of Masonry Bearing Plates",Second World Congress on Joints and Bearings, Amerionn Concrete Institute, August, 1986.

"Standard Specifications for Highway Bridges", Twelfth edition (Adopted by the American Association of State Highw ay and Transportation Officials).

"Standard Specifications for Road and Bridge Constructions", State of Rhode Island \& Prvidence Plantations, Dept. of Transportation, Div. of Public Works. 